\author{
UNIVERSIDADE DE SÃO PAULO \\ ESCOLA DE ENGENHARIA DE SÃO CARLOS \\ DEPARTAMENTO DE ENGENHARIA ELÉTRICA
}

AFONSO CELSO TURCATO

Desenvolvimento de método para detecção de intrusão em redes PROFINET baseado em técnicas de Aprendizado de Máquina

São Carlos

2020 



\section{Desenvolvimento de método para detecção de intrusão em redes PROFINET baseado em técnicas de Aprendizado de Máquina}

Tese apresentada à Escola de Engenharia de São Carlos da Universidade de São Paulo, para obtenção do título de Doutor em Ciências pelo Programa de Engenharia Elétrica.

Área de Concentração: Sistemas Dinâmicos

Orientador: Prof. Dr. Rogério Andrade Flauzino

São Carlos

2020

Trata-se da versão corrigida da tese. A versão original se encontra disponível na EESC/USP que aloja o Programa de Pós-Graduação de Engenharia Elétrica. 


\section{AUTORIZO A REPRODUÇÃO TOTAL OU PARCIAL DESTE TRABALHO, POR QUALQUER MEIO ÇONVENCIONAL OU ELETRÔNICO, PARA FINS DE ESTUDO E PESQUISA, DESDE QUE CITADA A FONTE.}

Ficha catalográfica elaborada pela Biblioteca Prof. Dr. Sérgio Rodrigues Fontes da EESC/USP com os dados inseridos pelo(a) autor(a).

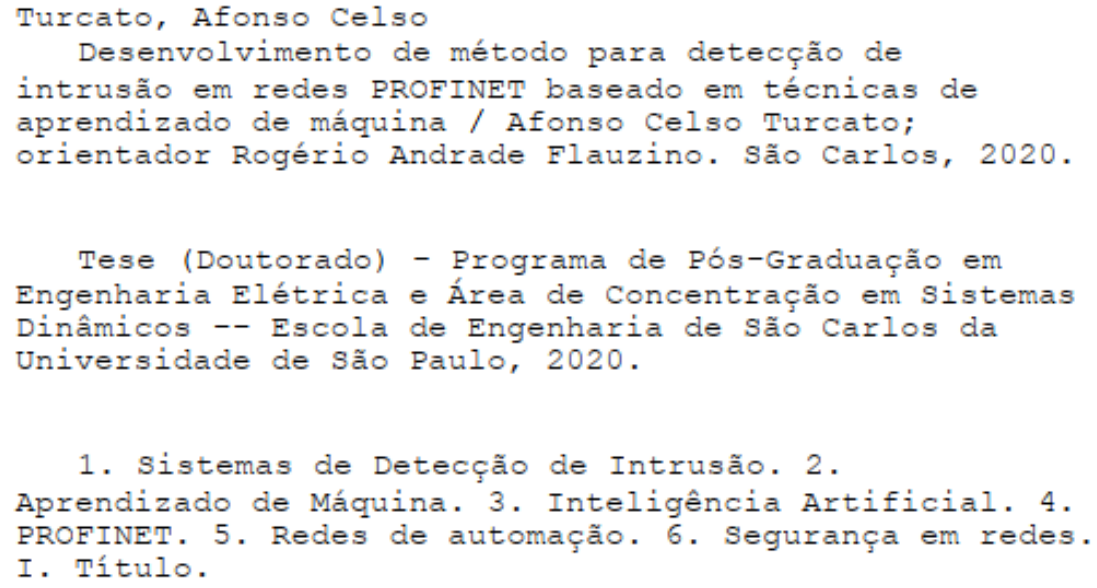

Eduardo Graziosi Silva - CRB - 8/8907 


\section{FOLHA DE JULGAMENTO}

Candidato: Engenheiro AFONSO CELSO TURCATO.

Título da tese: " Desenvolvimento de método para detecção de intrusão em redes PROFINET baseado em técnicas de aprendizado de máquina".

Data da defesa: $13 / 08 / 2020$

Comissão Julqadora:

Prof. Associado Rogério Andrade Flauzino

(Orientador)

(Escola de Engenharia de São Carlos - EESC/USP)

Prof. Associado Dennis Brandão

(Escola de Engenharia de São Carlos - EESC/USP)

Prof. Dr. Marcio José da Cunha

(Universidade Federal de Uberlândia/UFU)

Prof. Dr. Karl Heinz Kienitz

(Instituto Tecnológico de Aeronáutica/ITA)

Prof. Dr. Rodrigo Palucci Pantoni

(Instituto Federal de Educação, Ciência e Tecnologia/IFSP Sertãozinho)

\section{Resultado}

Aprovado

Aprovado

Aprovado.

Aprovado

Aprovado

Coordenador do Programa de Pós-Graduação em Engenharia Elétrica:

Prof. Titular Ivan Nunes da Silva

Presidente da Comissão de Pós-Graduação:

Prof. Titular Murilo Araujo Romero 

Dedico este trabalho aos meus pais, Antônio e Inês, pelo exemplo de persistência e garra frente às adversidades da vida. Dedico também, com carinho e estima à minha esposa Cintia pelo constante incentivo e compreensão da importância deste trabalho e, em especial, ao meu filho João Henrique, presente de Deus e minha maior alegria. 



\section{Agradecimentos}

Agradeço primeiramente a Deus por me dar forças para a realização deste trabalho.

Agradeço a toda a minha família em especial aos meus pais e irmãos Daniel e Andréia, a minha esposa Cintia, por todo apoio necessário para que eu alcançasse meus objetivos.

Ao meu orientador Prof. Dr. Rogério Andrade Flauzino pela confiança, apoio e orientação por toda a jornada de estudos na confecção deste trabalho.

Ao professor Dr. Dennis Brandão pelo incentivo, recomendações e por permitir o desenvolvimento deste trabalho nas instalações do Laboratório de Automação Industrial.

Ao professor Dr. Ivan Nunes Silva pelos valiosos ensinamentos transmitidos.

Aos amigos Andre Luis Dias e Guilherme Serpa Sestito pela enorme contribuição para a conclusão deste trabalho, pelo esforço dedicado aos artigos científicos, pela amizade e pelas 'intermináveis' conversas.

À Universidade de São Paulo por disponibilizar os recursos necessários para o desenvolvimento deste trabalho.

Ao Programa de Pós-Graduação em Engenharia Elétrica da EESC, pela minha aceitação como pesquisador.

Aos professores da área de Elétrica e Computação do Instituto Federal de Educação, Ciência e Tecnologia de São Paulo campus Sertãozinho pelo incentivo a pósgraduação. 

"If I have seen further, it is by standing upon the shoulders of giants"

Isaac Newton 



\section{Resumo}

TURCATO, A. C. (2020). Desenvolvimento de método para detecção de intrusão em redes PROFINET baseado em técnicas de Aprendizado de Máquina. 265p. Tese de Doutorado - Escola de Engenharia de São Carlos, Universidade de São Paulo, São Carlos, 2020.

O aumento na quantidade de informações importantes que percorrem as redes de computadores faz com que a segurança seja fundamental para garantir a integridade, a confidencialidade e a disponibilidade dos dados trafegados. No ambiente industrial isso não é diferente. Em busca desse aumento da segurança, são utilizados dispositivos como Firewalls e Sistemas de Detecção de Intrusão (SDI). Hoje em dia, algoritmos de Aprendizado de Máquina (AM) da área de Inteligência Artificial (IA) estão sendo aplicados para a melhoria de desempenho desses dispositivos. Este trabalho propõe investigar, desenvolver, implementar e validar um método para detectar intrusão em redes PROFINET com uso de técnicas de Aprendizado de Máquina. O método utilizado está fundamentado na análise das características de comunicação do protocolo PROFINET e na identificação e classificação de padrões, sendo esta, uma das principais aplicações de classificadores inteligentes como as Redes Neurais Artificiais (RNA), as Máquinas de Vetores Suporte (SVM). As intrusões são identificadas por meio da análise do tráfego da rede em sua fase de operação utilizando-se classificadores unários e binários. Ao todo, 114 estruturas de classificação unárias e 196 estruturas de classificação binárias foram avaliadas com dados de 10 cenários distintos de tráfego de rede PROFINET. Os SDI propostos apresentaram Taxa de Detecção média de 98,1\% e Taxa de Alarmes Falsos média de 0,4\% utilizando-se classificadores unários e Taxa de Detecção de 100\% e Taxa de Alarmes Falsos de 0\% utilizando-se classificadores binários.

Palavras-chaves: Sistemas de Detecção de Intrusão. Aprendizado de Máquina. Inteligência Artificial. PROFINET. Redes de automação. Segurança em redes. 

TURCATO, A. C. (2020). Development of a method for intrusion detection in PROFINET networks based on Machine Learning techniques. 265p. Ph.D. Thesis São Carlos School of Engineering, University of São Paulo, São Carlos, 2020.

The increase in the amount of important information that travels through computer networks makes security essential to guarantee the integrity, confidentiality, and availability of the data being transferred. In the industrial environment, this is no different. In research of this increased security, devices such as Firewalls and Intrusion Detection Systems (IDS) are used. Nowadays, Machine Learning (ML) algorithms, from the Artificial Intelligence (AI) area, are being applied to improve the performance of these devices. This work proposes to investigate, develop, implement, and validate a method to detect intrusion in PROFINET networks using Machine Learning techniques. The method used is based in the analysis of the communication characteristics of the PROFINET protocol and the identification and classification of patterns, which is one of the main applications of intelligent classifiers such as Artificial Neural Networks (ANN), Support Vector Machines (SVM). Intrusions are identified through the analysis of network traffic in the operation phase using unary and binary classifiers. In total, 114 unary classification structures and 196 binary classification structures were evaluated using data from 10 different PROFINET network traffic scenarios. The proposed IDS had average Detection Rate of $98.1 \%$ and average False Alarm Rate of $0.4 \%$ using unary classifiers and a Detection Rate of $100 \%$ and a False Alarm Rate of $0 \%$ using binary classifiers.

Keywords: Intrusion Detection Systems. Machine Learning. Artificial Intelligence. PROFINET. Automation Networks. Security Network. 



\section{Índice de Figuras}

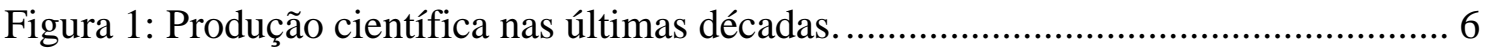

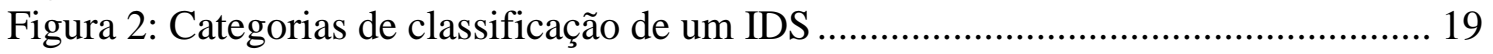

Figura 3: Sistemas de Detecção baseados em Rede ................................................... 21

Figura 4: Sistemas de Detecção baseados em Host .......................................................... 23

Figura 5: Sistemas de Detecção Híbridos (Distribuídos) .............................................. 24

Figura 6: Sistemas de Detecção baseados em Assinatura .............................................. 25

Figura 7: Sistemas de Detecção baseados em Anomalias .............................................. 26

Figura 8: Incidentes de segurança mais comuns em redes de automação ...................... 33

Figura 9: Vulnerabilidades mais exploradas pelos hackers em redes industriais........... 33

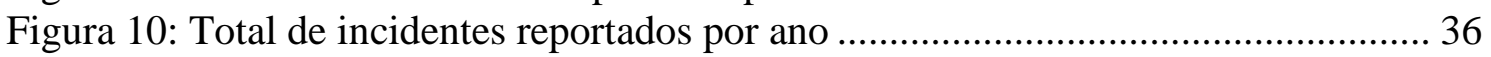

Figura 11: Protocolos de comunicação industrial mais utilizados em 2020.................. 46

Figura 12: Troca de dados entre os dispositivos de uma rede PROFINET.................. 47

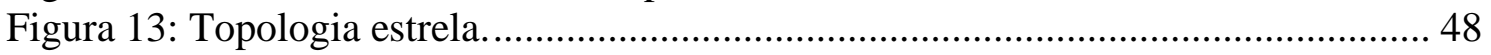

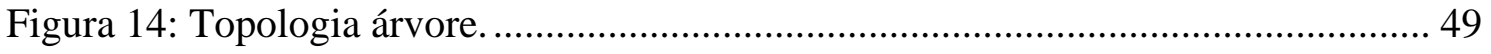

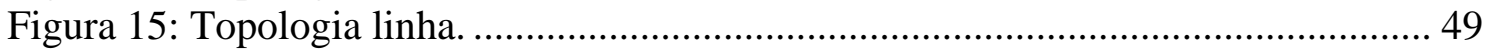

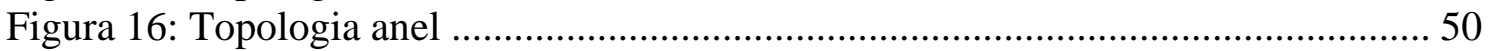

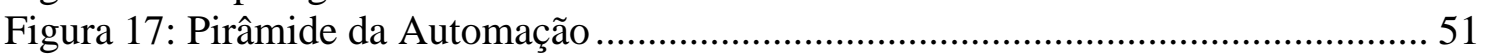

Figura 18: A "nova" Pirâmide da Automação.............................................................. 54

Figura 19: Ciclo de vida de um sistema de segurança................................................... 57

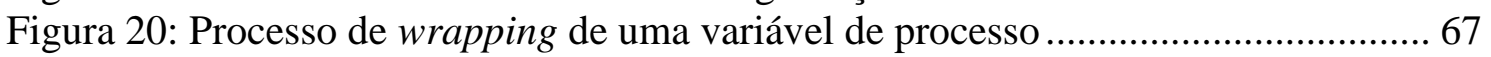

Figura 21: Modelo de segurança com topologia em árvore que implementa a abordagem

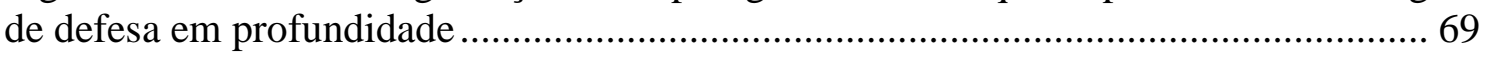

Figura 22: Exemplo de segmentação de rede com firewalls e IDS ............................... 70

Figura 23: Arquitetura de comunicação segura de duas etapas usando módulos de segurança (SM) ou tokens de segurança (por exemplo, cartões inteligentes) para um

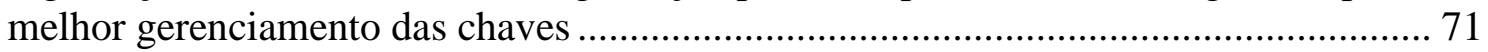

Figura 24: Exemplo da estratégia 'defesa em profundidade' associada com mecanismos

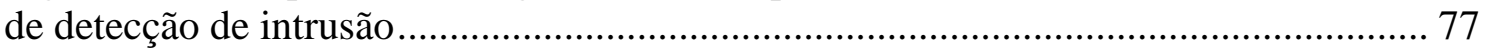

Figura 25: Interrelações do Aprendizado de Máquina .................................................. 79

Figura 26: Fluxograma de Aprendizado de Máquina para Classificação........................ 80

Figura 27: Fluxograma de Aprendizado de Máquina clássico ..................................... 83

Figura 28: Divisão em conjuntos Treinamento, Validação e Teste................................. 84

Figura 29: Principais áreas do Aprendizado de Máquina............................................... 86

Figura 30: Processo de extração de atributos por meio da Janela Deslizante (estado j) 88

Figura 31: Processo de extração de atributos por meio da Janela Deslizante (estado j+1)

Figura 32: Exemplo de processo de extração de atributos por meio da Janela Deslizante

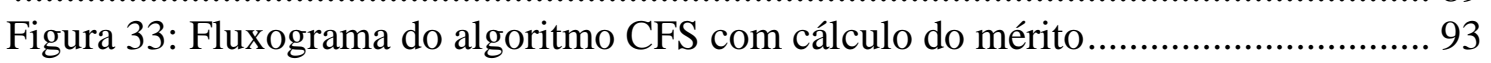

Figura 34: A estrutura de uma rede Autoencoder..................................................... 97

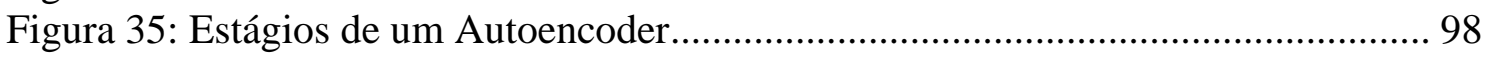

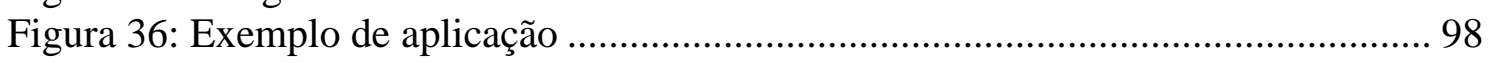

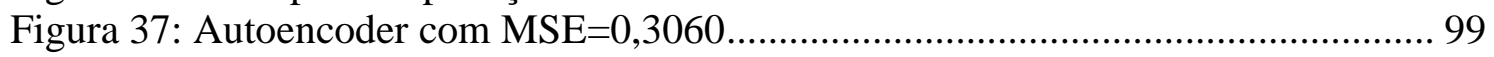

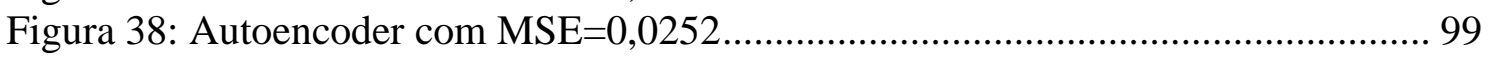

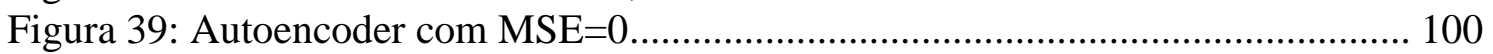

Figura 40: Exemplo de balanceamento do Conjunto de Treinamento com SMOTE ... 103

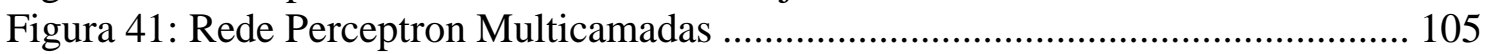

Figura 42: Exemplo de hiperplano de separação de classes ........................................ 107 
Figura 43: Influência do parâmetro $\gamma$ no kernel gaussiano.......................................... 108

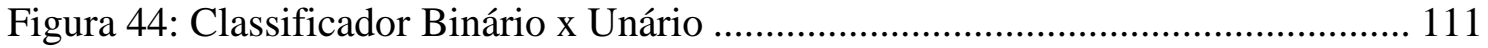

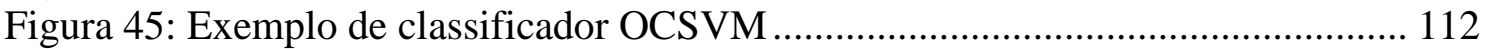

Figura 46: Validação Cruzada com 5 partições ........................................................ 114

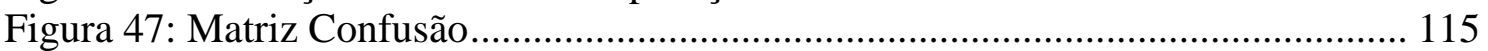

Figura 48: Ilustração das métricas de avaliação de classificadores .............................. 116

Figura 49: Fluxograma da metodologia proposta.................................................... 124

Figura 50: Interligação dos equipamentos para a captura ........................................ 125

Figura 51: Configuração da rede PROFINET no software TIA Portal ......................... 126

Figura 52: Interligação dos equipamentos para o Cenário 1 ....................................... 129

Figura 53: Interligação dos equipamentos para o Cenário 2 ........................................ 130

Figura 54: Interligação dos equipamentos para o Cenário 3 ........................................ 130

Figura 55: Interligação dos equipamentos para o Cenário 4 ....................................... 131

Figura 56: Tela principal do software Wireshark ........................................................ 132

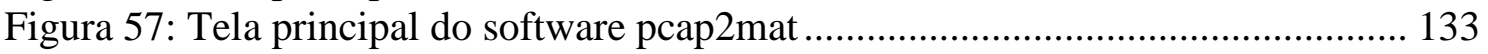

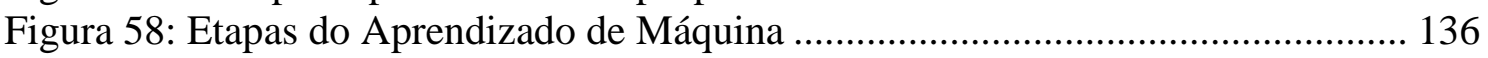

Figura 59: Separação do Conjunto de Dados em Conjunto de Treinamento e Teste ... 136

Figura 60: Etapas do treinamento para a abordagem binária ..................................... 137

Figura 61: Etapas do treinamento para a abordagem unária ....................................... 138

Figura 62: Fluxograma do algoritmo de treinamento dos classificadores binários ...... 139

Figura 63: Fluxograma do algoritmo de treinamento dos classificadores unários ....... 140

Figura 64: Fluxograma do algoritmo de teste dos classificadores binários.................. 143

Figura 65: Fluxograma do algoritmo de teste dos classificadores unários .................... 143

Figura 66: Estrutura geral do IDS proposto .................................................................. 144

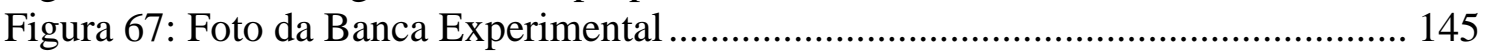

Figura 68: Captura do Cenário 4 no software Matlab ................................................ 147

Figura 69: Captura do Cenário 4 no software Excel ................................................. 147

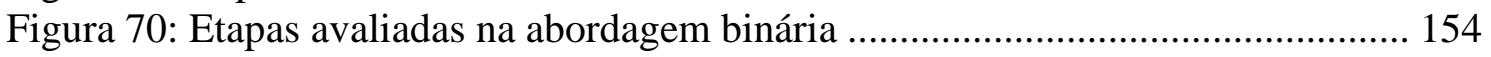

Figura 71: Etapas avaliadas na abordagem unária...................................................... 154

Figura 72: Comparativo de Acurácia média, Tempo de Execução médio e RMSE médio

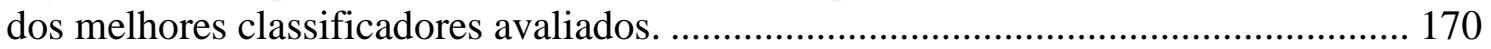

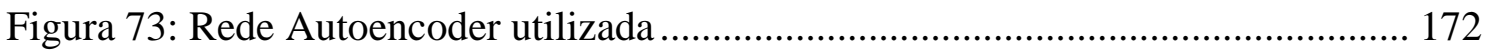

Figura 74: Valores de acurácia para cada valor de $\mathrm{N}$ analisado (O.F.Tr. $=0,000) \ldots \ldots 175$

Figura 75: Valores de acurácia para cada valor de $\mathrm{N}$ analisado (O.F.Tr. $=0,001) \ldots \ldots 178$

Figura 76: Valores de acurácia para cada valor de $\mathrm{N}$ analisado (O.F.Tr. $=0,002) \ldots \ldots 180$

Figura 77: Valores de acurácia para cada valor de $\mathrm{N}$ analisado (O.F.Tr. $=0,003) \ldots \ldots 182$

Figura 78: Valores de acurácia para cada valor de $\mathrm{N}$ analisado (O.F.Tr. $=0,010) \ldots \ldots .185$

Figura 79: Valores de acurácia para cada valor de $\mathrm{N}$ analisado (O.F.Tr. $=0,020) \ldots \ldots 187$

Figura 80: RNA com 3 entradas e 15 neurônios na camada escondida ........................ 192 


\section{Índice de Tabelas}

Tabela 1: Produção científica (critério Detecção de Ataques em Redes)......................... 4

Tabela 2: Produção científica (critério Detecção de Ataques em Redes Industriais)....... 4

Tabela 3: Produção científica (critério Ataques em Redes) ........................................... 4

Tabela 4: Produção científica (critério Ataques em Redes Industriais) ............................ 5

Tabela 5: Produção científica (critério Segurança em Redes Industriais)....................... 5

Tabela 6: Produção científica (critério Segurança em Redes PROFINET)...................... 6

Tabela 7: Produção científica (critério Detecção de Ataques em Redes PROFINET) .... 6

Tabela 8: Produção científica (critério Ataques em Redes PROFINET) ......................... 7

Tabela 9: Produção científica nas últimas décadas (sumário)......................................... 7

Tabela 10: Profiles do Ethernet industrial definidos na norma IEC61784 ......................62

Tabela 11: Serviços de segurança em diferentes camadas conforme o modelo ISO/OSI

Algumas funções kernel utilizadas pela SVM

Tabela 13: Equipamentos utilizados para a implementação da rede PROFINET ........ 125

Tabela 14: Softwares utilizados para a implementação e captura do tráfego da rede

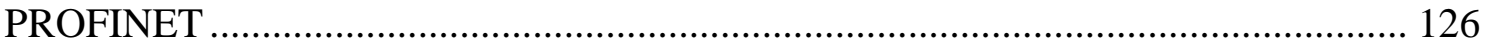

Tabela 15: Parâmetros da rede PROFINET configurada ............................................. 126

Tabela 16: Parâmetros de rede dos equipamentos envolvidos na captura.................... 127

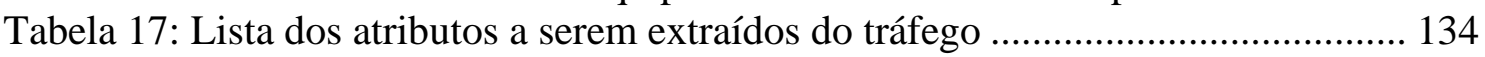

Tabela 18: Equipamentos PROFINET contidos em cada cenário................................. 146

Tabela 19: Informações do tráfego da rede PROFINET em cada cenário ..................... 146

Tabela 20: Valores Mínimos e Máximos para cada Atributo em cada cenário............. 148

Tabela 21: Quantidade de instâncias do Conjunto de Dados em cada cenário ............. 148

Tabela 22: Características estatísticas de cada atributo, após pré-processamento, para o

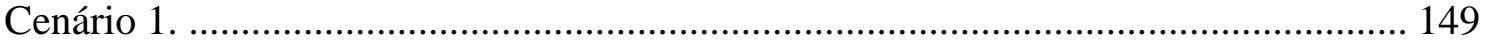

Tabela 23: Características estatísticas de cada atributo, após pré-processamento, para o

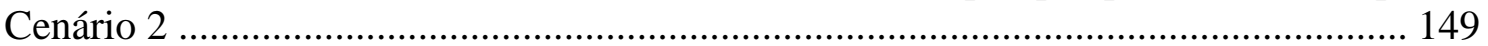

Tabela 24: Características estatísticas de cada atributo, após pré-processamento, para o

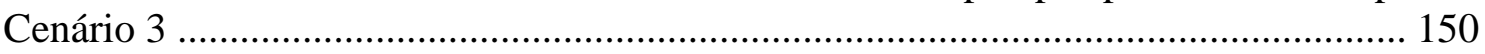

Tabela 25: Características estatísticas de cada atributo, após pré-processamento, para o

Cenário 4

Tabela 26: Quantidade de instâncias do Conjunto de Dados em cada cenário após a etapa

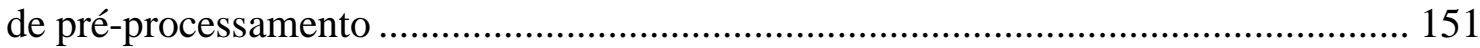

Tabela 27: Quantidade de amostras do Conjunto de Dados antes e depois da etapa de pré-

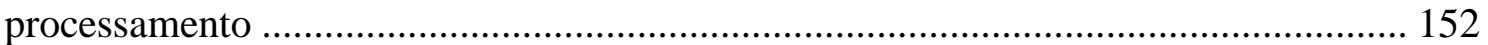

Tabela 28: Sequências e técnicas avaliadas nesse trabalho....................................... 153

Tabela 29: Conjunto Total de amostras dividido entre Conjunto de Treinamento e

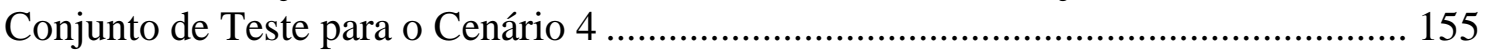

Tabela 30: Ranqueamento dos atributos com o método CFS para o Cenário 4. .......... 156

Tabela 31: Treinamentos realizados com vários valores de N ................................... 157

Tabela 32: Treinamentos realizados com vários valores de N1 e N2 com todos os atributos

Tabela 33: Treinamentos realizados com vários valores de $\mathrm{N}$

Tabela 34: Treinamentos realizados com vários valores de N1 e N2 com todos os atributos 158

Tabela 35: Treinamentos realizados com vários valores de $\mathrm{N}$................................. 158

Tabela 36: Treinamentos realizados com vários valores de N1 e N2 com todos os atributos 
Tabela 37: Treinamentos realizados com vários valores de $\mathrm{C}$ e $\gamma \ldots \ldots \ldots \ldots \ldots \ldots \ldots \ldots \ldots . . . . . . . . . . . . .159$

Tabela 38: Treinamentos realizados com vários valores de $\mathrm{C}$ e $\gamma$.............................. 159

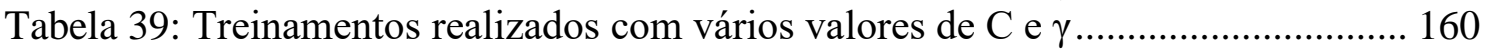

Tabela 40: Ranqueamento dos atributos com o método SVM RFE para o Cenário 4 . 161

Tabela 41: Treinamentos realizados com vários valores de $\mathrm{N}$................................... 162

Tabela 42: Treinamentos realizados com vários valores de N1 e N2 ......................... 162

Tabela 43: Treinamentos realizados com vários valores de $\mathrm{N}$.................................. 162

Tabela 44: Treinamentos realizados com vários valores de N1 e N2 ........................ 163

Tabela 45: Treinamentos realizados com vários valores de $\mathrm{N}$......................................163

Tabela 46: Treinamentos realizados com vários valores de N1 e N2 …..................... 163

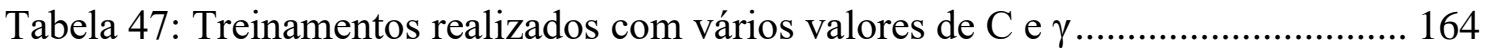

Tabela 48: Treinamentos realizados com vários valores de $\mathrm{C}$ e $\gamma$................................ 164

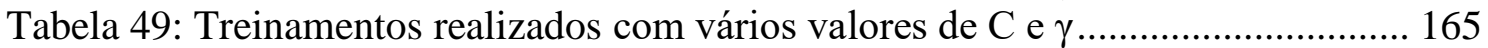

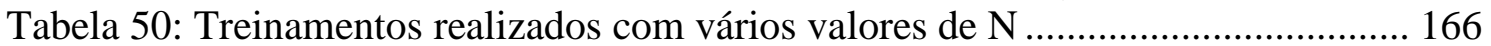

Tabela 51: Treinamentos realizados com vários valores de N1 e N2 ............................. 166

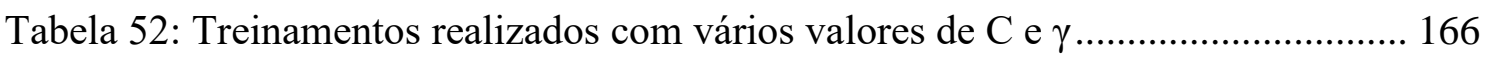

Tabela 53: Acurácia, tempo de execução e erro dos melhores classificadores frente ao

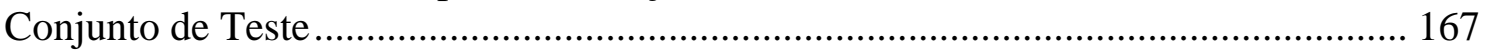

Tabela 54: Acurácia, tempo de execução e erro dos melhores classificadores frente ao

Conjunto de Teste treinados previamente sem o balanceamento de classes ................ 167

Tabela 55: Acurácia, tempo de execução e erro dos melhores classificadores frente ao

Conjunto de Teste treinados previamente sem o Pré-processamento........................... 168

Tabela 56: Acurácia, tempo de execução e erro dos melhores classificadores frente ao Conjunto de Teste treinados previamente sem o pré-processamento e sem o

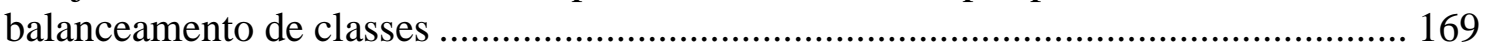

Tabela 57: Acurácia média, tempo de execução médio e erro médio dos melhores classificadores para cada caso analisado ............................................................... 169

Tabela 58: Conjunto Total de amostras dividido entre Conjunto de Treinamento e

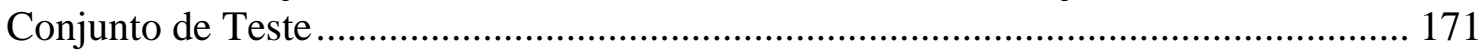

Tabela 59: Conjuntos de Treinamentos avaliados com diferentes valores de Outlier

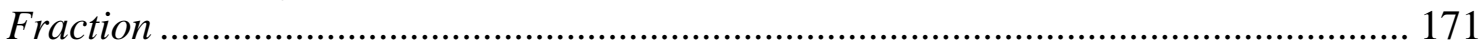

Tabela 60: Treinamentos do Autoencoder realizados com vários valores de $\mathrm{N}$ frente ao

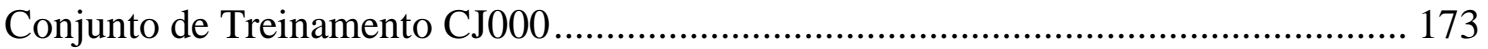

Tabela 61: Treinamentos realizados com vários valores de $\mathrm{N}$ frente ao ....................... 174 Tabela 62: Desempenho dos classificadores frente ao Conjunto de Teste (O.F.Te. =

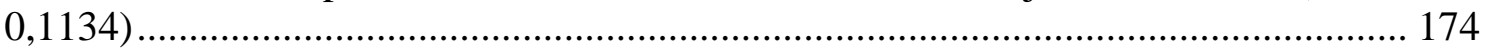

Tabela 63: Treinamentos do Autoencoder realizados com vários valores de $\mathrm{N}$ frente ao Conjunto de Treinamento CJ001 ........................................................................... 176

Tabela 64: Treinamentos realizados com vários valores de OutlierFraction frente ao 176 Tabela 65: Desempenho dos classificadores frente ao Conjunto de Teste (O.F.Te. =

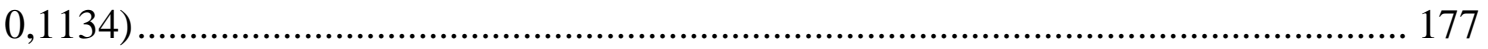

Tabela 66: Treinamentos do Autoencoder realizados com vários valores de $\mathrm{N}$ frente ao

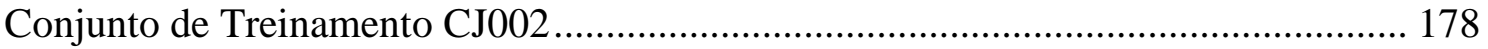

Tabela 67: Treinamentos realizados com vários valores de OutlierFraction frente ao 179 Tabela 68: Desempenho dos classificadores frente ao Conjunto de Teste (O.F.Te. = $0,1134)$.....

Tabela 69: Treinamentos do Autoencoder realizados com vários valores de $\mathrm{N}$ frente ao Conjunto de Treinamento CJ003..... 180

Tabela 70: Treinamentos realizados com vários valores de $\mathrm{N}$ frente ao 181 
Tabela 71: Desempenho dos classificadores frente ao Conjunto de Teste (O.F.Te. $=$ $0,1134)$

Tabela 72: Treinamentos do Autoencoder realizados com vários valores de $\mathrm{N}$ frente ao

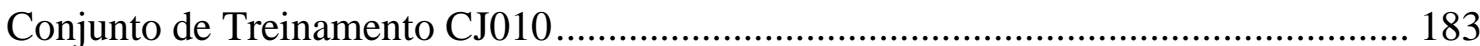

Tabela 73: Treinamentos realizados com vários valores de $\mathrm{N}$ frente ao ...................... 183

Tabela 74: Desempenho dos classificadores frente ao Conjunto de Teste (O.F.Te. = $0,1134)$

Tabela 75: Treinamentos do Autoencoder realizados com vários valores de $\mathrm{N}$ frente ao Conjunto de Treinamento CJ020. 185

Tabela 76: Treinamentos realizados com vários valores de OutlierFraction frente ao 186 Tabela 77: Desempenho dos classificadores frente ao Conjunto de Teste (O.F.Te. = $0,1134)$ 186

Tabela 78: Treinamentos realizados sem a redução da dimensionalidade. .................. 187 Tabela 79: Desempenho dos classificadores frente ao Conjunto de Teste (O.F.Te. = $0,1134)$ 188

Tabela 80: Acurácia, tempo de execução e desempenho dos melhores classificadores unários frente ao Conjunto de Teste 188

Tabela 81: Valores de MSE Total dos Autoencoders para cada valor de O.F.Tr. avaliado 190

Tabela 82: Valores de desempenho dos melhores classificadores para cada valor de

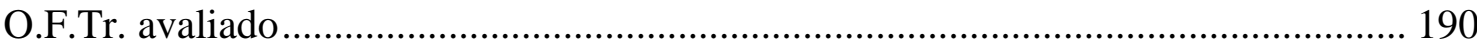

Tabela 83: Conjuntos de Amostras utilizadas em cada cenário ................................... 192

Tabela 84: Resultados do IDS com o classificador binário......................................... 193

Tabela 85: Resultados do IDS com o classificador unário .............................................. 193

Tabela 86: Dispositivos da rede PROFINET em cada novo cenário ............................. 194

Tabela 87: Informações do tráfego da rede PROFINET em cada novo cenário ........... 195

Tabela 88: Conjuntos de Amostras utilizadas em cada novo cenário ........................... 195

Tabela 89: Resultados da classificação unária em cada cenário .................................. 195 



\section{Lista de Abreviatura e Siglas}

ACL Access Control List

AE Autoencoder

AM Aprendizado de Máquina

ARP Address Resolution Protocol

CERT Centro de Estudos para Resposta e Tratamento de Incidentes em Computadores

CFS Correlation-based Feature Selection

CLP Controlador Lógico Programável

CNN Convolutional Neural Network

CPS Cyber-Physical System

CSV Comma-separated Values

DCP Discovery and Configuration Protocol

DCS Distributed Control System

DES Data Encryption Standard

DIDS Distributed Intrusion Detection System

DMZ Demilitarized Zone

DoS Denial of Service

DPN Deep Neural Network

DVP Desvio Padrão

FDI False Data Injection

FNR False Negative Rate

FPR False Positive Rate

GAN Generative Adversarial Network

HIDS $\quad$ Host Intrusion Detection System

IA Inteligência Artificial 
IACS Industrial Automation and Control Systems

IDS Intrusion Detection System

IEC International Electrotechnical Commission

IEEE Institute of Electrical and Electronic Engineers

IHM Interface Homem-Máquina

IPS Intrusion Prevention System

ISA International Society of Automation

ISO International Organization for Standardization

KDD Knowledge Discovery in Databases

LAN Local Area Network

LDA Linear Discriminant Analysis

MAC Media Access Control

MAT Formanto de arquivo de dados do software Matlab

MITM Man In The Middle

MLP Multilayer Perceptron

MMS Manufacturing Messaging System

MSE Mean Square Error

NIDS Network Intrusion Detection System

NNI Número de conexões normais

NTA Número Total de Ataques

NTN Número Total de conexões Normais

OCC One-Class Classification

OCSVM One-Class Support Vector Machine

OPC-UA Open Platform Communications Unified Architecture

OSI Open System Interconnection

PCA Principal Component Analysis 
PMC Perceptron Multicamadas

RBAC Role-Based Access Control

$\mathrm{RF}$

Random Forest

RFE

Recursive Feature Elimination

RISI Repository for Industrial Security Incidents

RMSE Root Mean Square Error

RNA Rede Neural Artificial

RTE Real Time Ethernet

SAE Stacked Autoencoder

SCADA Supervisory Control and Data Acquisition

SDI Sistemas de Detecção de Intrusão

SMO Sequential Minimal Optimization

SMOTE Synthetic Minority Over-sampling Technique

SNMP Simple Network Management Protocol

SSL Secure Socket Layer

SVM Support Vector Machine

TAF Taxa de Alarmes Falsos

TCP Transmission Control Protocol

TD Taxa de Detecção

TLS Transport Layer Security

TNR True Negative Rate

TPR True Positive Rate

UDP User Datagram Protocol

VPN $\quad$ Virtual Private Network

WEKA Waikato Environment for Knowledge Analysis 


\section{Sumário}

\section{Capítulo 1}

Introdução à tese de doutorado ...................................................................1 1

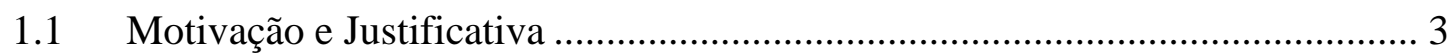

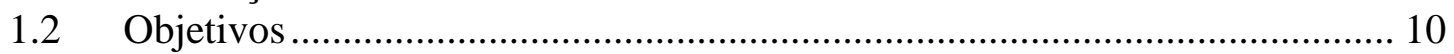

1.3 Contribuição original e Lastro da Pesquisa ..................................................... 10

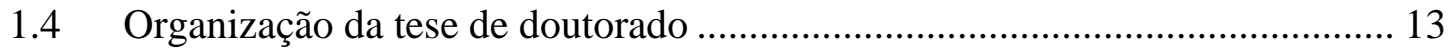

\section{Capítulo 2}

\section{Sistemas de Detecção de Intrusão e Ataques em Redes Industriais..... 15}

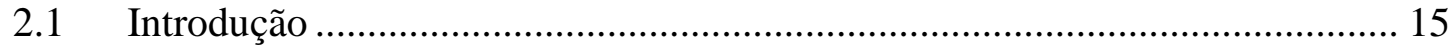

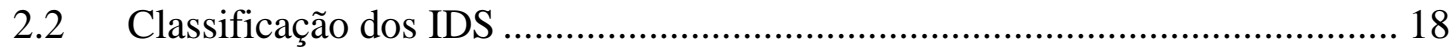

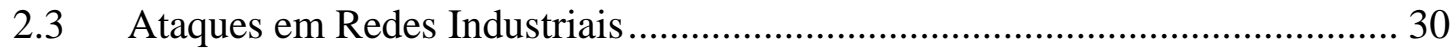

2.4 Trabalhos correlatos em deteç̧ão de anomalias ............................................ 39

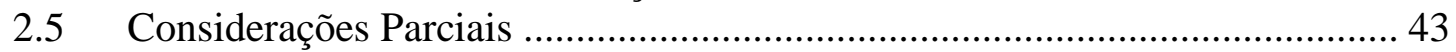

\section{Capítulo 3}

Aspectos da Tecnologia PROFINET e de Segurança em Redes Industriais ......................................................................................................................445

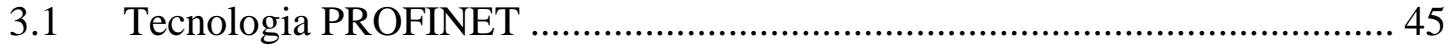

3.2 Segurança em redes de Automação ............................................................ 51

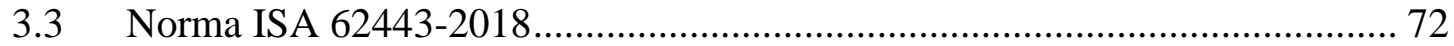

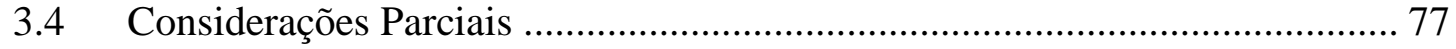

\section{Capítulo 4}

Ferramentas Matemáticas e Computacionais .........................................79

4.1 Conceitos básicos sobre Aprendizado de Máquina …...................................... 79

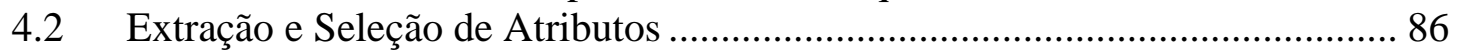

4.3 Balanceamento do conjunto de dados ........................................................ 100

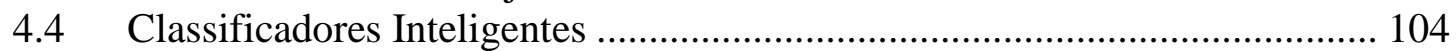

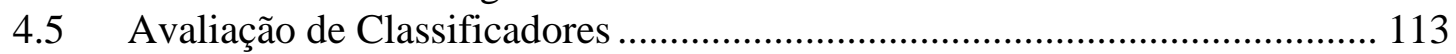

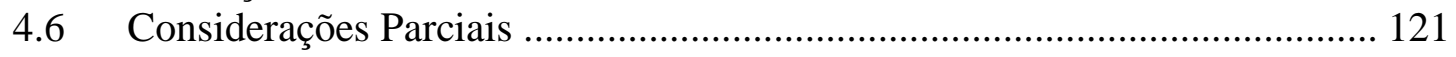

\section{Capítulo 5}

Método para detecção de intrusão em redes PROFINET baseado em técnicas de Aprendizado de Máquina ........................................................... 123

5.1 Implementação da rede em bancada experimental ..................................... 124

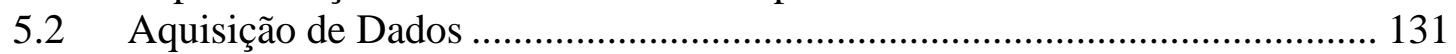




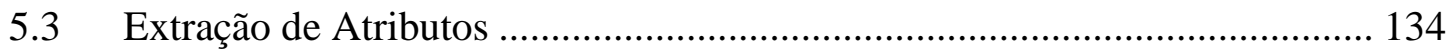

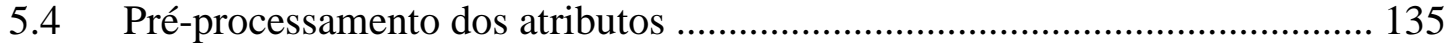

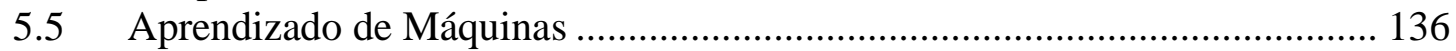

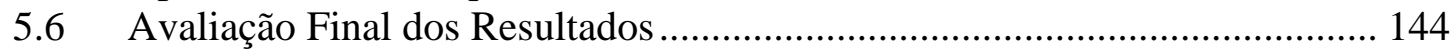

\section{Capítulo 6}

Resultados e Discussões ....................................................................145

6.1 Implementação da rede em bancada experimental ...................................... 145

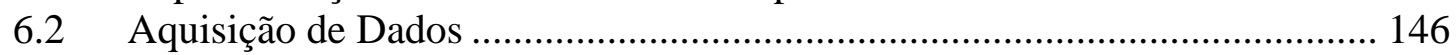

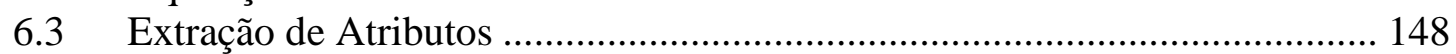

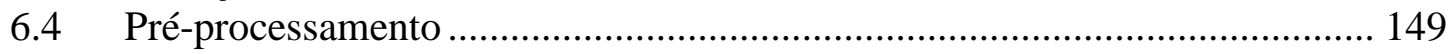

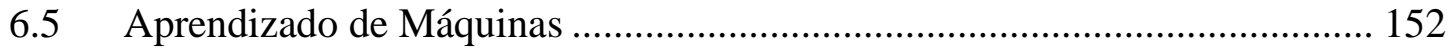

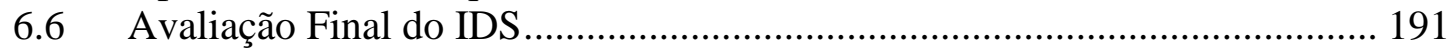

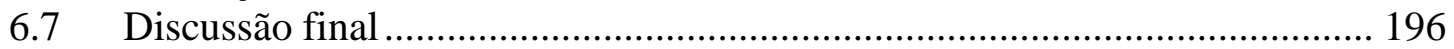

\section{Capítulo 7}

Considerações finais do trabalho......................................................................2203

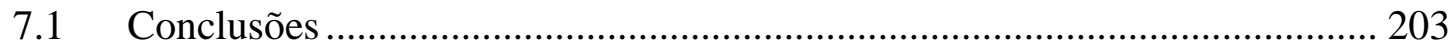

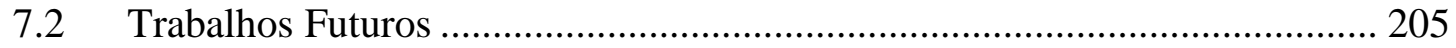

Referências Bibliográficas .......................................................................207

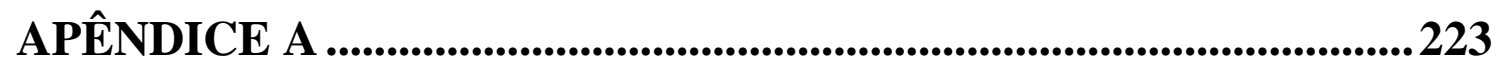

APÊNDICE B ............................................................................................ 227 


\section{Capítulo 1}

\section{Introdução à tese de doutorado}

Em um cenário de Indústria 4.0, Internet das Coisas e Big Data, a comunicação industrial é de grande importância e um dos pontos chave para a automação moderna. Ela é utilizada para controlar, monitorar máquinas e sistemas nos processos de produção e de manufatura (SESTITO, 2018). Soluções fáceis de implementar e com grande capacidade de fornecer disponibilidade em tempo real, topologias flexíveis e integração com demais protocolos, até mesmo em grandes distâncias, são necessidades reais (PROFIBUS \& PROFINET INTERNATIONAL, 2015).

O PROFINET é um padrão aberto de RTE (Real Time Ethernet) para automação criado em 2002 cujas suas capacidades foram aprimoradas para satisfazer as condições mais severas encontradas nas aplicações industriais (POPP; WEBER, 2004). Em 2020, os protocolos RTE já ocupam 64\% do mercado mundial. Considerando-se apenas os protocolos RTE, o PROFINET já representa $17 \%$ de todo o mercado (CARLSSON, 2020).

$\mathrm{O}$ aumento na quantidade de informações importantes que percorrem as redes de computadores faz com que a segurança seja fundamental para garantir a integridade, a confidencialidade e a disponibilidade dos dados trafegados. No ambiente industrial isso não é diferente. Em busca desse aumento da segurança, são utilizados dispositivos como firewalls e Sistemas de Detecção de Intrusão (SDI) e outros (SAUTER; TREYTL, 2015).

As redes de comunicação atuais evoluem rapidamente, o mesmo é verdadeiro para os ataques cibernéticos a essas redes. Novas vulnerabilidades aparecem todos os dias e são rapidamente exploradas em ataques zero-day ${ }^{1}$ (CERT.BR, 2019).

Os recentes avanços na tecnologia de manufatura, como sistemas CPS (Cyber Physical Systems), a Internet industrial, IA (Inteligência Artificial) e o aprendizado de máquina, impulsionaram a evolução das arquiteturas de manufatura em redes integradas de dispositivos, serviços e empresas de automação. Um dos desafios resultantes dessa

\footnotetext{
${ }^{1}$ Ataque zero-day é um ataque virtual que ocorre no mesmo dia em que uma vulnerabilidade do software é descoberta. Então, ele é explorado antes que o fornecedor disponibilize uma correção (KASPERSKY, 2019).
} 
evolução é o aumento da necessidade de interoperabilidade em diferentes níveis do ecossistema de manufatura (ZEID et al., 2019).

Além disso, as redes de comunicação compõem parte crítica da infraestrutura nos sistemas de controle de processos onde ocorrem trocas de informações cruciais via rede de dados (LINDA; VOLLMER; MANIC, 2009). Essa infraestrutura crítica, que cada vez mais está focada em segurança, pode ser encontrada em sistemas tipo SCADA (Supervisory Control And Data Acquisition) e em plantas nucleares (KIM; REDDY, 2008; YANG; USYNIN; HINES, 2005).

O comprometimento destes sistemas pode não somente levar a grandes perdas financeiras, como também, colocar em perigo a segurança pública. Desta forma, fica evidente a necessidade de proteção destas infraestruturas críticas frente a possíveis anomalias (LINDA; VOLLMER; MANIC, 2009).

Uma anomalia, no contexto de redes de comunicação, pode ser definida como qualquer desvio ocorrido em relação ao comportamento normal e que, na maioria dos casos, foi criada com a intenção de comprometer ou causar o mau funcionamento do sistema. Algumas anomalias podem ser tentativas de invasão por parte de entidades não autorizadas (ex. hackers) para terem acesso à informação confidencial ou então, para comprometer o funcionamento do sistema (BARFORD et al., 2002).

Já os Sistemas de Detecção de Intrusão (IDS - Intrusion Detection Systems) têm como objetivo rastrear e identificar alguma atividade imprópria, ilegal ou anômala na rede. As tecnologias de detecção de intrusão são utilizadas para viabilizar a observação de conjuntos de dados de rede, em busca de ameaças potenciais ou conhecidas no tráfego de rede e/ou nos dados de auditoria registrados nos próprios equipamentos (NORTHCUTT; NOVAK, 2002).

Em termos gerais, existem dois tipos de IDS, os baseados em assinaturas e os baseados em anomalias. Para que os sistemas baseados em assinatura funcionem, é necessária uma base de dados que contenha todas as assinaturas dos casos de intrusões já conhecidas e identificadas. Em contrapartida, os sistemas baseados em anomalias buscam por desvios ocorridos em relação ao comportamento normal assimilado em sua etapa de aprendizado. Assim, este tipo de sistema de detecção constrói um modelo representativo baseado exclusivamente em casos anteriores de comportamento normal e não assimila informações sobre as características de intrusões futuras (SILVA, 2008). 
Muitas aplicações de Aprendizado de Máquina do mundo real envolvem o aprendizado de conjuntos de dados desbalanceados como é o caso das aplicações de detecção de intrusão (LEE; STOLFO, 2000).

Aprender a partir de conjuntos de dados que contêm pouquíssimos exemplos da classe minoritária (ou de interesse) geralmente produz classificadores tendenciosos que têm uma maior acurácia preditiva sobre a(s) classe(s) maioritária, mas menor acurácia preditiva sobre a classe minoritária. É importante também considerar o alto custo em se obter amostras de tráfego anômalo para o treinamento dos algoritmos, uma vez que, esse tráfego anômalo pode implicar a parada da rede de comunicação impactando diretamente no tempo de parada da planta industrial.

Neste trabalho é apresentado um roteiro para o uso de aprendizado de máquina para detecção de anomalias em redes industriais. Para isso, a abordagem de detecção baseada em anomalia foi adotada para o desenvolvimento de um IDS.

Utiliza-se técnicas de aprendizado de máquina para a extração de atributos do tráfego da rede, para o balanceamento de classes do conjunto de amostras obtidos, para a seleção dos atributos principais (reduzindo-se a dimensionalidade e as informações redundantes) e classificadores unários e binários. Para a classificação do tráfego, são aplicadas duas técnicas amplamente utilizadas para a classificação de padrões, são elas: redes neurais artificiais (RNA) e máquina de vetores suporte (SVM), que ficam responsáveis por identificar e classificar o fluxo de pacotes entre as classes 'NORMAL' e 'ANÔMALO'.

\subsection{Motivação e Justificativa}

Em uma pesquisa de revisão bibliográfica quantitativa, considerando publicações científicas realizadas até Dezembro de 2018, selecionando-se todas as bases de dados disponíveis pelo mecanismo de busca e configurando como critério de filtro as keywords: 'intrusion detection system' ou 'anomaly detection system' e 'network', foram encontrados $\underline{9076}$ resultados entre Artigos, Jornais, Revistas, Atas de Conferências, entre outros, no período compreendido entre 1977 e 2018. 
Os resultados estão descritos na Tabela 1.

Tabela 1: Produção científica (critério Detecção de Ataques em Redes) FONTE: Adaptado de (IEEE, 2019).

\begin{tabular}{crr} 
ANO & \multicolumn{2}{c}{ RESULTADOS } \\
\hline Até 1985 & 2 & $0,02 \%$ \\
\hline $1986-1995$ & 66 & $0,73 \%$ \\
\hline $1996-2005$ & 1208 & $13,3 \%$ \\
\hline $2006-2015$ & 5666 & $62,4 \%$ \\
\hline $2016-2018$ & 2134 & $23,5 \%$ \\
\hline TOTAL & 9076 & $100 \%$ \\
\hline
\end{tabular}

Alterando-se o critério de busca com as keywords: 'intrusion detection system' ou 'anomaly detection system' e 'industrial network', foram encontrados $\underline{347}$ resultados no período entre 1994 e 2018. Os resultados estão descritos na Tabela 2.

Tabela 2: Produção científica (critério Detecção de Ataques em Redes Industriais) FONTE: Adaptado de (IEEE, 2019).

\begin{tabular}{crr} 
ANO & \multicolumn{2}{c}{ RESULTADOS } \\
\hline Até 1985 & 0 & $0,00 \%$ \\
\hline $1986-1995$ & 4 & $1,15 \%$ \\
\hline $1996-2005$ & 22 & $6,34 \%$ \\
\hline $2006-2015$ & 183 & $52,8 \%$ \\
\hline $2016-2018$ & 138 & $39,8 \%$ \\
\hline TOTAL & 347 & $100 \%$ \\
\hline
\end{tabular}

Alterando-se a busca com as keywords: 'intrusion' ou 'cyber attack' e 'network', foram encontrados $\underline{12327}$ resultados no período entre 1977 e 2018. Os resultados estão descritos na Tabela 3.

Tabela 3: Produção científica (critério Ataques em Redes) FONTE: Adaptado de (IEEE, 2019).

\begin{tabular}{crr} 
ANO & \multicolumn{2}{c}{ RESULTADOS } \\
\hline Até 1985 & 3 & $0,02 \%$ \\
\hline $1986-1995$ & 71 & $0,58 \%$ \\
\hline $1996-2005$ & 1515 & $12,3 \%$ \\
\hline $2006-2015$ & 7371 & $59,8 \%$ \\
\hline $2016-2018$ & 3367 & $27,3 \%$ \\
\hline TOTAL & 12327 & $100 \%$ \\
\hline
\end{tabular}

Adicionalmente, quando a busca foi realizada com as keywords: 'intrusion' ou 'cyber attack' e 'industrial network', foram encontrados apenas $\underline{589}$ resultados no período entre 1992 e 2018. Os resultados estão descritos na Tabela 4. 
Tabela 4: Produção científica (critério Ataques em Redes Industriais) FONTE: Adaptado de (IEEE, 2019).

\begin{tabular}{crr} 
ANO & \multicolumn{2}{c}{ RESULTADOS } \\
\hline Até 1985 & 0 & $0,00 \%$ \\
\hline $1986-1995$ & 3 & $0,51 \%$ \\
\hline $1996-2005$ & 21 & $3,57 \%$ \\
\hline $2006-2015$ & 283 & $48,1 \%$ \\
\hline $2016-2018$ & 282 & $47,9 \%$ \\
\hline TOTAL & 589 & $100 \%$ \\
\hline
\end{tabular}

Quando as keywords foram alteradas para: 'security' e 'industrial network', foram encontrados $\underline{3545}$ trabalhos publicados entre os anos 1967 e 2018 . Os resultados estão descritos na Tabela 5 .

Tabela 5: Produção científica (critério Segurança em Redes Industriais) FONTE: Adaptado de (IEEE, 2019).

\begin{tabular}{crr} 
ANO & \multicolumn{2}{c}{ RESULTADOS } \\
\hline Até 1985 & 3 & $0,08 \%$ \\
\hline $1986-1995$ & 21 & $0,59 \%$ \\
\hline $1996-2005$ & 251 & $7,08 \%$ \\
\hline $2006-2015$ & 2023 & $57,1 \%$ \\
\hline $2016-2018$ & 1247 & $35,2 \%$ \\
\hline TOTAL & 3545 & $100 \%$ \\
\hline
\end{tabular}

Detalhe que merece atenção nos resultados dessas buscas é que grande parte da produção científica, para cada caso supracitado, ocorreu na última década, sendo que, aproximadamente $35 \%$ (em média) de toda a produção científica ocorreu apenas nos últimos dois anos do período analisado, evidenciando o aumento das atividades de pesquisas nesses temas. A Figura 1 ilustra esses resultados. 


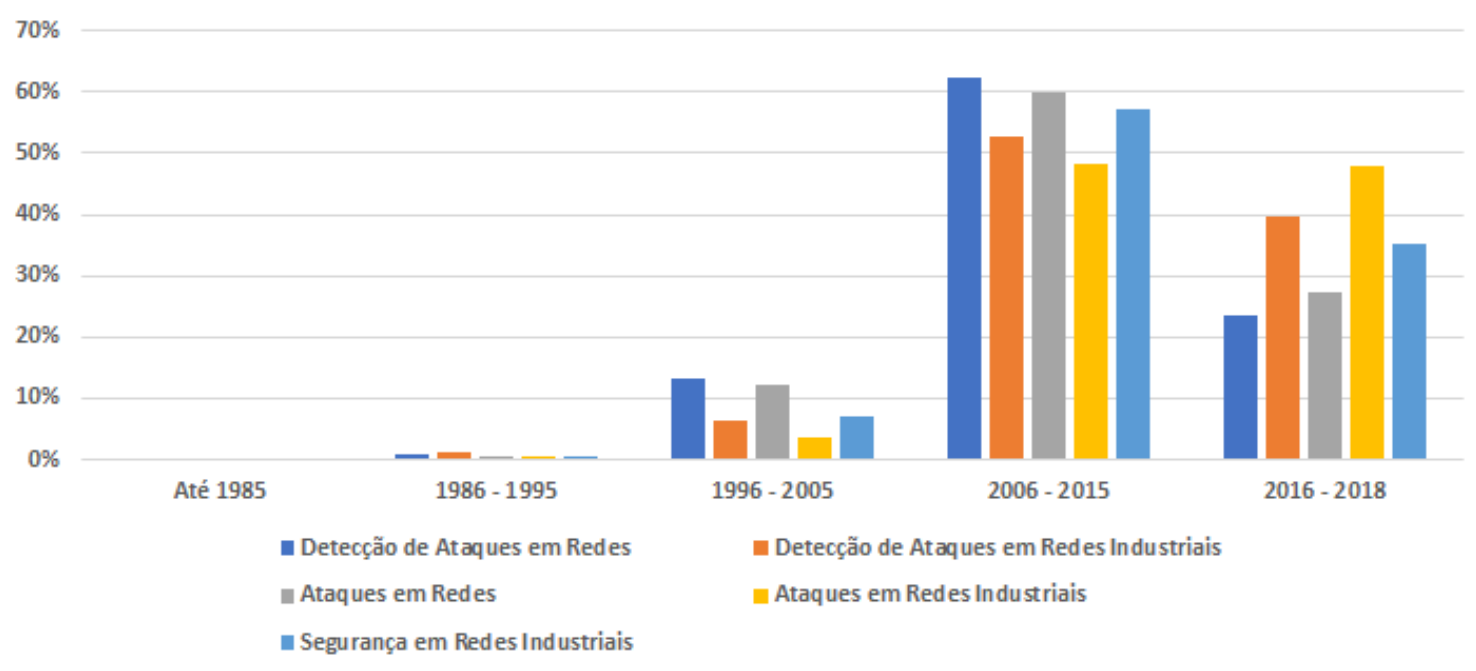

Figura 1: Produção científica nas últimas décadas. FONTE: Baseado nos dados de (IEEE, 2019).

Em contrapartida, quando a busca foi realizada com as keywords: 'security' $\mathrm{e}$ 'profinet', apenas $\underline{14}$ resultados foram encontrados no período compreendido entre 2006 e 2018. Os resultados estão dispostos na Tabela 6.

Tabela 6: Produção científica (critério Segurança em Redes PROFINET) FONTE: Adaptado de (IEEE, 2019).

\begin{tabular}{ccc} 
ANO & RESULTADOS \\
\hline Até 1985 & 0 & $0,00 \%$ \\
\hline $1986-1995$ & 0 & $0,00 \%$ \\
\hline $1996-2005$ & 0 & $0,00 \%$ \\
\hline $2006-2015$ & 7 & $50,0 \%$ \\
\hline $2016-2018$ & 7 & $50,0 \%$ \\
\hline TOTAL & 14 & $100 \%$ \\
\hline
\end{tabular}

Complementando a análise, refazendo-se a busca e configurando como critério de filtro as palavras-chaves 'intrusion detection system' ou 'anomaly detection system' e 'profinet', apenas quatro trabalhos foram retornados. Os resultados estão dispostos na Tabela 7.

Tabela 7: Produção científica (critério Detecção de Ataques em Redes PROFINET) FONTE: Adaptado de (IEEE, 2019).

\begin{tabular}{ccr} 
ANO & RESULTADOS \\
\hline Até 1985 & 0 & $0,00 \%$ \\
\hline $1986-1995$ & 0 & $0,00 \%$ \\
\hline $1996-2005$ & 0 & $0,00 \%$ \\
\hline $2006-2015$ & 0 & $0,00 \%$ \\
\hline $2016-2018$ & 4 & $100 \%$ \\
\hline TOTAL & 4 & $100 \%$ \\
\hline
\end{tabular}


Dentre os quatro trabalhos retornados, dois são de autoria do grupo de pesquisa do autor dessa tese:

SESTITO, G. S.; TURCATO, A. C.; DIAS, A. L.; FlAUZINO, R. A.; BRANDAO, D. Detection of Anomalies Related to the Operation of the Profinet Network Through Feature Extraction and Classification. IEEE Latin America Transactions, v.16, p. 1855-1861, 2018.

SESTITO, G. S.; TURCATO, A. C.; DIAS, A. L.; ROCHA, M. S.; DA SILVA, M. M.; FERRARI, P.; BRANDAO, D. A method for anomalies detection in Real Time Ethernet data traffic applied to PROFINET. IEEE Transactions on Industrial Informatics, v. 14, p. 2171-2180, 2017.

Alterando-se as palavras-chaves para: 'intrusion' ou 'cyber attack' e 'profinet', somente quatro trabalhos são retornados.

Tabela 8: Produção científica (critério Ataques em Redes PROFINET) FONTE: Adaptado de (IEEE, 2019).

\begin{tabular}{ccr} 
ANO & RESULTADOS \\
\hline Até 1985 & 0 & $0,00 \%$ \\
\hline $1986-1995$ & 0 & $0,00 \%$ \\
\hline $1996-2005$ & 0 & $0,00 \%$ \\
\hline $2006-2015$ & 0 & $0,00 \%$ \\
\hline $2016-2018$ & 4 & $100 \%$ \\
\hline TOTAL & 4 & $100 \%$ \\
\hline
\end{tabular}

A Tabela 9 resume as informações coletadas por meio das buscas pelo mecanismo de busca IEEE Xplore. Adicionalmente, na mesma tabela são apresentados os resultados das pesquisas pelo mecanismo de busca Scopus. Nota-se que os resultados das pesquisas apresentam os mesmos comportamentos e tendências nas duas bases de dados.

Tabela 9: Produção científica nas últimas décadas (sumário). FONTE: Adaptado de (IEEE, 2019; SCOPUS, 2019).

\begin{tabular}{llrr} 
ID & KEYWORDS & IEEE Xplore & Scopus \\
\hline 1 & 'intrusion detection system' OU 'anomaly detection system' E 'network' & 9076 & 24366 \\
\hline 2 & 'intrusion detection system' OU 'anomaly detection system' E 'industrial network' & 278 & 195 \\
\hline 3 & 'intrusion' OU 'cyber attack' E 'network' & 11246 & 80477 \\
\hline 4 & 'intrusion' OU 'cyber attack' E 'industrial network' & 469 & 450 \\
\hline 5 & 'security' E 'industrial network' & 3092 & 1369 \\
\hline 6 & 'security' E 'profinet' & 10 & 190 \\
\hline 7 & 'intrusion' OU 'cyber attack' E 'profinet' & 4 & 49 \\
\hline 8 & 'intrusion detection system' OU 'anomaly detection system' E 'profinet' & 4 & 23 \\
\hline
\end{tabular}


ATUALIZAÇÃO: no dia 05/06/2020 foram refeitas as buscas no sistema IEEE Xplore para cada combinação das keywords da Tabela 9. Os itens de 1 a 6 tiveram um aumento médio de 55\% em relação aos resultados encontrados anteriormente (até 2018). No entanto, nenhum aumento foi registrado para os itens 7 e 8 que estão diretamente relacionados a intrusão em redes PROFINET.

No tocante à produção de patentes, em uma pesquisa na base de patentes americana, são encontradas algumas invenções fortemente relacionadas ao desenvolvimento de sistemas de deteç̧ão de intrusão em redes de comunicação, de grandes empresas da área tecnológica. São elas:

- US20190014134A1

○ Empresa: Cisco Technology Inc (KOPP et al., 2017)

○ Título: "Private-Learned IDS"

○ Resumo: "Um método para identificar um botnet em uma rede, incluindo a análise de dados históricos da rede usando uma heurística pré-determinada para determinar os valores de um recurso baseado no gráfico de conectividade nos dados históricos da rede, obtendo um conjunto de dados reais com rótulos atribuídos a unidades de dados no dados históricos da rede identificando nós maliciosos conhecidos na rede."

- US20160261482A1

○ Empresa: Rosemount (MIXER; LAW; CUTCHIN, 2015)

○ Título: "Anomaly detection in industrial communications networks"

○ Resumo: "Um sistema de detecção de anomalias instalado em uma rede de comunicações da planta detecta alterações inesperadas ou anomalias nos padrões de tráfego na rede de comunicações para detectar nós infectados ou potencialmente infectados. O sistema de detecção de anomalias inclui vários módulos de coleta de dados em cada um dos nós da rede que operam para visualizar o tráfego de mensagens dentro e fora do nó e para gerar metadados relativos ao tráfego de mensagens." 
- US9483742B1

○ Empresa: Amazon (AHMED, 2014)

○ Título: "Intelligent traffic analysis to detect malicious activity"

○ Resumo: "As técnicas compreendem a identificação e/ou classificação de atividades maliciosas em uma plataforma de serviços da web usando técnicas de aprendizado de máquina. Sistemas, métodos e meios legíveis por computador podem fazer com que um ou mais nós de computação monitorem o primeiro tráfego de rede, gerem informações de rede com base no primeiro tráfego de rede monitorado, treine um algoritmo de aprendizado de máquina com base em pelo menos uma primeira parte das informações de rede geradas, testar o algoritmo de aprendizado de máquina com base em pelo menos uma segunda parte das informações de rede geradas, gerar um preditor usando o algoritmo de aprendizado de máquina treinado e testado e identificar o segundo tráfego de rede como um ou mais de atividade maliciosa e atividade benigna usando o preditor."

- US20120304007A1

○ Empresa: Boeing (HANKS; DORRIS; AYYAGARI, 2011)

○ Título: "Methods and systems for use in identifying abnormal behavior in a control system"

○ Resumo: "Métodos e aparelhos para uso na identificação de comportamento anormal em um sistema de controle. Os eventos operacionais associados a um sistema de controle são recebidos e um comportamento real do sistema de controle é determinado com base nos eventos operacionais recebidos. O comportamento real é comparado ao comportamento esperado para determinar se o comportamento real difere do comportamento esperado. $\mathrm{O}$ comportamento esperado inclui uma correlação entre uma pluralidade de eventos operacionais associados ao sistema de controle. O comportamento esperado é atualizado com base em uma indicação de se o comportamento real é anormal de um usuário."

A avaliação desses resultados indica que, nos últimos anos, tem ocorrido um aumento significativo na produção técnica e científica relacionada à segurança em redes de comunicação, inclusive em redes industriais, e no desenvolvimento de mecanismo para a detecção de intrusão/anomalias nessas redes, além da preocupação por parte das grandes empresas do setor. Contudo, especificamente para redes PROFINET ainda pouco tem sido produzido. Esse fato foi aspecto de motivação para o desenvolvimento desta tese. 


\subsection{Objetivos}

Diante da lacuna identificada, este trabalho propõe investigar, desenvolver, implementar e validar um método para detectar intrusão em redes PROFINET com uso de técnicas de Aprendizado de Máquina.

Dentro deste contexto, os objetivos específicos a serem alcançados pela metodologia proposta são:

- Desenvolver estratégias baseadas na técnica de janela deslizante para a extração de atributos do tráfego de redes PROFINET para auxiliar na identificação de intrusão à rede;

- Selecionar, projetar e aplicar ferramentas de aprendizagem de máquinas que, a partir dos atributos extraídos do tráfego, sejam capazes de identificar a ocorrência de intrusão;

- Obter altas taxas de detecção e, principalmente, êxito na identificação da presença de intrusão na rede com baixos valores de alarmes falsos.

Para o desenvolvimento deste trabalho são apresentados: o detalhamento do protocolo PROFINET, os mecanismos de segurança mais utilizados atualmente, os tipos de SDI existentes e os principais tipos de ataques em redes de comunicação conhecidos na literatura. Com estes conceitos em mente são apresentados alguns ensaios que possibilitam a comparação de desempenho entre as diversas técnicas avaliadas em busca da melhoria na taxa de detecção do SDI desenvolvido. Ensaios utilizando-se uma infraestrutura de rede instalada em laboratório, com diferentes equipamentos interligados foram realizados e os resultados apresentados.

\subsection{Contribuição original e Lastro da Pesquisa}

A principal inovação deste trabalho está relacionada à aplicação de combinações de técnicas e métodos para detecção de intrusão no tráfego de redes PROFINET por meio da aplicação de técnicas de Aprendizado de Máquina, que podem ser empregadas pelos Sistemas de Detecção de Intrusão para o diagnóstico avançado em redes de automação. 
O trabalho apresenta a integração de técnicas de extração e seleção de atributos, com a técnica de redução de dimensionalidade aplicando-se redes autoencoders, com o método SMOTE para o balanceamento das amostras do conjunto de dados e com o uso de classificadores one-class para a detecção de anomalias.

Portanto, a principal contribuição original é: comprovar que ao extrair os atributos, selecionar e/ou reduzir a dimensão, fazer o balanceamento das classes e classificar as características relevantes do tráfego de rede PROFINET, com técnicas de aprendizado de máquinas a partir de uma abordagem com classificadores unários e binários, é possível desenvolver um sistema de detecção de intrusão com alta taxa de detecção e baixa taxa de alarmes falsos.

Outras contribuições são:

- Aplicação da abordagem one-class para a implementação de um sistema de detecção de intrusão sem a necessidade prévia de tráfego anômalo para o treinamento do algoritmo de classificação.

- Criação de ferramenta online que permite aos usuários converterem os arquivos de captura em formato binário para formato CSV e MAT facilmente processados por ferramentas de manipulação de dados (como Matlab, WEKA, Excel...). Ferramenta já utilizada em (DIAS, 2019; SESTITO, 2018; TURCATO et al., 2017, 2018, 2020).

- Disponibilizar um método factível para usuários da tecnologia PROFINET a ser utilizado como identificação de anomalias (sendo elas ataques cibernéticos ou não) reduzindo o tempo de parada da planta industrial, os custos com manutenção corretiva e assim, contribuindo com o aumento da disponibilidade do sistema produtivo industrial.

A relevância do tema e sua atualidade contribuíram direta ou indiretamente para o desenvolvimento dos seguintes trabalhos já publicados:

TURCATO, A. C.; DIAS, A. L.; SESTITO, G. S.; FLAUZINO, R. A.; BRANDÃO, D.; SISINNI, E.; FERRARI, P.; Introducing a cloud-based architecture for the distributed analysis of Real Time Ethernet traffic. IEEE International Workshop on Metrology for Industry 4.0 \& IoT, Brescia, Itália, 2020.

DiAS, A. L.; SESTITO, G. S.; TURCATO, A. C.; BRANDÃO, D. Panorama, challenges and opportunities in PROFINET protocol research. 13th IEEE 
International Conference on Industry Applications (INDUSCON), São Paulo, Brazil, 2018, pp. 186-193. 2018.

SESTITO, G. S.; TURCATO, A. C.; DIAS, A. L.; BRANDÃO, D. Panorama, challenges and opportunities in PROFIBUS protocol research. 13th IEEE International Conference on Industry Applications (INDUSCON), São Paulo, Brazil, 2018, pp. 692-697. 2018.

SESTITO, G. S.; TURCATO, A. C.; DIAS, A. L.; FLAUZINO, R. A.; BRANDÃO, D. Detection of Anomalies Related to the Operation of the Profinet Network Through Feature Extraction and Classification. IEEE Latin America Transactions, v. 16, p. 1855-1861, 2018.

TURCATO, A. C.; DIAS, A. L.; SESTITO, G. S.; FLAUZINO, R. A., Ferramenta em Software Baseado em Web para Pré-Processamento de Tráfego de Redes Real Time Ethernet. In: $3^{\circ}$ CONGRESSO DE PÓS-GRADUAÇÃO DO IFSP, 2018, Boituva/SP. $3^{\circ}$ CONGRESSO DE PÓS-GRADUAÇÃO DO IFSP, 2018.

SESTITO, G. S.; TURCATO, A. C.; DIAS, A. L.; ROCHA, M. S.; DA SILVA, M. M.; FERRARI, P.; BRANDAO, D. A method for anomalies detection in Real Time Ethernet data traffic applied to PROFINET. IEEE Transactions on Industrial Informatics, v. PP, p. 1-1, 2017.

TURCATO, A. C.; DIAS, A. L.; BRANDAO, D.; FLAUZINO, R. A., Ferramenta em Software para Pré-Processamento de Tráfego de Redes PROFINET. In: $2^{\circ}$ CONGRESSO DE PÓS-GRADUAÇÃO DO IFSP, 2017, Cubatão/SP. $2^{\circ}$ CONGRESSO DE PÓS-GRADUAÇÃO DO IFSP, 2017.

TURCATO, A. C., Protocolos na Indústria 4.0. Controle \& Instrumentação, p. 19 - 29, 16 fev. 2017.

SESTITO, G. S.; TURCATO, A. C.; DIAS, A. L.; ROCHA, M. S.; BRANDAO, D.; TORRES, R. V. Case of study of a Profinet network using ring topology. In: 2016 IEEE International Symposium on Consumer Electronics (ISCE), 2016, Sao Paulo. 2016 IEEE International Symposium on Consumer Electronics (ISCE), 2016. p. 91.

DIAS, A. L.; SESTITO, G. S.; TURCATO, A.; ROCHA, M. S.; MOSSIN, E. A.; BRANDAO, DENNIS. Sistemas de medição para redes de comunicação industrial baseadas em Ethernet. In: IV Congresso de Automação e Inovação Tecnológica, 2016, Sertãozinho-SP. IV Congresso de Automação e Inovação Tecnológica, 2016.

TURCATO, A. C., Desenvolvimento de uma metodologia baseada em redes neurais artificiais para identificação de anomalias em redes de comunicação Profinet. Dissertação de Mestrado, Departamento de Engenharia Elétrica e Computação, EESCUSP, 2015.

TURCATO, A. C.; FlAUZINO, R. A.; SESTITO, G. S.; DIAS, A.; BRANDAO, D., Ataque denial of service em redes Profinet: estudo de caso. In: XII Simpósio Brasileiro de Automação Inteligente (SBAI), 2015, Natal/RN. XII Simpósio Brasileiro de Automação Inteligente (SBAI), 2015.

TURCATO, A. C.; SESTITO, G. S.; DIAS, A.; RAPANELLO, R. M., Recomendações de segurança em redes Profinet. In: III Congresso de Automação e Inovação 
Tecnológica Sucroenergética, 2015, Sertãozinho. III Congresso de Automação e Inovação Tecnológica Sucroenergética, 2015.

RAPANELLO, R. M.; TURCATO, A. C.; BRANDAO, D., Visão geral sobre segurança funcional utilizando redes industriais Profibus e Profinet com PROFISAFE. In: III Congresso de Automação e Inovação Tecnológica Sucroenergética, 2015, Sertãozinho. III Congresso de Automação e Inovação Tecnológica Sucroenergética, 2015.

SESTITO, G. S.; DIAS, A.; TURCATO, A. C.; BRANDAO, D.; Estudo de caso de uma rede Profinet com grande quantidade de dispositivos. In: I Congresso de Automação ISA Estudantil, 2015, Sertãozinho. I Congresso de Automação ISA Estudantil, 2015.

DIAS, A.; SESTITO, G. S.; TURCATO, A.; TOLEDO, P. H. T. O. E.; BRANDAO, D., Um Estudo sobre a Tecnologia Profinet. In: I Congresso de Automação e Inovação Tecnológica Sucroenergética, 2013, Sertãozinho. I Congresso de Automação e Inovação Tecnológica Sucroenergética, 2013.

SESTITO, G. S.; DIAS, A.; TURCATO, A. C.; TOLEDO, P. H. T. O. E.; BRANDAO, D., Análise Comparativa de Redes Profibus e Profinet. In: $17^{\circ}$ CONGRESSO INTERNACIONAL E EXPOSIÇÃO DE AUTOMAÇÃO, SISTEMAS E INSTRUMENTAÇÃO, 2013, São Paulo. Análise Comparativa de Redes Profibus e Profinet, 2013.

TURCATO, A. C., Diagnóstico de redes PROFINET IO utilizando software Wireshark. Revista Saber Eletrônica, v. 48, p. 34-40, 2012.

TURCATO, A. C.; BELLEZI, M. A., Desenvolvimento de um Software para obtenção de Parâmetros de Equipamentos HSE. Revista T.I.S - Tecnologias, Infraestrutura e Software, v. 1, p. 50-58, 2012.

\subsection{Organização da tese de doutorado}

A tese está organizada em capítulos. O Capítulo 2 apresenta os principais conceitos relacionados os Sistemas de Detecção de Intrusão como arquiteturas e métodos de detecção e os trabalhos correlatos relacionados à detecção de anomalias com técnicas de Aprendizado de Máquina. No Capítulo 3 são apresentados os conceitos técnicos sobre o protocolo PROFINET, focando principalmente em aspectos de segurança em redes industriais. Já no Capítulo 4, aspectos ligados a ferramentas matemáticas e computacionais empregadas neste trabalho, como técnicas de mineração de dados, de extração e de seleção de atributos, e utilização de sistemas inteligentes no desenvolvimento de classificadores. O Capítulo 5 fundamentalmente expõe a metodologia que será aplicada para a aquisição de dados e aplicação das técnicas de Aprendizado de Máquina e avaliação dos classificadores. O Capítulo 6 apresenta e discute 
os resultados obtidos. Finalmente, no Capítulo 7, são apresentadas as conclusões do trabalho e diretivas para trabalhos futuros. 


\section{Capítulo 2}

\section{Sistemas de Detecção de Intrusão e Ataques em Redes Industriais}

Este capítulo tem por finalidade a apresentação dos principais conceitos relacionados aos Sistemas de Detecção de Intrusão (IDS), como arquiteturas e métodos de detecção. Detecção de Intrusão é uma técnica utilizada para detectar ataques ou perturbações a um sistema computacional ou rede de computadores. Também serão apresentados os principais tipos de ataques em redes industriais e suas classificações e, ao final, os principais trabalhos correlatos relacionados à detecção de anomalias com técnicas de Aprendizado de Máquina.

\subsection{Introdução}

Sistemas IDS (Intrusion Detection System) são ferramentas que visam incrementar o nível de segurança em um sistema computacional (NORTHCUTT; NOVAK, 2002). O IDS usa as informações coletadas do sistema monitorado (computador, rede ou segmento de rede) para detectar intrusões. Enquanto as medidas de prevenção ativamente buscam evitar que ataques aconteçam, os sistemas de detecção procuram identificar ataques pela análise passiva do tráfego da rede ou os logs do sistema. Após a detecção de um ataque, um IDS deve gerar uma resposta, que pode ser uma intervenção automatizada no sistema ou um alerta para intervenção humana (KIZZA, 2017).

Segundo Costa (2007), os primeiros conceitos sobre sistemas capazes de detectar intrusões foram propostos por Anderson (1980) (ANDERSON, 1980). Na época, observou-se que os invasores agiam de forma diferente dos usuários comuns do sistema e que essa diferença poderia ser detectada, tornando-se possível uma análise quantitativa e qualitativa do ataque. Assim, para identificar os eventos anormais nos sistemas, tornouse necessária a criação de ferramentas automatizadas que se baseiam no histórico de operações do sistema, nos protocolos de rede, nas estatísticas computacionais e na mineração de dados (WANG, 2009). 
Especificamente para redes de comunicação, existem os NIDS (Network Intrusion Detection System) que utilizam informações coletadas da própria rede ou segmento de rede para identificar ataques que estejam ocorrendo ou que já tenham ocorrido.

Os sistemas NIDS usam geralmente dois tipos de abordagem: abordagem baseada em assinatura e abordagem baseada em anomalia sendo que cada uma dessas abordagens possui suas vantagens e desvantagens.

A abordagem baseada em assinaturas requer um conhecimento prévio a respeito da forma como cada ataque ocorre, ou seja, sua assinatura. Assim, os NIDS baseados em assinaturas são menos eficientes na identificação de ataques que usam técnicas ainda desconhecidas (SILVA, 2008).

Já a abordagem baseada na detecção de anomalias, que por sua vez, procura detectar alterações no padrão do tráfego em relação ao comportamento normal, pode gerar um excesso de falsos positivos, inviabilizando a intervenção automatizada ou acarretando na geração de excessivos falso-positivos (KRUEGEL; VIGNA, 2003).

Na pesquisa e desenvolvimento de um Sistema de Detecção de Intrusão baseado em anomalia em redes, é essencial o levantamento do perfil da rede. Essa construção do perfil da rede depende do método de análise usado e implica o conhecimento das características específicas do tráfego de dados da rede. Assim, nessa direção, existem diversos métodos de detecção de anomalias no tráfego de rede, como métodos baseados em análise estatística (SAMAAN; KARMOUCH, 2008), estatística bayesiana (LIU et al., 2008), cadeias de Markov (WANG et al., 2011); métodos de mineração de dados de formação de rankings (QIAN et al., 2013), algoritmos genéticos (A.A. OJUGO, A.O. EBOKA, O.E. OKONTA, R.E YORO (MRS), 2012) e métodos baseados na análise de sinais com transformada Wavelet (LU; TAVALLAEE; GHORBANI, 2008).

Muitos trabalhos também apresentam a utilização de técnicas de Aprendizado de Máquina no desenvolvimento de um IDS, como em (ABUROMMAN; REAZ, 2017) que usa classificadores híbridos, em (HORNG et al., 2011) que utiliza agrupamento hierárquico e SVMs, como em (SANGKATSANEE; WATTANAPONGSAKORN; CHARNSRIPINYO, 2011) que implementa o classificador com o algoritmo de Árvores de Decisão. Redes Neurais Artificiais são utilizadas em (AKASHDEEP; MANZOOR; KUMAR, 2017) para o desenvolvimento de um sistema de detecção de intrusão com poucas características do tráfego na entrada. Em (YANG et al., 2017), os autores utilizam 
o algoritmo de Enxame de Abelhas para calcular os pesos dos neurônios de uma rede neural artificial PMC. Em (WU; BANZHAF, 2010), Sistemas Imunológicos Artificiais, Inteligência Distribuída e soluções híbridas são avaliadas. Em (WENLI SHANG et al., 2015), os autores utilizam uma abordagem de classificadores one-class com o algoritmo SVM para a detecção dos ataques. Finalmente, em (PFRANG; MEIER, 2018) um modelo baseado em regras é testado para detectar ataques em redes industriais.

Nos diversos métodos citados, o processo de detecção de ataques realizado por um NIDS pode ser dividido em três atividades fundamentais (NORTHCUTT; NOVAK, 2002):

- Coleta: corresponde à obtenção dos dados do sistema monitorado e pode ser feita diretamente ou por meio de uma ferramenta de software ou hardware chamado sniffer. Os dados geralmente são oriundos de um computador, uma rede ou um segmento de rede.

- Análise: consiste no processamento desses dados coletados, procurando identificar a ocorrência de uma intrusão. Há diferentes métodos de análise que seguem a abordagem baseada em assinaturas ou baseada em anomalias que serão apresentados nas próximas seções.

- Resposta: representa o conjunto de ações que o IDS realiza quando detecta uma intrusão. É muito comum a geração de alarmes e registro em relatórios, mas o IDS também pode ser programado para fazer uma intervenção automatizada no sistema em caso de intrusão.

Os IDS estão se tornando um importante mecanismo de defesa para sistemas de controle supervisório e aquisição de dados (SCADA). É provável que os sistemas SCADA se tornem mais dinâmicos, levando à necessidade de pesquisas sobre como as mudanças na arquitetura de rede que são monitoradas afetam o desempenho dos mecanismos de defesa (STEWART et al., 2017).

O uso do aprendizado de máquina para detecção de anomalias em redes industriais enfrenta desafios que restringem sua implantação comercial em larga escala. Esses desafios vão desde a padronização da comunicação dentro das fábricas até a garantia legal 
de informações confidenciais pertencentes a vários atores envolvidos (MESHRAM; HAAS, 2017).

Os sistemas de comunicação industrial são baseados em protocolos de barramento de campo de décadas como o PROFIBUS e protocolos baseados em Ethernet desenvolvidos recentemente, como o PROFINET. Esses protocolos com fio são usados em células de produção de indústrias de manufatura com requisitos de alta confiabilidade e latência.

Linhas de produção modernas são fortemente conectadas em rede. Seus controladores e sistemas embarcados se comunicam de forma independente, os sistemas de planejamento baseados na nuvem calculam tarefas e utilização da máquina, os operadores da planta monitoram e controlam o sistema remotamente, a equipe de manutenção pode acessar e alterar a configuração da planta de qualquer lugar do planeta. As medidas de proteção de hoje para as plantas de produção devem ir muito além do local da fábrica. Os invasores podem se infiltrar e manipular sistemas; o malware pode colocar os subsistemas fora de ação, causando danos materiais significativos, sem mencionar os riscos à saúde das pessoas envolvidas.

Para proteger contra danos e interrupções de produção, são necessárias medidas adequadas para evitar incidentes de segurança. Um aspecto de segurança é a utilização de Sistemas de Identificação de Intrusão (IDS) no monitoramento do tráfego de rede para detectar anomalias que podem ser causadas por ataques cibernéticos nas linhas de produção.

\subsection{Classificação dos IDS}

Os sistemas de detecção de intrusão podem ser classificados levando-se em conta vários critérios: frequência de uso, o comportamento deste após a detecção dos eventos intrusivos, a arquitetura do sistema e método de detecção utilizado (SILVA, 2008). A Figura 2 ilustra essa classificação. 


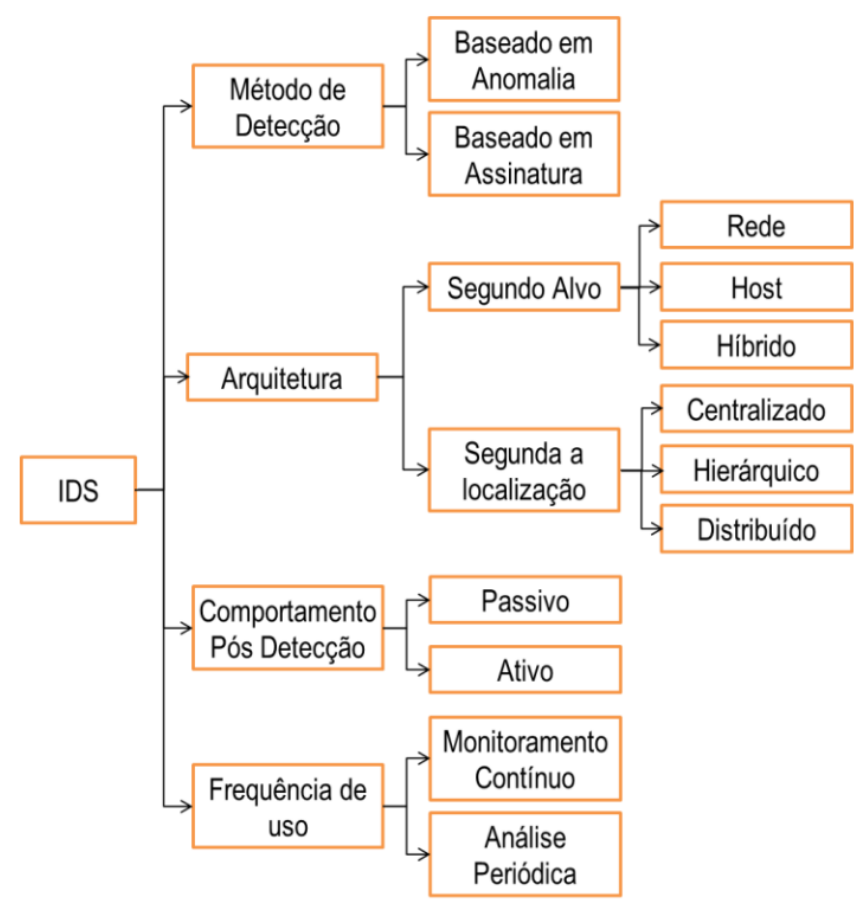

Figura 2: Categorias de classificação de um IDS FONTE: Adaptado de (SILVA, 2008)

\subsubsection{Frequência de uso}

Quanto à frequência de uso, dependendo de quando as detecções são utilizadas, os IDS podem ser classificados (WANG, 2009):

- Detecções em tempo real: analisam os dados quando eles chegam;

- Detecções em lote: analisam os dados quando um conjunto de dados coletados chegou em um tamanho específico;

- Detecções periódicas: analisam os dados periodicamente, em instantes pré-definidos.

\subsubsection{Comportamento após detecção}

Um IDS que é projetado para realizar, por exemplo, um bloqueio de conexões provenientes de uma origem não confiável, é denominado ativo, pois executa ações reativas após a detecção de intrusos. Alguns autores denominam esse tipo de sistema como IPS (Intrusion Prevention System) (LIAO et al., 2013).

Já os IDS passivos são aqueles que examinam as informações da rede ou sistemas e alertam sobre os ataques e ameaças emergentes, não reagindo ativamente aos ataques. 


\subsubsection{Arquitetura - localização do IDS}

Segundo a localização, o IDS pode ter arquitetura centralizada, distribuída ou hierárquica:

- Centralizada: possui seus módulos de detecção instalados em um único host e apresenta a vantagem da facilidade no desenvolvimento, na instalação e na configuração.

- Distribuída: possui seus módulos de detecção distribuídos em várias máquinas pela rede, que se comunicam de modo cooperativo por meio da troca de mensagens para garantir uma redundância intrínseca.

- Hierárquica: consiste na distribuição parcial dos componentes do IDS de modo que os módulos de detecção distribuídos fiquem subordinados a alguns módulos 'gerentes' e se comuniquem segundo uma coordenação centralizada, ou seja, os módulos obedecem a uma estrutura hierárquica, com a interação entre os módulos do sistema sendo regida por relações de subordinação.

A arquitetura distribuída apresenta como grande vantagem, em relação à centralizada, é a modularidade além de maior robustez. Como o IDS é dividido em vários elementos, há certa facilidade na adição de novos mecanismos ao sistema de acordo com a necessidade. Outra vantagem desta arquitetura é a possibilidade da distribuição de tarefas, retirando-se de um único ponto o custo e a responsabilidade de todo o processamento, além da vantagem adicional de se ter uma maior abrangência de detecção, com módulos espalhados pelos mais diferentes pontos do sistema. A desvantagem óbvia, é o custo e o gerenciamento desses inúmeros módulos.

Já a abordagem hierárquica foi desenvolvida para resolver alguns problemas referentes à implementação de sistemas completamente distribuídos. Algumas vantagens próprias dos sistemas distribuídos continuam a existir, enquanto a solução de problemas no sistema, como por exemplo na detecção de falhas nos módulos, é facilitada devido à estrutura hierárquica. Contudo, aumentam as chances de ataques ao sistema, principalmente pela criação de pontos únicos de falha, representados pelos módulos 'gerentes', os mais altos da estrutura hierárquica. Se um desses módulos falhar, todo o sistema pode tornar-se indisponível, sendo este, um contrassenso à principal motivação no uso de sistemas distribuídos (SILVA, 2008). 


\subsubsection{Arquitetura - conforme o alvo}

Uma das vantagens de um IDS em relação aos métodos tradicionais de análise de incidentes é a possibilidade de correlacionar diferentes tipos de dados coletados. Estas atividades de coleta de dados, no entanto, sejam elas feitas no próprio host ou na rede, determinam o tipo do IDS, baseado em rede, no próprio host ou híbrido.

\section{- $\quad$ Baseado em rede:}

Sigla NIDS (Network Intrusion Detection System).

Realizam a monitoração do sistema por meio da captura e análise de cabeçalhos (header) e conteúdo de pacotes (payload) de rede, os quais podem ser comparados com padrões de ataques conhecidos ou assinaturas previamente armazenadas em regras, arquivos ou bancos de dados, ou com padrões normais do tráfego, para verificação de algum desvio do comportamento normal da rede. A fonte de informação usada por um NIDS é a coleta dos dados que trafegam na própria rede (pacotes) e sendo essa informação bem diversificada devido aos inúmeros protocolos que podem coexistir em um mesmo segmento de rede.

A Figura 3 apresenta um exemplo de uso de NIDS em redes de computadores.

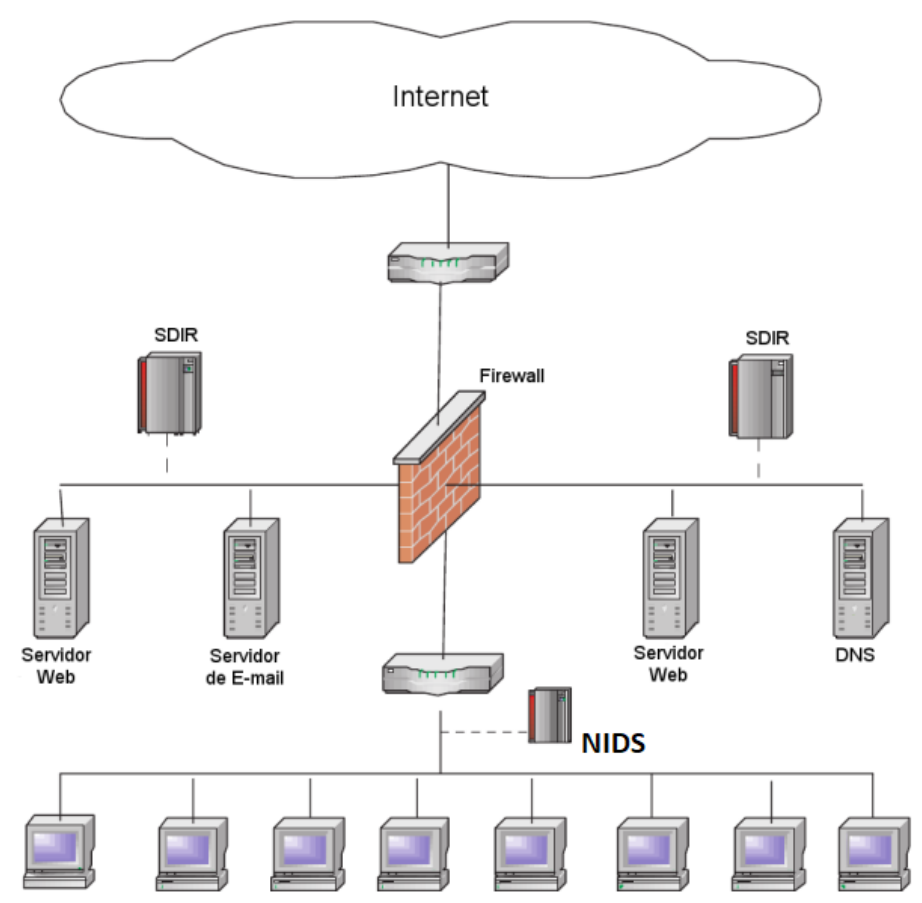

Figura 3: Sistemas de Detecção baseados em Rede FONTE: Adaptado de (BEALE et al., 2004) 
Segundo (DEMIRAY, 2005), as principais vantagens de um NIDS são:

○ uma grande rede pode ser monitorada por um número reduzido de sensores, pois estes sensores são instalados apenas nos pontos críticos da rede, como nos switches, hubs, roteadores etc.;

○ um sistema NIDS geralmente atua em modo passivo e consequentemente, não afeta o funcionamento normal da rede;

○ um sistema NIDS, muitas vezes, nem sequer é percebido pelos atacantes das redes.

Já as principais desvantagens são:

- em redes em que o tráfego de rede é elevado, pode ser difícil processar todos os pacotes que trafegam na rede;

- sistemas NIDS não conseguem analisar integralmente os pacotes de tráfego criptografado (somente dados do header, como origem/destino e tipo);

- pacotes de redes malformados podem fazer com que um sistema baseado em rede pare de funcionar.

\section{- Baseado em host}

\section{Sigla HIDS (Host Intrusion Detection System).}

Utilizam dados coletados na própria máquina como arquivos de log e registros de auditoria o que permite a determinação exata de quais usuários e processos executaram operações indevidas no sistema, o que garante boa precisão na detecção. Este tipo de IDS é capaz de monitorar os acessos à máquina, as alterações em arquivos críticos do sistema, modificações nos privilégios dos usuários, processos, programas que estão sendo executados, a disponibilidade de processamento e memória, entre outros eventos. Após a coleta destas informações, o sistema busca por padrões de ataques ou de desvios de comportamento de hosts ou usuários.

A Figura 4 apresenta um exemplo de uso de HIDS em redes de computadores. 


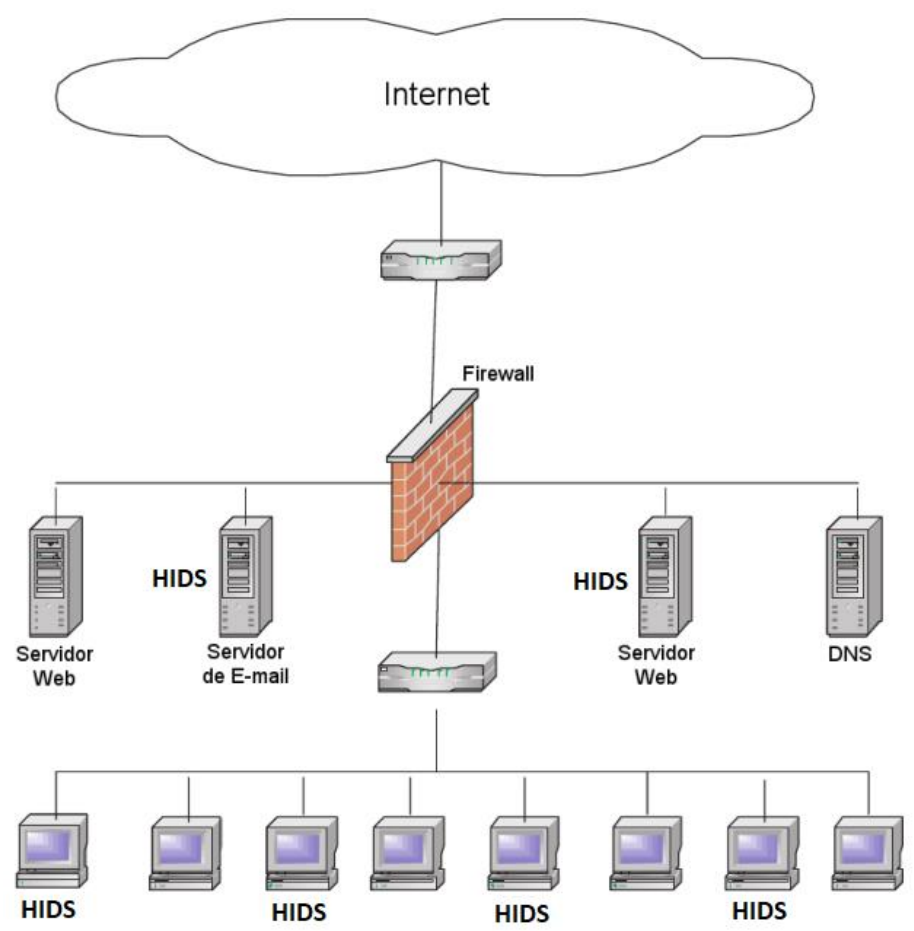

Figura 4: Sistemas de Detecção baseados em Host FONTE: Adaptado de (BEALE et al., 2004)

Segundo (DEMIRAY, 2005), as principais vantagens de um HIDS são:

○ como eles monitoram atividades locais, eles podem identificar ataques que não são detectados por um sistema NIDS;

- a base de dados desses sistemas geralmente é composta por arquivos textos simples, armazenados localmente e, portanto, podem operar perfeitamente em redes cujo tráfego de rede é criptografado;

○ a desempenho de um sistema baseado em Host não é afetado pela topologia de rede que operam e podem funcionar perfeitamente em redes comutadas (switches).

As principais desvantagens são:

- mais custoso gerenciar e manter um HIDS porque eles devem ser instalados/configurados em cada Host (individualmente);

○ um ataque sobre a máquina que executa o HIDS pode fazer com que o próprio sistema de detecção seja desativado; 
○ um sistema HIDS visualiza apenas os pacotes que são recebidos pela máquina onde ele está instalado, ou seja, é ineficaz para ataques que envolvem toda a rede;

○ Os sistemas HIDS compartilham os recursos da máquina onde estão instalados (CPU, memória RAM, HD etc.), consequentemente podem afetar o desempenho da máquina que o hospeda;

\section{- Híbrido}

Em busca de equilíbrio entre desempenho, simplicidade, abrangência e robustez, algumas implementações, mais avançadas de IDS, coletam diferentes dados de hosts e do tráfego de rede, mesclando mecanismos centralizados e mecanismos distribuídos. Grande parte das ferramentas de detecção de intrusão explora o melhor das arquiteturas baseadas em host e rede, adotando soluções híbridas (NORTHCUTT; NOVAK, 2002).

A Figura 5 apresenta um exemplo de uso de IDS híbrido.

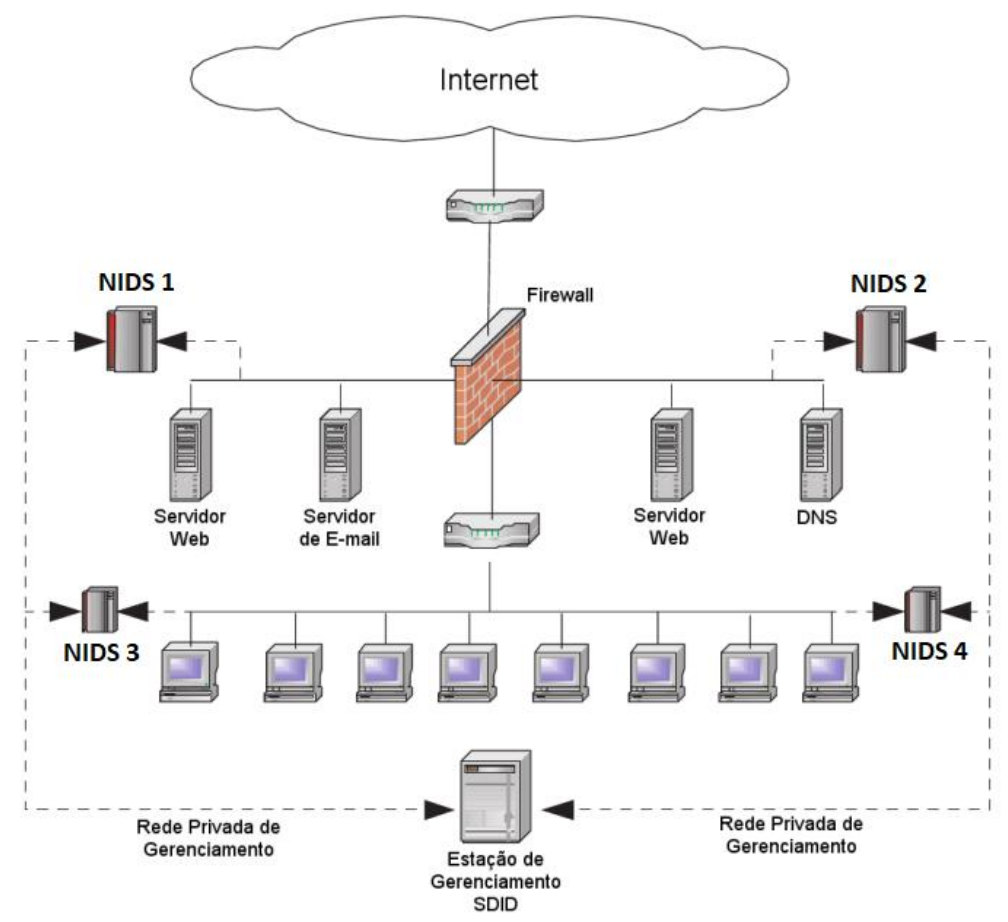

Figura 5: Sistemas de Detecção Híbridos (Distribuídos) FONTE: Adaptado de (BEALE et al., 2004) 


\subsubsection{Método de detecção}

Um IDS pode ser baseado em anomalias (baseado em comportamento) ou em assinatura (abuso ou baseado em conhecimento prévio). Anomalias são desvios do comportamento normal de uso, e assinaturas, por outro lado, são padrões conhecidos de ataques.

O método de detecção baseado em assinatura consiste no casamento de padrões de dados contra bases de dados contendo padrões de ataques conhecidos por eventos passados. Sistemas deste tipo são bastante eficientes na identificação de ataques e vulnerabilidades conhecidos, mas fracos na identificação de novas ameaças aos sistemas (vide Figura 6).

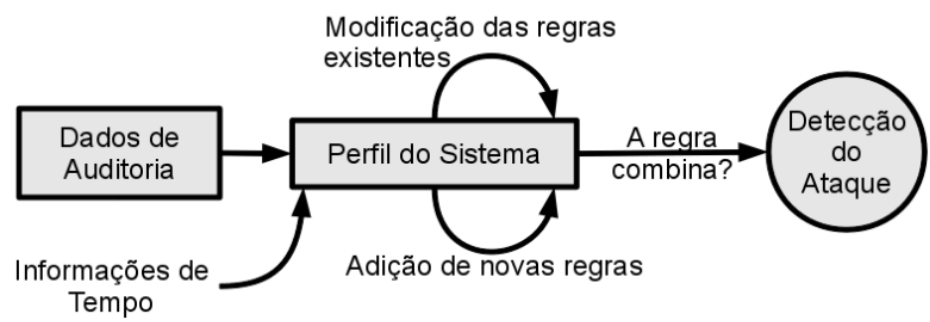

Figura 6: Sistemas de Detecção baseados em Assinatura FONTE: Adaptado de (SUNDARAM, 1996)

O método de detecção baseado em anomalia, por outro lado, busca dados inéditos ou não usuais em um conjunto de dados, aplicando várias técnicas matemáticas, estatísticas, de inteligência artificial (conforme descrito anteriormente), para comparar atividades dos usuários, rede ou sistemas com o conhecimento histórico armazenado sobre estes elementos. Os problemas mais comuns, com os sistemas baseados em anomalias, são os que requerem treinamento intensivo por meio de algoritmos de aprendizagem de máquinas, grande quantidade de dados históricos, e tendem a ser computacionalmente mais caros, porque devem realizar medições com mais frequência, alta capacidade armazenamento para manter os dados coletados e serem atualizados a cada novo comportamento do sistema, usuários ou rede. Isto resulta em armazenamento de grande quantidade de dados e consideráveis recursos de CPU para processá-los (vide Figura 7). 


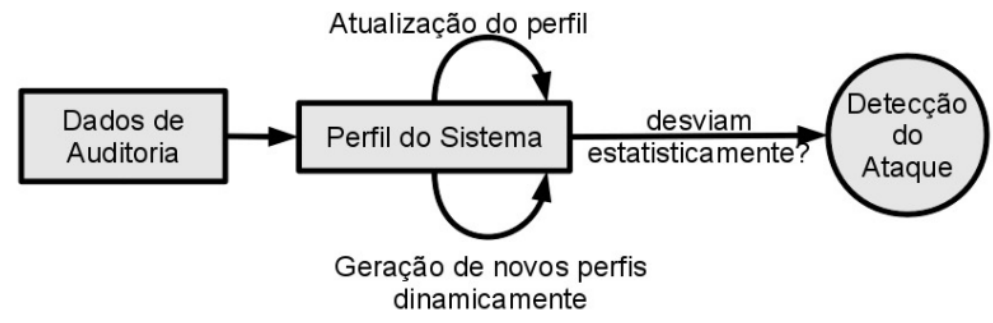

Figura 7: Sistemas de Detecção baseados em Anomalias FONTE: Adaptado de (SUNDARAM, 1996)

Os métodos de detecção de intrusão baseado em anomalia podem ser divididos em três categorias: Métodos baseados em Estatística, Métodos baseados em Conhecimento e Métodos baseados em Aprendizado de Máquina (WENLI SHANG et al., 2015).

A seleção do conjunto de variáveis, usadas no processo de análise dos dados capturados, tem grande influência na capacidade de detecção do IDS. O número de variáveis tem grande impacto no desempenho computacional da ferramenta, contudo, a seleção das variáveis, geralmente, é feita por meio de métodos empíricos. Esta seleção, que consiste em uma tarefa preliminar de um sistema IDS, é muito importante, porque o sucesso do sistema de detecção de intrusão depende fortemente da decisão tomada sobre o conjunto das características que o sistema vai utilizar para detectar o ataque (ABDOLLAH et al., 2008).

A seleção de variáveis consiste na escolha das características (ou atributos) de rede a serem utilizadas na análise do tráfego capturado. Normalmente, faz-se a distinção entre as características referentes a uma única conexão, ou a nenhuma conexão, com àquelas referentes à múltiplas conexões. As características do tráfego de rede podem ser classificadas como 'Básicas' ou 'Derivadas'. As 'Básicas' se referem às características retiradas diretamente dos pacotes de tráfego da rede, enquanto as características 'Derivadas' relacionam dados de vários pacotes a fim de identificar padrões de comportamento dinâmico. São também conhecidas como características de tráfego (ONUT; GHORBANI, 2007).

Importante destacar também que as variáveis selecionadas dependem do tipo de IDS usado e dos tipos de anomalias de interesse. Por exemplo, para um HIDS normalmente se está interessado nos endereços de origem e destino, portas e protocolos dos pacotes de rede. Quanto aos dados coletados em uma rede, um NIDS pode utilizar os 
dados do payload do pacote, como em (KRUEGEL; VIGNA, 2003), ou apenas as informações do header, como em (KIM; REDDY, 2008).

$\mathrm{Na}$ coleta destas características, podem ser usados dois métodos baseados em na metodologia 'Janela de Observação': o primeiro tipo é baseado em uma janela com tamanho em unidades de tempo (por exemplo, 3 segundos), enquanto que no segundo método é baseado em uma janela com tamanho contado em pacotes ou conexões (por exemplo, 20 pacotes) (LINDA; VOLLMER; MANIC, 2009).

Devido à diversidade de protocolos e serviços de rede existentes, a quantidade de características possíveis de serem extraídas é imensa. Embora seja factível o desenvolvimento de um IDS que considera um número grande de características de rede para a detecção de anomalias, o esforço computacional é altíssimo e muitas vezes proibitivo. Portanto, as características de rede devem ser escolhidas conforme a necessidade do IDS.

O conjunto de amostras, ordenadas no tempo, de uma variável forma uma série temporal, que por sua vez, é usada como entrada nos diversos algoritmos de Aprendizado de Máquina e Classificadores Inteligentes pela grande maioria dos sistemas de detecção de intrusão desenvolvidos atualmente (ABUROMMAN; REAZ, 2017).

Uma desvantagem do uso de técnicas de aprendizado de máquina para executar classificações é a possibilidade de adversários tentarem contornar os classificadores. $\mathrm{O}$ campo que estuda esses tipos de ataques é chamado de 'aprendizado de máquina adversária' e foi amplamente explorado em algumas áreas, como classificação de imagens e detecção de spam; sua exploração ainda é pequena em outras áreas, como na detecção de intrusões. Basicamente, exemplos contraditórios são apresentados para um classificador criado especificamente para enganar o modelo, causando erros de classificação. Os modelos são treinados muitas vezes por conveniência ou facilidade de cálculo, como independência de recurso e separabilidade linear dos dados, mas esses tipos muitas vezes, as hipóteses podem abrir possibilidades para ataques (MARTINS et al., 2020).

No trabalho de (LINDA; VOLLMER; MANIC, 2009), um método estatístico chamado de leave-one-out (KOHAVI, 1995) foi utilizado para identificar as características mais significantes na identificação das anomalias por meio da análise do tráfego capturado. Em (ZAMAN; KARRAY, 2009), o autor usou uma técnica de 
aprendizagem de máquina conhecida como Support Vector Machines (SVM) para a classificação e seleção das características de rede. Em (GHALI, 2009) propôs um algoritmo baseado em Rede Neural Artificial para a seleção de variáveis. Já em (CHOU; YEN; LUO, 2008), o autor propõe o uso de um algoritmo baseado em lógica fuzzy.

O crescente número de ataques requer uma atualização contínua da base de conhecimento dos sistemas de detecção baseados em assinaturas. Além disto, existe também um número desconhecido de vulnerabilidades descobertas, mas não reveladas e que não se encontram disponíveis para análise e inclusão na base de conhecimento. A maioria dos ataques é polimorfa e os atacantes exploram este polimorfismo para enganar os sistemas detectores (SILVA, 2008).

\subsubsection{Avaliação de um IDS}

A avaliação de um IDS consiste em criar índices que classifique o sistema de detecção em suas diversas modalidades.

Segundo (SILVA, 2008), essa tarefa é complexa pois:

- Rotular os dados coletados como pertencentes as classes 'normal' ou 'anômalo' nem sempre é uma tarefa fácil e requer muito esforço por parte dos especialistas humanos;

- Mudanças constantes no tráfego podem introduzir novos conceitos de anomalia e podem, também, alterar aspectos de comportamento normal, tornando a construção de referências muito difícil;

- Quando se avalia o desempenho de um IDS, mede-se a 'taxa de detecção' (quantidade de ataques detectados corretamente), e também a 'taxa de alarmes falsos' (quantidade de conexões normais incorretamente detectadas como ataques), assim como o impacto real (custo) que uma classificação incorreta pode ocasionar;

- A complexidade da avaliação de um IDS torna-se também alta pelo fato de que alguns tipos de ataques (por exemplo, DoS e Probing) podem usar centenas de pacotes ou conexões de rede, enquanto outros tipos de ataques, tais como U2R e R2L, geralmente usam somente algumas poucas 
conexões. Detalhes sobre esses tipos de ataques serão apresentados na Seção 2.3.

Um IDS pode indevidamente gerar dois tipos de alarmes: 'falso-negativo' ou 'falso-positivo':

- Falso-negativos são ocorrências de eventos intrusivos sinalizados pelo IDS como normais, geralmente ocorrem nos sistemas baseados em assinaturas.

- Falso-positivos (ou alarmes falsos) são ocorrências de eventos normais sinalizados pelo IDS como intrusivos, gerados com frequência pelos IDS baseados em anomalias.

Desta forma, a taxa de detecção (TD) de um IDS é calculada como a razão entre o número de ataques corretamente detectados (NA) e o número total de ataques (NTA). Já a taxa de alarmes falsos (falso-positivos) (TAF) é calculada como a razão entre o número de conexões normais (NNI) que são incorretamente classificadas como ataques (alarmes falsos) e o número total de conexões normais (NTN).

$$
\begin{aligned}
& T D=\frac{N A}{N T A}[\%] \\
& T A F=\frac{N N I}{N T N}[\%]
\end{aligned}
$$

Esses dois índices serão utilizados para a geração dos resultados desse trabalho na avaliação comparativa dos diversos algoritmos de aprendizado de máquina a serem utilizados nessa pesquisa.

A taxa de falsos positivos é importante no que se refere à aceitação do sistema pelo usuário. Frente aos diversos alarmes falsos, os usuários aprendem a ignorar as advertências do sistema. Deste modo, positivos verdadeiros são ignorados e não levados a sério. Portanto, um classificador bem-sucedido tem que exibir especificidade excepcional (SILVA, 2008). Sistemas IDS baseados em detecção de anomalia são mais flexíveis, ou seja, generalizam bem para novos cenários de ataques. Porém, devido à grande diversidade das atividades de comunicação que normalmente ocorrem em um ambiente de rede, estes modelos em geral produzem uma grande taxa de alarmes falsos. 


\subsection{Ataques em Redes Industriais}

Conforme descrito em (BRANQUINHO et al., 2014), com aumento da atividade terrorista em meados dos anos 1990, o governo norte-americano começou a se preocupar com sua infraestrutura e seus pontos críticos no que se refere a segurança. Com isso, diversas normas e leis foram criadas com o intuito de o grau de segurança física e virtual.

No Brasil, de acordo como Diário Oficial da União n..$^{\circ}$ 27, de 11 de fevereiro de 2008, são consideradas infraestruturas críticas, instalações, serviços e bens que, se forem interrompidos, provocarão sério impacto social, econômico e/ou político. São exemplos de infraestruturas críticas:

- Geração e Distribuição de energia elétrica

- Estações de Fornecimento e Tratamento de água

- Telecomunicações

- Saúde pública

- Serviços de segurança (polícia, exército...)

Órgãos governamentais da administração pública brasileira sofrem diariamente com ataques que levam à indisponibilidade de serviços e pichações em seus sites. Esses ataques chamam a atenção porque mostram como os hackers e suas ferramentas de ataque estão cada vez mais poderosas. Os autores do livro destacam "que o fato de os ataques terem sido amplamente divulgados na mídia expõe ao mundo que não existe um site totalmente seguro e que os hackers sabem muito bem disso".

A guerra cibernética é uma modalidade de guerra na qual o conflito não ocorre com armas físicas, mas por intermédio do confronto com meios eletrônicos e informáticos no chamado ciberespaço. Em seu uso mais comum e livre, o termo é usado para designar ataques, represálias ou intrusão ilícita em um computador ou uma rede de comunicação. Atualmente, os ataques cibernéticos estão cada vez mais poderosos a medida que o controle de usinas hidroelétricas e nucleares, o controle do tráfego aéreo, do fornecimento de água e etc. são operados por sistemas de computação fortemente interligados que podem ser alvos potenciais de hackers no mundo inteiro, tem-se um cenário com enorme risco iminente. Imagine as consequências de uma invasão no sistema de controle de uma 
estação de tratamento de água ou uma invasão que gerasse o desligamento de usinas hidroelétricas inteiras, gerando blecautes por todo o país. Todas essas ameaças à infraestrutura crítica são bastante plausíveis hoje em dia (BRANQUINHO et al., 2014).

As principais características de uma guerra cibernética são:

- Silenciosa: os ataques são realizados contra alvos específicos inseridos em infraestruturas críticas, ataques estes muito difíceis de detectar e interceptar em plantas industriais.

- Anônima: as ferramentas (software) utilizados são desenvolvidas com código criptografado, sendo impossível descobrir seus autores. Utilizam muitas vezes servidores "sequestrados" de outras empresas ou pessoas, o que torna o rastreio do ataque uma tarefa muito árdua.

- Sem território definido: é praticamente impossível provar que um ataque cibernético partiu de determinada nação, mesmo quando se consegue detectar que o ataque partiu de um determinado endereço IP, é difícil provar que ele faz parte de um plano coordenado de uma nação, o que caracterizaria com um ato hostil de guerra.

- Sem reação: como reagir a um ataque do qual não se sabe a procedência, nem a autoria? Ciberataques, quando realizados por profissionais do crime, não tem reação.

- Excelente relação Custo/Destruição: calcula-se que uma excelente ciberarma capaz de desabilitar uma instalação crítica, custe muito menos que uma guerra tradicional.

Crime cibernético é o nome utilizado para se referir a toda atividade em que um computador ou uma rede de computadores é utilizada como ferramenta, base de ataque ou meio de cometer um crime.

As infraestruturas críticas também sofrem com essas invasões em seus dados e informações confidenciais. Os crimes ocasionam são somente danos financeiros. Os crimes mais comuns praticados na indústria são:

- Espionagem Industrial: obtenção de informações sobre projetos industriais sem autorização prévia. Caracteriza-se como crime de inviolabilidade de segredos, conforme o Código Penal brasileiro. 
- Violação de Autorização: quando se utiliza da autorização de outra pessoa para finalidades desconhecidas nos sistemas de controle. Caracteriza-se com crime de falsidade ideológica, de acordo com o Código Penal brasileiro.

- Sabotagem: ocorre quando dados são alterados ou excluídos com o intuito de alterar o funcionamento do sistema de controle e supervisão da planta industrial. É crime previsto pelo Código Penal.

- Negação de Serviço: ocorre quando há a paralisação dos sistemas de controle, comumente conhecidos como ataque DoS (Denial of Service). Esse tipo de crime pode ser tipificado como crime de sabotagem conforme o artigo 202 do Código Penal brasileiro.

Invadir ou atacar uma planta industrial de uma infraestrutura crítica não é uma tarefa simples. Nos dias atuais, os hackers são pessoas habilidosas, engenheiros sociais com conhecimentos de computação e automação industrial, com capacidade de produzirem armas cibernéticas poderosas e específicas para redes de automação industrial. Um bom exemplo disso é o STUXNET (LANGNER, 2011).

\subsubsection{Incidentes de segurança}

Define-se como um incidente de segurança qualquer evento adverso relacionado à segurança de sistemas de computação ou de redes de computadores. Quando um incidente de segurança é provocado de forma intencional, denomina-se 'ataque' (BRANQUINHO et al., 2014).

Muitos trabalhos de pesquisa têm sido desenvolvidos em busca de soluções para eliminar ou minimizar os efeitos de um ataque cibernético às infraestruturas críticas. Como por exemplo, o trabalho de (FARRAJ; HAMMAD; KUNDUR, 2017) que analisa o impacto de um ataque cibernético em um sistema de geração e transmissão de energia. Nesse trabalho, os autores propõem um método adaptativo de controle para eliminar ou minimizar os efeitos do ataque de FDI - False Data Injection na rede de energia.

Analisando o RISI - Repository for Industrial Security Incidents (EXIDA LLC, 2015), um banco de dados que reúne informações coletadas de incidentes de segurança que se tornaram públicos e que afetaram sistemas de controle de plantas industriais ou 
sistemas SCADA (Supervisory Control And Data Acquisition), segundo os autores, o incidente mais comum em redes de automação é o ataque por malwares, seguidos por sabotagem, invasão e $D o S$. Os valores percentuais do ano 2013 podem ser encontrados na Figura 8.

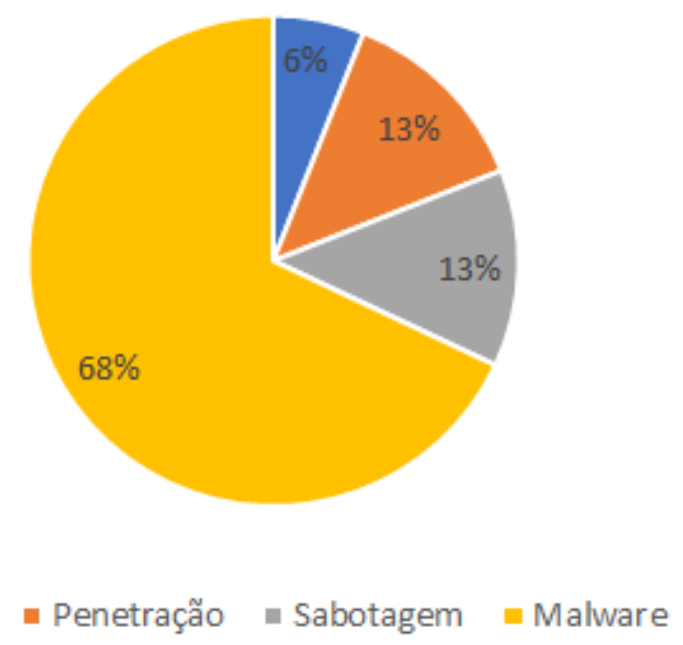

Figura 8: Incidentes de segurança mais comuns em redes de automação FONTE: Adaptado de (BRANQUINHO et al., 2014)

Conforme os dados do RISI, as vulnerabilidades mais exploradas por hackers em redes industriais estão detalhadas na Figura 9.

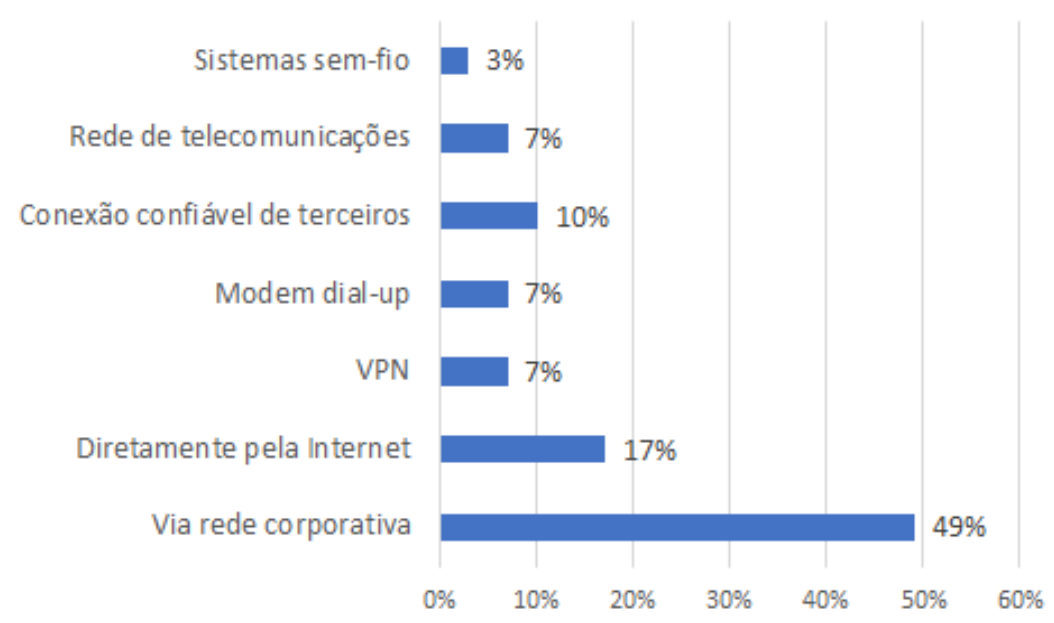

Figura 9: Vulnerabilidades mais exploradas pelos hackers em redes industriais FONTE: Adaptado de (BRANQUINHO et al., 2014)

Todos os ataques efetuados nas redes de comunicação devem ser considerados anomalias nestas redes. Anomalias estas que podem ser definidas como ações diferentes das observadas no comportamento normal do tráfego, que podem ser indicativos de ataques, abuso (mau uso) na rede, eventos de falha na rede, problemas de infraestrutura na coleta de dados, entre outros. Assim, nem toda anomalia na rede pode ser considerada 
um ataque, mas sempre representa uma informação suspeita que deve ser analisada (BARFORD et al., 2002).

\subsubsection{Anomalia no tráfego}

Anomalias no tráfego de redes podem ser classificadas em quatro categorias, sendo: anomalias na operação da rede, anomalias flash-crowd, anomalias na medição e ataques (BARFORD et al., 2002).

\subsubsection{Anomalias na operação}

As anomalias de operação da rede incluem os eventos de falhas na rede, tais como interrupção do funcionamento de dispositivos, adição de equipamentos ou configuração inadequada de dispositivos na rede.

No entanto, sejam as anomalias de rede maliciosas ou não intencionais, é importante analisá-las por dois motivos (LAKHINA; CROVELLA; DIOT, 2004):

- Anomalias podem criar congestão na rede e estressar a utilização de recursos de um equipamento;

- Algumas anomalias podem não necessariamente gerar impacto na rede, mas causar grande impacto para um cliente ou um usuário final.

Nesta categoria estão inclusos os eventos de falhas na rede, tais como interrupção de funcionamento dos dispositivos na rede, ou eventos que geram mudanças significativas no comportamento da rede, tais como a adição de novos equipamentos e configuração incorreta de dispositivos (mesmo que temporariamente). Por exemplo, quando em uma rede PROFINET, um dispositivo IO-Supervisor insere uma série de pacotes ARP/SNMP na rede para levantamento de informações. Anomalias desta categoria podem ser identificadas visualmente por meio de aclives e declives (alterações súbitas da taxa de bits seguidas de uma estabilidade da taxa) para um nível diferente durante certo período. O trabalho de (SESTITO, 2018) desenvolve um método para detectar esse tipo de anomalia em redes RTE.

\subsubsection{Anomalias flash-crowd}

As anomalias flash-crowd são aquelas que representam um rápido aumento no tráfego da rede, geralmente de um determinado tipo ou para um destino bem conhecido 
(um servidor, por exemplo). Sendo que, geralmente, esse tráfego excessivo é gradualmente reduzido com o tempo.

Anomalias desta categoria são caracterizadas por um rápido crescimento do tráfego de um determinado tipo (exemplo, tráfego DCP) ou para um destino bem definido, com redução gradativa com o passar do tempo. Por exemplo, um acréscimo no tráfego oriundo de uma Estação de Engenharia para um IO-Controler representando um download de configuração neste controlador.

\subsubsection{Anomalias na medição}

As anomalias na medição representam as falhas no sistema de diagnóstico e/ou da coleta de dados, gerando assim, uma análise distorcida das informações de status da rede. Problemas com a infraestrutura de coleta de dados, tal como uma sobrecarga na porta espelhada do switch, ou o rompimento do cabo de interligação com a estação de captura, representam tipos de anomalias de medição.

Nota-se aqui que este tipo de anomalia não ocorre devido a problemas de infraestrutura ou uso abusivo da rede.

\subsubsection{4 $\underline{\text { Ataques }}$}

Os ataques são também considerados anomalias na rede e podem ser identificados principalmente por meio do fluxo do tráfego de dados. Estes ataques compreendem um "conjunto de ações ilícitas que tentam comprometer a integridade, confidencialidade, ou disponibilidade de recursos na rede". A infraestrutura de rede pode ficar comprometida, regras de privacidade podem ser quebradas, comprometendo assim a confidencialidade da informação, e essas informações podem também ser modificadas comprometendo a integridade dos dados (SILVA, 2008).

A maioria dos ataques bem-sucedidos ocorre devido a vulnerabilidades ou falhas potenciais existentes nos elementos da rede, tais como configurações incorretas e/ou falhas no desenvolvimento dos protocolos. Essas vulnerabilidades são exploradas por meio de vários tipos de ataques, desde tentativas simples de negação de serviço a ataques mais sofisticados que visam um impacto maior, comprometendo todo o sistema.

Os ataques se distinguem das anomalias 'flash crowd', das 'anomalias na operação' da rede e das 'anomalias na medição' por não serem detectados por meio de medições de taxas de bits e/ou pacotes. Para esses casos, uma análise sobre as tendências 
e/ou comportamento do fluxo de pacotes da rede claramente indicam essas atividades abusivas a partir de atributos específicos extraídos desse fluxo.

A detecção de ataques é o foco deste trabalho.

\subsubsection{Classificação dos ataques}

Ataques em redes de comunicação compreendem um conjunto de ações ilícitas que tentam comprometer a integridade, confidencialidade, ou disponibilidade de recursos na rede (NORTHCUTT; NOVAK, 2002). Informações podem ser adulteradas quebrando a integridade dos dados. Regras de privacidade podem não ser respeitadas devido ao um ataque, comprometendo a confidencialidade da informação. A infraestrutura de rede pode ficar indisponível e não confiável afetando assim, a disponibilidade de recursos na rede.

Segundo estatísticas Centro de Estudos, Resposta e Tratamento de Incidentes de Segurança no Brasil (CERT.BR, 2019), com o passar dos anos, o número de ataques (incidentes) cresce de forma significativa. Veja na Figura 10 o crescimento do total de incidentes nos últimos anos.

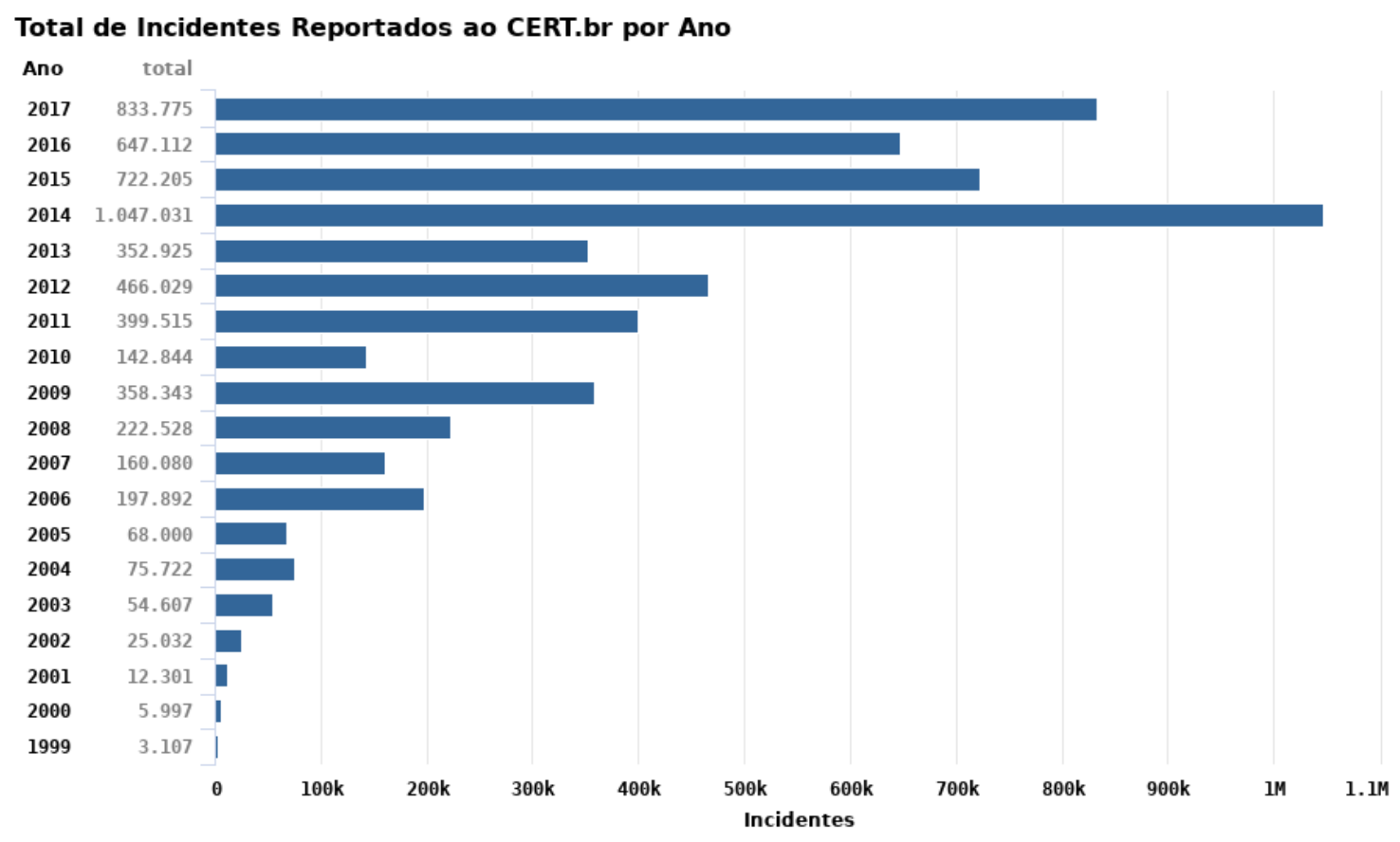

Figura 10: Total de incidentes reportados por ano FONTE: (CERT.BR, 2019)

Conhecer os principais ataques e as vulnerabilidades mais exploradas é fundamental para a criação de mecanismos de identificação e proteção das redes. 
Os ataques podem ser classificados de diversas formas, tomando-se critério de classificação a sua origem, o seu destino ou alvo e objetivos (SHIREY, 2000).

\subsubsection{Origem}

Quanto à origem, os ataques podem ser externos ou internos. Os externos são aqueles que são disparados por um atacante de fora da rede enquanto os internos são aqueles provenientes de usuários internos à rede que abusam de seus direitos e privilégios para realizar atividades não autorizadas.

\subsubsection{Alvo}

A classificação com base em alvo é dividida em ataques à rede propriamente dita e ataques a sistemas. $\mathrm{O}$ primeiro tipo refere-se àqueles ataques que visam impedir que os recursos da rede sejam utilizados ou algum serviço fique indisponível.

Já o segundo tipo refere-se aos ataques que tem como propósito comprometer o sistema todo, alterando senhas e adulterando configurações críticas dos equipamentos. $\mathrm{O}$ mais famoso ataque deste tipo, no contexto da Automação Industrial, foi o STUXNET (LANGNER, 2011).

\subsubsection{Objetivos}

Quanto a seus objetivos, os ataques mais frequentes a redes podem ser classificados como: DoS (Denial of Service), Probing, R2L (Remote to Local) e U2R (User to Root). Estes ataques podem ser disparados no local ou remotamente, através de uma conexão de rede que utiliza o acesso público previamente concedido pelo sistema alvo (SUNG; MUKKAMALA, 2003).

O tipo de ataque $D o S$ é aquele em que o atacante faz com que os recursos computacionais ou de memória dos equipamentos fiquem sobrecarregados de tal forma que, as requisições normais oriundas da rede não possam ser atendidas e assim, o equipamento fique indisponível por não poder ser acessado. Este tipo de ataque aproveita falhas de protocolos e/ou programas para deixarem o equipamento, ou até mesmo uma rede inteira, impossibilitada de executar sua tarefa. Exemplos tradicionais desse tipo de ataque em redes de computadores são: smurf, Neptune, ping-of-death, mail-bomb e UDPStorm. 
Segundo (BERTHOLDO; ANDREOLI; TAROUCO, 2003), as principais estratégias utilizadas pelos ataques $D o S$ incluem:

- Inundar uma rede visando impedir que usuários legítimos façam uso dela;

- Impedir ou romper a conexão entre duas máquinas visando impedir o acesso a um serviço;

- Impedir o acesso de um determinado serviço ou servidor;

- Impedir ou negar um serviço a um sistema ou pessoa específica.

Os três tipos principais de ataques $D o S$ são:

- Exploração de falhas: exploram vulnerabilidades no software do sistema alvo causando falhas em seu processamento ou extinguindo seus recursos.

- Flooding: sobrecarregam um sistema enviando mais informação do que ele é capaz de manipular. Mesmo que a capacidade de processamento do sistema não seja totalmente tomada, o atacante pode ser capaz de monopolizar a conexão de rede do alvo, bloqueando assim qualquer tipo de uso deste recurso.

- $\quad D D o S$ (Distributed $D o S$ ): representam uma série de ataques $D o S$ onde os atacantes utilizam-se de vários locais para lançar o ataque e assim, rapidamente sobrecarregar um determinado sistema alvo. Neste tipo de ataque é realizada uma sobrecarga ou inundação de pacotes contra um determinado serviço, host ou rede, gerando muitas vezes uma quantidade de dados global maior que a rede ou host pode suportar, tornando a rede ou serviços instáveis e consequentemente prejudicando o seu desempenho.

No tipo Probing, o invasor efetua uma varredura na rede ou nos equipamentos da rede com o propósito de identificar fraquezas ou vulnerabilidades que posteriormente possam ser exploradas de modo a comprometer o sistema. Estes tipos de ataques por sondagem não penetram ou comprometem os sistemas. Estes ataques possuem várias denominações, dependendo das atividades que executam: network/port scanners, port/network mappers ou vulnerability scanners. Essa técnica é geralmente usada na mineração de dados através das ferramentas saint, portsweep, mscan e nmap. As respostas 
recebidas destes sistemas são utilizadas pelo atacante para aprender sobre as características da rede e dos sistemas, incluindo a topologia da rede, os hosts ativos e suas respectivas configurações de software, incluindo sistema operacional, software do servidor e versões de aplicativos.

Já nos ataques de penetração, conhecidos como ataques $R 2 L$ e $U 2 R$, realizam aquisição ou alteração não autorizada dos privilégios, recursos ou dados do sistema, violando as propriedades de integridade e controle dos recursos e dados. Com estes ataques, pode-se ganhar controle de um sistema ao explorar uma variedade de falhas de software.

Na categoria $R 2 L$ (Remote to Local), o atacante envia pacotes para o equipamento através da rede externa (Internet, por exemplo), a fim de expor as vulnerabilidades e explorar privilégios que somente um usuário local poderia ter acesso. Exemplos desse tipo de ataque são: xlock, guest, xnsnoop e phf.

Já na categoria U2R (User to Root), os ataques consistem daqueles casos em que o localmente, o atacante tenta explorar as vulnerabilidades do sistema a fim de obter privilégios adicionais como administrador da máquina. Exemplos desse tipo de ataque são: perl e xterm.

\subsection{Trabalhos correlatos em detecção de anomalias}

As características e a crescente sofisticação dos ataques faz com que aumente a demanda por técnicas de detecção mais precisas para o monitoramento contínuo da rede de comunicação industrial e que seja capaz de lidar como novos tipos de ataques, poder ser facilmente integrada aos demais mecanismos de proteção da rede sem sobrecarregar a comunicação (MAGLARAS, 2018).

Em (TURCATO, 2015) classificadores binários com RNA são avaliados. Uma interessante característica desse trabalho é que as amostras anômalas do conjunto de treinamento foram artificialmente geradas de forma randômica, assim, os dados reais de ataque coletados estavam contidos apenas no conjunto de teste.

Em (WENLI SHANG et al., 2015) é investigado o uso de OCSVM para detectar intrusão em redes industriais com protocolo Modbus-TCP em um sistema de controle industrial simulado por software. 
Em (JUNEJO; GOH, 2016) são classificadas anomalias de um processo industrial de tratamento de água, simulado em bancada, aplicando algoritmos com RNA, SVM entre outros. Neste trabalho, informações relacionadas ao processo industrial são utilizadas, tais como: vazão de água, nível do reservatório, posição das válvulas e velocidade das bombas.

Em (SHANG et al., 2016) os autores exploram a detecção de ataques em redes Modbus-TCP simulando situações reais de tráfego em laboratório. A seleção de atributos e posterior classificação usando SVM é avaliada.

Em (BUCZAK; GUVEN, 2016) é apresentada uma extensa revisão bibliográfica sobre métodos de mineração de dados e aprendizado de máquina para detecção de intrusão na área da segurança cibernética. Nesse trabalho são apresentados inúmeros trabalhos para ataques do tipo probing.

Em (SHIRAZI et al., 2016) apresenta uma ampla revisão das abordagens de detecção de intrusões baseadas em aprendizado de máquina para sistemas de controle industrial. Nesse trabalho foram utilizados dados criados a partir de um sistema SCADA de gasoduto do laboratório da universidade estadual de Mississippi com amostras normais e anômalas. Foram utilizados classificadores K-means e Nä̈ve Bayesian para classificação binária. Para a abordagem unária foram avaliados os classificadores PCASVD (Principal Component Analysis usando Singular Value Decomposition) e GMM (Gaussian Mixture Model).

Em (YANG et al., 2017) é utilizado um algoritmo de detecção de intrusão chamado de OPSO-BPNN, que utiliza um algoritmo de Enxame de Partículas para otimizar os pesos sinápticos da rede neural usando conjunto de amostras de Sistemas Elétricos de Potência.

Em (LEE; JO; HWANG, 2017) foi utilizada uma DPN (Deep Neural Network) para a detecção de falhas no rotor e nos rolamentos de motores de indução trifásicos aplicando algumas técnicas de balanceamento de classe como a técnica SMOTE (Synthetic Minority Over-sampling Technique).

Já em (AL-YASEEN; OTHMAN; NAZRI, 2017) é proposto e avaliado um IDS que utiliza um modelo híbrido de SVM para a classificação de ataques em redes de computadores utilizando o conjunto popular KDD Cup 1999. 
Em (VAVRA; HROMADA, 2017) é avaliado um sistema de detecção de anomalia em sistemas SCADA onde são investigados os desempenhos de cinco tipos de classificadores (Bayes Network, Nä̈ve Bayes, Random Forest, Decision Table e IB1).

Em (QU et al., 2018) é avaliada o desempenho de um classificador OCSVM frente ao tráfego do sistema SCADA em uma planta industrial de Gás e Óleo.

Em (SESTITO, 2018) um método para a detecção de anomalias em tráfego de redes Real Time Ethernet é desenvolvido com classificadores binários para os vários modelos de RNA avaliados. Nesse trabalho, foram analisados e classificados eventos de falhas nos dispositivos em redes PROFINET.

Em (NGUYEN et al., 2018) é avaliado o uso de classificador OCSVM para detectar intrusões em redes de computadores.

Em (MAGLARAS, 2018) é proposto um mecanismo de detecção de intrusão integrado, chamado de IT-OCSVM, que é distribuído em uma rede SCADA como parte de um sistema de detecção de intrusão distribuído (DIDS), fornecendo dados precisos sobre a origem e a hora de uma invasão. Nesse trabalho é feita a análise da Taxa de Detecção e da Taxa de Alarmes Falsos quando a rede foi submetida a quatro tipos de ataques: ARP spoofing, Probing, DoS e MITM.

Em (MISHRA et al., 2019) é feita uma ampla investigação e análise detalhada de várias técnicas de aprendizado de máquinas encontradas nas bases de dados científicas. Nesse trabalho são apontadas altas taxas de detecção quando se utilizou RNA ou SVM para a classificação.

Em (DIAS, 2019), técnicas de seleção de atributos e algoritmos de classificação são investigados para o diagnóstico de anomalias em aplicações de acionamento de motores elétricos a partir de dados de processo de rede PROFINET utilizando classificadores unários e binários.

Em (ANTON; SINHA; DIETER SCHOTTEN, 2019) dados de rede de comunicação contendo informações de processo industrial são analisados com algoritmos de detecção de anomalias baseados em aprendizado de máquina e em séries temporais, a fim de descobrir ataques injetados no tráfego. São avaliados dois conjuntos de dados distintos, um com tráfego de controle de gasoduto com protocolo Modbus e outro com o controle em batelada com protocolo OPC-UA. Para a detecção do ataque, dois algoritmos foram utilizados: SVM e Random Forest (RF). 
Em (AKPINAR; OZCELIK, 2019) é analisado o tráfego em redes EtherCAT em uma planta industrial de controle de nível de água com classificadores RNA e SVM.

Em (ALEESA et al., 2019) é feito um estudo que fornece uma extensa base de publicações científicas baseadas em técnicas de Aprendizado Profundo. Nesse estudo que considerou 68 pesquisas publicadas entre 2015 e 2018 revela que a combinação entre duas técnicas, a SAE (Stacked Autoencoder) e a RF (Random Forest) apresentou os melhores valores de acurácia.

Em (ZHOU et al., 2020) os autores desenvolveram um método baseado em GAN (Generative Adversarial Network) em conjunto com autoencoders para lidarem com dados não-balanceados característicos da área de diagnóstico de falhas. A Acurácia média obtida foi incrementada quando a técnica SMOTE foi usada para o balanceamento dos conjuntos de amostras com várias taxas de desbalanceamento.

Em (ALDWEESH; DERHAB; EMAM, 2020) os autores reuniram informações sobre diversos trabalhos científicos que utilizaram dois famosos datasets (KDD99 e NSLKDD) muito utilizados pelos pesquisadores para a avaliação de métodos de detecção de intrusão. Os autores comparam as acurácias obtidas por cinco diferentes técnicas de Aprendizado Profundo: Autoencoder (AE), Deep Belief Network (DBN), Recurrent Neural Network (RNN), Convolutional Neural Network (CNN) e Ensemble.

Em (GONZÁLEZ-MUÑIZ; DÍAZ; CUADRADO, 2020) foi proposto e avaliado um sistema para monitoramento de condições e detecção de falhas em máquinas rotativas com base em uma rede neural convolucional profunda, que mescla as tarefas de extração e classificação de atributos em um único estágio de aprendizado. O sistema proposto foi projetado para uso em uma máquina rotativa com sete estados operacionais possíveis e provou ser capaz de determinar as condições operacionais da máquina quase com a mesma precisão que os classificadores convencionais, mas sem a necessidade de conhecimento prévio da máquina.

Em (LI; LI; MA, 2020) é adotado um método de treinamento baseado em três estágios: pré-treinamento com autoencoders, agrupamento com k-means e classificação com redes neurais para aprendizado não-supervisionado em dois conjuntos de dados de máquinas rotativas. A Acurácia Média obtida com o método proposto usando autoencoders superior quando não foram utilizados autoencoders no estágio de prétreinamento. 


\subsection{Considerações Parciais}

Neste capítulo foram apresentados os principais tipos de ataques em redes industriais, suas classificações e como muitos desses ataques são ou podem ser detectados através da utilização de dois diferentes tipos de IDS, que por sua vez, apresentam vantagens e desvantagens para certas aplicações. Pesquisas correlatas também foram apresentadas, a fim de embasar o estudo e a metodologia utilizados neste trabalho.

No próximo capítulo são apresentados os principais conceitos teóricos do protocolo PROFINET necessários para o entendimento da proposta deste trabalho. De forma sucinta será dada ênfase na dinâmica de comunicação, aos principais protocolos envolvidos e aos mecanismos de segurança existentes e definidos por normas internacionais. 


\section{Capítulo 3}

\section{Aspectos da Tecnologia PROFINET e de Segurança em Redes Industriais}

Este capítulo tem por finalidade a apresentação dos conceitos teóricos do protocolo PROFINET necessários para o entendimento da proposta deste trabalho. De forma sucinta será dada ênfase na dinâmica de comunicação, aos principais protocolos envolvidos e aos mecanismos de segurança existentes e definidos por normas internacionais.

\subsection{Tecnologia PROFINET}

O PROFINET é um padrão aberto de Ethernet Industrial para automação criado em 2002 cujo suas capacidades foram aprimoradas para satisfazer as condições mais severas encontradas nas aplicações industriais. Permite o estabelecimento de comunicação em tempo real, sendo regido pelas normas internacionais IEC 61158 e IEC 61784 e mantido por uma associação internacional de empresas do segmento de automação industrial denominada PI (Profibus International) (POPP; WEBER, 2004).

Assim como o PROFINET, outras nove tecnologias já existentes são consideradas como Real Time Ethernet (RTE) e descritas na norma IEC 61784-2. São elas: PROFINET, Ethernet-IP, EtherCAT, Modbus/TCP, P-NET, Vnet/IP, TCnet, Ethernet Powerlink, EPA e SERCOS III, todos baseados no padrão IEEE 802. Atualmente a tecnologia RTE está bastante disseminada nos diversos segmentos industriais, suas aplicações estão se expandindo e seu uso está em ascensão (WU; XIE, 2019).

Essa tecnologia é utilizada nos diversos níveis da pirâmide da automação (YANG; LI, 2014). A Figura 11 apresenta as principais tecnologias de redes de comunicação digital utilizadas pelas indústrias em 2020. 


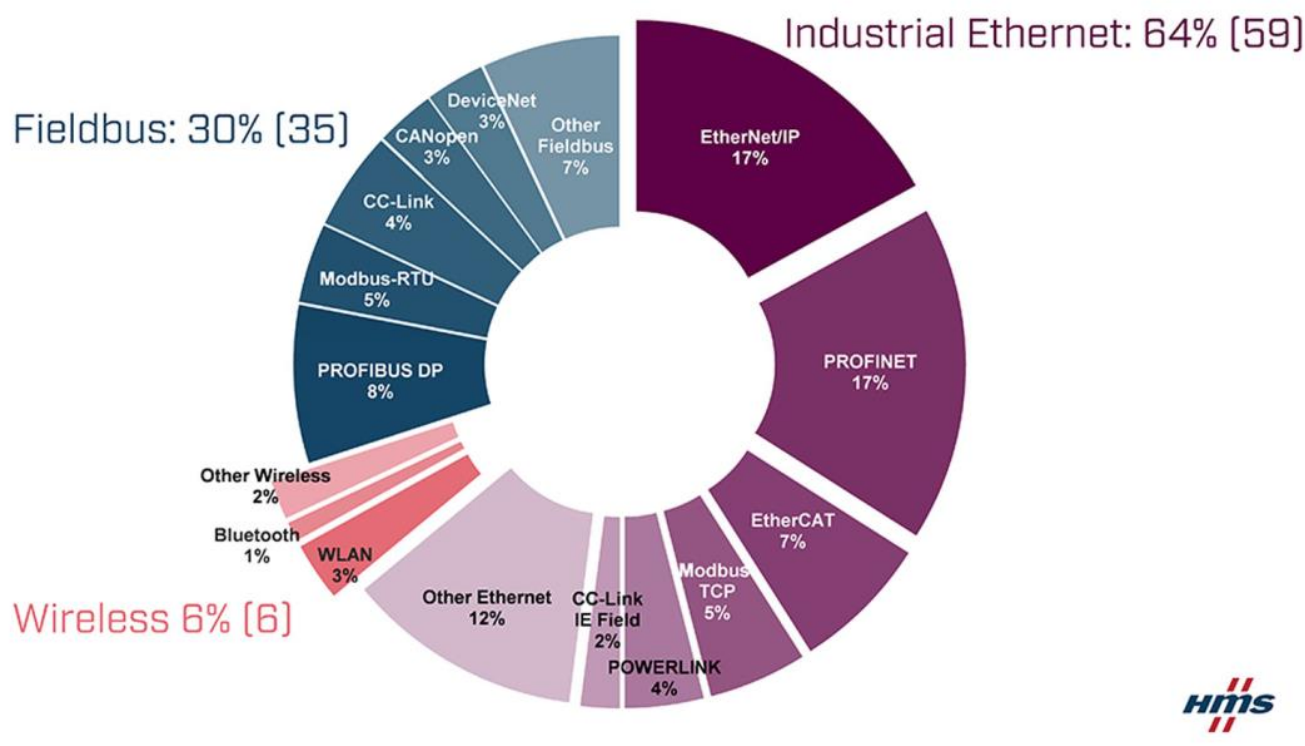

Figura 11: Protocolos de comunicação industrial mais utilizados em 2020 FONTE: Adaptado de (CARLSSON, 2020)

Observa-se que os protocolos baseados em Ethernet Industrial, já ocupam 64\% do mercado mundial (era 59\% no ano anterior). Valor esse bastante expressivo frente aos $30 \%$ dos protocolos convencionais (fieldbus) para o mesmo período. Os protocolos RTE já representam quase 2/3 do mercado (64\%). Considerando-se apenas os protocolos RTE, o PROFINET (17\%) aparece empatado em primeiro lugar com o Ethernet/IP (17\%).

Nessa pesquisa, a estimativa para 2020 foi baseada no número de novos nós instalados em 2019 (CARLSSON, 2020).

\subsubsection{Conceitos Básicos}

O protocolo PROFINET utiliza modelo Provider/Consumer na comunicação entre uma estação central e dispositivos descentralizados, onde um dispositivo Provider disponibiliza os dados para o Consumer. O PROFINET é responsável pela comunicação com os dispositivos de campo. É por meio dessa versão que os dados de processo, oriundos das entradas e saídas dos equipamentos, são tratados.

O padrão define os seguintes tipos de dispositivos, os quais não possuem hierarquia entre si:

- IO-Controller: representa o dispositivo central de inteligência, como um controlador lógico programável (CLP) ou um computador com plataforma 
para aplicações industriais (PC Industrial). É o equipamento responsável pela configuração e parametrização de outros dispositivos associados da rede e controla a processo de transferência de dados.

- IO-Device: É o dispositivo de campo responsável por informar, ao $I O$ Controller, os dados de processo e/ou executar alguma função dada por ele. Em sua maioria, podem gerar também dados de alarmes e de diagnóstico.

- IO-Supervisor: representa a estação de engenharia para programação, configuração ou diagnóstico, como um computador com a ferramenta de configuração do CLP ou um monitor de rede (PROFIBUS NUTZERORGANISATION, 2014).

A Figura 12 apresenta um exemplo de interligação destes dispositivos.

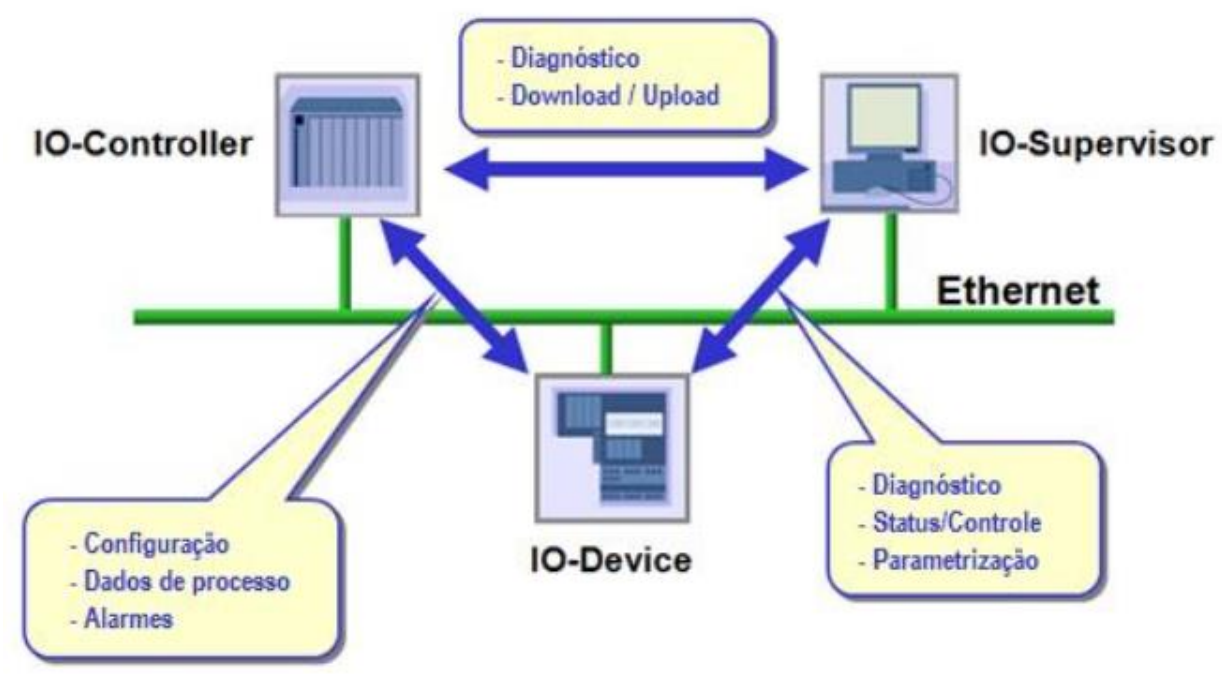

Figura 12: Troca de dados entre os dispositivos de uma rede PROFINET. FONTE: Adaptado de (PROFIBUS NUTZERORGANISATION, 2014)

O sinal é transmitido no padrão 100BASE-TX, cabo blindado, par trançado, dois pares de cabo Categoria CAT 5e FTP (Foiled Twisted Pair). A cor característica é verde e internamente há pares branco e azul, amarelo e laranja. A velocidade de transmissão utilizada é de 100 Mbps. Os conectores podem ser RJ45 ou M12 (Figura 5) sendo que o comprimento máximo do cabo é de 100 metros.

Uma integração ampla com outros protocolos é possível. Um estudo, realizado em 2005, analisou a integração do protocolo PROFINET com os protocolos PROFIBUS e INTERBUS. Neste estudo, os autores concluíram que é possível mapear todas as propriedades dos protocolos PROFIBUS e INTERBUS em um único dispositivo PROFINET, por meio da utilização de gateways e destaca inclusive que, o PROFINET é 
uma plataforma fortemente indicada para plantas industriais com protocolos de comunicação heterogêneos (JASPERNEITE; FELD, 2005).

\subsubsection{Topologias}

Durante a fase de projeto de uma rede de automação, muitos fatores devem ser considerados: interferência eletromagnética a fim de evitar ruídos, o correto aterramento, as distâncias máximas entre dispositivos, a quantidade de dados na rede precisa ser monitorada e muitos outros fatores regidos pelas normas. Contudo, mesmo levando-se em consideração todos esses aspectos, restrições físicas das instalações são fatores que exigem habilidade do projetista. Um protocolo com uma série de topologias de rede facilita ao projetista atender os requisitos do projeto. Neste quesito, o PROFINET é bem flexível e, quatro diferentes topologias podem ser usadas em conjunto, se preciso (INTERNATIONAL, 2014).

\subsubsection{Topologia Estrela (star)}

Muito comum em redes PROFINET devido ao intenso uso de switches. Consiste geralmente em muitos IO-Devices conectados em um único switch. Se um único nó PROFINET falhar ou for removido, os outros nós PROFINET continuam a operar normalmente. No entanto, se o switch falhar, a comunicação de todos os nós conectados será comprometida. A Figura 13 ilustra um caso típico de topologia estrela.

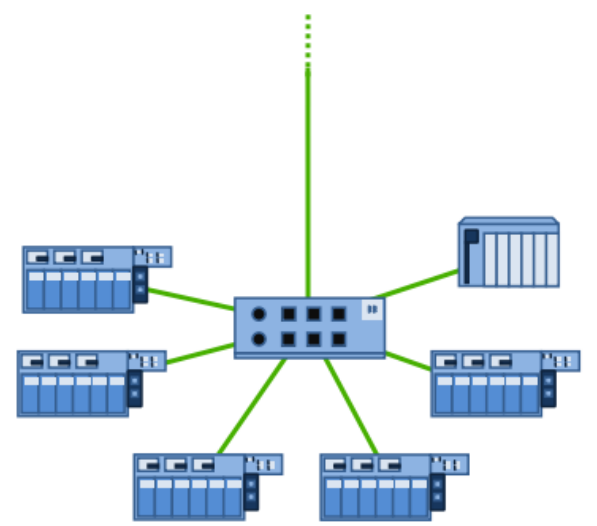

Figura 13: Topologia estrela. FONTE: (INTERNATIONAL, 2014)

\subsubsection{Topologia Árvore (tree):}

Formada pela junção de topologias em estrela em um único switch que trabalha como distribuidor de sinal. O switch funciona como um distribuidor de sinal para as 
extremidades em estrela. Dessa forma, o sinal de uma topologia estrela não é visto pela topologia estrela vizinha, a menos que esta esteja em troca de dados com a primeira. A topologia em árvore é um típico exemplo de uma planta de automação sendo agrupada de diferentes ilhas industriais. A Figura 14 ilustra um caso típico de topologia árvore.

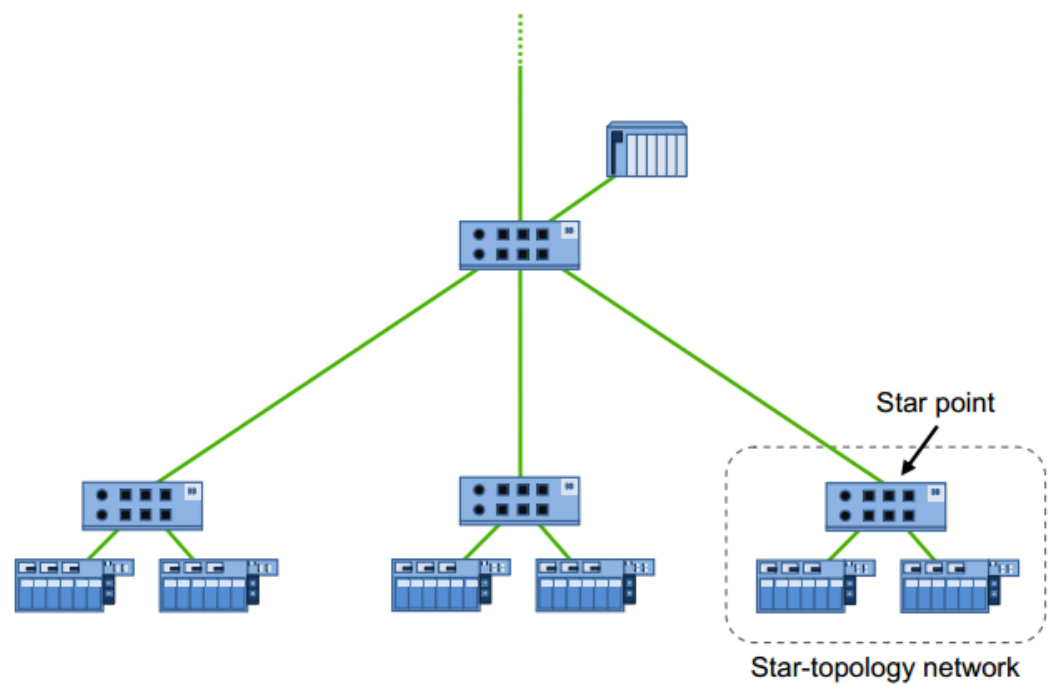

Figura 14: Topologia árvore. FONTE: (INTERNATIONAL, 2014)

\subsubsection{Topologia Linha (bus):}

A mais conhecida na área de automação industrial. A maioria dos IO-Devices possui um switch interno que facilita a implantação dessa topologia. Como pode ser observado pela figura, elimina-se assim, a necessidade de um switch central. A Figura 15 ilustra um caso típico de topologia linha.

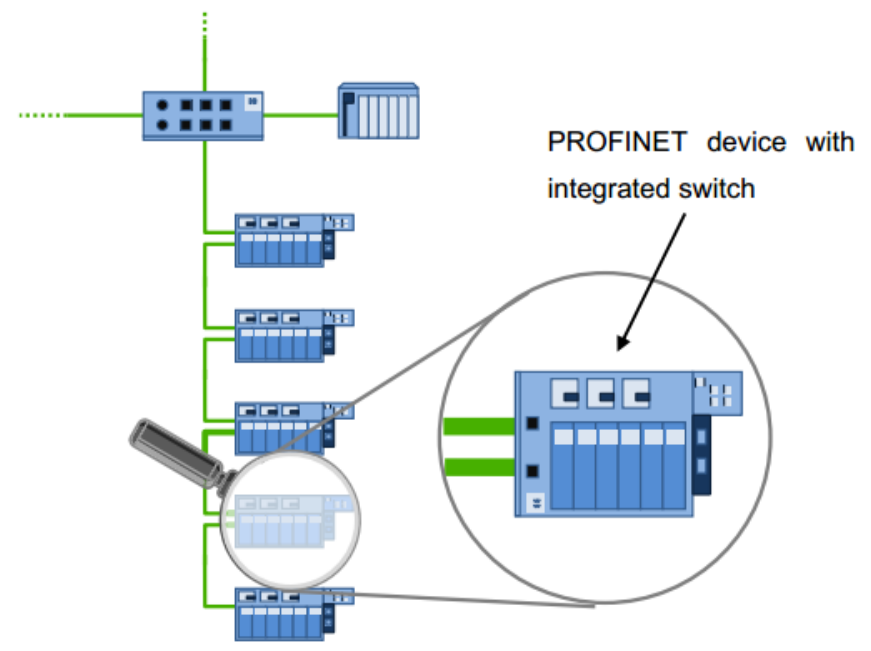

Figura 15: Topologia linha.

FONTE: (INTERNATIONAL, 2014) 


\subsubsection{Topologia Anel (ring):}

Consiste basicamente na interligação da topologia em linha/barramento (bus) com as extremidades do cabo conectadas em um mesmo ponto. Essa forma de conexão cria um caminho alternativo para o tráfego de dados, caso a rota principal seja interrompida. A Figura 16 ilustra um caso típico de topologia anel.

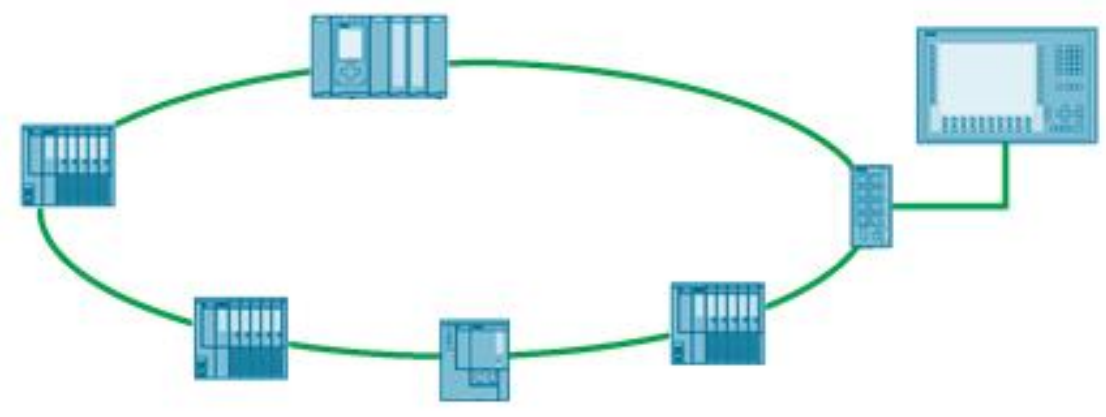

Figura 16: Topologia anel FONTE: (INTERNATIONAL, 2014)

\subsubsection{Aspectos de Segurança}

A comunicação baseada em Ethernet está cada vez mais assumindo um papel central na área da automação. A principal vantagem de se utilizar a Ethernet é a integração entre diferentes tecnologias. No entanto, esse fator faz com que se aumente o risco de violações de acesso, ataques de vírus e/ou outros programas maliciosos. Assim, há necessidade de se avaliar os riscos potenciais para as redes de automação e assim, implementar conceitos de segurança adequados.

Por estas razões, no documento PROFINET Security Guideline (NUTZERORGANISATION, 2013) é apresentado um conceito de segurança para sistemas de automação que incorpora as experiências das empresas associadas à PI Profibus International, aliado ao conhecimento detalhado do ambiente de automação. A simples proteção das redes e dos componentes de automação não é suficiente, é também essencial que os conceitos e mecanismos utilizados sejam práticos e que não afetem a operação da planta industrial.

Detalhes acerca dos aspectos de segurança as serem considerados em redes de automação são apresentados a seguir. 


\subsection{Segurança em redes de Automação}

Durante os últimos trinta anos, o foco principal no desenvolvimento de redes fieldbus foi para atender aos requisitos técnicos das diferentes áreas de aplicação, resultando em uma ampla variedade de sistemas. Esforços paralelos de padronização, que ainda continuam, levaram à conclusão de que, para enfrentar com sucesso os requisitos encontrados nas diversas áreas de aplicação, são necessárias diferentes soluções coexistentes (SAUTER, 2010). Nas últimas três décadas também foram concebidas as tecnologias que compõem a Internet de hoje, que, em última análise, levaram ao enorme surto de utilização na década de 1990, juntamente com a ampla adoção da família do protocolo IP (Internet Protocol) para uso em redes locais (LANs - Local Area Network). Esse crescimento exponencial da Internet fez com que houvesse um incremento da comunicação vertical na Pirâmide da Automação ilustrada na Figura 17.

$\mathrm{Na}$ base da pirâmide está frequentemente envolvido o Controlador Lógico Programável (CLP), atuando via inversores, conversores ou sistemas de partida suave sobre máquinas e motores e outros processos produtivos. No topo da pirâmide, a característica marcante é a informação ligada ao setor corporativo da empresa (MORAES; CASTRUCCI, 2007).

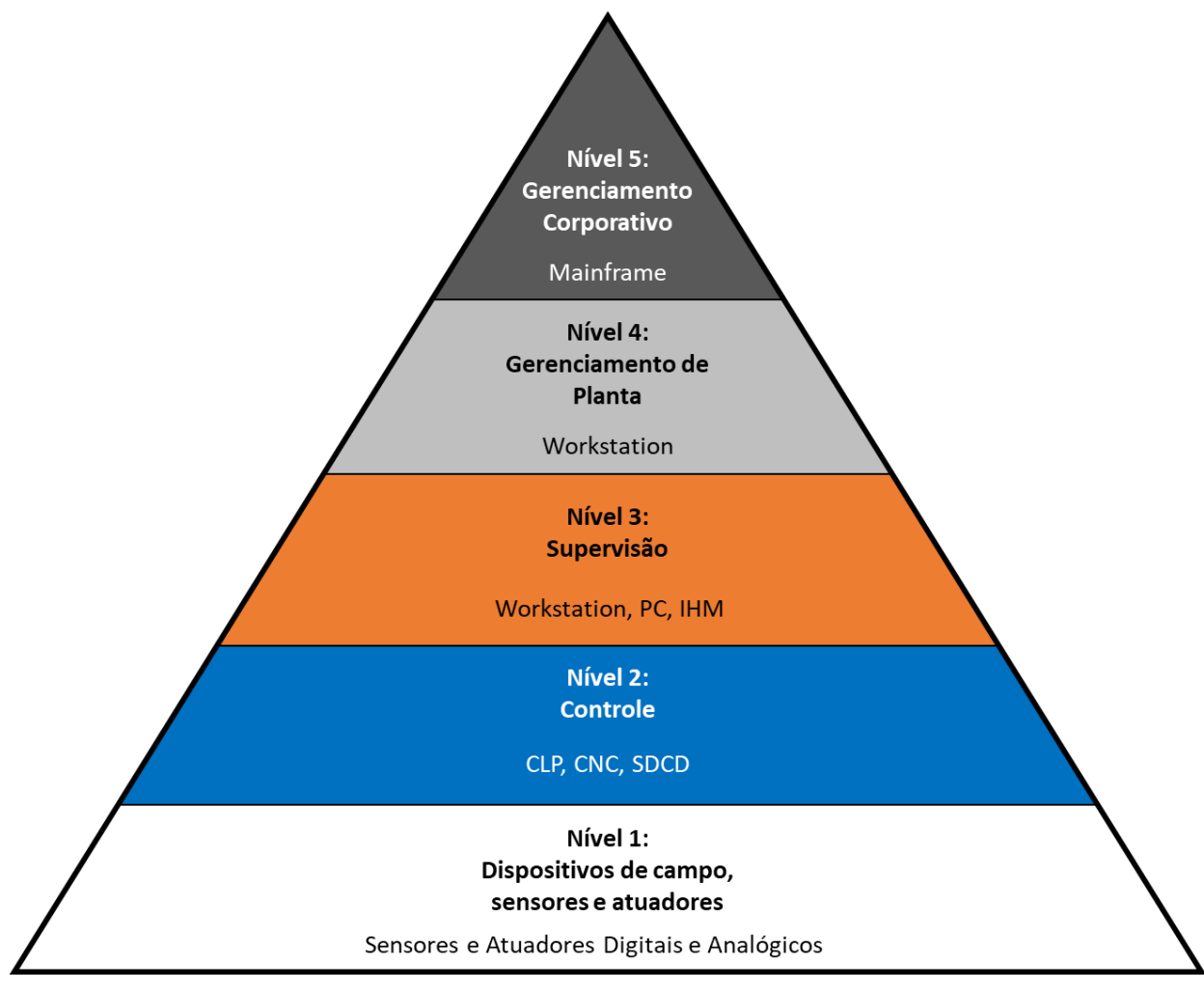

Figura 17: Pirâmide da Automação FONTE: Adaptado de (MORAES; CASTRUCCI, 2007) 
Os níveis da pirâmide são descritos como:

- Nível 1: é o nível das máquinas, dispositivos e componentes (chão-defábrica).

- Nível 2: é o nível dos controladores digitais, dinâmicos e lógicos, e de algum tipo de supervisão associada ao processo. Aqui se encontram concentradores de informações sobre o Nível 1 e as Interfaces HomemMáquina (IHM).

- Nível 3: permite o controle do processo produtivo da planta; normalmente é constituído por bancos de dados com informações dos índices de qualidade da produção, relatórios e estatísticas de processo, índices de produtividade, algoritmos de otimização da operação produtiva. Ex.: avaliação e controle da qualidade em processo químico ou alimentício; supervisão de um laminador de tiras a frio.

- Nível 4: é o nível responsável pela programação e pelo planejamento da produção, realizando o controle e a logística de suprimentos. Ex.: controle de suprimentos e estoques em função da sazonalidade e da distribuição geográfica.

- Nível 5: é o nível responsável pela administração dos recursos da empresa, em que se encontram os softwares para gestão de vendas e gestão financeira; é também onde se realizam a decisão e o gerenciamento de todo o sistema.

Somente com o advento do acesso remoto aos sistemas de automação e a ampla conscientização do usuário com problemas de segurança na Internet, a segurança se tornou um problema na automação. Ainda assim, no final da década de 1990, foi destacada a importância desse tema (DEPRIEST, 1997; KNIZAK et al., 1999; PALENSKY; SAUTER, 2000). Estendendo o alcance de protocolos típicos de nível fieldbus para redes baseadas em IP e interconectando-os mesmo fora das instalações por meio de padrões de TI, no entanto, tornou-se óbvia a necessidade de segurança. Ademais, um aumento significativo no número de incidentes que afetaram os sistemas de automação (BYRES, 2004), como o worm Stuxnet, evidenciaram ainda mais essa necessidade. Portanto, tornou-se necessário encontrar soluções para combater potenciais 
ameaças de segurança bem conhecidas na Internet ou redes sem fio (CHEMINOD et al., 2009; LONG; WU; HUNG, 2005; SHIN et al., 2010).

No âmbito da integração em automação, o foco da discussão está na conexão de redes fieldbus com a Internet. Isso pode ser feito por meio de abordagens de tunelamento ou por vários tipos de gateways. Neste contexto, a notória má reputação da Internet em termos de segurança, que em sua forma original não forneceu segurança alguma, exige a conscientização dos problemas de segurança em nível de campo. Ainda assim, é necessário não se limitar a estudar as questões de segurança que surgem somente com a conexão fieldbus - Internet, uma abordagem mais ampla deve ser adotada e que inclua medidas de segurança no próprio nível de campo. Por fim, as características de segurança devem ser aceitas e apropriadamente aplicadas na seleção de um sistema de comunicação em nível de campo para uma determinada aplicação. Questões de segurança devem se tornar tão importantes quanto outras propriedades da rede, como: topologia, estrutura, velocidade e características de segurança funcional (safety) (SAUTER; TREYTL, 2015).

Um CPS (Cyber Physical System) são os sistemas computacionais de entidades colaboradoras que estão em intensa conexão com o mundo físico circundante e seus processos em andamento, fornecendo e usando, ao mesmo tempo, serviços de acesso a dados e processamento de dados disponíveis na Internet. Em outras palavras, o CPS pode ser geralmente caracterizado como "sistemas físicos e de engenharia cujas operações são monitoradas, controladas, coordenadas e integradas por um núcleo de computação e comunicação". O CPS consiste em elementos e subsistemas autônomos e cooperativos que são conectados com base no contexto dentro e através todos os níveis de produção, desde processos até máquinas e redes de produção e logística (MONOSTORI et al., 2016).

A Figura 18 ilustra a transformação da tradicional Pirâmide da Automação para um novo formato que representa essa ampla conexão entre todos os níveis de produção. 

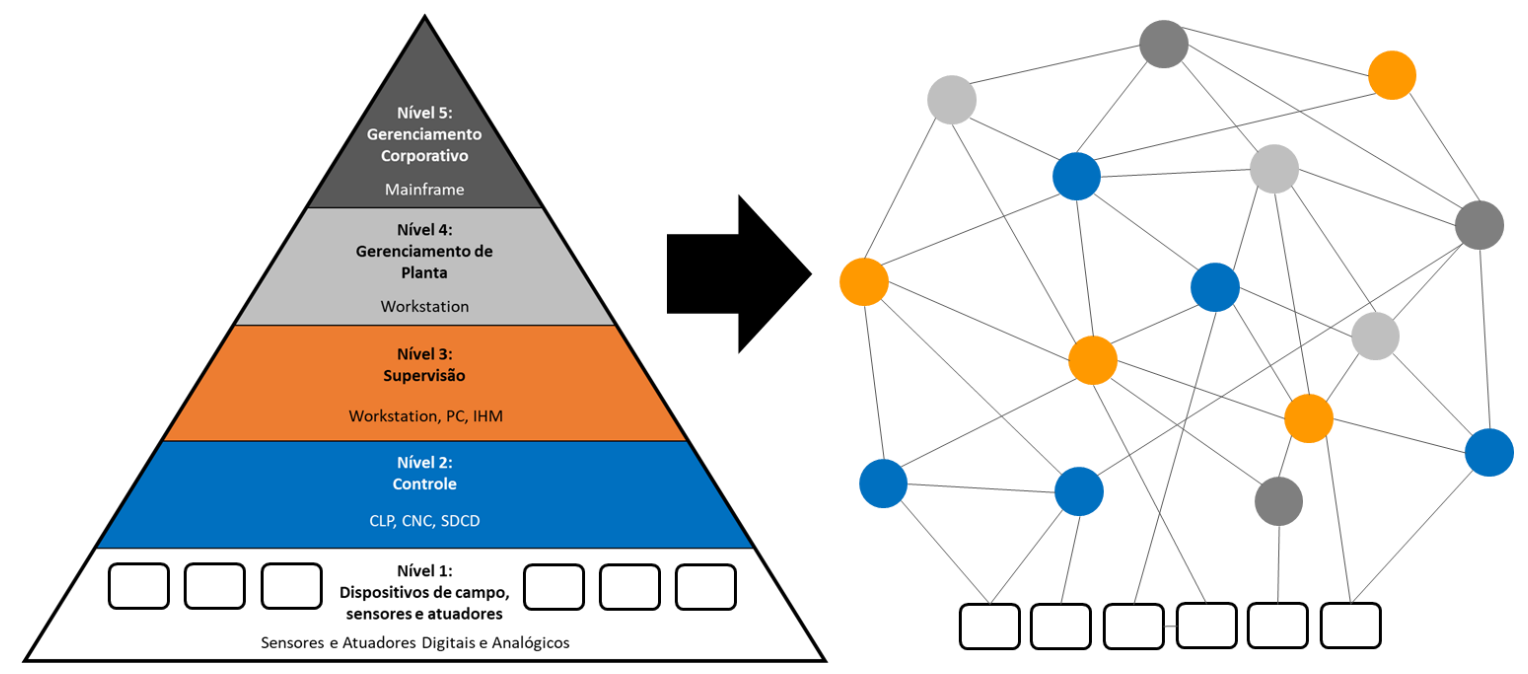

Figura 18: A "nova" Pirâmide da Automação FONTE: Adaptado de (MONOSTORI et al., 2016)

A multiplicação acelerada dos algoritmos de aprendizado de máquina e dos recursos de computação forneceu potenciais sem precedentes para darem suporte às operações e decisões de manufatura, com informações adicionais de seus conjuntos de dados disponíveis. Exemplos de tais capacidades incluem, entre outros, o processamento de dados de alta dimensão, reduzindo a complexidade dos dados, adaptando-se a novos processos e ambientes, identificando relações, correlações e causalidade. No cenário de fabricação, a análise de dados e as técnicas de aprendizado de máquina são extensivamente aplicadas em várias áreas, como gerenciamento de qualidade, manutenção preventiva, diagnóstico e prognóstico de falhas, tomada de decisão, sequenciamento e programação de produção (ZEID et al., 2019).

Os atuais avanços da digitalização e o com conceito da Indústria 4.0 trazem novos desafios para os sistemas de automação. Para permitir a interoperabilidade e a integração vertical dos sistemas de gerenciamento corporativo, essas redes evoluíram de soluções anteriormente proprietárias para a aplicação de padrões de comunicação e Internet baseados em Ethernet. Esse desenvolvimento é acompanhado por um aumento no número de ameaças. Embora o objetivo mais crítico de proteção de TI para sistemas de automação seja a disponibilidade, geralmente nenhum mecanismo de segurança foi originalmente integrado aos protocolos de automação (MEHNER; KÖNIG, 2019). 


\subsubsection{Conceitos Básicos}

As medidas de segurança para sistemas de TI em qualquer organização visam atingir três metas básicas de segurança: confidencialidade, integridade e disponibilidade. Essas medidas protegem os dados de acesso e manipulação não autorizados e garantem que os dados estejam acessíveis quando necessário. Além do mais, outra meta de segurança que é desejada é a não-repúdio, que vincula uma entidade à sua transação negociada (SAUTER; TREYTL, 2015).

As soluções implementadas para atingir essas metas geralmente são baseadas em uma política de segurança que declara explicitamente o seguinte:

- Os objetivos de segurança e o escopo da política que defendem a abordagem de risco da organização e descrevem os ativos de uma organização.

- Uma definição de metas de negócios e segurança para evitar conflitos e possíveis violações da política pelos usuários de um sistema.

- Quem é responsável pela implementação e manutenção da política. A segurança é um processo contínuo que precisa ser atualizado regularmente.

- Uma descrição das medidas e regras de segurança implementadas por meio das quais as pessoas recebem acesso aos ativos de uma organização.

Qualquer política de segurança desse tipo deve ser respaldada pela equipe de gestão da organização e comunicada aos usuários do sistema de TI. Vale ressaltar que $80 \%$ da segurança precisa ser investida em medidas organizacionais que permitam que as tecnologias de segurança funcionem adequadamente (SAUTER; TREYTL, 2015).

Para o desenvolvimento de uma política de segurança e sugestões de melhores práticas em ambientes de TI, os passos seguintes precisam ser obedecidos (FRASER, 1997; ISO, 2000):

- Análise de risco para identificação e categorização de riscos; as ameaças são múltiplas e podem variar de ativas (modificação de dados, reprodução de dados, disfarce de usuário autorizado, negação de serviço a usuários autorizados), bem como ataques passivos (espionagem, divulgação de informações ou análise de tráfego). 
- Tratamento da análise atribuindo uma probabilidade de ocorrência e extensão dos danos a cada risco, dando-lhes um certo peso no contexto da política de segurança.

- Análise das vulnerabilidades e rastreamento do sistema.

- Planejamento e implementação de medidas de segurança.

Em seguida, uma discussão sobre a segurança no contexto do ciclo de vida dos sistemas de TI e uma visão geral das técnicas mais aplicadas para atingir as metas de segurança estabelecidas no plano e que, também são aplicáveis às redes de campo (fieldbus), são apresentadas.

\subsubsection{Ciclo de vida de um sistema de segurança}

Embora as atividades de segurança possam ser iniciadas a qualquer momento no ciclo de vida de um sistema, geralmente é desejável (embora muitas vezes não seja possível) integrá-las em todo o ciclo de vida, onde cinco etapas são definidas (NIELES; DEMPSEY; YAN PILLITTERI, 2017).

Durante a fase de inicialização, quando o sistema é projetado, um projeto básico de segurança é estabelecido por meio de uma avaliação de sensibilidade. Essa avaliação resulta em uma estimativa dos dados a serem manipulados pelo sistema e seu impacto na segurança.

$\mathrm{Na}$ fase de desenvolvimento, os requisitos de segurança, bem como os métodos para implementá-los, são selecionados e incluídos na especificação geral do sistema. Então segue a fase de implementação, durante a qual os recursos de segurança do sistema são ativados e testados.

Na fase de operação e manutenção, ocorrem operações relacionadas à segurança, como trocas de chaves. Também nesse estágio, as auditorias e o monitoramento do sistema podem levar a alterações no sistema se novos riscos de segurança que precisam ser resolvidos forem encontrados. Finalmente, na fase de eliminação, o descarte de informações em hardware e software precisa ser tratado. Aqui, o armazenamento de chaves criptográficas de longa data é uma tarefa importante. A Figura 19 apresenta essas fases. 


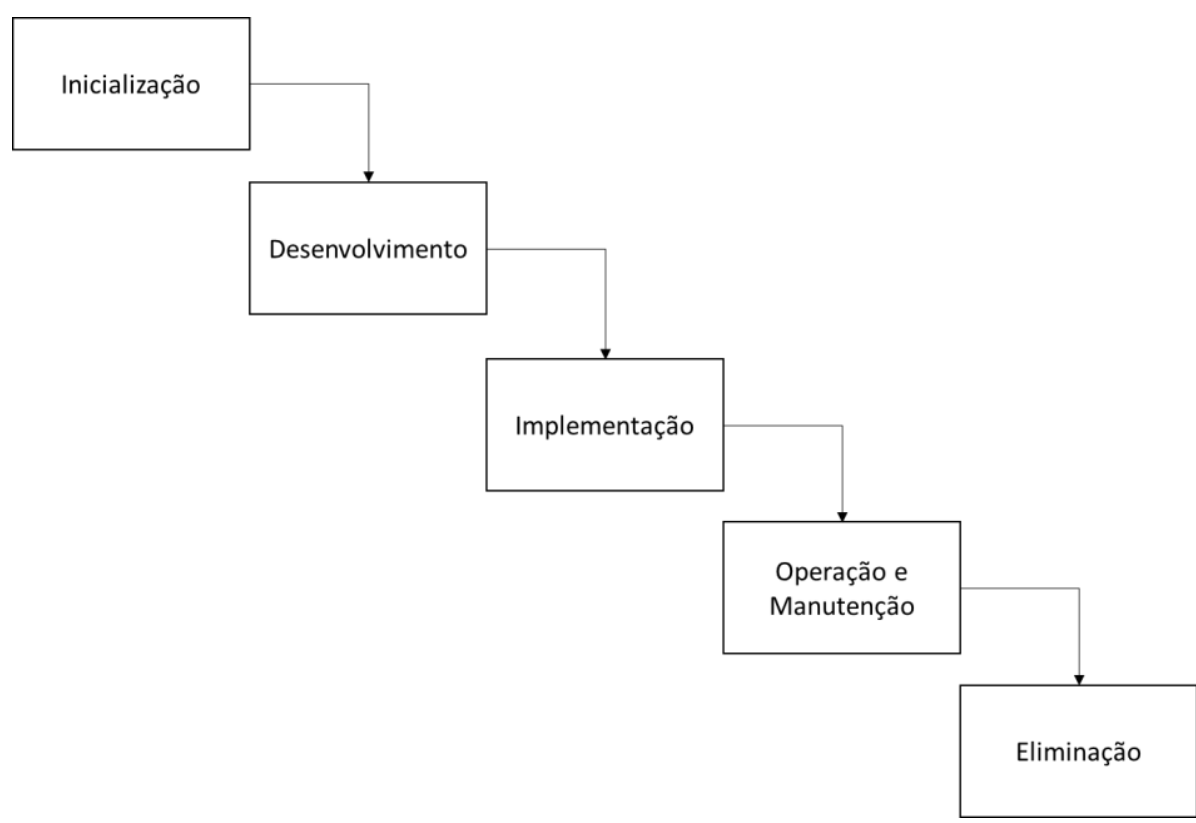

Figura 19: Ciclo de vida de um sistema de segurança FONTE: Adaptado de (SAUTER; TREYTL, 2015)

Relatórios técnicos especializados como ("Cyber Security for Industrial Automation and Control Systems (IACS)," 2016; NCSC-UK, 2016), estruturam cada fase em um loop fechado, começando com a identificação dos ativos e objetivos de segurança, análise de ameaças e riscos, seleção e implementação de medidas e auditoria contínua que fecha o ciclo. Essa atualização estruturada e contínua da política de segurança dentro de um estágio do ciclo de vida reflete o fato de que novas ameaças aparecem, mas também que as aplicações e a configuração das redes mudam continuamente.

\subsubsection{Medidas de segurança mais comuns}

Atualmente, questões de segurança em rede de comunicação é mais associada à Internet. A maioria das medidas de segurança atualmente disponíveis - com exceção da criptografia - são de alguma forma adaptadas à Internet, embora também sejam aplicáveis a uma gama mais ampla de sistemas. Sem entrar em detalhes específicos, esta seção apresenta os seguintes aspectos de segurança:

- Criptografia

- Autenticação e controle de acesso

- Firewalls e sistemas de detecção de intrusão

- Avaliações de segurança 
A criptografia é apropriada para implementar serviços em que a confidencialidade e a integridade são necessárias. Os principais blocos de construção da criptografia são os seguintes: Geradores de números com criptografia pseudoaleatória, usados para gerar entidades aparentemente aleatórias, como chaves secretas; Funções hash criptográficas, usadas em conjunto com assinaturas eletrônicas ou para gerar códigos de autenticação de mensagens (MACs) para proteger a integridade dos dados; Funções de criptografia / assinatura simétricas e assimétricas usadas para proteger a confidencialidade dos dados ou para construir MACs ou assinaturas eletrônicas (MENEZES; VAN OORSCHOT; VANSTONE, 1996; STINSON, 2005).

As medidas de autenticação são usadas para estabelecer a identidade de uma entidade, por exemplo, a de um usuário do sistema. Uma distinção clara deve ser feita entre autenticação fraca (como encontrada em sistemas baseados em senha como Unix ou Windows) e autenticação forte, que geralmente é baseada em protocolos do tipo challenge-response que dependem de criptografia simétrica ou assimétrica como Kerberos (STEINER; NEUMAN; SCHILLER, 1988).

As entidades autenticadas podem estar sujeitas a mecanismos de controle de acesso que permitam a determinação da legalidade ou, de outra forma, da ação desejada de uma entidade. Além de modelos simples, como listas de controle de acesso (ACLs Access Control Lists) e outros modelos discricionários, existem modelos mais rígidos que são encontrados principalmente em sistemas militares. Ambos os modelos podem ser implementados por meio da técnica de controle de acesso baseado em papeis (RBACRole Based Access Control) (SANDHU et al., 1996).

Já os Firewalls (GONCALVES, 1998; SCARFONE; HOFFMAN, 2009) e os Sistemas de Detecção de Intrusão (IDS - Intrusion Detection Systems) (ASLI; SUTIC, 2009; BACE; MELL, 2015; SHIN et al., 2010) são tecnologias complementares geralmente associadas a conexões LAN-fieldbus com a Internet, embora também sejam úteis em um ambiente de LAN puro ou em que uma LAN esteja conectada em uma rede fieldbus e a LAN é compartilhada entre as diferentes entidades organizacionais. Os Firewalls tentam impedir o acesso ilegal às conexões de entrada e/ou de saída, por exemplo, quando os IDSs que monitoram e analisam os padrões de acesso à rede e tentam reconhecer violações e/ou ataques à segurança.

O projeto de um sistema seguro é uma tarefa complexa, que envolve uma variedade de habilidades e conhecimentos diferentes, mas ainda assim pode não ter 
sucesso, mesmo se os cuidados necessários forem tomados (ANDERSON, 2001). Um exemplo proeminente de um sistema de segurança com falha é o WEP (Wired Equivalent Privacy - privacidade equivalente com fio), que foi projetado para proteger LANs sem fio 802.11, mas que falhou drasticamente em fazê-lo (BORISOV; GOLDBERG; WAGNER, 2001).

A Third-party Security Evaluation (avaliação de segurança terceirizada) é um método com o qual se obtém o nível de confiança em um sistema além das instruções de segurança do fabricante. A ISO/IEC 15408-1:2009 (ISO, 2009), por exemplo, é uma norma internacional que regulamenta as avaliações de segurança e uma avaliação positiva de uma meta de segurança (ou seja, o produto). Baseado nessa norma, um certificado internacionalmente reconhecido é gerado. Além dessa garantia, relacionada aos esforços de engenharia de segurança, o próprio certificado contém uma descrição da funcionalidade da segurança que foi avaliada durante o processo.

Além disso, para ajudar a preparar a certificação, existem os chamados perfis de proteção (PP) que descrevem conjuntos de requisitos de segurança independentes de implementação para áreas de segurança específicas, por exemplo, para os firewalls. Um exemplo de PP usado na área de transmissão de energia elétrica é o alemão Smart Grid Protection Profile (KREUTZMANN; VOLLMER; TEKAMPE, 2014).

\subsubsection{Segurança em redes de Automação Industrial}

Para redes de automação, em particular, aquelas usadas no nível de campo da pirâmide da automação (Figura 17), muitas tecnologias de comunicação diferentes estão disponíveis hoje (SAUTER, 2010). Os sistemas fieldbus clássicos formaram as primeiras redes, seguidas por vários desenvolvimentos baseados no padrão Ethernet. Nos últimos anos, as tecnologias sem fio estão se tornando cada vez mais importantes. Todas essas redes distintas são também diferentes em relação aos seus níveis de segurança.

\subsubsection{Redes fieldbus}

É incorreto afirmar que os sistemas fieldbus de hoje não implementam nenhuma medida de segurança. Na verdade, isso não é totalmente verdade. Existem tais conceitos em sistemas de comunicação para automação predial (GRANZER; PRAUS; KASTNER, 2010; SCHWAIGER; TREYTL, 2003), e há até mesmo traços em alguns paradigmas de 
automação industrial (TREYTL; SAUTER; SCHWAIGER, 2004). No entanto, essas abordagens são bastante limitadas. Os sistemas fieldbus para automação industrial e de processos atualmente padronizados pela IEC nas normas IEC 61784-1 (INTERNATIONAL ELECTROTECHNICAL COMMISSION (IEC), 2007) e na série IEC 61158 (IEC (INTERNATIONAL ELECTROTECHNICAL COMMISSION), 2003) são, apesar de todos os esforços, uma coleção heterogênea de soluções. No que diz respeito aos recursos de segurança, no entanto, eles se enquadram em duas categorias principais: sistemas como ControlNet, P-Net e SwiftNet não usam quase nenhuma estratégia de segurança significativa. Já Foundation Fieldbus, o Profibus, o WorldFIP e o Interbus compartilham serviços e protocolos da camada de aplicativos muito semelhantes, modelados após o seu ancestral MMS (Manufacturing Messaging System). O mecanismo de proteção de acesso é inspirado no gerenciamento de direitos de acesso ao sistema baseado no UNIX proprietário/grupo/papel, por exemplo, em sistemas baseados em UNIX. Cada objeto tem uma senha associada a ele (com 8 bits de comprimento), bem como uma lista de grupos de acesso (também uma palavra de 8 bits, correspondente a oito grupos diferentes). Tanto a senha quanto o grupo de acesso são transferidos formato de texto simples pela rede (TREYTL; SAUTER; SCHWAIGER, 2004). O tipo de acesso depende do tipo de objeto (como ler, gravar, executar, excluir etc.) e podem ser ativados com a senha (equivalente ao proprietário no UNIX), os grupos e todos os parceiros de comunicação sem restrição.

Infelizmente, esses meios de segurança não são obrigatórios para implementação, o que limita sua usabilidade. A senha em si não tem proteção explícita, muito menos criptografia. Uma nota na norma revela a real intenção destes mecanismos de segurança: "Esta não é uma proteção contra o uso intencional e indevido dos recursos de comunicação de um dispositivo de campo, mas ajuda a proteger um sistema do uso incorreto acidental dos dados de processo."

A situação é bem diferente na área de automação predial. Os dois sistemas mais utilizados nessa área são o LonWorks e o KNX, ambos já possuem recursos de segurança dedicados. O LonWorks oferece um mecanismo de autenticação; A KNX oferece um controle de acesso baseado em senha. O algoritmo criptográfico usado pelo LonWorks é baseado em um protocolo de desafio-resposta de quatro etapas. Esse algoritmo calcula um valor de hash de 64 bits sobre a mensagem e um número aleatório usando uma chave secreta compartilhada. No entanto, o comprimento curto da chave e várias falhas já 
descobertas no protocolo tornam este mecanismo inseguro (SCHWAIGER; TREYTL, 2003). Já o sistema KNX fornece apenas um esquema básico de controle de acesso baseado em senhas de tex to não criptografado. Até 255 níveis de acesso diferentes podem ser definidos, cada um deles associado a um diferente conjunto de privilégios. Para cada nível de acesso, uma senha de 4 bytes (key) pode ser especificada. Este mecanismo de controle de acesso rudimentar, no entanto, não oferece uma segurança forte e não está disponível para a troca de dados de processo (GRANZER et al., 2006).

Outro sistema que possui muitas aplicações em automação predial é o BACnet, utilizado principalmente no nível gerencial, ou seja, acima dos demais, sendo também o mais recente dos três. Os mecanismos de segurança implementados aqui são mais maduros e amplamente orientados para o atual estado da arte em tecnologia da informação, incluindo um serviço de autenticação, bem como serviços de segurança que garantam a confidencialidade e integridade dos dados. Esses mecanismos usam o algoritmo padrão de criptografia de dados (DES) e um servidor de chaves confiável responsável por gerar e distribuir as chaves secretas.

O fato de que os sistemas de automação predial se preocuparem mais com segurança não é surpreendente. Primeiro, eles foram desenvolvidos significativamente depois de muitas redes de automação industrial. Em segundo lugar e mais importante, tais sistemas são muito mais complexos, porque o número de nós envolvidos em uma única rede de edifícios pode exceder, de longe, os de uma planta de produção que compreende usualmente subsistemas bem definidos. Por outro lado, o aspecto mais importante, no entanto, é que intrusos em potencial podem ter acesso quase ilimitado à rede (SAUTER; LOBASHOV, 2011).

\subsubsection{Ethernet industrial}

Já foi dito que a segurança não foi uma preocupação primordial no desenvolvimento das redes fieldbus e que, consequentemente, os mecanismos para proteger dados e equipamentos contra o acesso não autorizado em barramento de campo contemporâneos são muito limitados. No momento em que a importância da segurança na automação torna-se óbvia (DEPRIEST, 1997; PALENSKY; SAUTER, 2000), já é tarde demais para introduzir mudanças. No que diz respeito ao nível de campo, não existem, de facto, muitas opções para criar canais de comunicação seguros (NESPOLI et al., 2018; SCHWAIGER; SAUTER, 2002). Com a crescente utilização do padrão 
Ethernet na automação, foi possível reconsiderar a segurança no nível de campo sendo esta, uma área com bastante potencial de inovação para o desenvolvimento de tecnologias que integrem recursos de segurança em redes em nível de campo (FELSER; SAUTER, 2004).

Uma visão geral dos profiles do Ethernet industrial definidos na IEC61784 e seus principais recursos de segurança são apresentados na Tabela 10.

Tabela 10: Profiles do Ethernet industrial definidos na norma IEC61784. FONTE: Adaptado de (SAUTER; TREYTL, 2015)

\begin{tabular}{ll} 
IEC61784 Profile & Serviços relacionados à segurança \\
\hline CPF1 - Foundation Fieldbus & Proteção simples de acesso, opcional \\
\hline CPF2 - Ethernet/IP & Nenhuma medida específica de segurança \\
\hline CPF3 - PROFINET & $\begin{array}{l}\text { Proteção em switches dedicados para evitar a sobrecarga em } \\
\text { segmentos com tráfego em tempo real }\end{array}$ \\
\hline CPF4 - P-NET/IP & Nenhuma medida específica de segurança \\
\hline CPF10 - VNET/IP & $\begin{array}{l}\text { A segurança deve estar na camada de enlace de dados, mas não está } \\
\text { especificada }\end{array}$ \\
\hline CPF11 - Tcnet & Nenhuma medida específica de segurança \\
\hline CPF12 - EtherCAT & Nenhuma medida específica de segurança \\
\hline CPF13 - Ethernet Powerlink & $\begin{array}{l}\text { Proteção em switches dedicados para evitar a sobrecarga em } \\
\text { segmentos com tráfego em tempo real }\end{array}$ \\
\hline CPF14 - EPA & $\begin{array}{l}\text { Bridges ou Firewalls entre as redes de campo e as redes de supervisão } \\
\text { ou a Internet }\end{array}$ \\
\hline CPF15 - MODBUS RTPS & Controle de acesso baseado em endereços IP \\
\hline CPF16 - SERCOS III & Nenhuma medida específica de segurança \\
\hline
\end{tabular}

Nota-se que aspectos de segurança ficaram de fora das redes industriais baseadas no Ethernet. Os poucos mecanismos de segurança, quando existem, concentram-se em switches especiais para bloquear o tráfego de segmentos de rede ou no projeto de dispositivos dedicados (appliance) que evitam a sobrecarga da pilha de protocolos implementada. Se for necessária segurança que vá além de simples aspectos de gerenciamento de tráfego entre os segmentos, as camadas superiores da pilha de protocolos devem ser usadas. No entanto, muitas soluções Ethernet industriais permitem o tráfego IP paralelamente ao tráfego em tempo real dos dados de processo. Portanto, a mesma base tecnológica de comunicação da maioria das LANs e da Internet também está disponível no nível de campo e, em princípio, permite uma aplicação direta de mecanismos de segurança já bem conhecidos e disseminados no contexto da Internet. Por exemplo, versões seguras dos protocolos TCP, UDP e IP podem oferecer valiosas medidas de segurança. Isso pode estar na camada de rede, por exemplo, usando IPsec (TREYTL; SAUTER; SCHWAIGER, 2004), na camada de transporte (por exemplo, 
usando TLS / SSL) ou na camada de aplicação (por exemplo, Kerberos). No entanto, essas implementações apresentam as seguintes desvantagens:

- Diminuem significativamente as características de tempo real. Desta forma, elas são aplicáveis principalmente na transmissão segura de dados de configuração e na transmissão de dados (através de redes públicas) para unidades de gerenciamento remotas.

- A complexidade das pilhas de protocolos seguros demanda bastante esforço computacional dos sistemas embarcados encontrados no nível de campo e, às vezes, até mesmo no nível de controle. Em particular, a criptografia assimétrica aumenta em demasia a carga nos dispositivos de campo.

De qualquer forma, deve-se notar que o uso de versões seguras do protocolo IP não é genuinamente algo abrangido pelas soluções de Ethernet industrial existentes, o uso continua sendo uma solução alternativa em uma faixa muito limitada de aplicações, como também será mostrado na próxima seção.

\subsubsection{Medidas de segurança adicionais}

O que se tem atualmente disponível no nível de campo em termos de mecanismos de segurança não é muito promissor. Portanto, se a segurança é um problema crítico em um determinado sistema de controle industrial, medidas complementares apropriadas devem ser implementadas. Ao considerar o uso de tais medidas adicionais, um consentimento comum deve ser de obedecer ao princípio de Kerckhoff's, assumindo que apenas mecanismos de segurança bem conhecidos e bem testados devem ser empregados, o que, por sua vez, significa utilizar apenas abordagens já bem estabelecidas do mundo de TI (SAUTER; TREYTL, 2015). Embora essa seja, em geral, a única solução viável, é preciso observar que os ambientes de TI e automação são consideravelmente diferentes:

- Protocolos de segurança para a Internet, como SSL / TLS e IPsec, operam no topo das camadas ou na camada de rede (de acordo com o modelo ISO/OSI). Essas camadas não estão presentes em muitos sistemas fieldbus onde, por razões de velocidade e simplicidade, normalmente apenas as camadas 1, 2 e 7 do modelo são implementadas. 
- Os sistemas fieldbus não possuem mecanismos de segurança intrínsecos e, geralmente, são projetados para serem sistemas de comunicação leves. Os mecanismos de segurança adicionais podem acarretar uma grande sobrecarga.

- As operações necessárias para a inserção de criptografia necessária para proteger a comunicação em nível de campo, podem ser proibitivas devido ao poder de processamento limitado dos equipamentos de campo atuais, ainda mais se as necessidades em tempo real precisarem também serem atendidas. Desta forma, a criptografia geralmente passa a ser limitada em operações de configuração ou gerenciamento.

- Um sistema fieldbus pode estar instalado em ambientes hostis, onde os meios de transmissão e os equipamentos da rede ficam localizados no chão-de-fábrica. Esse também é um caso da automação predial; outro exemplo extremo é o caso de aplicações de medição remota (TREYTL; ROBERTS; HANCKE, 2004; TREYTL; SAUTER, 2005).

- A variedade de sistemas fieldbus existentes é muito alta para permitir soluções unificadas. Mecanismos de segurança bem estabelecidos para um sistema fieldbus podem não ser adequados para outro.

- Extensões de segurança proprietárias adicionadas a um determinado protocolo fieldbus, inevitavelmente acarretarão incompatibilidade com as instalações padrões e/ou legadas.

- Segurança e gerenciamento de rede fácil são, de certa forma, contraditórios. Em alguns casos, é possível acessar dados de configuração e aplicação de um nó sem autenticação nenhum e/ou reprogramar um dispositivo gravando diretamente em sua memória (PALENSKY; SAUTER, 2000).

Levando-se tudo isso em consideração, a única opção restante é usar simplesmente o barramento fieldbus como um canal de transporte e encapsular os pacotes dados sobre protocolos seguros e serviços padrões do fieldbus. Essa abordagem no nível da aplicação pode atingir a segurança de ponta a ponta, que, de qualquer maneira, é desejada na maioria das aplicações industriais. 
No entanto, adicionar esse mecanismo de segurança provavelmente causará problemas de interoperabilidade, a menos que todos os dispositivos da rede adiram a esse novo padrão aprimorado, ou seja, haveria uma mistura de dispositivos seguros e inseguros que normalmente seria inviável. Outro problema é o tamanho limitado da mensagem em alguns sistemas fieldbuses que deixa pouco espaço para o acréscimo extensões de segurança eficientes. Especialmente, os serviços de integridade exigem blocos de dados adicionais, por exemplo, códigos hash, reduzindo assim a carga útil realmente disponível por pacote e, consequentemente, o desempenho de um canal seguro (SAUTER; TREYTL, 2015).

\subsubsection{Abordagem de segurança no nível de equipamento}

Embora não se tenha tido problemas de segurança por muito tempo nas redes de automação, questões de segurança em redes de computadores, fortemente interconectadas, foram mais rápidas. Aspectos de segurança já haviam sido discutidos na antecessora da Internet, a Arpanet (LUKASIK, 2011), mas sem quaisquer consequências diretas. As deficiências de segurança no projeto global da Internet foram reconhecidas apenas nos anos 80. Finalmente, em 1989, mas ainda muito antes da invenção da WWW e do subsequente sucesso da Internet, a ISO emitiu uma nova parte do modelo OSI abrangendo questões de segurança em sistemas de comunicação aberta (ISO, 1989). Essa nova versão identifica e mapeia vários serviços de segurança indicando em qual camada do modelo ( 1 a 7) há possibilidade de implementação. Detalhes podem ser vistos na Tabela 11.

Tabela 11: Serviços de segurança em diferentes camadas conforme o modelo ISO/OSI FONTE: Adaptado de (SAUTER; TREYTL, 2015)

\begin{tabular}{ll} 
Serviço de Segurança & Possível(s) Camada(s) \\
\hline Autenticação das entidades & $3,4,7$ \\
\hline Autenticação da origem & $3,4,7$ \\
\hline Controle de acesso & $3,4,7$ \\
\hline Confidencialidade na conexão & 1 a 7 \\
\hline Confidencialidade no tráfego de dados & 2 a 7 \\
\hline Integridade na conexão & 4,7 \\
\hline Integridade no tráfego de dados & 7 \\
\hline Mecanismos de não-repúdio & 7 \\
\hline
\end{tabular}


Além disso, a nova versão descreve os mecanismos de segurança que podem ser usados para alcançar tais serviços de segurança. Embora a arquitetura de segurança proposta não seja tão amplamente utilizada e conhecida como o modelo OSI original, a abordagem em camadas é útil, especialmente para redes que não implementam todas as sete camadas, o que é o caso usual dos sistemas fieldbus.

Os serviços de segurança acima da camada de aplicação, que são geralmente desejáveis para obter segurança de ponta a ponta, estão fora do escopo e, portanto, não estão abordados nessa norma. Levando-se em conta que no nível de campo encontram-se os microcontroladores dedicados e projetados para lidarem com uma interface de fieldbus e protocolos específicos, uma solução de segurança que é planejada para a camada 7 parece ser uma escolha sensata em todos os casos.

Além disso, em sistemas onde se encontra uma camada de abstração acima da camada 7, a inclusão de serviços de segurança nessa camada também é de especial interesse. Tal solução traz um especial benefício de que a camada de usuário de um sistema fieldbus é tipicamente voltada para a padronização de serviços interoperáveis ou perfis de aplicação. O processo de padronização desses serviços é realizado por um grupo de usuários (geralmente composto pelas organizações envolvidas no desenvolvimento do fieldbus), levando a uma ampla aceitação na indústria. Além da aceitação esperada, essa solução fornece segurança de ponta a ponta em seu sentido mais restrito: ela protege toda a comunicação entre dois nós no nível da aplicação. Na ausência de uma camada de usuário amplamente aceita na qual os serviços de segurança podem ser integrados, ou em casos em que um grupo de usuários específico não vê necessidade de adicionar tais serviços (como muitas vezes pode ser o caso), uma solução mais genérica, acima da camada 7 ainda pode ser criada. A desvantagem seria uma inevitável perda de interoperabilidade com outras soluções, resultando em maiores esforços de desenvolvimento e consequentemente aumento de custos.

Em ambas as abordagens, os serviços de segurança podem ser fornecidos por um mecanismo de wrapping. Esse mecanismo transforma um valor de uma variável de processo em unidade de engenharia (ou seja, um valor medido de entrada que foi obtido por um sensor de campo) e aplica a esse valor um mecanismo de checagem de integridade ou a um mecanismo de integridade/confidencialidade. A Figura 20 mostra um exemplo do segundo caso em que o Cabeçalho contém informações sobre as transformações de 
confidencialidade aplicadas. O campo MAC contém informações de verificação de integridade.

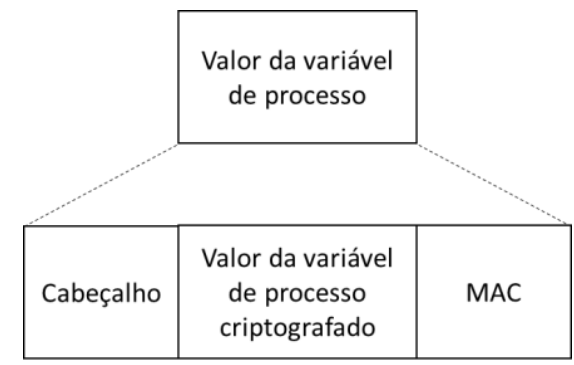

Figura 20: Processo de wrapping de uma variável de processo FONTE: Adaptado de (SAUTER; TREYTL, 2015)

Contudo, a integração de mecanismos de integridade e confidencialidade na maioria dos sistemas fieldbus de hoje pode ser proibitiva, pois, conforme já mencionado anteriormente, exige uma capacidade de processamento que pode estar fora do alcance dos microprocessadores de 8 bits e de baixo custo encontrados normalmente nesses dispositivos de campo. Outra desvantagem dessas soluções como a descrita na Figura 20 é que o limite de tamanho do payload das mensagens do sistema fieldbus pode inviabilizar a transmissão da mensagem completa com os campos adicionais responsáveis pela confidencialidade e integridade. Este é um problema especialmente para os mecanismos de integridade, pois eles necessariamente adicionam dados à mensagem transmitida. Para o modo somente confidência, pode-se simplesmente criptografar o valor de engenharia e omitir o cabeçalho da mensagem. Neste cenário, os dois nós comunicantes precisariam saber antecipadamente se os dados a serem enviados/recebidos estão ou não criptografados.

Considerações sobre a segurança física e a desativação automática de nós em caso de adulteração, a possibilidade de incluir mecanismos de detecção de intrusão em um dispositivo ou na rede como um todo, é algo bastante promissor.

Esse mecanismo pode se tornar ainda mais viável em instalações que permanecem inalteradas após a implantação, o que significa que nenhum equipamento é adicionado ou removido e que, os padrões de comunicação entre os nós permanecem inalterados ou, somente mudam de uma maneira previamente planejada. Assim, com esse sistema de detecção, assim que que uma intrusão for detectada poderia disparar um alarme no sistema e/ou desativá-lo. No entanto, também é necessário determinar precisamente o tempo correto para a desativação, pois, por exemplo, seria inconveniente e perigoso se o 
sistema de comunicação de um carro parasse de funcionar enquanto o carro estiver sendo conduzido.

\subsubsection{Abordagem de segurança no nivel do sistema-Defense in Depth}

Considerando-se que os sistemas de automação normalmente são constituídos por uma hierarquia de redes, também é possível adotar um modelo de segurança hierárquico seguindo a abordagem de 'defesa em profundidade' (Defense in Depth em inglês) sugerida em (NUTZERORGANISATION, 2013; SCHWAIGER; SAUTER, 2002).

A ideia principal é focar nos níveis de rede que normalmente estão separados uns dos outros por equipamentos dedicados (gateways, bridges e firewalls). Esses equipamentos, que interligam as redes de nível de campo aos níveis superiores, geralmente são equipados com hardware mais potente e podem ser usados como pontos de ancoragem para a implementação da estratégia de segurança.

A 'defesa em profundidade' depende da existência de camadas de segurança diferentes para proteger os ativos valiosos da rede: usando a famosa analogia da cebola: ao remover a camada mais externa (segurança) revela-se outra camada e, além disso, muitas outras camadas ainda precisam ser removidas antes que os ativos se tornem vulneráveis.

\section{Modelo de segurança de três zonas}

O modelo de segurança de três zonas mostrado na Figura 21 é otimizado para o uso em aplicações de automação industrial e segue os níveis típicos de rede de uma empresa (KHAN; MAD; TREYTL, 2007): A 'zona interna' compreende os sistemas de comunicação em nível de campo localizados no chão de fábrica, onde os mecanismos de segurança podem ser limitados como discutido nas seções anteriores. A 'zona da intranet' é geralmente construída sobre $L A N s$ baseadas em IP dentro da planta industrial e também pode incluir zonas desmilitarizadas $(D M Z s)$ além da verificação de domínios ou estruturas internas de segurança para fortalecer a segurança. Por fim, a 'zona da Internet' conecta várias fábricas, clientes ou fornecedores horizontalmente ao longo da cadeia produtiva. Nos níveis baseados em IP do sistema de automação, os mecanismos de segurança padrão conhecidos do mundo de TI, como IPsec ou TLS podem ser usados. 


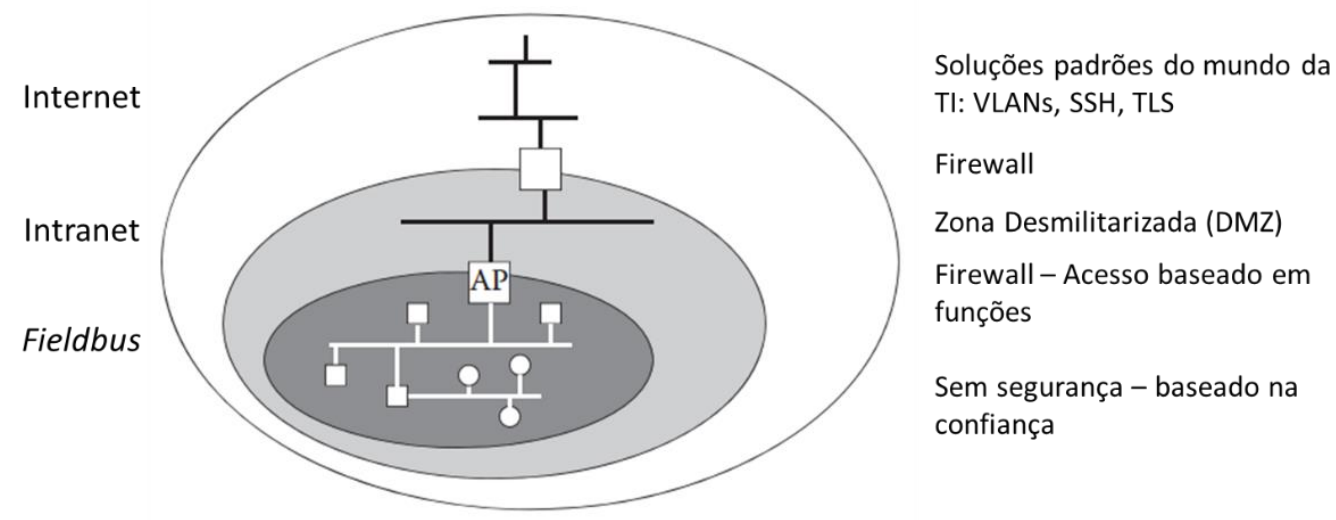

Figura 21: Modelo de segurança com topologia em árvore que implementa a abordagem de defesa em profundidade

FONTE: Adaptado de (SAUTER; TREYTL, 2015)

Os nós que separam as diferentes zonas são sempre pontos naturais para implementação dos mecanismos de segurança. Eles representam a única parte do sistema de automação que medidas de segurança podem ser facilmente implementadas, já que, conforme apresentado nas seções anteriores, a maioria dos sistemas fieldbus não possui medidas de segurança intrínsecas.

O nó que interliga as zonas da Intranet com a Interna, é chamado de Ponto de Acesso (AP - Access Point em inglês) devido ao fato de que, ele também pode implementar a funcionalidade da tradução de protocolos e meios de acesso para a devida troca de dados entre as duas redes. Atualmente, o próprio AP tem sido o foco principal de interesse na maioria das pesquisas da área de segurança em redes industriais. Uma abordagem muito comum no modelo de defesa em profundidade é combinar o AP com um firewall, que é a medida de segurança mais amplamente utilizada em projetos de interconexões de rede atualmente, mesmo no campo da automação (CHEMINOD; PIRONTI; SISTO, 2011; MIRANDA, 2016).

O principal objetivo de um firewall é separar uma intranet privada e com acesso restrito de uma rede acessível publicamente (GONCALVES, 1998). Essa separação é normalmente implementada no nível de IP, concedendo acesso apenas a computadores de um conjunto pré-definido de endereços IP ou domínios. Assim, somente solicitações de tais endereços são aceitas pelo firewall, e todas as outras são negadas. A Figura 22 ilustra um cenário deste. 


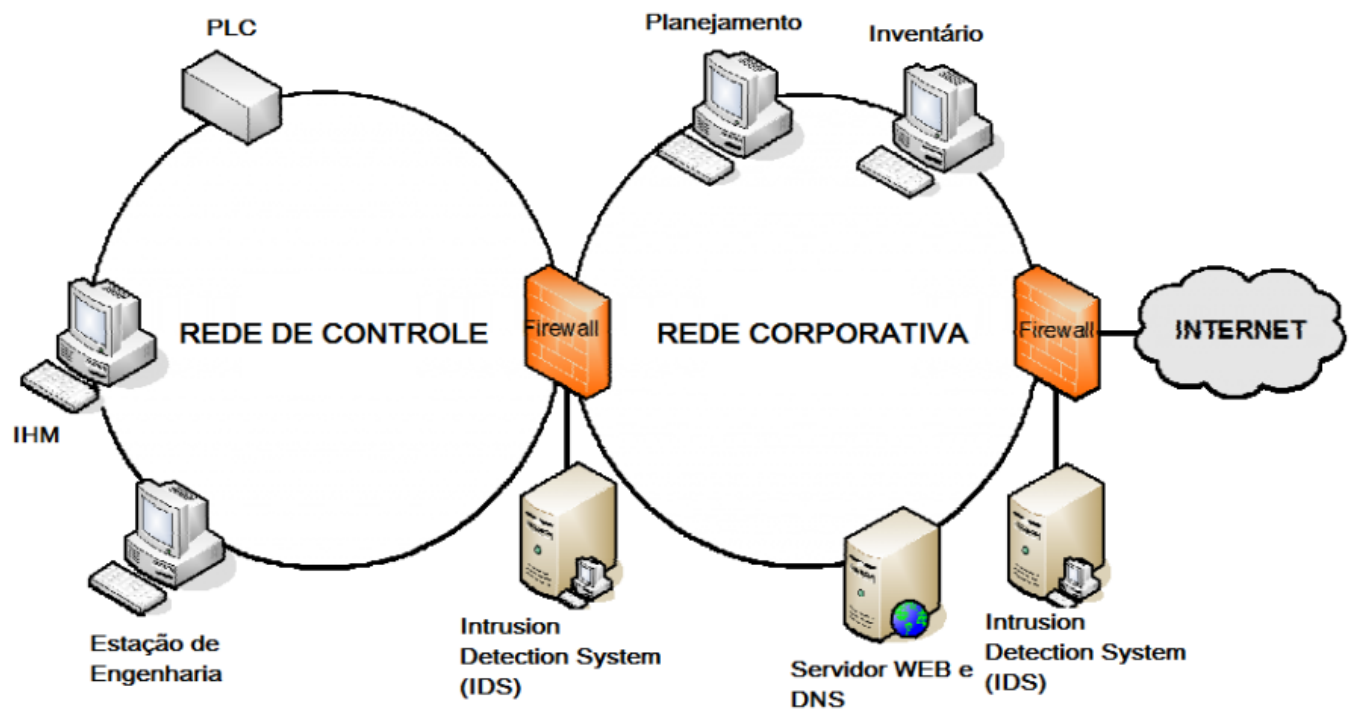

Figura 22: Exemplo de segmentação de rede com firewalls e IDS FONTE: Adaptado de (HAHN; GUILLEN; ANDERSON, 2005)

Isso requer que o firewall também funcione como um roteador IP conectando o segmento com IP privado e o segmento com IP público (aberto para a Internet). Como todo tráfego de rede é controlado pelo firewall, a intranet por trás pode ficar completamente escondida do lado de fora (restante do mundo). No entanto, o trajeto reverso, da intranet para a Internet, é menos restritivo: o firewall encaminha diretamente todo pacote de dados oriundos da rede interna.

Idealmente, o dispositivo localizado na intranet nem percebe a presença do firewall e, devido a esta característica assimétrica, o firewall quando integrado ao AP usa, por exemplo, o encaminhamento de porta para controlar o tráfego (RULAND; SASSMANNSHAUSEN, 2018). Além disso, outro cenário típico é tornar o firewall um gateway de VPN - Virtual Private Network, onde os firewalls roteiam o tráfego da rede de automação para a VPN. Tais implementações são baseadas principalmente no protocolo IPsec. Uma VPN também fornece uma alternativa simples e rápida para extensões de segurança baseadas em IP para os protocolos de rede de automação que não possuem seus próprios mecanismos de criptografia (a grande maioria, conforme apresentado nas seções anteriores).

Além de fornecer a funcionalidade básica do firewall, o AP também é o local ideal para controlar e gerenciar o acesso à zona do fieldbus. Para a implementação de qualquer política de segurança, a segurança de ponta a ponta é desejável, ou seja, o cliente, estando na Internet, estabelece um canal seguro para a fonte de dados no fieldbus, independentemente da estrutura de rede intermediária. Em redes de automação, o número 
de nós que precisam de comunicação segura é potencialmente muito alto. Na verdade, todos os sensores ou atuadores devem ser incluídos, o que torna o controle das relações de comunicação e, portanto, das chaves de segurança extremamente complexo, mesmo que tokens de segurança, sejam empregados (SCHWAIGER; SAUTER, 2002). Uma forma prática é interceptar um canal seguro no AP e implementar uma arquitetura de comunicação segura em duas etapas (Figura 23).

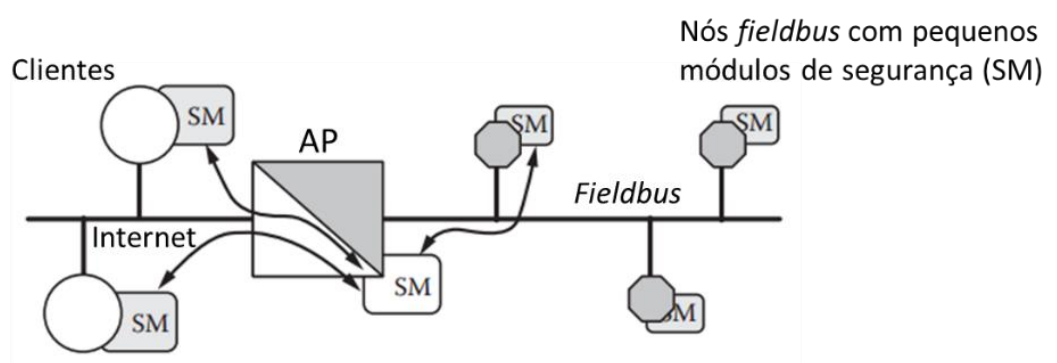

Figura 23: Arquitetura de comunicação segura de duas etapas usando módulos de segurança (SM) ou tokens de segurança (por exemplo, cartões inteligentes) para um melhor gerenciamento das chaves FONTE: Adaptado de (SAUTER; TREYTL, 2015)

O AP mantém uma lista das conexões autorizadas da zona da Internet e controla diretamente o acesso aos dados ou aos canais de comunicação, dependendo do tipo de operação do AP: como entrada de um túnel ou como gateway (MIRANDA, 2016). Por outro lado, os equipamentos da rede fieldbus, necessitam apenas conectar ao seu AP e manipular os tokens de segurança, se houver (PALENSKY; SAUTER, 2000). Esse tipo de abordagem facilita a atualização e/ou manutenção da estrutura de controle de acesso da rede (SAUTER; LOBASHOV, 2011). Um modelo adequado para lidar com o controle de acesso em tal cenário é o RBAC (RULAND; SASSMANNSHAUSEN, 2018), onde todos os parceiros de comunicação (usuários, dispositivos e ferramentas) estão associados a funções específicas dependendo do contexto da troca de dados. No ambiente da TI, esse conceito é bastante empregado e também pode ser usado no contexto da automação (PARKER, 2018).

No entanto, embora as tecnologias de segurança do mundo de TI estejam maduras, sua aplicação nos sistemas de automação não é simples. Diferenças enormes existem nos requisitos das aplicações de TI e da automação. Mesmo que a abordagem de defesa em profundidade solucione os problemas técnicos, restam ainda as dificuldades organizacionais de definir e impor uma estratégia de segurança.

Um padrão recém-publicado na série, ISA/IEC 62443-4-2-2018, 'Segurança para Automação Industrial e Sistemas de Controle', fornece os requisitos técnicos de 
segurança cibernética para componentes que compõem um sistema de controle industrial, especificamente para os dispositivos embarcados, componentes de rede, componentes do host e softwares. O padrão estabelece recursos de segurança que permitem que um componente diminua as ameaças para um determinado nível de segurança sem a necessidade de contramedidas externas adicionais. Detalhes acerca desse padrão são apresentados na próxima seção.

\subsection{Norma ISA 62443-2018}

A norma internacional ISA/IEC 62443, desenvolvida pelo comitê ISA99 e adotada globalmente pela IEC - International Electrotechnical Commission, foi projetada para fornecer uma estrutura flexível para abordar e mitigar vulnerabilidades de segurança atuais e futuras em automação industrial e sistemas de controle (IACS - Industrial Automation and Control Systems) (INTERNATIONAL SOCIETY OF AUTOMATION, 2018).

O padrão recém-publicado na série, ISA/IEC 62443-4-2-2018, 'Segurança para Automação Industrial e Sistemas de Controle: Requisitos Técnicos de Segurança para Componentes de um IACS', fornece os requisitos técnicos de segurança cibernética para componentes que compõem um IACS, especificamente para os dispositivos embarcados, componentes de rede, componentes do host e softwares. O padrão estabelece recursos de segurança que permitem que um componente diminua as ameaças para um determinado nível de segurança sem a necessidade de contramedidas externas adicionais.

A definição de um padrão para os componentes de segurança do sistema estabelece uma linguagem comum entre os fornecedores de produtos e todas as demais entidades envolvidas com o IACS. Isso implica uma simplificação dos processos de aquisição e integração de computadores, softwares, equipamentos de rede e dispositivos de controle que compõem um IACS.

A nova versão publicada em fevereiro de 2018 da ISA/IEC 62443-4-1, 'Requisitos do Ciclo de Vida no Desenvolvimento de Segurança do Produto', que especifica requisitos para um processo seguro do desenvolvimento de produtos utilizados em IACS e define um ciclo de vida para o desenvolvimento seguro e manutenção de produtos relacionados à segurança. $\mathrm{O}$ ciclo de vida inclui a definição de requisitos de segurança, 
design seguro, implementação segura (incluindo diretrizes de codificação), verificação e validação, gerenciamento de defeitos, gerenciamento de patches e da vida útil do produto. Esses requisitos podem ser aplicados em novos processos ou aos já existentes, no desenvolvimento, na manutenção e na desativação de hardware, software ou fïmware dos produtos. Tais requisitos se aplicam ao desenvolvedor e ao mantenedor de um produto, mas não ao integrador ou usuário final do produto.

O comitê de normas ISA99 se baseia na contribuição de especialistas em segurança de IACS de todo o mundo para desenvolver padrões de consenso aplicáveis a todos os setores da indústria e infraestrutura crítica. Os documentos anteriores da série ISA/IEC 62443 abrangem terminologia, conceitos e modelos; estabelecimento de um programa de segurança do IACS; gerenciamento de patches; e requisitos de segurança do sistema e níveis de segurança.

\subsubsection{Escopo}

O conceito de automação industrial e sistemas de controle de segurança eletrônica é aplicado no sentido mais amplo possível, abrangendo todos os tipos de plantas industriais nos diversos segmentos de mercado.

Os sistemas de manufatura e controle incluem, mas não estão limitados a sistemas de hardware e software, como DCS - Distributed Control System, PLC - Programmable Logic Controller, SCADA - Supervisory Control And Data Acquisition, sistemas de detecção eletrônica em rede e sistemas de monitoramento e diagnóstico.

\subsubsection{Objetivos da norma}

O principal objetivo da série de normas 62443 é melhorar a segurança, disponibilidade, integridade e confidencialidade dos componentes ou sistemas utilizados para automação e controle industrial, e estabelecer critérios para aquisição e implementação de sistemas de automação e controle industrial seguros.

\subsubsection{Organização}

A série 62443 é composta por quatro grupos principais. São eles:

- Geral: este grupo inclui elementos que abordam tópicos comuns a toda a série. 
○ O padrão 62443-1-1 introduz os conceitos e modelos usados em toda a série. O público-alvo inclui qualquer pessoa que deseje se familiarizar com o conhecimento dos conceitos que formam a base para a série. A primeira edição deste padrão foi lançada em 2007.

○ O relatório técnico 62443-1-2 contém um glossário mestre dos termos e abreviações usados ao longo da série. Este relatório está disponível no formato de rascunho. A publicação final ocorrerá depois de todos os outros elementos já tiverem sido publicados.

○ Já a norma 62443-1-3 descreve uma série de métricas quantitativas derivadas dos requisitos fundamentais do sistema e associados. Ainda apenas em formato de rascunho.

○ O relatório técnico 62443-1-4 fornece uma descrição mais detalhada do ciclo de vida de segurança do IACS, bem como vários casos de uso ilustrando várias aplicações (os trabalhos neste relatório ainda não começaram).

- Políticas e Procedimentos: neste grupo concentram-se as políticas e procedimentos associados à segurança do IACS.

- A norma 62443-2-1 descreve o que é necessário para definir e implementar um sistema de gerenciamento de segurança cibernética do IACS. O público-alvo aqui inclui usuários finais e proprietários de ativos que têm responsabilidade pelo projeto e implementação de tal programa. A primeira edição desta norma foi lançada em 2009 e o comitê ISA99 está desenvolvendo uma segunda edição atualizada que se alinhará melhor com a série ISO27000 de padrões de segurança cibernética geral de TI.

○ A norma 62443-2-2 fornece orientação específica sobre o que é necessário para operar um sistema eficaz de gerenciamento de segurança cibernética do IACS. O público-alvo inclui os usuários finais e proprietários de ativos que são responsáveis pela operação de tal programa. Este padrão está disponível em forma de rascunho. 
○ Já o relatório técnico 62443-2-3 fornece orientação específica o gerenciamento de patches do IACS. O público-alvo inclui quem tem responsabilidade pelo design e pela a implementação de procedimentos para o gerenciamento de patches. Este relatório foi aprovado e publicado pela ISA e pela IEC em 2015.

- A norma 62443-2-4 especifica requisitos para fornecedores de IACS. O público principal inclui os fornecedores de soluções de sistemas de controle. Este padrão foi desenvolvido pelo comitê IEC TC65 WG10 e será formalmente adotado pela ISA como parte da série ISA-62443.

- Requisitos de sistema: os elementos no terceiro grupo abordam os requisitos em nível de sistema.

○ O relatório técnico 62443-3-1 descreve a aplicação de várias tecnologias de segurança no ambiente de um IACS. O público-alvo inclui qualquer pessoa que deseja aprender mais sobre a aplicabilidade de tecnologias específicas em um ambiente de sistemas de controle. A segunda edição foi publicada em 2007, e o comitê ISA99 está atualmente trabalhando em a terceira edição.

○ O padrão 62443-3-2 aborda a avaliação de riscos de segurança e o projeto de sistemas de segurança para IACS. Esse padrão é direcionado principalmente aos proprietários de ativos ou usuários finais. Está disponível em formato de rascunho.

- A norma 62443-3-3 descreve os requisitos de segurança fundamentais de um sistema e os níveis de garantia de segurança. Este padrão foi publicado pela ISA e pela IEC em 2013.

- Requisitos de componentes: o quarto e último grupo inclui elementos que fornecem informações sobre os requisitos mais específicos e detalhados associados ao desenvolvimento de produtos IACS.

○ A norma 62443-4-1 descreve os requisitos aplicáveis ao desenvolvimento de produtos. $\mathrm{O}$ público principal inclui fornecedores de sistemas de controle soluções. Esse padrão está disponível no formato de rascunho. 
○ O padrão 62443-4-2 contém um conjunto de requisitos que fornecem um mapeamento detalhado dos requisitos do sistema para subsistemas e componentes do sistema em consideração. O público principal inclui fornecedores de soluções de sistemas de controle. Esse padrão está disponível também no formato de rascunho.

A conformidade com os requisitos da série 62443 destina-se a melhorar a segurança eletrônica e ajudar a identificar e solucionar vulnerabilidades, reduzindo o risco de comprometer as informações ou causar degradação ou falha do equipamento (hardware e software) de plantas industriais. O conteúdo da série é dirigido aos responsáveis pela concepção, implementação ou gestão de automação industrial e sistemas de controle. Esta informação também se aplica a usuários, integradores de sistemas, profissionais de segurança e fabricantes e fornecedores de sistemas de controle.

As vulnerabilidades de segurança em redes industriais foram detectadas, analisadas e suas soluções foram formuladas em um esquema de segurança de rede amplamente conhecido como 'defesa em profundidade' (GALLOWAY; HANCKE, 2013) conforme já citado.

Nesse esquema, a segurança é implementada em todas as camadas da rede de comunicação, com cada camada isolando as camadas subsequentes das ameaças externas. A camada mais externa da 'defesa em profundidade' impede o acesso não autorizado à rede a partir de fontes externas. Para restringir o acesso à rede industrial apenas a engenheiros, operadores de controle e redes comerciais, os Firewalls são usados e o acesso remoto é protegido usando Redes Privadas Virtuais (VPN). Para aumentar ainda mais a segurança entre redes comerciais e industriais, é utilizada uma configuração de firewall da Zona Desmilitarizada (DMZ), na qual dois firewalls são colocados em série entre as redes. O equipamento compartilhado entre redes comerciais e industriais é colocado na DMZ para acesso, evitando tentativas de comunicação direta entre as redes. A operação não autorizada de equipamentos de rede através do acesso físico também pode danificar a funcionalidade da rede.

A Figura 24 apresenta um caso típico da aplicação da estratégia de 'defesa em profundidade' com vários mecanismos de detecção e prevenção. No exemplo, a VPN é usada para acesso remoto seguro. Com base em conjunto de regras, o Firewall, em combinação com a Segmentação da Rede, pode limitar a capacidade de um invasor 
acessar vários pontos da rede. Os Sistemas de Detecção de Intrusão tornam possível detectar possíveis ataques. A proteção é aprimorada ainda mais com o Controle de Acesso, onde usuários e serviços precisam ser autenticados para executar ações no sistema. Já a DMZ, por sua vez, diminui as possibilidades de um invasor se espalhar pela rede. Uma DMZ cria um segmente de rede adicional usado, por exemplo, para trocar dados dentre diferentes zonas de rede não conectadas diretamente (PFRANG; MEIER, 2018).

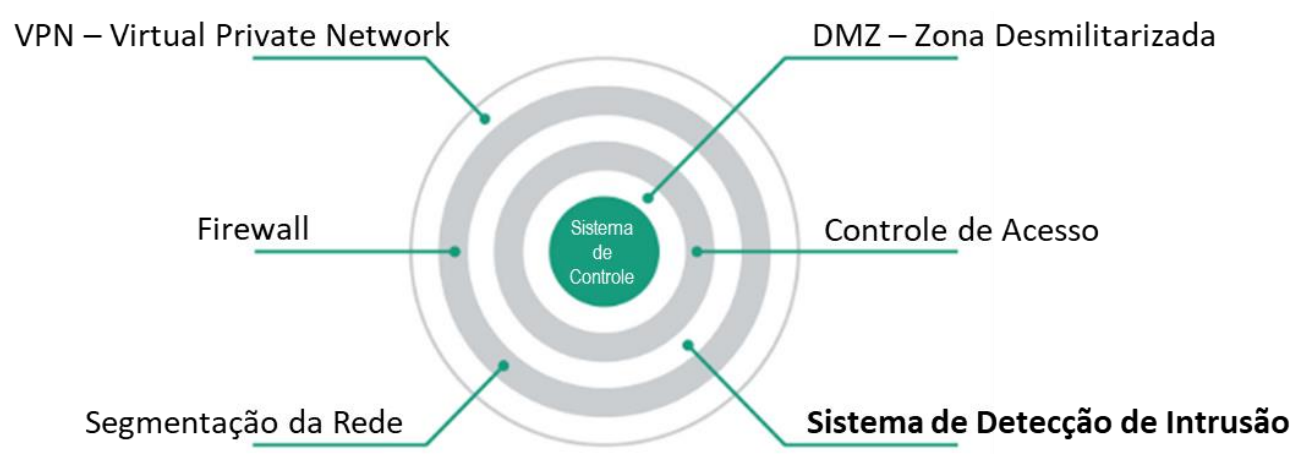

Figura 24: Exemplo da estratégia 'defesa em profundidade' associada com mecanismos de detecção de intrusão

FONTE: Adaptado de (PFRANG; MEIER, 2018)

Para que a estratégia 'defesa em profundidade' seja eficaz, as diferentes camadas devem empregar mecanismos de proteção distintos para garantir que a violação de uma camada não implique na violação de outras (GALLOWAY; HANCKE, 2013).

\subsection{Considerações Parciais}

A segurança se tornou um problema na automação. Embora não esteja previsto no início do desenvolvimento de sistemas de automação, o grau cada vez maior de integração e interconexão das plantas de automação revelou as deficiências de segurança que precisam urgentemente de solução.

Este capítulo apontou tópicos importantes para o embasamento teórico sobre os protocolos de redes baseados no padrão Ethernet, focando principalmente nas características do protocolo PROFINET. Foi dada ênfase nas topologias de rede, na estrutura de comunicação. Estas informações são de extrema importância para o 
entendimento do método de captura, do algoritmo de extração de atributos e dos cenários de testes realizados neste trabalho.

O caminho natural para atingir a tão desejada e já compulsória segurança na automação industrial é bem claro: somente com o uso de estratégias comprovadas podem ser empregadas, o que equivale a usar mecanismos de segurança desenvolvidos para o domínio da TI, onde os aspectos de segurança têm sido estudados e aplicados por um longo tempo e, onde a comunidade científica já desenvolve e testa novos conceitos e algoritmos de segurança há muito mais tempo (vide tabelas da Seção 1.1), como por exemplo a utilização de Sistemas de Detecção de Intrusão, foco deste trabalho.

No próximo capítulo são detalhadas as principais características das ferramentas matemáticas e computacionais utilizadas para a extração e seleção dos atributos do tráfego da rede de comunicação, dos sistemas de inferência para classificação do tráfego utilizados e, das estratégias para verificação do desempenho do método proposto. Estes aspectos servirão de embasamento teórico para o desenvolvimento do método proposto apresentado no Capítulo 5. 


\section{Capítulo 4}

\section{Ferramentas Matemáticas e Computacionais}

Nesta pesquisa são utilizadas ferramentas matemáticas e computacionais para a extração e seleção dos atributos do tráfego da rede de comunicação, alguns sistemas de inferência para classificações de padrões baseados em ferramentas de aprendizagem de máquinas e, estratégias para verificação do desempenho do sistema de detecção de intrusão proposto. Detalha-se então, nas próximas seções, os modelos e algoritmo considerados.

\subsection{Conceitos básicos sobre Aprendizado de Máquina}

Aprendizado de Máquina é uma área da Inteligência Artificial cujo objetivo é o desenvolvimento de técnicas computacionais sobre o aprendizado bem como a construção de sistemas capazes de adquirir conhecimento de forma automática. Um sistema de aprendizado é um programa de computador que toma decisões baseado em experiências acumuladas através da solução bem sucedida de problemas anteriores (MONARD; BARANAUSKAS, 2003). A Figura 25 apresenta as interrelações principais envolvidas no Aprendizado de Máquina.

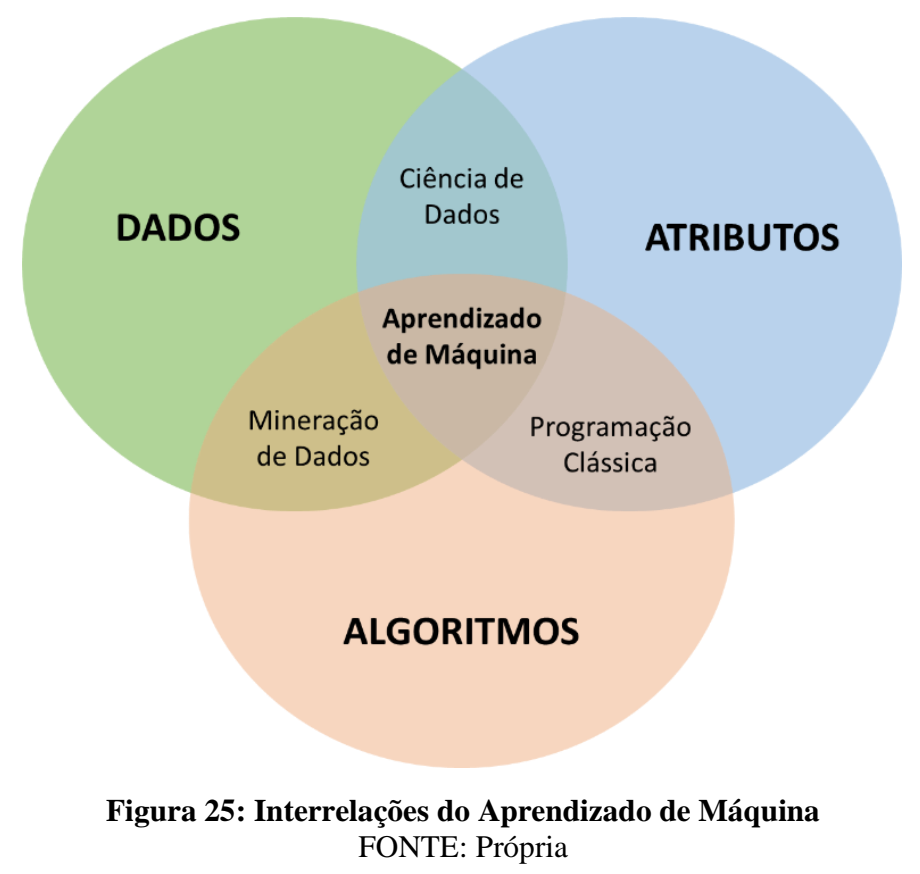


Os diversos sistemas de aprendizado de máquina possuem características particulares e comuns que possibilitam sua classificação quanto à linguagem de descrição, modo, paradigma e forma de aprendizado utilizado.

As técnicas de Aprendizado de Máquina empregam um princípio de inferência denominado indução, no qual obtém-se conclusões genéricas a partir de um conjunto particular de exemplos (amostra de dados). A Figura 26 ilustra um fluxograma típico de Aprendizado de Máquina aplicado em classificação.

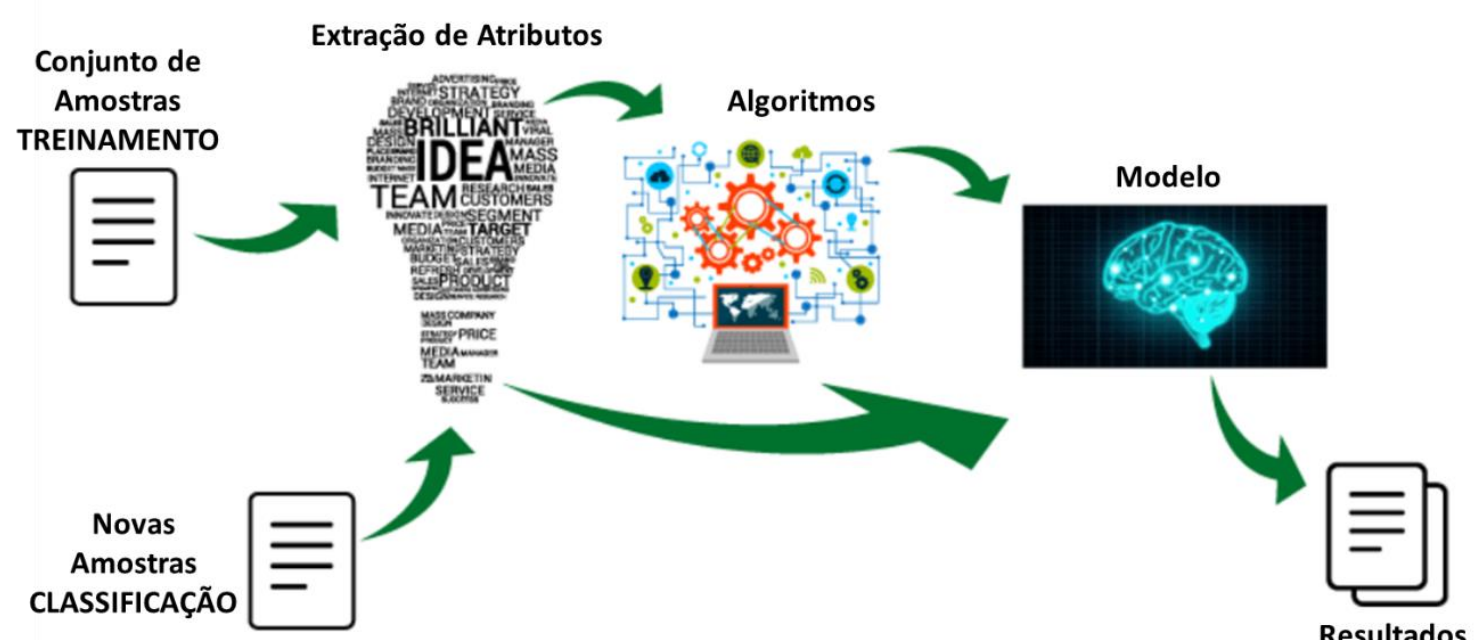

Figura 26: Fluxograma de Aprendizado de Máquina para Classificação FONTE: Própria

O processo de Aprendizado de Máquina pode ser dividido em cinco estágios:

\subsubsection{Reunir informações}

O processo de coleta de dados depende do tipo de projeto que se deseja criar. Se deseja criar um projeto de Aprendizado de Máquina que use dados em tempo real, podese, por exemplo, construir um sistema de IoT usando dados de diferentes sensores.

O conjunto de dados pode ser coletado de várias fontes, como arquivo, banco de dados, sensores e muitas outras fontes, mas os dados coletados não podem ser usados diretamente para executar o processo de análise, pois pode haver muitos dados ausentes, valores extremamente grandes, desorganizados dados de texto ou dados ruidosos. Assim, para resolver esse problema, a preparação de dados é deve ser realizada. 


\subsubsection{Pré-processamento dos dados}

O pré-processamento de dados é uma das etapas mais importantes no aprendizado de máquina. É a etapa mais importante que ajuda na construção de modelos de aprendizado de máquina com maior precisão.

O pré-processamento de dados é um processo de limpeza dos dados brutos, ou seja, os dados são coletados e convertidos em um conjunto de dados limpos. Em outras palavras, sempre que os dados são coletados de diferentes fontes, eles são coletados em formato bruto que devem ser sistematicamente trabalhados para tornarem-se viáveis para a análise. Assim, certas tarefas são executadas para converter os dados em um conjunto de dados limpos, essa parte do processo é chamada como pré-processamento de dados.

A maioria dos dados do mundo real é confusa, alguns desses tipos de dados são:

1. Dados ausentes: os dados ausentes podem ser encontrados quando não são criados continuamente ou devido a problemas técnicos no sistema e comunicação e/ou aplicação em sistemas IoT, por exemplo.

2. Dados ruidosos: esse tipo de dado também é chamado de outlier, isso pode ocorrer devido a erros humanos (humanos reunindo manualmente os dados) ou algum problema técnico do dispositivo no momento da coleta de dados.

3. Dados inconsistentes: esse tipo de dado pode ser coletado devido a erros humanos (erros com o nome ou valores) ou duplicação de dados. Exemplo: massa corporal de uma pessoa ser registrada erroneamente como $750 \mathrm{~kg}$.

\subsubsection{Definição dos modelos/algoritmos}

Buscar o modelo (algoritmo) ou os modelos que serão melhores para o tipo de dados e objetivos do Aprendizado de Máquina.

Aqui o principal objetivo é elencar modelos para serem treinados e avaliados nas etapas posteriores.

Os modelos podem ser classificados em dois tipos principais: modelos para aprendizado Supervisionado e modelos para aprendizado Não-Supervisionado.

No aprendizado supervisionado tem-se a figura de um professor externo, o qual apresenta o conhecimento do ambiente por conjuntos de exemplos na forma: entrada, 
saída desejada. O algoritmo de aprendizado de máquina extrai a representação do conhecimento a partir desses exemplos. O objetivo é que a representação gerada seja capaz de produzir saídas corretas para novas entradas não apresentadas previamente (HAYKIN, 1999). Existem duas categorias para esse tipo: Classificação e Regressão.

O problema de Classificação é quando a variável de destino é categórica (ou seja, a saída pode ser classificada em classes - ela pertence à Classe A ou B, por exemplo). Um problema de classificação ocorre quando a variável de saída é uma categoria, como "vermelho" ou "azul", "normal" ou "anômalo" e "com spam" ou "sem spam".

Em contrapartida, um problema de Regressão é definido quando a variável de destino é contínua (ou seja, a saída é numérica), como por exemplo um número real que representa o índice pluviométrico previsto para chuva em certa localidade.

No aprendizado não-supervisionado não há a presença de um professor, ou seja, não existem exemplos previamente rotulados. $\mathrm{O}$ algoritmo de aprendizado aprende a representar (ou agrupar) as entradas submetidas segundo uma medida de qualidade. Essas técnicas são utilizadas principalmente quando o objetivo é encontrar padrões ou tendências que auxiliem no entendimento dos dados (MONARD; BARANAUSKAS, 2003).

As classes (rótulos) representam o fenômeno de interesse sobre o qual se deseja fazer predições. As classes assumem valores discretos 1, ..., k. Tem-se então um problema de classificação. Caso as classes possuam valores contínuos, tem-se uma regressão. Um problema de classificação no qual $\mathrm{k}=2$ é denominado binário. Para $\mathrm{k}>2$, configura-se um problema multiclasses (MITCHELL, 1997).

Cada amostra é tipicamente representada por um vetor de características. Cada característica, ou atributo, expressa um determinado aspecto da amostra (MONARD; BARANAUSKAS, 2003). Normalmente, há dois tipos básicos de atributos: nominal e contínuo. Um atributo é definido como nominal (ou categórico) quando não existe uma ordem entre os valores que ele pode assumir (por exemplo, entre cores). No caso de atributos contínuos, é possível definir uma ordem linear nos valores assumidos (LORENA; DE CARVALHO, 2007).

A Figura 27 ilustra o fluxograma de Aprendizado de Máquina clássico. 


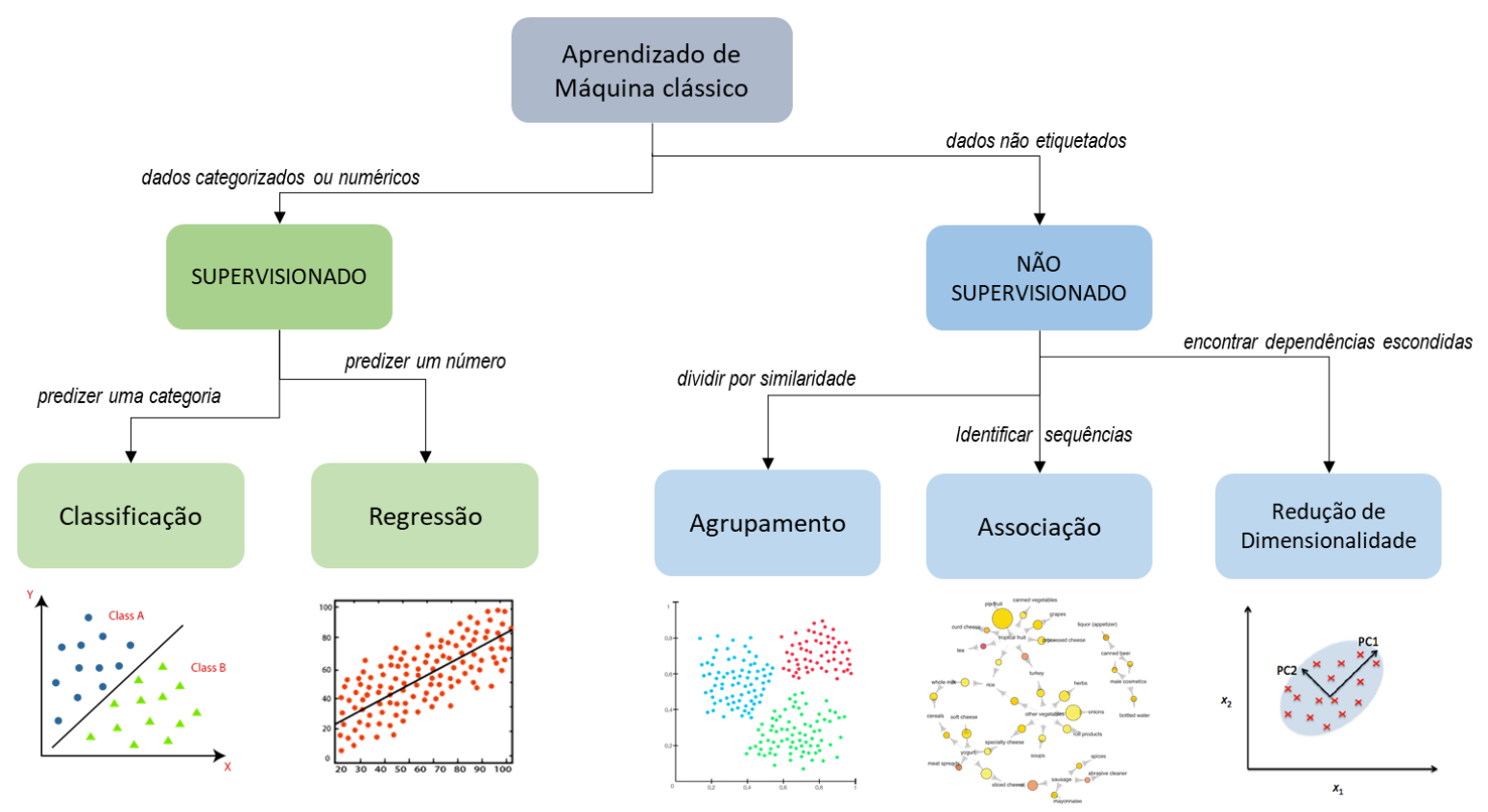

Figura 27: Fluxograma de Aprendizado de Máquina clássico FONTE: Própria

Um requisito importante para as técnicas de aprendizagem de máquina é que elas sejam capazes de lidar com dados imperfeitos, denominados ruídos. Muitos conjuntos de dados apresentam esse tipo de caso, sendo alguns erros comuns a presença de dados com rótulos e/ou atributos incorretos.

A técnica deve idealmente ser robusta a ruídos presentes nos dados, procurando não fixar a obtenção dos classificadores sobre esse tipo de caso. Deve-se também minimizar a influência de ruídos no processo de indução. Os ruídos são exemplos muito distintos dos demais presentes no conjunto de dados. Esses dados podem ser ruídos ou casos muito particulares, raramente presentes no domínio (LORENA; DE CARVALHO, 2007).

A obtenção de um classificador por um algoritmo de aprendizagem de máquina a partir de uma amostra de dados também pode ser considerada um processo de busca. Procura-se, entre todas as hipóteses que o algoritmo é capaz de gerar a partir dos dados, aquela com melhor capacidade de descrever o domínio em que ocorre o aprendizado (MITCHELL, 1997).

A resposta para a pergunta "Qual algoritmo de aprendizado de máquina deve ser usado?" é sempre "depende". Depende do tamanho, da qualidade e da natureza dos dados. Depende do que se quer fazer com a resposta. Depende de como a matemática do algoritmo foi traduzida em instruções para o computador que se está usando. E isso 
depende de quanto disponível se tem. Mesmo os cientistas de dados mais experientes não podem dizer qual algoritmo terá melhor desempenho antes de testá-los (AZUREMLSTUDIODOCS, 2017).

\subsubsection{Treinar e Testar os modelos}

Para treinar um modelo, inicialmente divide-se o conjunto de dados em três seções, que são: 'Dados de Treinamento', 'Dados de validação' e 'Dados de teste'.

Treina-se o classificador usando o 'conjunto de dados de treinamento', ajusta os parâmetros usando o 'conjunto de validação' e depois testa o desempenho do seu classificador em um 'conjunto de dados de teste'. Um ponto importante a ser observado é que, durante o treinamento do classificador, apenas o conjunto de treinamento e/ou validação é utilizado. O conjunto de dados de teste não deve ser usado durante o treinamento do classificador. O conjunto de testes estará disponível apenas durante o teste do classificador.

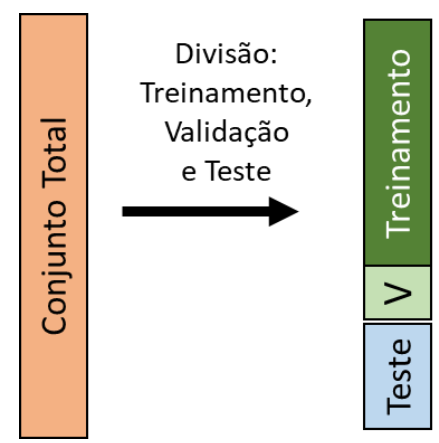

Figura 28: Divisão em conjuntos Treinamento, Validação e Teste FONTE: Própria

- Conjunto de Treinamento: o conjunto de treinamento é onde estão as informações através das quais o computador aprende como processá-las. O aprendizado de máquina usa algoritmos para executar o treinamento. Ou seja, é o conjunto de dados usado para ajustar os parâmetros do classificador.

- Conjunto de validação: a validação cruzada é usada principalmente no aprendizado de máquina aplicado para estimar a habilidade de um modelo de aprendizado de máquina em dados invisíveis. Um conjunto de dados invisíveis é usado a partir dos dados de treinamento para ajustar os parâmetros de um classificador. Maiores detalhes dessa técnica estão descritos na Seção 4.5.1. 
- Conjunto de testes: um conjunto de dados usados apenas para avaliar o desempenho de um classificador previamente treinado.

Em um conjunto de dados, um conjunto de treinamento é reservado para construir um modelo, enquanto um conjunto de teste (ou validação) é para validar o modelo construído. Os pontos de dados no conjunto de treinamento são excluídos do conjunto de teste (validação). Geralmente, um conjunto de dados é dividido em um conjunto de treinamento, um conjunto de validação (alguns cientistas usam "conjunto de teste") em cada iteração ou dividido em um conjunto de treinamento, um conjunto de validação e um conjunto de testes em cada iteração.

\subsubsection{Avaliação do modelo}

A avaliação é parte final do processo de desenvolvimento do modelo. Ajuda a encontrar o melhor modelo que representa os dados e o quão bem o modelo escolhido funcionará para novas amostras de dados.

Para melhorar o modelo, ajusta-se os hiperparâmetros de cada técnica/algoritmo que compõem o modelo na tentativa de melhorar a acurácia.

A Figura 29 apresenta algumas das principais técnicas/ferramentas de Aprendizado de Máquina utilizadas atualmente divididas em quatro grandes grupos: Aprendizado Clássico, Aprendizado Profundo, Aprendizado por Reforço e métodos Ensemble.

Destacadas em azul estão as técnicas utilizadas neste trabalho. 


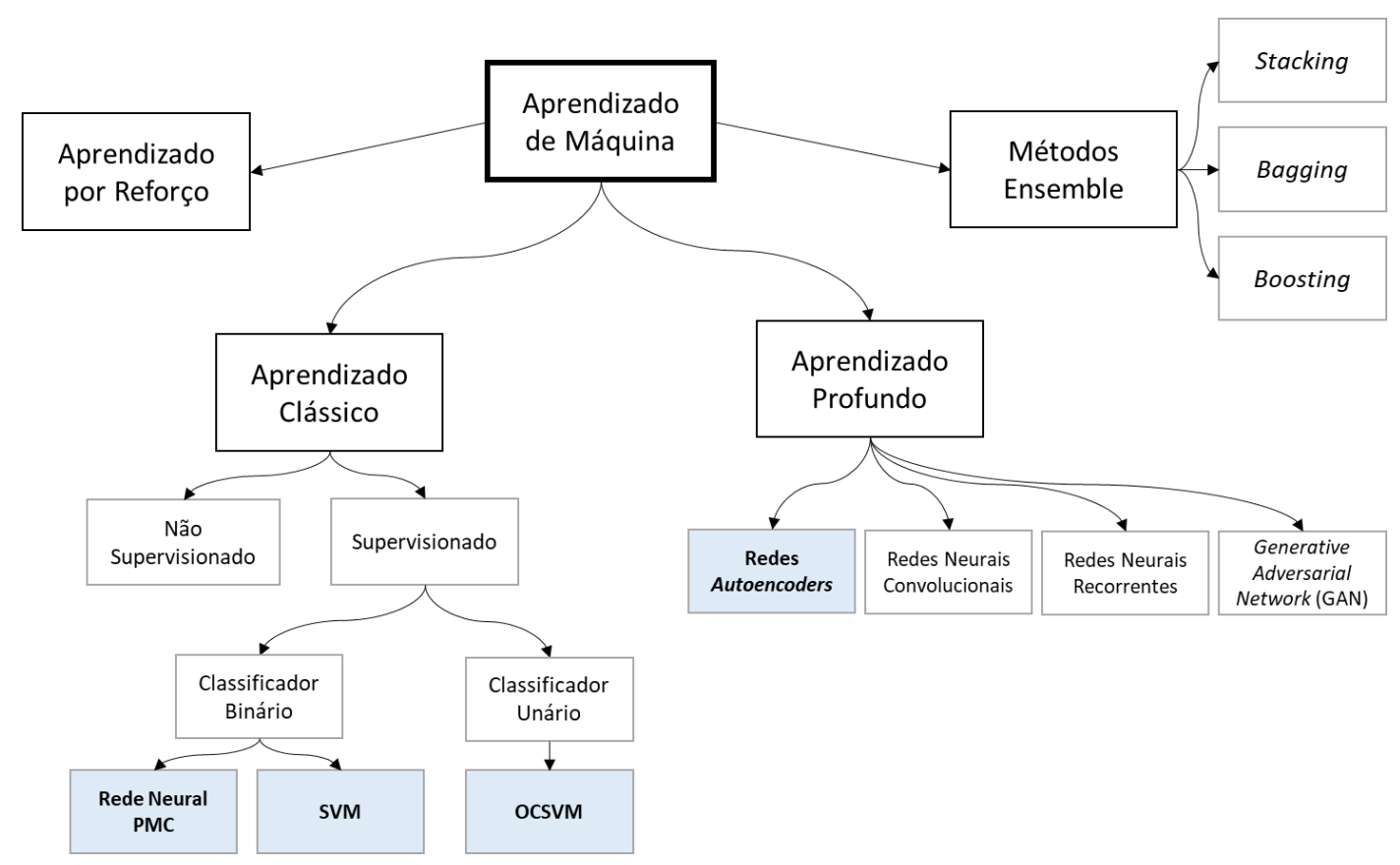

Figura 29: Principais áreas do Aprendizado de Máquina FONTE: Própria

A próxima seção apresenta informações importantes a respeito de outra importante etapa do Aprendizado de Máquina que é a Extração e Seleção de Atributos já apresentado na Figura 25.

\subsection{Extração e Seleção de Atributos}

A mineração de dados caracteriza-se pelo processo de busca de informações relevantes a partir de uma massa de dados muito grande utilizando-se ferramentas matemáticas, de maneira automatizada ou semi-automatizada (WITTEN; FRANK, 2005). Na maioria dos problemas que envolvem a mineração de dados, como dados do genoma humano, categorização de textos, recuperação de imagens e recuperação de informações, tem-se grandes quantidades de dados multivariados em termos de quantidade de amostras/instâncias e atributos. Esse grande volume de dados supera em muito a capacidade do ser humano de entender e lidar com isso. A tarefa de mineração de dados desempenha um papel importante para descobrir padrões em um volume tão grande de dados. É um desafio para o aprendizado de máquina encontrar dados relevantes e não redundantes nos dados, que contêm centenas de milhares de atributos (CHORMUNGE; JENA, 2017). 
A extração de atributos de um sinal visa obter, para cada amostra coletada, um vetor de características que a descrevem, ou seja, se extraem valores matemáticos que possuem informações relevantes do sinal, isto é, da aplicação, que pode ser analisado, por exemplo com ferramentas de mineração de dados e aprendizagem de máquinas (MAITA, 2016).

Em problemas que visam a classificação de padrões, a redução da dimensionalidade dos dados é extremamente importante. Essa redução deve ser feita de maneira a eliminar as características redundantes do conjunto original. Desta forma, o processo que transforma os dados de entrada em um novo padrão adequado para posterior classificação é chamado de extração de atributos (KHALID; KHALIL; NASREEN, 2014; SALEM; MOHAMED; SAMAD, 2010).

\subsubsection{Extração de Atributos}

A quantidade de atributos pode ser muito elevada, impedindo a utilização de ferramentas de aprendizagem de máquinas diretamente, devido a necessidade de recursos computacionais proibitivos. A extração de atributos, também conhecida como extração de características, é, portanto, um dos pontos chaves para o reconhecimento de padrões, de modo que o melhor classificador apresentará baixa taxa de acertos se os atributos não forem bem escolhidos. Assim, a etapa de extração de atributos deve reduzir o vetor original para uma menor dimensão, preservando todas as informações úteis a partir do vetor original (UYAR; YILDIRIM; GENCOGLU, 2009).

Neste trabalho, uma técnica de extração de atributos específica, baseada em janela deslizante é utilizada para a extração dos dados reais capturados de uma rede de comunicação industrial criada em laboratório. Os vetores de características extraídos por essa técnica representam com precisão a natureza e as tendências de comportamento (em séries temporais) do fluxo de pacotes de dados da rede (LINDA; VOLLMER; MANIC, 2009).

\subsubsection{Algoritmo da Janela Deslizante}

$\mathrm{O}$ algoritmo da janela deslizante é baseado em uma janela de comprimento $\beta$ (que neste trabalho representa uma quantidade de pacotes) que é deslocada em ordem temporal de um passo $\lambda$ sobre os demais pacotes de dados do fluxo capturado da rede, permitindo 
que seja possível representar diversas características instantâneas do tráfego em um único vetor de valores (TURCATO, 2015).

O processo de extração dos atributos por meio da Janela Deslizante é ilustrado nas Figura 30 e Figura 31.

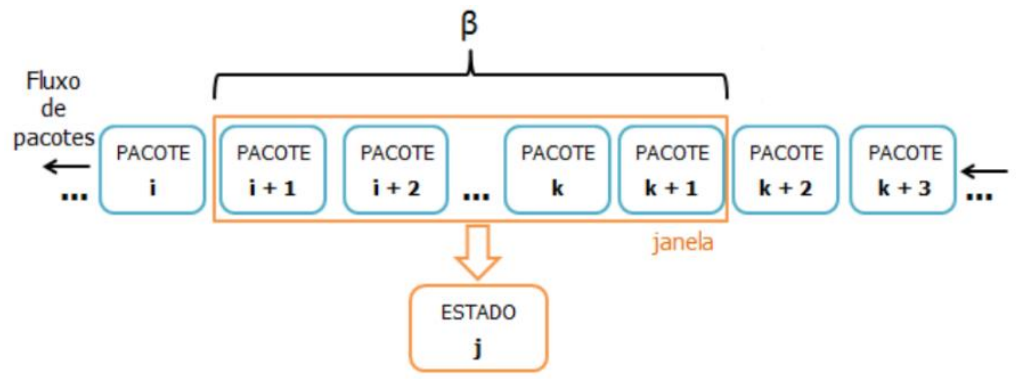

Figura 30: Processo de extração de atributos por meio da Janela Deslizante (estado j) FONTE: (TURCATO, 2015)

A janela é deslocada de um em um pacote $(\lambda=1)$ até percorrer todo o fluxo capturado. Desta forma, para cada posição da janela, são extraídas informações estatísticas a respeito dos pacotes contidos nela. Informações estas que servem de base para o cálculo dos atributos, que por sua vez, representam o estado momentâneo do tráfego.

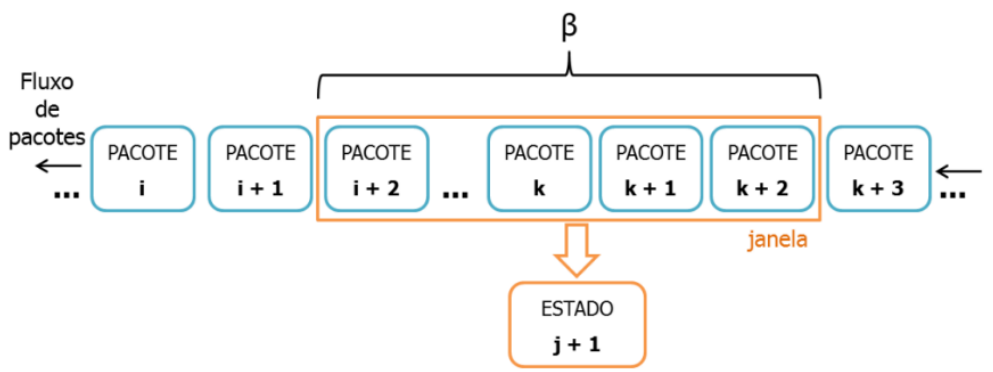

Figura 31: Processo de extração de atributos por meio da Janela Deslizante (estado j+1) FONTE: (TURCATO, 2015)

A Figura 32 ilustra um caso aonde um fluxo com 15 pacotes foi capturado e as amostras foram extraídas utilizando-se janela com comprimento $\beta$ igual a 9 e passo $\lambda$ igual a 1, ao final, 7 amostras são obtidas. 


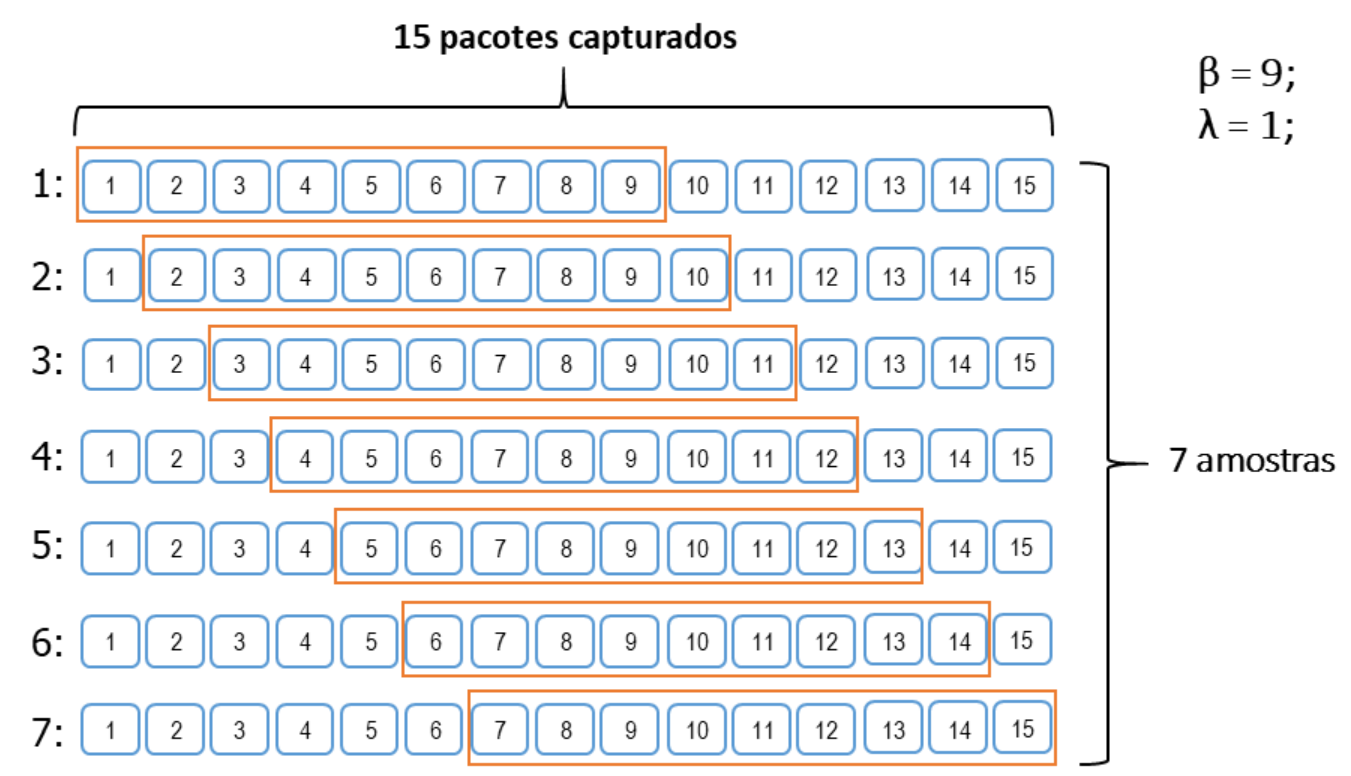

Figura 32: Exemplo de processo de extração de atributos por meio da Janela Deslizante FONTE: Própria

O número de amostras (NA) obtidas de acordo com o número de pacotes (NP), o tamanho da janela $(\beta)$ e o passo $(\lambda)$ é dado pela Eq. 4.1 :

$$
N A=1+\frac{N P-\beta}{\lambda} \quad(N P \geq \beta ; \lambda \geq 1)
$$

O parâmetro $\beta$ deve ser calculado levando-se em conta o compromisso de se obter um valor suficiente grande para o cálculo preciso de informações estatísticas sobre o fluxo de pacotes e um valor suficientemente pequeno para não mascarar os ataques de curta duração (LINDA; VOLLMER; MANIC, 2009).

No trabalho de (SHENG; XU; LIU, 2001) que utiliza esse mesmo algoritmo para a extração dos atributos de imagens de texturas, os autores afirmam que o valor do parâmetro $\beta$ é muito importante para a extração de características capazes de diferencias as diversas texturas utilizadas. Constataram que se o tamanho escolhido for grande, a velocidade de processamento cai e, se o tamanho for pequeno, diminui drasticamente a precisão do algoritmo de classificação. Assim, na maioria das vezes, é necessário prédefinir, de forma subjetiva, o valor do comprimento da janela de acordo com a textura (classe) para se obter um compromisso entre velocidade de processamento e precisão.

No trabalho de (LINDA; VOLLMER; MANIC, 2009) e (TURCATO, 2015), os autores desenvolveram um IDS, utilizando a mesma técnica para a extração de atributos e calcularam o tamanho da janela, baseando-se nas abordagens empíricas realizadas em conjunto com uma sistemática que utiliza o cálculo da correlação dos atributos gerados 
com a classe desejada. Já os autores em (WANG; CHEN; TIAN, 2016), utilizaram um método baseados na Teoria do Caos para obterem o tamanho ideal da janela de maneira sistemática.

No trabalho (SESTITO, 2018), o autor utilizou um método de otimização conhecido como Pattern Search para a busca de valores ótimos do tamanho da janela e do passo, tendo a função objetivo do algoritmo de otimização baseada na correlação dos atributos com a classe desejada. Valores de acurácia do classificador obtidos por esse método são muito bons, em contrapartida, o método exige alto poder de processamento e demasiado tempo de execução (na ordem de horas).

\subsubsection{Seleção/Redução de Atributos}

A seleção de atributos é uma técnica essencial para reduzir o problema de dimensionalidade na tarefa de mineração de dados. Os algoritmos tradicionais de seleção de recursos não foram projetados para trabalharem em espaços de muitas dimensões. Atributos irrelevantes não alteram a forma de como o algoritmo de aprendizagem trabalha e os atributos redundantes não incluem nada de novo no modelo (JOHN; KOHAVI; PFLEGER, 1994). Contudo, esses atributos irrelevantes e redundantes aumentam significativamente o custo computacional de um processo de aprendizagem. Quando a dimensionalidade dos dados é muito alta, é computacionalmente caro ou praticamente impossível o aprendizado da máquina. Além disso, a existência de atributos ruidosos degrada o desempenho dos algoritmos de aprendizado, diminuindo sua precisão (CHORMUNGE; JENA, 2017; KANG; KIM, 2016).

Frente a um profundo entendimento dos dados e do problema de classificação a ser resolvido, a seleção de atributos pode ser realizada de forma manual, porém, o nível de dificuldade para realizar tal tarefa aumenta à medida que cresce o número de atributos. $\mathrm{Na}$ literatura correlata são encontrados diversos algoritmos para a seleção de atributos automática como em: (BIESIADA; DUCH, 2007; CHANDRASHEKAR; SAHIN, 2014; CHORMUNGE; JENA, 2017; JEON; PARK; ROSEN, 2013; NAPOLEON; PAVALAKODI, 2011; SILVA et al., 2015; THANTHRIGE; SAMARABANDU; WANG, 2016; XU; WANG; LAI, 2016). 
A maioria dos algoritmos de seleção de atributos usa medidas estatística como: informação mútua, correlação e ganho de informação. Baseado em tais medidas, existem basicamente três abordagens possíveis para seleção de atributos que são (GUYON, 2003):

- Filters: possuem menor complexidade computacional em comparação com outras abordagens, mas a precisão dos algoritmos de aprendizagem não é garantida. Este método é independente de algoritmos de aprendizagem com boa generalidade, o que é uma boa decisão quando os dados têm grande quantidade de atributos.

- Wrappers: proporcionam boa precisão, pois seleciona as melhores características para cada algoritmo de aprendizagem. No entanto, a complexidade computacional é grande.

- Embedded: é mais eficiente que outras abordagens porque incorpora a seleção de atributos como parte do processo de treinamento e é geralmente específico para os próprios algoritmos de aprendizagem. Algoritmos tradicionais de aprendizado de máquina, como árvores de decisão ou redes neurais artificiais redes neurais são exemplos de abordagens incorporadas. Esse método é uma combinação do filtro e do wrapper que busca melhorar o desempenho dos algoritmos de aprendizagem (DAS, 2001; XING; JORDAN; KARP, 2001).

O aumento da dimensionalidade dos dados representa um sério desafio para muitos métodos existentes de seleção de atributos (CHORMUNGE; JENA, 2017).

Nos próximos parágrafos é dada ênfase ao algoritmo recursivo de seleção de atributos baseado em correlação, o $C F S$.

\subsubsection{1 $\underline{\mathrm{CFS}}$}

O algoritmo de seleção de atributos baseado em correlação para aprendizado de máquina, Correlation Feature Selection (CFS), avalia a relevância de subconjuntos de atributos para o problema de classificação, levando em conta a correlação entre esse conjunto e as classes existentes. Assim, o algoritmo seleciona recursivamente os atributos fortemente correlacionados com a classe e com baixa correlação com os demais atributos do subconjunto a qual ele pertence. Desta forma, atributos irrelevantes e/ou redundantes são eliminados (HALL; SMITH, 1999). 
Desta forma, atributos irrelevantes e/ou redundantes são eliminados. Esse método de seleção de atributos é classificado como do tipo Filter (CHANDRASHEKAR; SAHIN, 2014).

Os métodos de filtro usam técnicas de classificação de variáveis como critério principal para a seleção de variáveis por pedido. Eles são usados devido à sua simplicidade e o bom sucesso é relatado em muitas aplicações práticas. Um critério de classificação adequado é usado para pontuar as variáveis e um limite é usado para remover variáveis abaixo desse limite (CHANDRASHEKAR; SAHIN, 2014).

São chamados de filtro pois são aplicados antes da classificação para filtrar as variáveis menos relevantes. Uma propriedade básica de um atributo exclusivo é conter informações úteis sobre as diferentes classes nos dados. Assim, a questão da relevância de um atributo deve ser levantada, ou seja, adotar uma forma de medir a relevância de um atributo com a classe.

Uma definição importante a ser considerada é que "um atributo pode ser considerado irrelevante se for condicionalmente independente dos rótulos da classe" (LAW; FIGUEIREDO; JAIN, 2004). Dessa forma, a correlação entre atributos desempenha um papel importante na determinação dos atributos exclusivos.

O melhor subconjunto de atributos pode ser encontrado quando todas as possibilidades forem analisadas, no entanto, dependendo do tamanho do conjunto, essa tarefa torna-se computacionalmente proibitiva (LIBONI, 2017).

Em aplicações práticas, o melhor conjunto é considerado aquele que implica maior acurácia do classificador. Devido a isso, um subconjunto ideal de atributos pode não ser exclusivo, pois pode ser possível obter a mesma acurácia do classificador usando diferentes conjuntos de atributos (CHANDRASHEKAR; SAHIN, 2014).

Uma métrica bastante utilizada é conhecida como Mérito do subconjunto de atributos, dado pela equação abaixo:

$$
M_{S}=\frac{k \cdot \overline{r_{c f}}}{\sqrt{k+k \cdot(k-1) \cdot \overline{r_{f f}}}}
$$

Sendo:

- $M_{s}$ : valor do Mérito do subconjunto escolhido com $k$ atributos selecionados 
- $\overline{r_{c f}}$ : representa o valor médio da correlação entre o atributo e a classe desejada

- $\overline{r_{f f}}$ : representa o valor médio da correlação mútua entre os atributos

As correlações podem ser obtidas de diferentes maneiras (Pearson, Kendall, Spearman etc.). Quando todos os atributos do conjunto de dados são numéricos, a correlação linear de Pearson pode ser empregada (HALL; SMITH, 1999).

A correlação de Pearson é definida como:

$$
R(i)=\frac{\operatorname{cov}\left(x_{i}, Y\right)}{\sqrt{\operatorname{var}\left(x_{i}\right) * \operatorname{var}(Y)}}
$$

Onde $\mathrm{x}_{\mathrm{i}}$ é o $i$-ésimo atributo, $\mathrm{Y}$ é a saída (valores da classe), $\operatorname{cov}($ ) é a covariância e var() é a variância. O ranking da correlação pode somente detectar dependências entre os atributos e a classe.

O algoritmo CFS é uma técnica capaz de gerar um ranking com todos os subconjuntos de atributos possíveis ordenados pelos seus respectivos valores de mérito (DIAS, 2019). A Figura 33 ilustra as etapas envolvidas no cálculo do mérito.

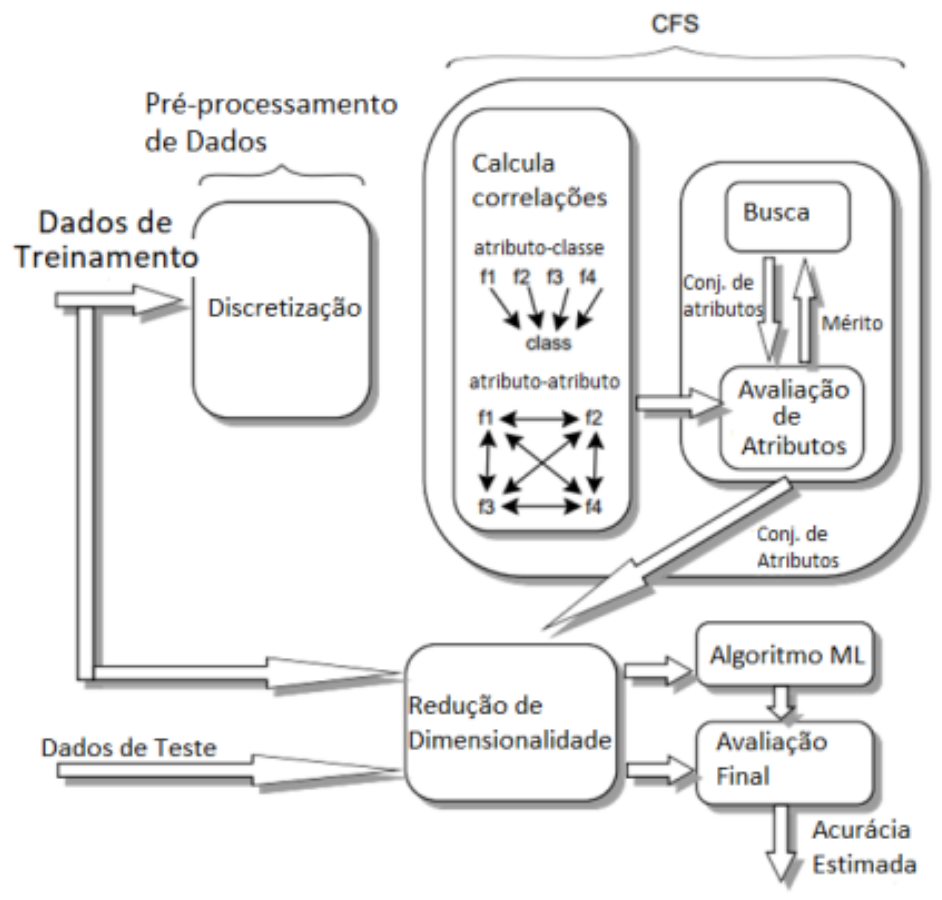

Figura 33: Fluxograma do algoritmo CFS com cálculo do mérito FONTE: (DIAS, 2019)

O software WEKA possui a técnica CFS utilizando algumas estratégias de busca do melhor subconjunto, uma vez que a verificação de todas as combinações de 
subconjuntos possíveis pode ser computacionalmente proibitiva. Alguns exemplos são: hill climbing, best first, gridystepwise (RICH; KNIGHT, 1991).

Neste trabalho, o método de busca utilizado é o gridystepwise que realizada uma busca de atributos dentro de uma grade de combinações.

A busca heurística varre então a grade e apenas para quando a adição ou deleção de qualquer outro atributo decresce a métrica M. Um ranking de atributos também pode ser gerado mediante o registro da sequência a qual os atributos são escolhidos (LIBONI, 2017).

\subsubsection{2 $\underline{\text { SVM RFE }}$}

Nesta seção será dada ênfase às Máquinas de Vetores Suporte (SVM), mais especificamente a uma aplicação específica dessa técnica, que é um algoritmo recursivo para a seleção automática de atributos conhecido como RFE (Recursive Feature Elimination).

Esse método de seleção de atributos é classificado como do tipo Embedded (CHANDRASHEKAR; SAHIN, 2014).

As SVMs são baseadas em algoritmos utilizados em classificação de padrões, regressão e detecção de novidades. As SVMs podem ser consideradas como algoritmos de aprendizado com uma camada escondida, treinamento supervisionado e baseado no princípio de minimização do risco estrutural, advindo das teorias de aprendizado estatístico (ALMEIDA, 2002).

Em problemas de classificação de padrões, o algoritmo maximiza a margem de separação entre os vetores de treinamento e um hiperplano de separação entre os padrões. Os vetores mais importantes, que definem o posicionamento do hiperplano, são chamados de vetores suporte.

No trabalho de (GUYON et al., 2002), demonstrou-se que as SVMs são eficientes para a descoberta de atributos relevantes em grandes bancos de dados e podem auxiliar de forma promissora a tarefa dos classificadores padrões.

Um conjunto de dados é composto por inúmeras entradas denominadas instâncias, que possuem n componentes denominados atributos ou características. Assim, o espaço de entrada é n-dimensional. Conforme já descrito no início da Seção 4.2.2, a redução da 
dimensionalidade do espaço de entradas é benéfica para a resolução de problemas de classificação. O erro de generalização é elevado quando o número de instâncias é pequeno e o número de atributos é grande, comprometendo o desempenho do classificador (GUYON et al., 2002).

Várias técnicas de redução do espaço de atributos já foram desenvolvidas, como é o caso da PCA (Principal Component Analysis). Nessa técnica, uma quantidade menor de novos atributos é gerada como uma combinação linear dos atributos originais. No entanto, uma desvantagem dessa técnica é que nenhum atributo original pode ser descartado além de não haver uma relação direta com os atributos relevantes do espaço original. A técnica $R F E$ funciona de maneira distinta. Ela utiliza a eliminação recursiva e ranqueamento de atributos de maneira a obter os atributos mais relevantes do conjunto original, resultando em uma verificação facilitada dos atributos e real possibilidade de descarte.

$\mathrm{O}$ ranqueamento de atributos permite classificar as características que mais influenciam um determinado problema, assim, permite formar um conjunto pequeno para um classificador. Pode-se, por exemplo, escolher um número fixo de melhores atributos ou alternativamente estipular um limiar, no qual apenas aqueles atributos com classificação superior serão levados em conta. Existem inúmeros algoritmos de ranqueamento, como aqueles que utilizam coeficiente de correlação, selecionando individualmente os melhores atributos (FUREY et al., 2000; GOLUB et al., 1999).

Para a utilização das técnicas de ranqueamento, é importante salientar a necessidade de, previamente, normalizar os dados, para que assim, os atributos possam ter escalas adequadamente comparáveis. As SVMs são bastante sensíveis à outliers e assim, um tratamento especial deve ser feito nos dados. Os autores (GUYON et al., 2002) sugerem que para cada atributo, deve-se subtrair a média do determinado atributo e dividir o resultado pelo desvio padrão da variável.

Fica claro no trabalho de (GUYON et al., 2002) que a seleção de atributos é mais importante que o próprio classificador utilizado no problema. Testes realizados com SVMs e outros classificadores como Redes Neurais Artificias e Árvores de Decisão, após uma mesma seleção de atributos, não monstraram diferenças significativas de desempenho. Contudo, nesses mesmos testes, alterações no ranqueamento dos atributos fazem com que o classificador modifique sensivelmente a sua precisão. 


\subsubsection{Redes Autoencoder}

Um autoencoder (AE), que é um tipo de RNA, é um algoritmo de aprendizado não-supervisionado usado para codificar eficientemente o conjunto de amostras para fins de redução de dimensionalidade (BENGIO, 2009; HINTON; SALAKHUTDINOV, 2006; SCHMIDHUBER, 2015).

Durante as últimas décadas, os AE estiveram na vanguarda entre as pesquisas sobre a RNA. Em 1988, (BOURLARD; KAMP, 1988) descobriram que um Perceptron Multicamadas (MLP) no modo de auto associação poderia alcançar compressão de dados e redução de dimensionalidade em áreas como processamento de informação (LIU et al., 2017).

O objetivo do AE é produzir um vetor de saída que seja tão similar ao vetor de entrada, assim o AE é construído para reconstruir o vetor de entrada original (MENG et al., 2017).

Arquitetonicamente, o AE é muito semelhante ao PMC que contém uma camada de entrada, uma ou mais camadas ocultas e uma camada de saída, como mostrado na Figura 34. A diferença entre um PMC e um AE é que o objetivo do AE é reconstruir a entrada, enquanto o propósito do PMC é predizer as classes a partir de certas amostras de entrada (BENGIO, 2009).

O número de neurônios na camada oculta pode ser igual, menor ou maior do que o número de neurônios na camada de entrada. Se o número for menor que os nós de entrada, o AE funcionará como uma forma de comprimir os dados de entrada, enquanto que, se for maior, estará funcionando como uma forma de expandi-los (DWIPUTRANTO; SETIAWAN; AJI, 2017).

Essencialmente, o AE busca aproximar a função de identidade nesse processo. Uma das principais vantagens do AE é que esse modelo pode extrair características úteis e filtrar as informações inúteis. Além disso, como o vetor de entrada é transformado em uma representação com menor dimensão no processo de codificação, a eficiência do processo de aprendizagem pode ser aprimorada devido a redução da dimensionalidade do problema (LIU et al., 2017).

O número de nós na camada de entrada e na camada de saída são idênticos. No processo de codificação, o AE primeiro converte o vetor de entrada $x$ em uma representação oculta $h$ usando uma matriz de ponderação $w$; depois, no processo de 
decodificação, o AE mapeia $h$ de volta ao formato original para obter $\tilde{x}$ com outra matriz de ponderação $w^{\prime}$. Teoricamente, $w^{\prime}$ deve ser a transposição de $w$.

Uma otimização de parâmetros deve ser realizada para minimizar o erro médio de reconstrução entre $x$ e $\tilde{x}$. A métrica MSE - Mean Square Error é usada para medir a precisão da reconstrução de acordo com as características de entrada (LING et al., 2015). O diagrama do modelo é mostrado Figura 34.

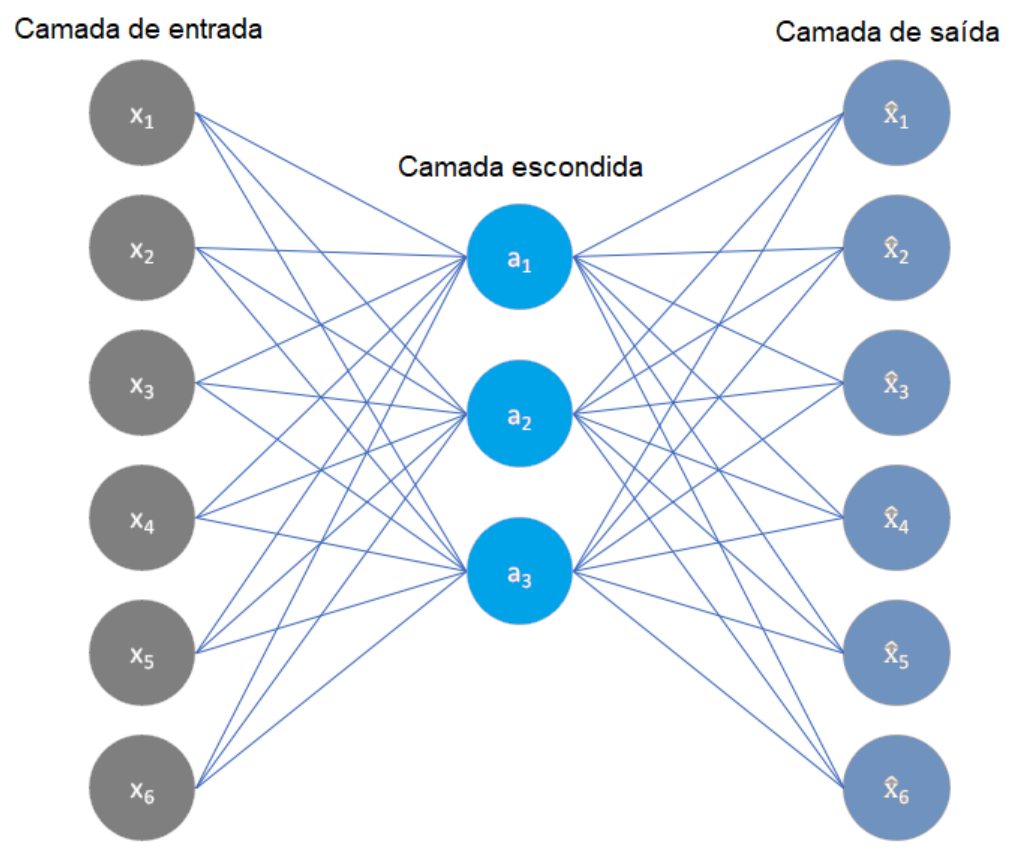

Figura 34: A estrutura de uma rede Autoencoder FONTE: Adaptado de (WANG; YAO; ZHAO, 2016)

$\mathrm{O}$ processo de treinamento para um $\mathrm{AE}$ pode ser dividido em dois estágios: o primeiro estágio é aprender as entradas usando aprendizado não supervisionado e o segundo é fazer o ajuste fino da rede usando o aprendizado supervisionado.

Para ser mais específico, no primeiro estágio, a propagação da rede feed-forward é executada primeiramente para cada entrada para obter o valor de saída $\tilde{x}$. Então, os erros quadrados são usados para medir o desvio de $\tilde{x}$ do valor de entrada $x$. Por fim, o erro é retro propagado pela rede para atualizar os pesos sinápticos. No estágio de ajuste fino, já com a rede com características adequadas em cada camada, adota-se o método padrão de aprendizado supervisionado e o algoritmo de gradiente descendente para ajustar os parâmetros em cada camada (LIU et al., 2017).

A Figura 35 ilustra os estágios Encoder e Decoder. 


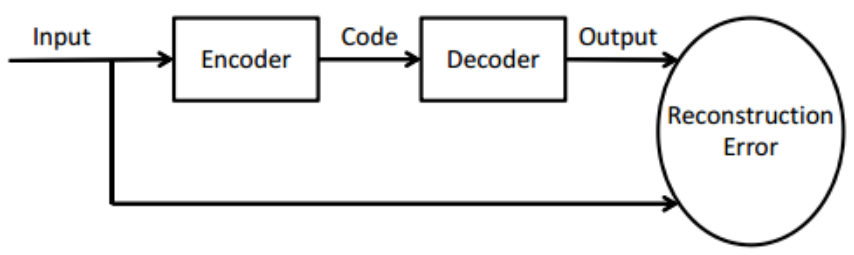

Figura 35: Estágios de um Autoencoder FONTE: Adaptado de (WANG; YAO; ZHAO, 2016)

A redução da dimensionalidade é um tema de pesquisa já antigo e dinâmico (BENGIO; COURVILLE; VINCENT, 2013). No trabalho de (WANG; YAO; ZHAO, 2016) são estudados métodos representativos de redução de dimensionalidade utilizandose os AE. Os autores investigaram a capacidade de redução de dimensionalidade do AE e, também, a influência que o número de nós da camada oculta tem no desempenho de reconstrução do AE.

A Figura 36 apresenta um exemplo de aplicação de AE com sinal de entrada e com o sinal reconstruído.

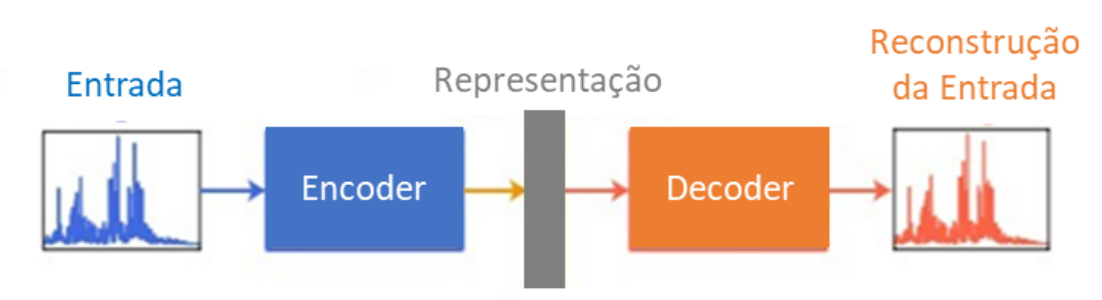

Figura 36: Exemplo de aplicação FONTE: Adaptado de (LI; LI; MA, 2020)

Geralmente, problemas com grande dimensionalidade superficialmente complexos podem ser descritos por uma pequena quantidade de variáveis na maioria das situações. Alguns autores classificam os métodos que utilizam AE como sendo Deep Learning (LI; LI; MA, 2020).

As figuras a seguir apresentam três exemplos de um conjunto de amostras originais (entrada do AE) representados pelos pontos azuis e sua aproximação (saída do AE) representados pelos círculos vermelhos.

A Figura 37 ilustra um caso em que o erro de aproximação médio (MSE) é de 0,3060 . 


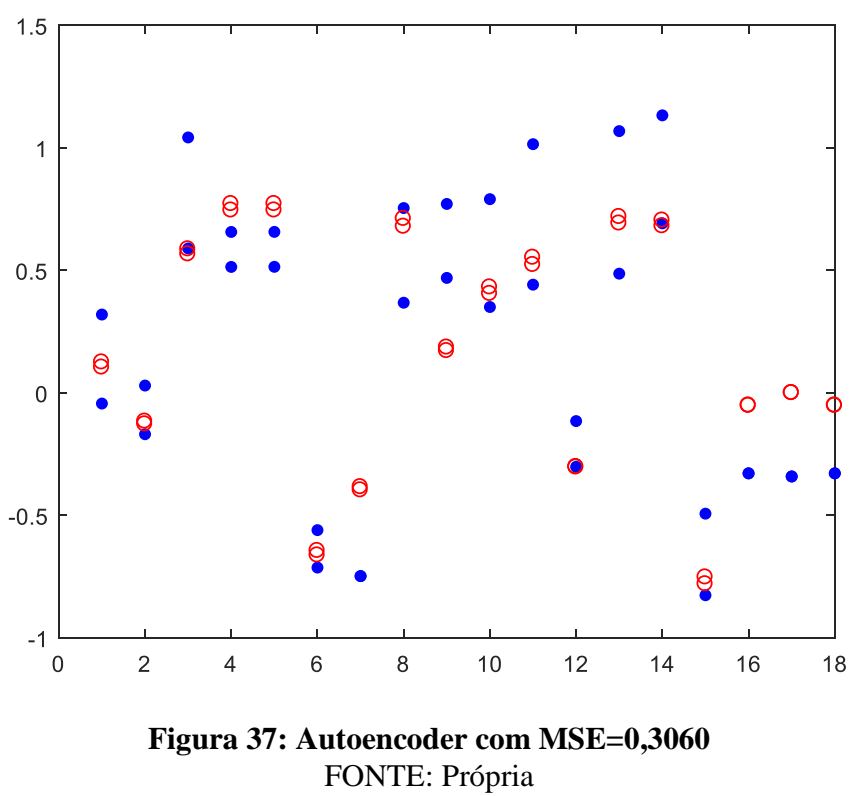

A Figura 38 apresenta um caso em que o erro de aproximação médio (MSE) é de 0,0252. É possível notar que os pontos estão mais próximos nesse caso.

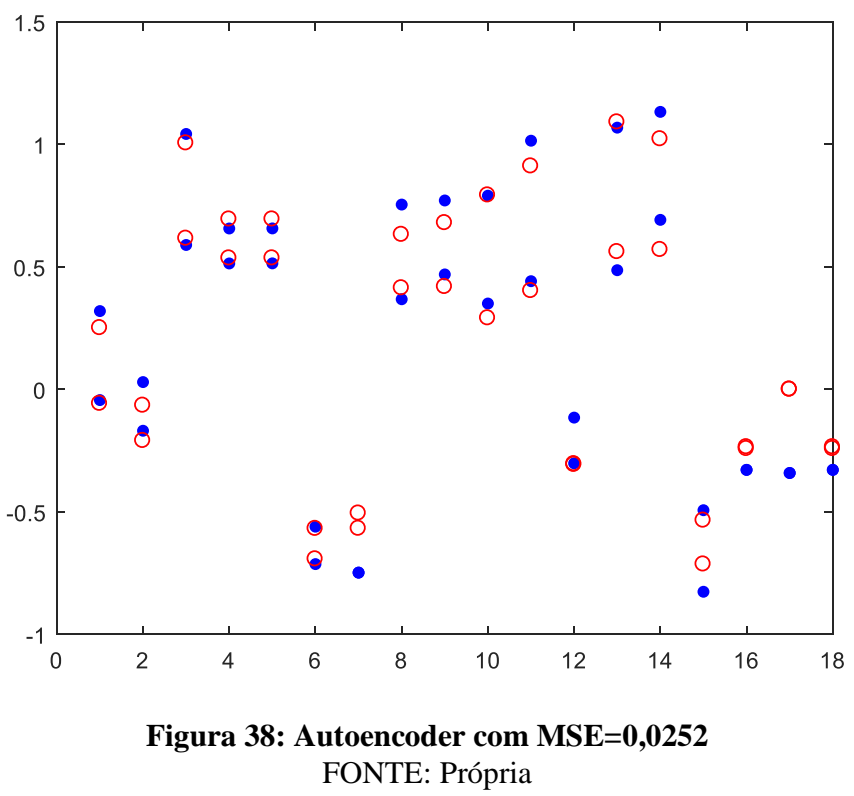

A Figura 39 ilustra um caso em que o erro (MSE) é de 0 (zero). Esse caso "hipotético" representa o caso em que o AE consegue reproduzir fielmente a entrada na saída. 


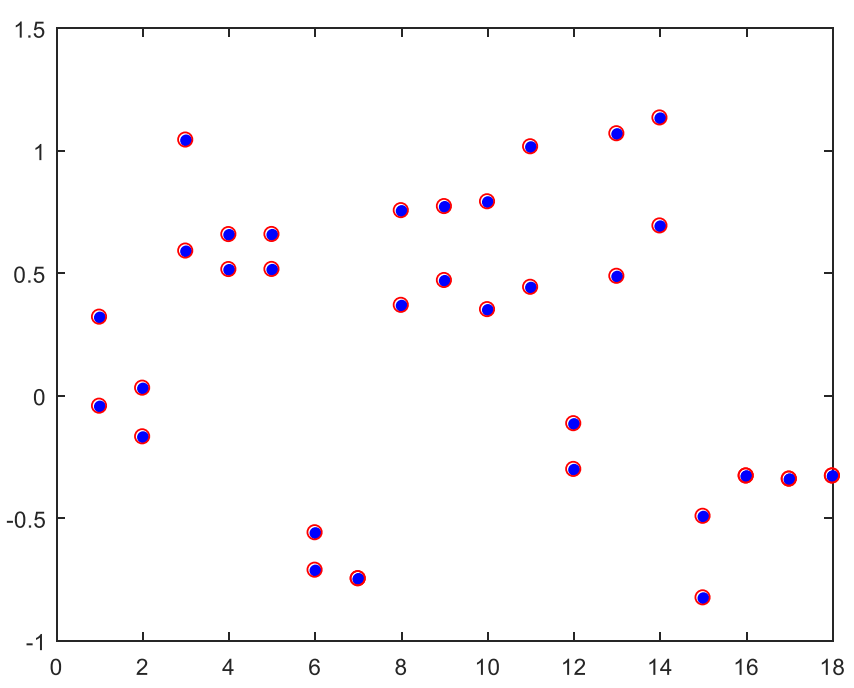

Figura 39: Autoencoder com MSE $=0$ FONTE: Própria

Em (WANG; YAO; ZHAO, 2016) os autores concluíram que os resultados obtidos com AE diferem de fato de outros métodos de redução de dimensionalidade. Em alguns casos, o AE não apenas reduz a dimensionalidade, mas também pode detectar estruturas redundantes nos dados. Afirmam que essa é uma boa propriedade que pode ser utilizada em diversas aplicações, inclusive afirmam que para os casos em que existem muitos dados repetitivos, o uso do AE para redução da dimensionalidade seja ainda mais adequado do que métodos mais tradicionais como PCA (Principal Component Analysis), LDA (Linear Discriminant Analysis), LLE (Locally Linear Embedding) e Isomap.

Em (ALDWEESH; DERHAB; EMAM, 2020) é apresentado um trabalho que utiliza o AE como uma técnica de redução de dimensionalidade. É proposta uma abordagem para reduzir a complexidade dos dados e o tempo gasto pelo sistema de detecção. Os resultados relatam um desempenho mais alto em comparação com as técnicas tradicionais de dimensionalidade linear, como PCA, LDA e KernalPCA não linear.

\subsection{Balanceamento do conjunto de dados}

Apesar de mais de duas décadas de desenvolvimento contínuo, o aprendizado com dados desequilibrados ainda é foco de intensa pesquisa. Com a expansão do aprendizado de máquina e da mineração de dados, combinada com a chegada da era da big data, 
obteve-se uma visão mais profunda da natureza do aprendizado desequilibrado e, ao mesmo tempo, o surgimento de novos desafios (KRAWCZYK, 2016).

O aprendizado de máquina tem sido uma ferramenta promissora no campo da detecção de anomalias, mas o problema de desequilíbrio dos dados é um desafio ao desenvolver o sistema e empregá-lo nas indústrias (LEE; JO; HWANG, 2017).

No campo do diagnóstico de falhas em fábricas inteligentes, é comum enfrentar o problema de dados fortemente desequilibrados/desbalanceados, pois o número de dados de falhas/anomalias, especialmente os dados de falhas catastróficas ou falhas mecânicas acidentais, é muito pequeno, enquanto o número de dados normais é muito grande (ZHOU et al., 2020).

Muitas aplicações de mineração de dados do mundo real envolvem o aprendizado de conjuntos de dados desbalanceados. Aprender a partir de conjuntos de dados que contêm pouquíssimos exemplos da classe minoritária (ou de interesse) geralmente produz classificadores tendenciosos que têm uma maior precisão preditiva sobre a(s) classe(s) maioritária, mas menor precisão preditiva sobre a classe minoritária. É importante também analisar os casos onde o custo de classificar erroneamente um exemplo anormal como um exemplo normal ser frequentemente muito maior do que o custo do erro inverso (BLAGUS; LUSA, 2013).

O problema do desbalanceamento de classe existe em muitas aplicações do mundo real à tempo, como telecomunicações (HILAS, 2009), detecção de resíduos de óleo em imagens de radar por satélite (KUBAT; HOLTE; MATWIN, 1998), classificação de texto (SEBASTIANI, 2002), diagnóstico médico (KONONENKO, 2001), detecção de intrusão (LEE; STOLFO, 2000) e detecção em fraude de cartão de crédito (SÁNCHEZ et al., 2009).

Os métodos para lidar com dados desbalanceados estão sendo constantemente aprimorados e as abordagens híbridas ganham popularidade crescente. As tendências recentes se concentram em analisar não apenas a desproporção entre classes, mas também outras dificuldades incorporadas na natureza dos dados. Novos problemas da vida real motivam os pesquisadores a se concentrarem em métodos computacionalmente eficientes, adaptáveis e em tempo real (KRAWCZYK, 2016).

Para balancear o conjunto de dados e assim, melhorar a acurácia do classificador, pode-se fazer basicamente três processos (HE; GARCIA, 2009): 
- Sobre-amostrar a classe minoritária: que consiste em duplicar as amostras da classe minoritária. No entanto, essa técnica pode fazer com que, com poucas amostras, o classificador sobre overfitting.

- Sub-amostrar da classe majoritária: que consiste em remover do conjunto de dados as amostras suplementares da classe majoritária. Contudo, essa técnica pode fazer com que a quantidade de amostras resultados no conjunto de dados resultante seja muito pequena para conseguir generalizar o aprendizado do classificador e/ou pode-se arriscar a remoção de algumas das instâncias da classe majoritária que são cruciais para a classificação.

- Sintetizar novas classes minoritárias: alguns algoritmos mais inteligentes estão disponíveis para fazer a sobre-amostragem dos dados com base nos valores dos vizinhos mais próximos, por exemplo, a técnica SMOTE. Para criar um ponto de dados sintético, o algoritmo cria um número aleatório para os atributos que se encontram entre o ponto atual e seus $\mathrm{K}$ vizinhos mais próximos. Detalhes acerca da técnica SMOTE são apresentados na seção seguinte.

Muitas pesquisas mostram que grande parte das técnicas de Aprendizado de Máquina resultam em baixo desempenho, especificamente ao lidar com conjuntos de dados desbalanceados de média e grande escala (CHAWLA, 2010; FARQUAD; BOSE, 2012; ZHOU et al., 2020).

A técnica SMOTE (Synthetic Minority Over-sampling TEchnique) é projetada especificamente para ser utilizada com algoritmos de aprendizado de máquina com conjuntos de dados desbalanceados (CHAWLA et al., 2003). As novas instâncias não são apenas cópias dos casos minoritários existentes; em vez disso, o algoritmo coleta amostras do espaço de características para cada classe de destino e seus vizinhos mais próximos e gera novos exemplos que combinam as características de destino com as características de seus vizinhos. Essa abordagem aumenta os atributos disponíveis para cada classe e torna as amostras mais gerais (BLAGUS; LUSA, 2013).

Essa é uma técnica estatística para aumentar o número de amostras no conjunto de dados de maneira equilibrada. O módulo funciona gerando novas instâncias a partir de 
casos minoritários existentes que são fornecidos como entrada. Esta implementação do SMOTE não altera o número de casos majoritários. O SMOTE toma todo o conjunto de dados como uma entrada, mas aumenta a porcentagem apenas dos casos minoritários.

A Figura 40 apresenta um exemplo de balanceamento de dados com SMOTE.

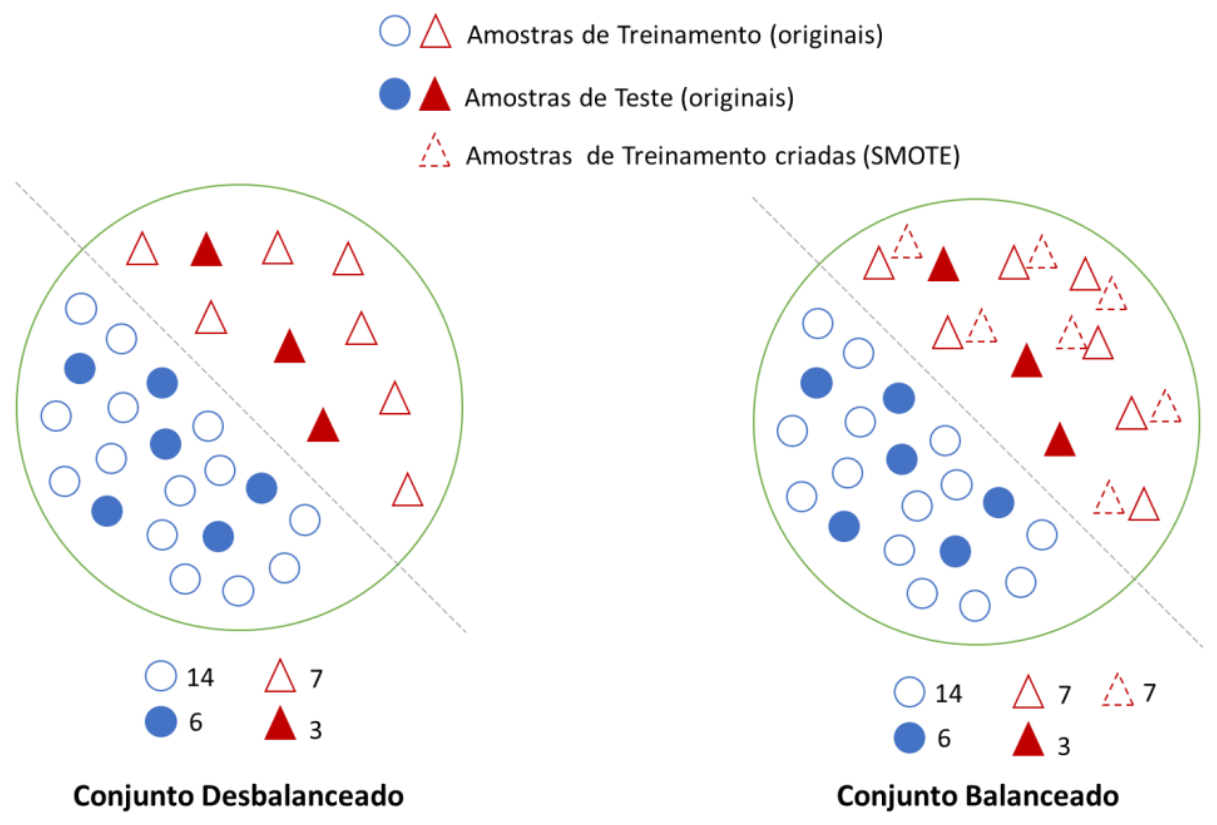

Figura 40: Exemplo de balanceamento do Conjunto de Treinamento com SMOTE FONTE: Baseado em (LI; LI; MA, 2020)

O desempenho dos algoritmos de aprendizado de máquina é normalmente avaliado usando apenas a Acurácia (mais detalhes na Seção 4.5). No entanto, isso não é apropriado quando as amostras estão desbalanceadas e/ou os custos de classificação incorreta variam consideravelmente. Por exemplo, um conjunto de dados de mamografia típico pode conter $98 \%$ de pixels normais e $2 \%$ de pixels anormais. Qualquer simples estratégia padrão de adivinhação da classe majoritária daria uma acurácia de classificação de $98 \%$. No entanto, a natureza da aplicação requer uma taxa razoavelmente alta de detecção correta na classe minoritária e permite uma pequena taxa de erro na classe majoritária para alcançar isso. O simples cálculo da acurácia não é claramente apropriado em tais situações (CHAWLA et al., 2002). Na Seção 4.5 algumas das métricas mais utilizadas para a avaliação e comparação de desempenho dos classificadores são apresentadas.

A técnica SMOTE pode ser problemática para os classificadores que assumem independência entre as amostras, como por exemplo, a regressão logística penalizada ou os métodos de análise discriminante. Além disso, executar a seleção de variáveis após o 
uso de SMOTE deve ser feito com algum cuidado, pois a maioria dos métodos de seleção de variáveis pressupõe que as amostras sejam independentes (BLAGUS; LUSA, 2013).

Em (FARQUAD; BOSE, 2012) é investigado a aplicação de várias técnicas de balanceamento de classes. Os resultados monstram que a sensibilidade dos classificadores aumenta quando é utilizada a técnica SMOTE.

Em (DONG; WANG, 2016) são discutidos diferentes métodos que são usados para classificar o tráfego de rede de computadores. Nesse trabalho é demonstrado que a precisão dos classificadores foi incrementada quando se utilizou a técnica SMOTE para o balanceamento das amostras do Conjunto de Treinamento.

Informações adicionais, detalhes acerca do algoritmo e índices de aumento de desempenho da técnica SMOTE podem ser obtidos em (BLAGUS; LUSA, 2013; CHAWLA et al., 2002; FARQUAD; BOSE, 2012; HE; GARCIA, 2009).

\subsection{Classificadores Inteligentes}

Sistemas de inferência foram empregados na metodologia desenvolvida com objetivo de classificar padrões encontrados no tráfego capturado. Essas ferramentas são baseadas em metodologias de aprendizagem de máquinas e inteligência artificial.

\subsubsection{Redes Neurais Artificiais}

As redes neurais artificiais (RNA) são modelos computacionais inspirados no sistema nervoso de seres vivos, que possuem capacidade de aquisição de conhecimento (baseado em informações), são compostas por um conjunto de unidades de processamento ou neurônios artificiais interligados por um grande número de conexões, que fazem a função comparáveis as conexões sinápticas. Estes sistemas são comumente utilizados para tarefas na área de engenharia, como classificação de padrões, aproximador universal de função, agrupamento de dados ou 'clusterização', previsões e mesmo para operações de controle de processos, normalmente com aspectos não-lineares, entre outras tarefas (SILVA; SPATTI; FLAUZINO, 2010).

As arquiteturas das RNA definem a forma como os seus diversos neurônios artificiais estão interligados e no direcionamento das informações entre eles. 
Adicionalmente existem diversas topologias que podem ser definidas como as diferentes formas de composições estruturais que a RNA pode assumir (SILVA; SPATTI; FLAUZINO, 2010).

Uma RNA pode ser dividida em três partes:

- Camada de entrada: usadas para o recebimento das informações, ou seja, dos atributos normalizados e selecionados previamente. Trata-se onde os padrões são inicialmente apresentados a RNA;

- Camadas intermediárias ou ocultas: utilizadas para extrair características associadas ao processo ou sistema a ser inferido. Neste trabalho extrai as características dos padrões (atributos) a serem classificados;

- Camada de saída: apresentam os resultados finais da rede.

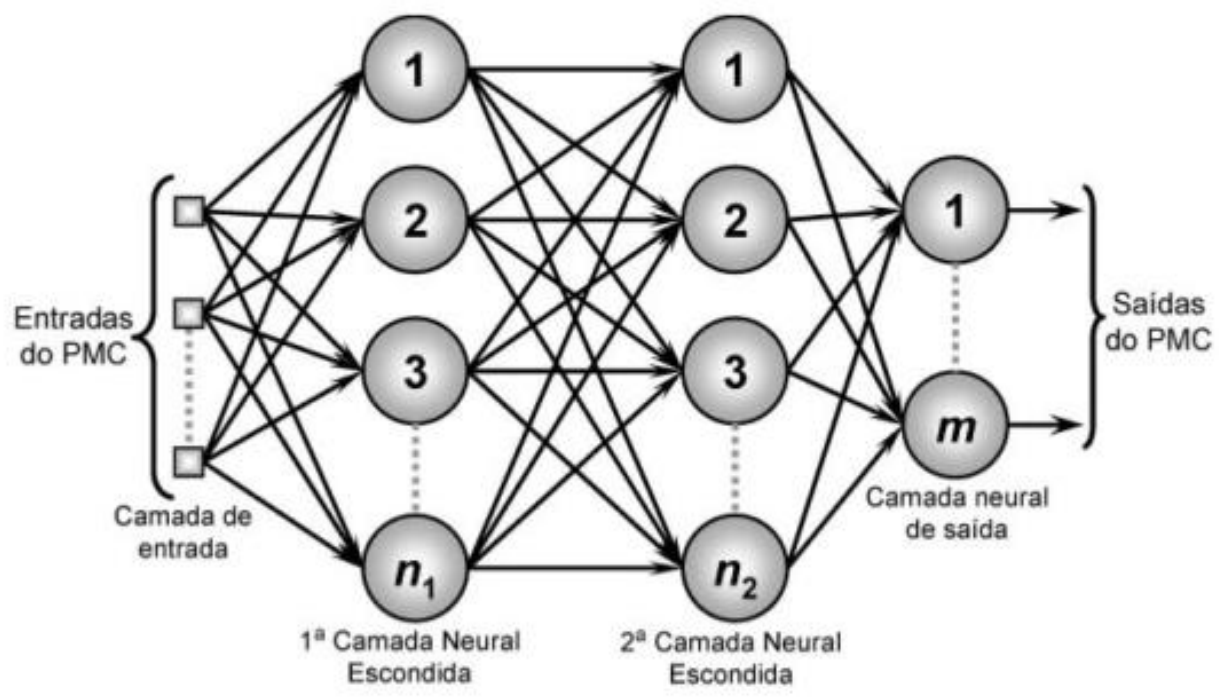

Figura 41: Rede Perceptron Multicamadas FONTE: (SILVA; SPATTI; FLAUZINO, 2010)

As arquiteturas de RNA consideram a disposição dos neurônios, formas de interligação e constituição de suas camadas. Podem ser divididas em:

- Redes Feedforward (camada única): caracteriza-se por ter uma única camada de neurônios de entrada e de saída. O fluxo de informação segue numa única direção, da camada de entrada para a camada de saída. Normalmente utilizadas em classificação de padrões e filtragem linear;

- Redes Feedforward (multicamadas): são constituídas pela presença de uma ou mais camadas escondidas de neurônios. Empregadas na solução de diversos tipos de problemas, como: aproximação de funções, 
classificação de padrões, identificação de sistemas, controle de processos etc. Os principais tipos são o Perceptron Multicamadas e a Função Base Radial;

- Redes recorrentes ou realimentada: são redes em que os sinais dos neurônios de saída são realimentados como sinais de entrada para outros neurônios. Assim, estas redes têm capacidade de utilizar seu comportamento com relação a padrões anteriormente apresentados, sendo utilizadas por exemplo na previsão de séries temporais, otimização e identificação de sistemas e controle de processo. Os principais tipos são Perceptron com realimentação e redes de Hopfield;

- Redes em estrutura reticulada: consiste na disposição espacial de seus neurônios visando propósito de extração de características. As aplicações são bem diversificadas, como clusterização, otimização de sistemas e grafos. A rede de Kohonen é a principal representante (SILVA; SPATTI; FLAUZINO, 2010).

As redes PMC podem ser consideradas as mais utilizadas na solução de problemas advindos de áreas relacionadas às ciências e às engenharias. Considerando-se o leque de aplicabilidade em que as redes PMC são passíveis de serem utilizadas, os problemas de classificação de padrões são destaque. Um problema de classificação de padrões consiste em associar um padrão de entrada (amostra) para uma daquelas classes que foram previamente definidas (SILVA; SPATTI; FLAUZINO, 2010).

Os trabalhos de (LINDA; VOLLMER; MANIC, 2009) e (TURCATO, 2015) monstraram que as redes PMC quando utilizadas para a detecção de anomalias no tráfego de redes industriais, apresentaram excelentes resultados com altas taxas de acurácia e baixo tempo de processamento.

\subsubsection{Máquinas de Vetores Suporte}

As Máquinas de Vetores de Suporte (SVM, do inglês Support Vector Machines) constituem uma técnica de aprendizado que vem recebendo crescente atenção da comunidade de Aprendizado de Máquina (AM) (MITCHELL, 1997). Os resultados da aplicação dessa técnica são comparáveis e muitas vezes superiores aos obtidos por outros algoritmos de aprendizado, como as Redes Neurais Artificiais (RNA) (HAYKIN, 1999). 
Exemplos de aplicações de sucesso podem ser encontrados em diversos áreas, como na categorização de textos (JOACHIMS, 2002), na análise de imagens (KIM et al., 2002; PONTIL; VERRI, 1998) e em Bioinformática (GUYON et al., 2002).

As SVM são baseadas na teoria de aprendizado estatístico, desenvolvida por Vapnik a partir de estudos iniciados em 1971 (VAPNIK; CHERVONENKIS, 1971). Essa teoria estabelece uma série de princípios que devem ser seguidos na obtenção de classificadores com boa generalização, definida como a sua capacidade de prever corretamente a classe de novos dados do mesmo domínio em que o aprendizado ocorreu.

O algoritmo tem como objetivo maximizar a margem entre duas classes de amostras, utilizando um hiperplano de separação, gerado a partir vetores de suporte, os quais seriam os mais importantes para o posicionamento deste hiperplano. A Figura 42 ilustra um exemplo de posicionamento do hiperplano em relação às amostras e a margem $\mathrm{T}$ a ser maximizada pelo algoritmo.

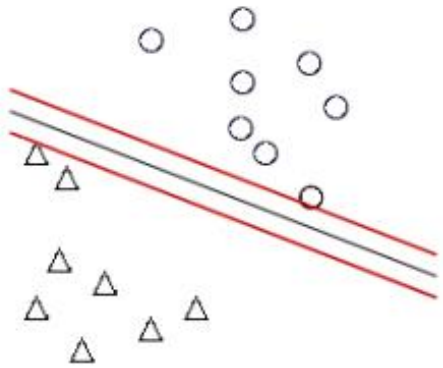

(a)

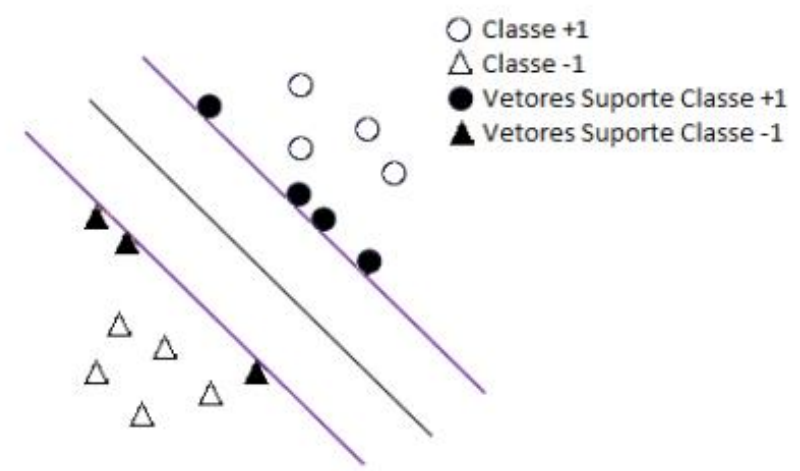

(b)

(a) Possivel hiperplano

(b) Hiperplano de separação com margem maximizada

Figura 42: Exemplo de hiperplano de separação de classes FONTE: Adaptado de (BENNETT; CAMPBELL, 2000)

Inicialmente, os algoritmos eram capazes de classificar duas classes com dados linearmente separáveis, chamados posteriormente de SVM com margem rígida (hard margins). Posteriormente o algoritmo foi senso aprimorado, e estratégias para classificação de dados não-linearmente separáveis passaram a ser implementadas, como a implementação de erros mínimos de classificação, chamado de SVM com margens flexíveis ou suaves (soft margins). Tempos depois, foi implementado a utilização do conceito de função kernel, para as aplicações em casos não lineares (LORENA; DE CARVALHO, 2007). As funções kernel criam outra dimensão para as amostras e existem 
inúmeras funções do tipo Polinomial, Gaussiana, Sigmoidal etc. A Tabela 12 apresenta mais detalhes dessas funções.

Tabela 12: Algumas funções kernel utilizadas pela SVM (DIAS, 2019)

\begin{tabular}{ccc} 
Kernel & Função & Parâmetros \\
\hline Polinomial & $\left(\delta\left(x_{i} * y_{j}\right)+k\right)^{k}$ & $\delta, \mathrm{k}, \mathrm{d}$ \\
\hline Sigmoidal & $\tanh \left(\delta *\left(x_{i} * y_{i}\right)+k\right)$ & $\delta, \mathrm{k}$ \\
\hline Gaussiano & $\exp \left(-\gamma *|| x_{i}-y_{i} \|^{2}\right)$ & $\gamma$ \\
\hline
\end{tabular}

O kernel gaussiano possui apenas um parâmetro de ajuste. Neste caso, quando $\gamma$ é elevado, a separação dos padrões fica similar a separação sem utilização da função kernel. Para valores pequenos de $\gamma$, o classificador é muito restrito, e não alcança generalização satisfatória (DIAS, 2019). A Figura 43 ilustra casos com diferentes valores para $\gamma$ do kernel gaussiano com o banco de dados IRIS disponível no Matlab.

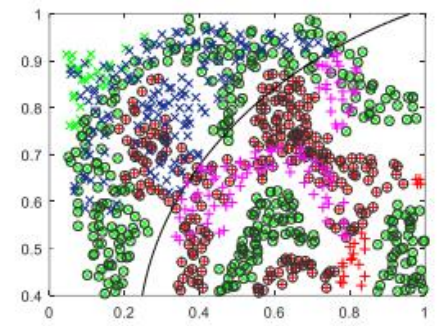

$\gamma=0.01$ Acurácia: $66.38 \%$

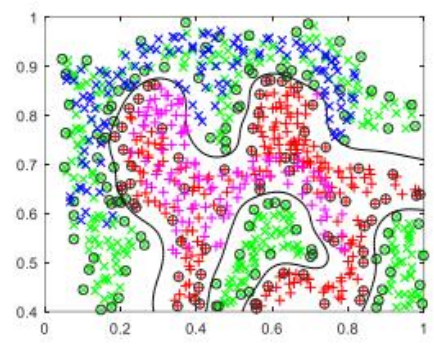

$\gamma=10$ Acurácia: $97.41 \%$

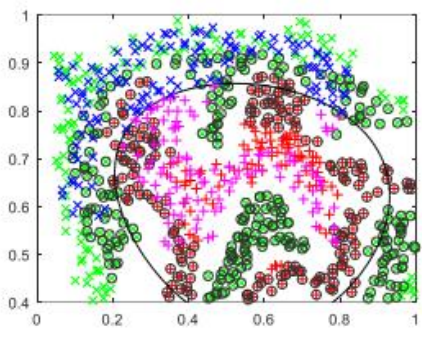

$\gamma=0.1$ Acurácia: $90.95 \%$

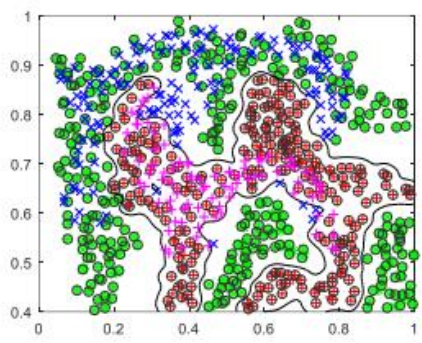

$\gamma=100$ Acurácia: $87.50 \%$

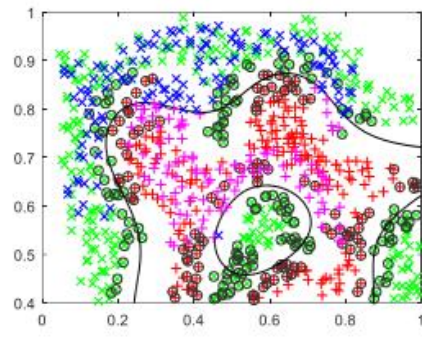

$\gamma=1$ Acurácia: $90.09 \%$

+ Conjunto de treinamento (negativo)

+ Conjunto de teste (negativo)

$\times$ Conjunto de treinamento (positivo)

$\times$ Conjunto de teste (positivo)

Vetores Suporte

Figura 43: Influência do parâmetro $\gamma$ no kernel gaussiano FONTE: (DIAS, 2019)

As SVM também são robustas diante de dados de grande dimensão, sobre os quais outras técnicas de aprendizado comumente obtêm classificadores super ou sub ajustados. Outra característica atrativa é a convexidade do problema de otimização formulado em seu treinamento, que implica a existência de um único mínimo global. Essa é uma vantagem das SVM sobre, por exemplo, as redes PMC (HAYKIN, 1999; SILVA; 
SPATTI; FLAUZINO, 2010), em que há mínimos locais na função objetivo minimizada. Além disso, o uso de funções kernel na não-linearização das SVM torna o algoritmo eficiente, pois permite a construção de simples hiperplanos em um espaço de alta dimensão de forma tratável do ponto de vista computacional (BURGES, 1998).

\subsubsection{Detecção de Novidades e Classificadores One-Class}

A detecção de novidade é a identificação de dados novos ou desconhecidos que um sistema de aprendizado de máquina não teve conhecimento durante a etapa de treinamento. A detecção de novidade é um dos requisitos fundamentais de um bom sistema de classificação ou identificação, pois às vezes os dados de teste contêm informações sobre objetos que não eram conhecidos no momento do treinamento do modelo (MARKOU; SINGH, 2003a, 2003b).

Os algoritmos de classificação de classe única (OCC - One-Class Classification) visam construir modelos de classificação quando a classe negativa está ausente, com pouca amostra ou não está bem definida. Essa situação única restringe o aprendizado de classificadores eficientes, definindo o limite da classe apenas com o conhecimento da classe positiva. O problema da OCC é aplicado em muitos temas de pesquisa, como detecção de outlier/novidades (KHAN; MADDEN, 2014).

O objetivo da classificação de padrões é distinguir os dados de teste dentre o número de classes, usando para isso, os dados de treinamento. No entanto, muitas vezes, tem-se apenas amostras pertencentes a uma só classe. Nesses casos, o objetivo se torna descobrir se as novas amostras são pertencentes a única classe das amostras do conjunto de treinamento. As SVM (Support Vector Machines) de uma só classe ganharam bastante popularidade nas últimas décadas para realizar tal tarefa (LIBONI, 2017).

Há uma infinidade de aplicações onde a detecção de novidades é extremamente importante, incluindo processamento de sinais, visão computacional, reconhecimento de padrões, mineração de dados e robótica (MARKOU; SINGH, 2003a, 2003b).

Em aprendizado de máquina, a classificação one-class, também conhecida como classificação unária, tenta identificar objetos de uma classe específica entre todos os objetos, aprendendo principalmente a partir de um conjunto de treinamento contendo apenas os objetos dessa classe (OLIVERI, 2017). Essa atividade é mais difícil do que o problema de classificação tradicional, que tenta distinguir entre duas ou mais classes com 
um conjunto de treinamento contendo objetos de todas as classes. Um exemplo clássico deste caso é a classificação do status operacional de uma usina nuclear como 'normal': nesse cenário, há poucos, se houver, amostras de situações catastróficas do sistema e somente as instâncias de operação normal são conhecidas e podem ser encontradas no conjunto de treinamento (TAX, 2001).

O termo classificação one-class foi criado por (MOYA; HUSH, 1996) e muitas aplicações podem ser encontradas na literatura científica, por exemplo, detecção de outliers, detecção de anomalias, detecção de novidades. A característica principal da classificação one-class é que ela usa apenas instâncias de amostra da classe designada, de modo que uma amostragem representativa não seja estritamente necessária para classes que não sejam o alvo (RODIONOVA; OLIVERI; POMERANTSEV, 2016).

Quando se utiliza classificadores unários (one-class), a literatura adota nomenclatura peculiar para os conjuntos de dados a serem utilizados. São elas:

○ Instâncias Targets: instâncias que pertencem a classe;

○ Instâncias Outliers: instâncias que NÃO pertencem a classe;

○ Conjunto de Treinamento: é "geralmente" composto por apenas instâncias pertencentes a classe (instâncias Targets). Alguns estudos demostram que, caso haja algumas instâncias Outliers disponíveis para serem utilizadas no Conjunto de Treinamento, a acurácia do classificador pode ser melhorada (MAGLARAS; JIANG, 2014).

○ Conjunto de Teste: é composto por instâncias pertencentes a classe (Target) e instâncias não pertencentes a classe (instâncias Outliers);

○ OutlierFraction: é a proporção da quantidade de instâncias Outliers contidas no Conjunto de Treinamento. Quando o Conjunto de Treinamento é composto exclusivamente por instâncias Targets, o valor da OutlierFraction é 0 (zero).

A Figura 44 ilustra um caso de amostras sendo classificadas com classificador binário ou classificador unário.

Para o treinamento do classificador unário, exemplificado na figura, todas as amostras (vermelhas e azuis) foram consideradas como pertencentes a mesma classe. 
Destaca-se que a amostra teste (ponto preto do gráfico) é classificada como pertencente a classe $\mathrm{C} 2$ se for utilizado o classificador binário ou como Outlier (não pertencente a classe) caso seja utilizado o classificador unário.

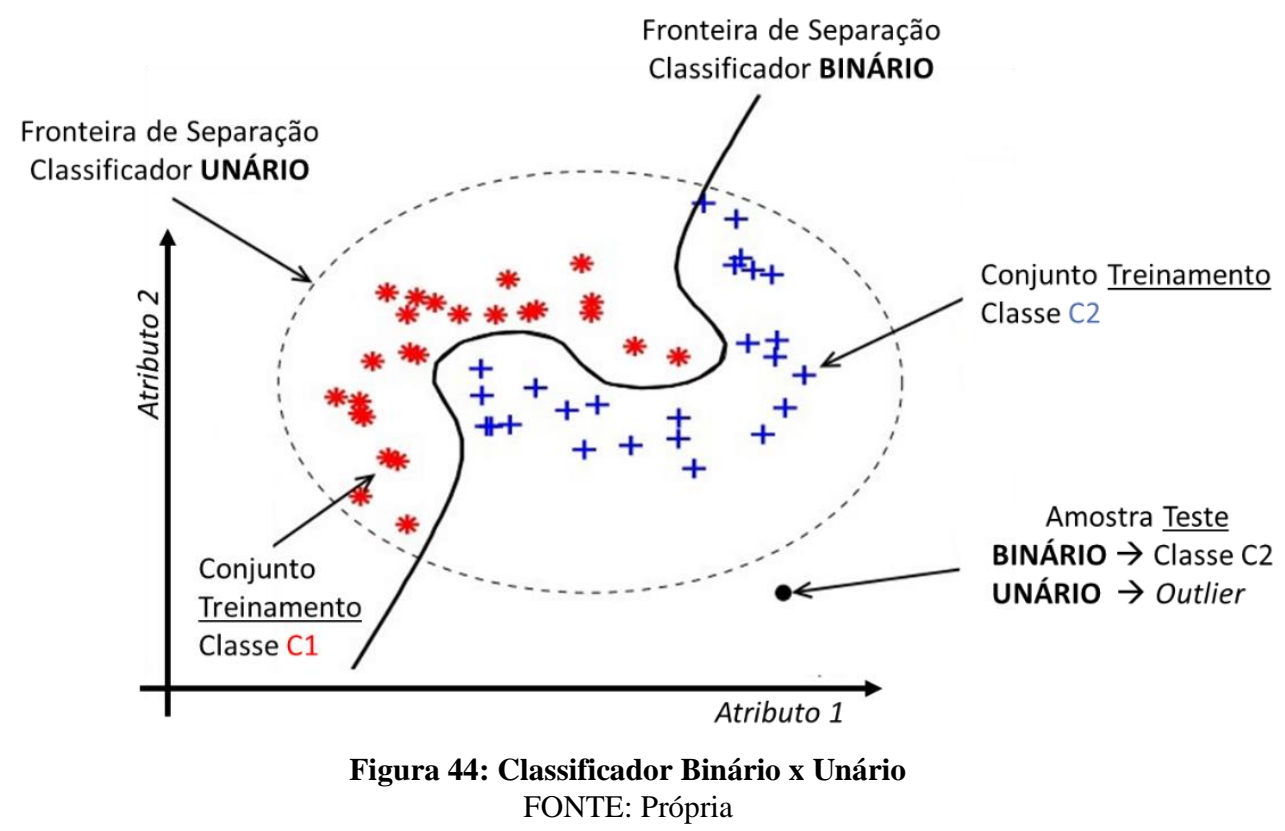

As SVM pertencem ao grupo de métodos para a detecção de anomalias baseados em Aprendizado de Máquina (WENLI SHANG et al., 2015). A SVM tradicional treina o modelo de classificação com amostras positivas e negativas, e é aplicável aos problemas de classificação de múltiplas classes. No entanto, em termos gerais, os atributos dos dados de sistemas SCADA, DCS e outros sistemas de controle industrial apresentam: poucas amostras anormais; alta dimensão e forte correlação com a classe (YASAKETHU; JIANG, 2013).

A SVM one-class (OCSVM) pode treinar o modelo de detecção de anomalias com amostras de apenas uma só classe, em um menor tempo e com um conjunto de amostras menor. Além disso, a OCSVM pode construir um modelo mais preciso e mais robusto com amostras ruidosas. Foi provado que uma SVM de uma só classe é um método eficaz de Aprendizado de Máquina para o desenvolvimento de sistema de detecção de intrusões em redes de comunicação (WENLI SHANG et al., 2015).

A Figura 45 ilustra um exemplo de classificador OCSVM treinado com 200 amostras Targets. No treinamento, o classificador classificou erroneamente 22 amostras como Outliers. Já na etapa de teste, todas as amostras Targets foram corretamente classificadas e apenas 2 amostras Outliers foram incorretamente classificadas. 


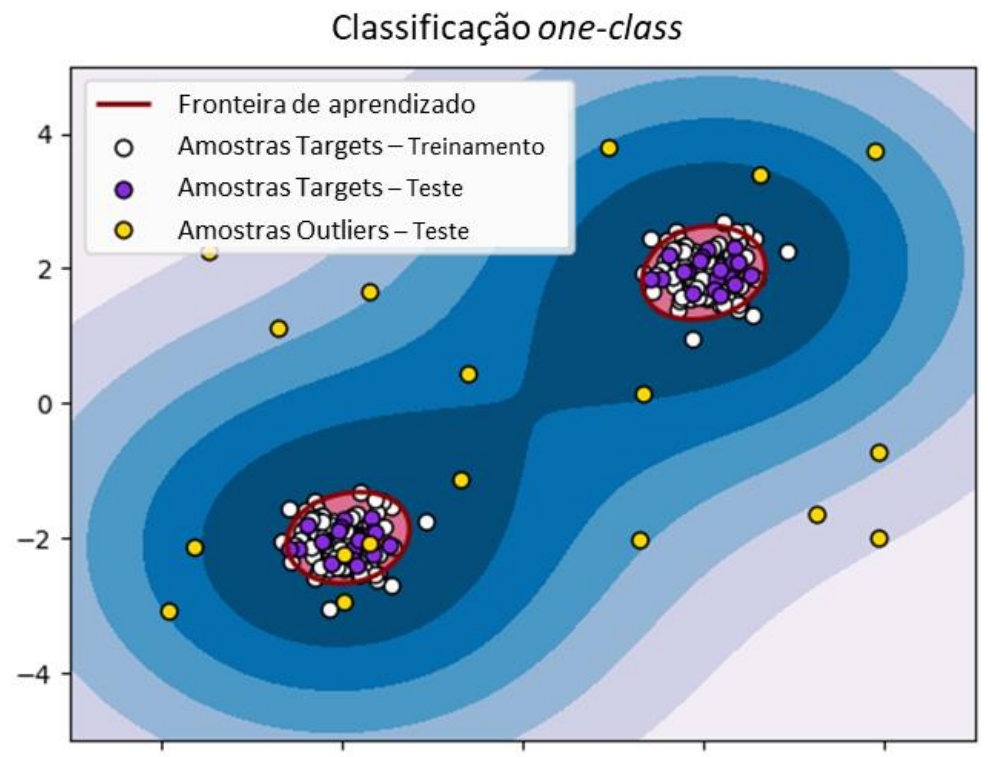

Erro Treino: 22/200; Erro Teste Targets: 0/40; Erro Teste Outliers: 2/40

Figura 45: Exemplo de classificador OCSVM FONTE: Própria

Em (SCHUSTER et al., 2015) são apresentados resultados experimentais da aplicação de uma classe OCSVM em vários cenários reais de tráfego industrial a partir de sistemas de controle industrial diversos. Em (NGUYEN et al., 2018), os autores investigaram a aplicação da SVM one-class com a otimização dos hiperparâmetros no desenvolvimento de um IDS. Em (MAGLARAS; JIANG, 2014), os autores criaram um novo sistema de detecção de intrusão adequado para sistemas em tempo real. Em (WINTER; HERMANN; ZEILINGER, 2011), foi projetado um sistema de detecção de intrusão baseado em vazamentos indutivos. Este sistema usou a OCSVM para treinar o modelo e considerar os dados da rede com base no modelo de fluxo como fonte de dados. A inovação deste estudo é que este sistema usa amostras de ataques mal-intencionados para treinar o modelo OCSVM, em vez de dados normais. Esse modelo também pode ser usado em uma ampla gama aplicações de classificações de ataque de rede.

Resumindo, a abordagem por classificadores one-class é fortemente indicada no desenvolvimento de sistema de detecção de intrusão em redes de automação industrial pois, conforme apresentado, nesse cenário há uma grande dificuldade de coletar amostras anormais, sendo difícil construir modelos de detecção de anomalia, dificuldade essa, causada pelo desequilíbrio das classes de amostras acarretando em menor precisão do modelo do classificador. 


\subsection{Avaliação de Classificadores}

Uma avaliação de um método ou sistema de detecção de intrusão, em termos de precisão ou qualidade, é algo dinâmico e efêmero. Com o passar do tempo, novas vulnerabilidades podem evoluir e as métricas atuais podem se tornar irrelevantes.

Nesta seção, várias medidas usadas para avaliar os métodos e os sistemas de detecção de intrusão em redes serão apresentados, conforme (BHUYAN; BHATTACHARYYA; KALITA, 2014).

\subsubsection{Validação Cruzada}

A Validação Cruzada consiste em mais uma metodologia para avaliar o desempenho de um algoritmo de aprendizado de máquina. Consiste em uma maneira sistemática de se obter os resultados do algoritmo de forma repetida e, dessa forma, diminuir a variância de testes únicos (LIBONI, 2017).

Seu objetivo é avaliar uma determinada topologia de algoritmo de aprendizado a partir de utilização de parte das amostras coletadas para ajuste dos seus parâmetros internos, denominado conjunto de treinamento, e utilizar amostras que não foram utilizadas para estes ajustes, chamada de amostras do conjunto de teste, para verificação do seu desempenho. Assim, se busca realizar a medição e identificar o melhor desempenho para o mapeamento de um determinado problema (KOHAVI, 1995).

A especificação da melhor topologia de uma RNA ou dos melhores hiper parâmetros a serem utilizados na SVM para a classificação de padrões normalmente é realizada de forma empírica. No caso de RNA, alguns fatores para se obter o melhor desempenho dependem de características como a complexidade do problema a ser mapeado, a distribuição espacial das amostras, a qualidade do conjunto de treinamento, como presença de outliers e ruídos, entre outras (SILVA; SPATTI; FLAUZINO, 2010).

Um tipo de validação cruzada bastante empregado é o denominado K-partições. Consiste na divisão do conjunto de dados em um número de $\mathrm{K}$ partições diferentes, utilizando-se K-1 partições para treinar o algoritmo e uma partição para o teste. O processo é feito de forma sistemática, de maneira que com a mesma divisão, se utilizando outras K-1 partição para treinamento e outra para teste. Realiza-se essa repetição por K vezes e os resultados são avaliados como métrica de desempenho do algoritmo de 
aprendizado. Um algoritmo com média alta de acertos alta, mas com grande desvio padrão indica que o algoritmo não está generalizando o conhecimento de forma adequada e o fenômeno de overfitting deste estar ocorrendo (LIBONI, 2017).

A Figura 46 ilustra um exemplo de aplicação da Validação Cruzada com 5 partições para as sistemáticas divisões do Conjunto de Treinamento.

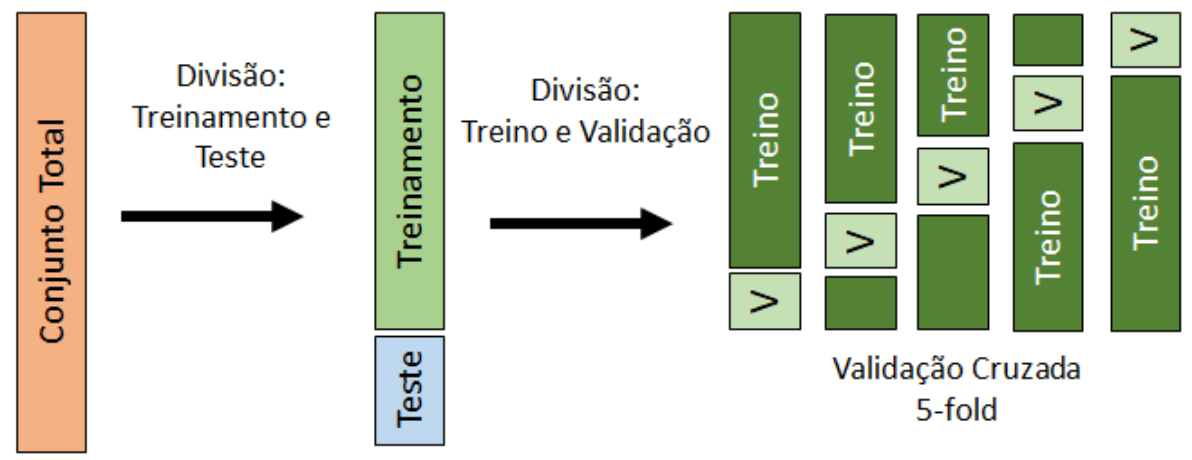

Figura 46: Validação Cruzada com 5 partições FONTE: Própria

\subsubsection{Erro Quadrático Médio}

O Erro Quadrático Médio, mais especificamente a Raiz do Erro Quadrático Médio (do inglês RMSE - Root Mean Square Error) representa a medida das diferenças entre os valores estimados pelo modelo e os valores realmente observados.

Nas especificações do software WEKA ele está definido como: o desvio padrão da amostra das diferenças entre os valores previstos e os valores observados. Ele agrega as magnitudes dos erros nas previsões em uma única medida de poder preditivo. É uma boa medida de precisão, mas apenas para comparar erros de previsão de diferentes modelos para uma variável específica e não entre variáveis, pois depende da escala.

Os valores de RMSE (Root Mean Square Error) é dado pela equação 5.1 onde $\hat{y}$ é o valor predito, $y$ o valor real e $n$ a quantidade de classificações.

$$
R M S E=\sqrt{\frac{\sum_{1}^{n}(\hat{y}-y)^{2}}{n}}
$$

Mais detalhes sobre o cálculo do Erro Quadrático Médio podem ser obtidos em (SILVA; SPATTI; FLAUZINO, 2010). 


\subsubsection{Matriz de Confusão}

A matriz de confusão é um método de classificação que pode ser aplicado a qualquer tipo de problema de classificação. O tamanho dessa matriz depende do número de classes distintas a serem detectadas.

O objetivo é comparar os rótulos das classes reais com os previstos, conforme mostrado na Figura 47. A diagonal representa a classificação correta. A matriz de confusão para detecção de intrusão é definida como uma matriz de 2 por 2 , uma vez que existem apenas duas classes conhecidas como intrusão e normal (GHORBANI; LU; TAVALLAEE, 2010).

Em um sistema de detecção de anomalias, existem quatro possíveis resultados descritos usando a matriz de confusão dada na Figura 47. Quando uma instância de teste anômala é classificada como anômala pelo classificador, é contado como verdadeiro positivo (TP - True Positive); se for classificada como normal, é contado como falso negativo (FN - False Negative). Por outro lado, se uma instância de teste normal for classificada como normal, ela é conhecida como verdadeira negativo (TN - True Negative), enquanto que será um falso positivo (FP - False Positive) se for classificada como anômala (GHORBANI; LU; TAVALLAEE, 2010; WANG, 2008).

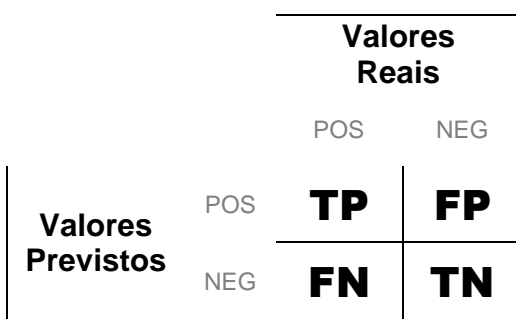

Figura 47: Matriz Confusão

FONTE: Adaptado de (BHUYAN; BHATTACHARYYA; KALITA, 2014)

Assim, os TN e TP que representam os casos corretamente previstos estão na diagonal da matriz, enquanto os FN e FP estão nos lados direito e esquerdo. Essa disposição das métricas, faz com que a relação entre eles possa ser facilmente compreendida (BHUYAN; BHATTACHARYYA; KALITA, 2014).

Todas essas métrica relacionadas à matriz de confusão estão ilustradas na Figura 48. 


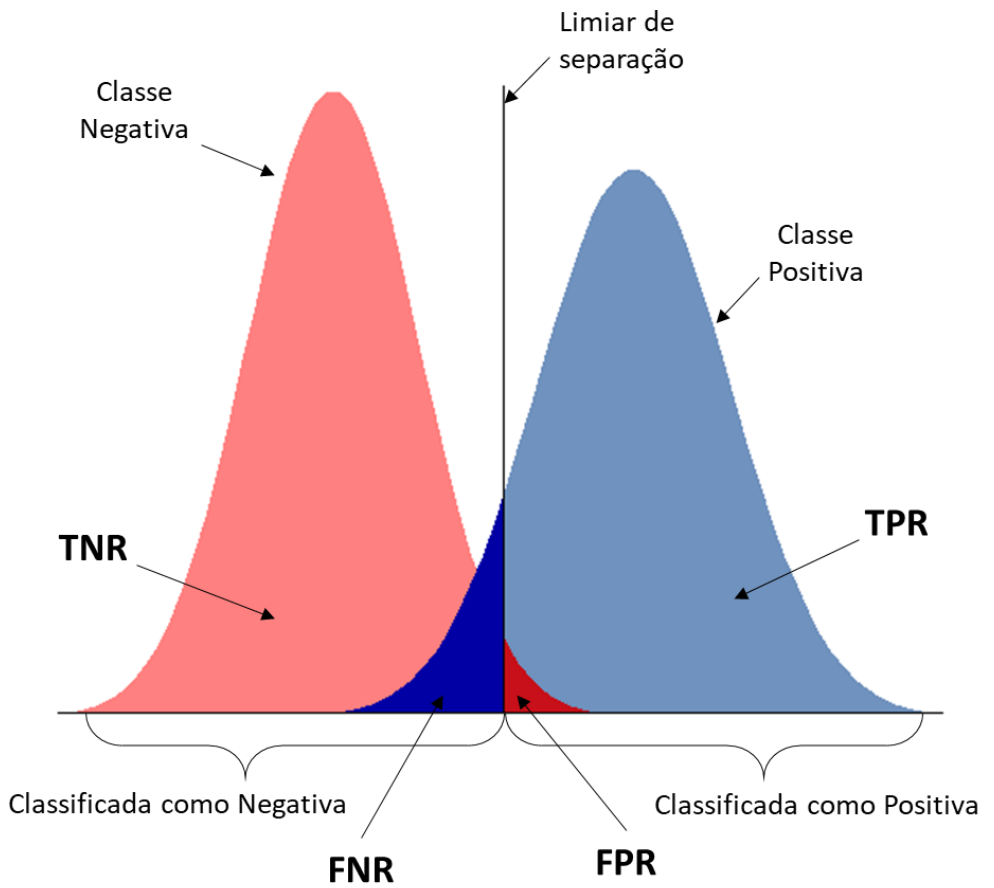

Figura 48: Ilustração das métricas de avaliação de classificadores FONTE: Adaptado de (BHUYAN; BHATTACHARYYA; KALITA, 2014)

\subsubsection{Principais métricas de desempenho}

A acurácia ou precisão ou exatidão são métricas que medem o quão corretamente um IDS funciona, medindo a porcentagem de detecção e falha, bem como o número de alarmes falsos que o sistema produz (AXELSSON, 2000; LIPPMANN et al., 2000).

Se um sistema tiver $80 \%$ de precisão, isso significa que ele classifica corretamente 80 instâncias de 100 em suas classes reais. Embora haja uma grande diversidade de ataques na detecção de intrusões, o foco principal é que o sistema seja capaz de detectar um ataque corretamente. A partir da experiência da vida real, pode-se concluir facilmente que a porcentagem real de dados anormais é muito menor do que a normal (JOSHI, MAHESH, AGARWAL, RAMESH, KUMAR, 2002; PORTNOY; ESKIN; STOLFO, 2001). Consequentemente, intrusões são mais difíceis de detectar do que o tráfego normal, resultando em alarmes falsos excessivos como o maior problema enfrentado pelos IDS.

A seguir estão apresentadas as principais métricas utilizadas neste trabalho extraídas de (MONARD; BARANAUSKAS, 2003).

A Acurácia trata da proporção de amostras classificadas corretamente pelo total de amostras classificadas. 


$$
\text { Acurácia }=\frac{T P+T N}{T P+F N+F P+T N}
$$

A taxa de verdadeiros positivos (TPR - True Positive Rate) é a proporção de instâncias anômalas classificadas corretamente sobre o número total de instâncias anômalas presentes no conjunto de teste. A TPR é também conhecida como $\underline{\text { Sensibilidade. }}$

$$
T P R=\frac{T P}{T P+F N}
$$

A taxa de falsos positivos (FPR - False Positive Rate) é a proporção de casos normais incorretamente classificados como anômalos sobre o número total de instâncias normais contidas no conjunto de teste.

$$
F P R=\frac{T P}{F P+T N}
$$

A taxa de verdadeiros negativos (TNR - True Negative Rate) é a proporção de instâncias normais classificadas corretamente sobre o número total de instâncias normais presentes no conjunto de teste. A TNR também é chamada de Especificidade.

$$
T N R=\frac{T N}{F P+T N}=1-F P R
$$

A taxa de falsos negativos (FNR - False Negative Rate) é a proporção de casos anômalos incorretamente classificados como normais sobre o número total de instâncias anômalas contidas no conjunto de teste.

$$
F N R=\frac{F N}{T P+F N}=1-T P R
$$

Precision é uma medida de como um sistema identifica as instâncias como ataques ou normais. Uma identificação é considerada precisa se ela de fato representar uma anomalia e for classificada como tal. Recall é uma medida de quantas amostras são identificadas corretamente.

$$
\begin{aligned}
& \text { Precision }=\frac{T P}{T P+F P} \\
& \text { Recall }=T P R=\frac{T P}{T P+F N}
\end{aligned}
$$

A Precision e a Recall são muitas vezes inversamente proporcionais entre si e normalmente há um conflito na escolha entre qual delas utilizar. Um classificador que 
gera baixa Precision e baixa Recall provavelmente apresenta defeitos a partir de erros conceituais em seu algoritmo (BHUYAN; BHATTACHARYYA; KALITA, 2014).

Já $F$-measure mistura as propriedades das duas medidas anteriores como a média harmônica da Precision e da Recall (GHORBANI; LU; TAVALLAEE, 2010). Se o objetivo é usar apenas uma métrica de precisão como critério de avaliação dos classificadores, a F-measure é a mais recomendada (BHUYAN; BHATTACHARYYA; KALITA, 2014).

$$
F_{\text {measure }}=\frac{2 * \text { Precision } * \text { Recall }}{\text { Precision }+ \text { Recall }}
$$

Observe que, quando a Precision e a Recall atingem 100\%, a F-measure é a máxima, ou seja, 1 significa que o classificador tem $0 \%$ de alarmes falsos e detecta $100 \%$ dos ataques. Desta forma, espera-se que um bom classificador obtenha a F-measure a mais alta possível.

Obviamente, o objetivo de um IDS é produzir tantos TP e TN quanto possível, ao tentar reduzir o número de ambos FP e FN. A maioria dos critérios de avaliação usa essas variáveis e as relações entre elas para modelar a precisão dos IDS.

\subsubsection{Outras métricas de desempenho}

A avaliação de desempenho de um IDS é uma tarefa importante. Envolve muitos aspectos que vão além do próprio IDS. Esses aspectos incluem a plataforma de hardware, o sistema operacional ou até mesmo a implantação do IDS.

\subsubsection{Desempenho}

Para um NIDS, o critério de avaliação mais importante para o seu desempenho é a capacidade do sistema de processar o tráfego de pacotes em uma rede de alta velocidade com perda mínima de pacotes ao trabalhar em tempo real. No tráfego de rede real, os pacotes podem ter vários tamanhos e a eficácia de um NIDS depende da sua capacidade de lidar com pacotes de qualquer tamanho.

Além da velocidade de processamento, o uso da CPU e da memória também podem servir como métricas de desempenho do NIDS (SEKAR et al., 1999). Essas são geralmente usadas como medidas indiretas que levam em conta as complexidades de 
tempo e espaço dos algoritmos de detecção de intrusão. Finalmente, o desempenho de qualquer NIDS é muito dependente da sua configuração individual, da rede que está monitorando e da sua posição nessa rede.

\subsubsection{Completude}

O critério de completitude representa o espaço das vulnerabilidades e dos ataques que podem ser cobertos por um IDS. Este critério é muito difícil de avaliar porque é impossível se ter o conhecimento sobre todos os tipos de ataques. A capacidade de um IDS é considerada completa, se abrange todas as vulnerabilidades e ataques conhecidos (BHUYAN; BHATTACHARYYA; KALITA, 2014).

\subsubsection{3 $\underline{\text { Pontualidade }}$}

Um IDS que realiza sua análise o mais rápido possível permite que o analista humano ou o mecanismo de resposta reaja prontamente antes que muito dano seja causado pela intrusão. Isso impede que o invasor subverta a fonte de auditoria ou o próprio IDS.

A resposta gerada pelo sistema ao combater um ataque é muito importante. Como os dados devem ser processados para descobrir intrusões, sempre há um atraso entre o momento real do ataque e a resposta do sistema. Isso é chamado de atraso total. Assim, o atraso total é a diferença entre o ataque e a resposta do IDS. Quanto menor o atraso total, melhor é um IDS em relação à sua resposta. Não importa se um IDS é baseado em anomalias ou baseado em assinatura, há sempre um gap entre o tempo de início de um ataque e s sua detecção (BHUYAN; BHATTACHARYYA; KALITA, 2014).

\subsubsection{Qualidade}

Avaliar a qualidade dos dados é outra tarefa importante na avaliação do NIDS. A qualidade dos dados é influenciada por vários fatores, como: fonte dos dados (deve ser de fontes confiáveis e apropriadas); seleção da amostra (deve ser imparcial); tamanho da amostra (não sobre dimensionada e nem subdimensionada); tempo de amostragem dos dados (devem ser atualizados com frequência em tempo real); complexidade dos dados (os dados devem ser simples o suficiente para serem manipulados facilmente pelo mecanismo de detecção), e assim por diante (BHUYAN; BHATTACHARYYA; KALITA, 2014). 


\subsubsection{Detecção de amostra desconhecida}

Novas vulnerabilidades estão evoluindo quase todos os dias. Um sistema de detecção de invasão de rede baseado em anomalia deve ser capaz de identificar ataques desconhecidos, além de ataques conhecidos. O IDS deve mostrar habilidades consistentes de detectar intrusões desconhecidas ou até mesmo modificadas (BHUYAN; BHATTACHARYYA; KALITA, 2014).

\subsubsection{Atualização de perfil}

Assim que novas vulnerabilidades ou invasões forem descobertas, assinaturas ou perfis devem ser atualizados para detecção futura. No entanto, escrever perfis ou assinaturas novas ou modificadas sem comprometer o desempenho do sistema é um desafio, considerando o atual cenário de rede de alta velocidade (BHUYAN; BHATTACHARYYA; KALITA, 2014)

\subsubsection{Estabilidade}

Qualquer sistema de detecção de anomalias deve executar consistentemente em diferentes cenários de rede e em diferentes circunstâncias. Ele deve consistentemente relatar eventos idênticos de maneira semelhante. Permitir que os usuários configurem diferentes alertas para fornecer mensagens diferentes em diferentes ambientes de rede pode levar a um sistema instável (BHUYAN; BHATTACHARYYA; KALITA, 2014).

\subsubsection{Riqueza de informações}

Os alertas gerados por um IDS devem ter significado suficiente para identificar claramente as razões por trás do evento a ser levantado e as razões pelas quais esse evento é de interesse. Deve também ajudar o analista a determinar a relevância e a reação apropriada a um determinado alerta. O sistema também deve especificar a origem do alerta e o destino do ataque (BHUYAN; BHATTACHARYYA; KALITA, 2014).

\subsubsection{Interoperabilidade}

Supõe-se que um mecanismo efetivo de detecção de invasões seja capaz de correlacionar informações de várias fontes, como logs do sistema, outros HIDS, NIDS, logs de firewall e quaisquer outras fontes de informações disponíveis. Isso ajuda a manter a interoperabilidade, quando se possui uma variedade de equipamentos e softwares de 
HIDS ou NIDS de vários fornecedores (BHUYAN; BHATTACHARYYA; KALITA, 2014).

\subsection{Considerações Parciais}

Neste capítulo foram apresentados conceitos gerais sobre Aprendizado de Máquina, também foram detalhados os modelos e algoritmos utilizados para a extração e seleção ou redução dos atributos do tráfego da rede, a técnica utilizada para o balanceamento do conjunto de dados a serem utilizados no treinamento dos classificadores binários, conceitos gerais sobre os sistemas de inferência para a classificação unária e binária, além das principais métricas utilizadas para a avaliação do desempenho dos classificadores investigados.

No próximo capítulo é exposta a metodologia que foi utilizada no desenvolvimento, aplicação e validação do método proposto realizados em laboratório para posterior apresentação dos resultados no Capítulo 6. 


\section{Capítulo 5}

\section{Método para deteç̧ão de intrusão em redes PROFINET baseado em técnicas de Aprendizado de Máquina}

Diante da motivação e justificativa apresentadas no Capítulo 1, dos aspectos de segurança em redes industrias expostos no Capítulo 2, dos principais tipos de sistemas de detecção de intrusão e de ataques em redes industriais descritos no Capítulo 3 e das ferramentas matemáticas e computacionais relacionadas ao Aprendizado de Máquina também descritas no Capítulo 4, adotou-se um conjunto de estratégias para a realização e desenvolvimento de um método para detecção de intrusão em redes PROFINET baseado em técnicas de Aprendizado de Máquina.

A metodologia desenvolvida está dividida em conjuntos de atividades apresentados de forma sucinta na Figura 49.

Por meio da metodologia adotada, acredita-se que este trabalho contribua para aprimoramento da área de conhecimento de redes de comunicação PROFINET, mais especificamente sobre os aspectos de segurança que ainda possui poucas informações na comunidade científica; além de sistemas inteligentes e técnicas de aprendizagem de máquina para detecção de anomalia e intrusão em redes industriais.

O método foi avaliado em bancada com equipamentos do LAI - Laboratório de Automação Industrial da Escola de Engenharia de São Carlos - USP. Ele se baseia nos trabalhos de (DIAS, 2019; LINDA; VOLLMER; MANIC, 2009; SESTITO, 2018; TURCATO, 2015) possibilitando a realização de estudos de caso a partir de dados reais de tráfego da rede. 


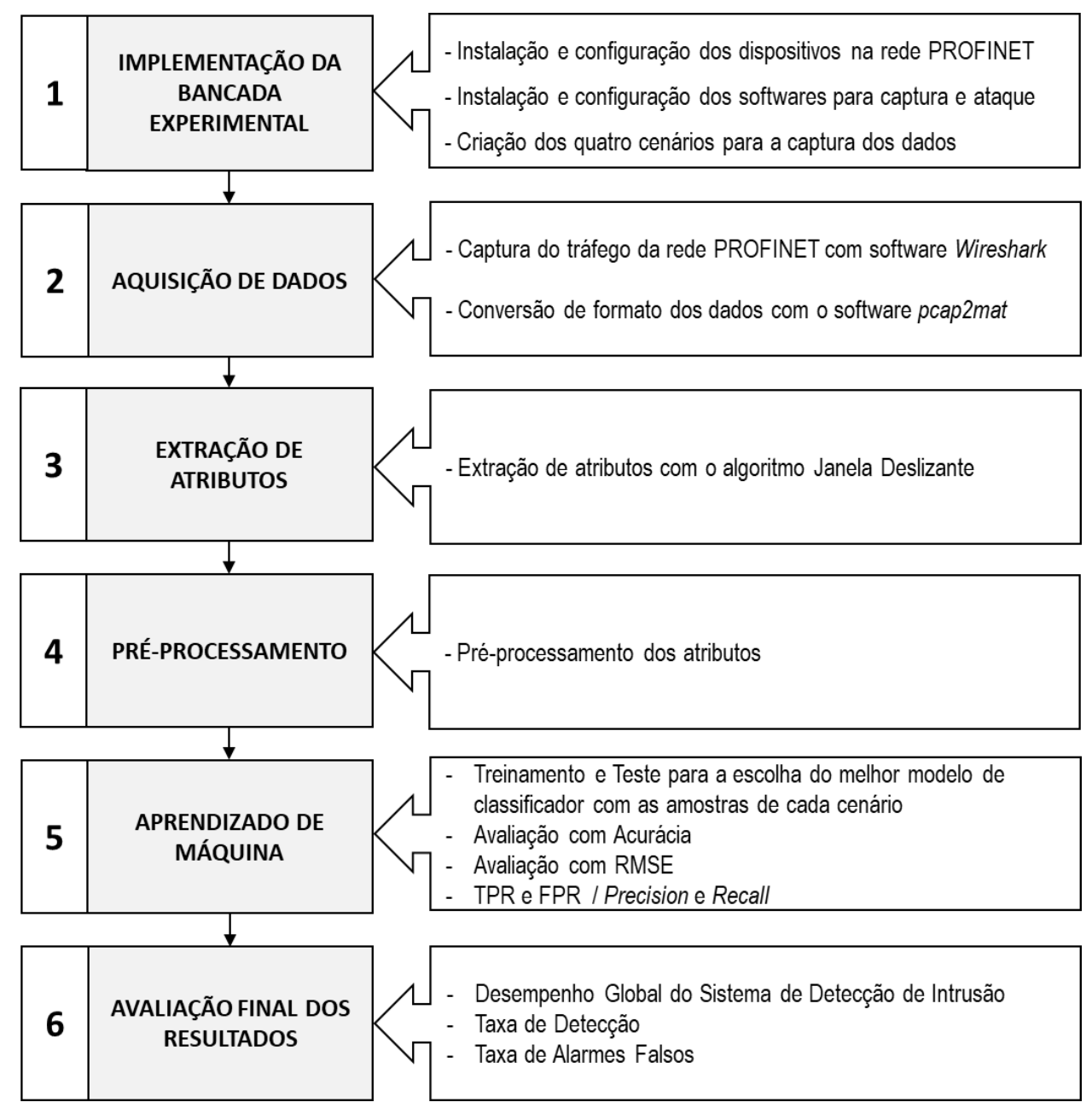

Figura 49: Fluxograma da metodologia proposta FONTE: Própria

\subsection{Implementação da rede em bancada experimental}

Esta etapa refere-se à instalação, energização e colocação em funcionamento dos equipamentos da rede PROFINET e dos computadores e softwares auxiliares responsáveis pela captura e ataque à rede. Aborda os principais aspectos sobre os cenários reproduzidos em laboratório para aquisição de dados. Baseia-se em uma aplicação comum em indústrias de manufatura e de processos, onde os equipamentos da rede PROFINET são interligados por meio de switches gerenciáveis com a possibilidade do espelhamento de porta (port mirroring) para coleta dos pacotes do tráfego da rede.

Técnicas supervisionadas de aprendizado de máquina requerem dados de treinamento em situações de tráfego normal e anômalo (ataque). Em geral, é impossível se obter sistematicamente dados dos ataques porque as infraestruturas críticas das plantas fabris do mundo real não estão disponíveis para experimentações disruptivas. Assim, para 
esse trabalho, foram criados cenários em bancadas experimentais no Laboratório de Automação Industrial (LAI).

A Figura 50 ilustra a forma de interligação dos equipamentos na rede PROFINET utilizando-se topologia estrela.

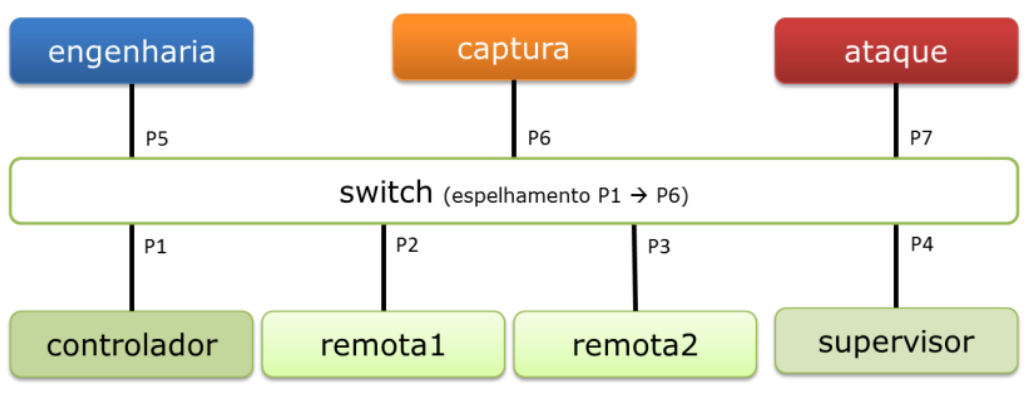

Figura 50: Interligação dos equipamentos para a captura FONTE: Própria

Mais detalhes acerca de cada componente da rede estão apresentados nas próximas seções.

\subsubsection{Instalação e configuração dos equipamentos na rede PROFINET}

A lista dos equipamentos e softwares utilizados para a criação dos cenários de testes pode ser encontrada nas Tabela 13 e Tabela 14.

Tabela 13: Equipamentos utilizados para a implementação da rede PROFINET

\begin{tabular}{cllll} 
Item & Modelo & Fabricante & Função & Nome \\
\hline 1 & CPU 1214C & Siemens & IO-Controller & controlador \\
\hline 2 & IM 151-3 & Siemens & IO-Device & remota1 \\
\hline 2.1 & PM-E RO DC & Siemens & Fonte de alimentação & - \\
\hline 2.2 & 8 DI 24V & Siemens & Módulo 8 entradas digitais & - \\
\hline 2.3 & 8 DO DC 24V & Siemens & Módulo 8 saídas digitais & - \\
\hline 2.4 & ST DC 24V & Siemens & Módulo 2 entradas digitais & - \\
\hline 3 & CI501-PNIO C2 & ABB & IO-Device & remota2 \\
\hline 4 & TH-Link & Trebing + & IO-Supervisor & supervisor \\
\hline 5 & SCALANCE X208 & Siemens & Switch & switch \\
\hline 6 & ThinkPad X220 & Lenovo & $\begin{array}{l}\text { Estação de Engenharia e } \\
\text { Supervisão }\end{array}$ & engenharia \\
\hline 7 & Inspiron 15R & Dell & Estação de Captura & captura \\
\hline 8 & Vostro 1310 & Dell & Estação de Ataque & ataque \\
\hline
\end{tabular}


Tabela 14: Softwares utilizados para a implementação e captura do tráfego da rede PROFINET

\begin{tabular}{clll} 
Item & Nome & Fabricante & Função \\
\hline 1 & TIA Portal V11 SP2 & Siemens & Configuração dos dispositivos da rede PROFINET \\
\hline 2 & Wireshark 3.2.1 & Wireshark & Captura de tráfego da rede \\
\hline 3 & Excel 2017 & Microsoft & Pré-processamento dos dados \\
\hline 4 & Matlab R2017 & MathWorks & $\begin{array}{l}\text { Pré-Processamento dos dados, Extração de } \\
\text { Atributos, Treinamento e Execução da OCSVM }\end{array}$ \\
\hline 5 & Weka 3.8 & Waikato & $\begin{array}{l}\text { Seleção de atributos e Treinamento e Execução das } \\
\text { RNA e SVM }\end{array}$ \\
\hline 6 & Nmap 6.47 & Nniversity & Geração do tráfego anômalo \\
\hline 7 & Nessus 5.2.7 & $\begin{array}{l}\text { Tenable } \\
\text { Network }\end{array}$ & Geração do tráfego anômalo \\
\hline 8 & pcap2mat & Security & (própria) \\
\hline
\end{tabular}

Utilizando-se o software TIA Portal, é configurada uma topologia de rede PROFINET conforme Figura 51.

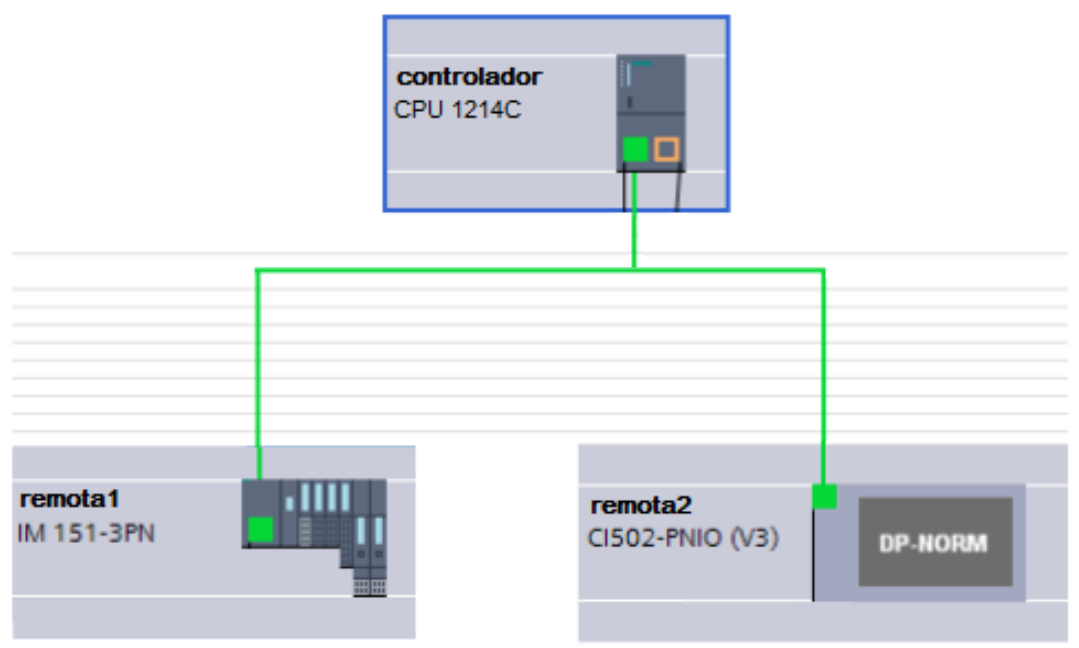

Figura 51: Configuração da rede PROFINET no software TIA Portal FONTE: Própria

Informações detalhadas sobre os parâmetros de comunicação estão na

Tabela 15.

Tabela 15: Parâmetros da rede PROFINET configurada

\begin{tabular}{cllll} 
Item & Nome & MAC Address & IP Address & Update time \\
\hline 1 & controlador & $00-1 \mathrm{C}-06-13-\mathrm{E} 3-\mathrm{C} 3$ & $192.168 .0 .10 / 24$ & - \\
\hline 2 & remota1 & $00-0 \mathrm{E}-8 \mathrm{C}-\mathrm{F} 6-96-96$ & $192.168 .0 .11 / 24$ & $32 \mathrm{~ms}$ \\
\hline 3 & remota2 & $00-24-59-00-68-38$ & $192.168 .0 .12 / 24$ & $64 \mathrm{~ms}$ \\
\hline
\end{tabular}




\subsubsection{Instalação e configuração dos softwares para captura e ataque}

Uma estação de trabalho é configurada para a captura de pacotes e armazenamento de dados. A esta estação é atribuído o nome de 'Estação De Captura' ou simplesmente 'captura'.

Após o estabelecimento da comunicação na rede PROFINET, é necessário também efetuar uma modificação para a correta captura do tráfego da rede. Essa modificação consiste no espelhamento de porta no switch. Este espelhamento consiste em copiar todo tráfego de pacotes de dados que passa pela porta onde o IO-Controller está conectado (porta P1 da Figura 50) e transferi-los para uma porta livre. Esta porta livre, por sua vez, é conectada ao computador com software Wireshark, a estação de captura (porta P6 da Figura 50).

O modelo de switch utilizado nos testes (apresentado na Tabela 13) permite a configuração por meio do navegador WEB e, assim, é possível escolher as portas que serão espelhadas sem a necessidade de software adicional.

Os endereços IP configurados estão descritos na tabela a seguir.

Tabela 16: Parâmetros de rede dos equipamentos envolvidos na captura

\begin{tabular}{cllll} 
Item & Nome & MAC Address & IP Address & Descrição \\
\hline 1 & controlador & $00-1 \mathrm{C}-06-13-\mathrm{E} 3-\mathrm{C} 3$ & $192.168 .000 .010 / 24$ & IO-Controller \\
\hline 2 & remota1 & $00-0 \mathrm{E}-8 \mathrm{C}-\mathrm{F} 6-96-96$ & $192.168 .000 .011 / 24$ & IO-Device \\
\hline 3 & remota2 & $00-24-59-00-68-38$ & $192.168 .000 .012 / 24$ & IO-Device \\
\hline 4 & supervisor & $00-14-13-00-0 \mathrm{C}-89$ & $192.168 .000 .125 / 24$ & IO-Supervisor \\
\hline 5 & engenharia & $\mathrm{F} 0-\mathrm{DE}-\mathrm{F} 1-\mathrm{FF}-5 \mathrm{E}-\mathrm{C} 4$ & $192.168 .000 .201 / 24$ & Laptop \\
\hline 6 & captura & $\mathrm{D} 4-\mathrm{AE}-52-\mathrm{FE}-\mathrm{B} 1-9 \mathrm{~B}$ & $192.168 .000 .202 / 24$ & Laptop \\
\hline 7 & ataque & $00-1 \mathrm{E}-\mathrm{C} 9-24-5 \mathrm{~A}-\mathrm{F} 9$ & $192.168 .000 .254 / 24$ & Laptop \\
\hline
\end{tabular}

Conforme descrito na Seção 3.1, o IO-Supervisor é um equipamento com a finalidade de enviar/receber parâmetros dos outros dispositivos da rede (configuração), sejam eles um IO-Device ou um IO-Controller. Também pode ser utilizado na identificação de falhas nesses dispositivos e/ou na rede (diagnóstico da rede).

Na prática, costuma-se deixar um IO-Supervisor operando constantemente na rede para levantamento das causas de falhas. Basicamente este equipamento envia comandos broadcast/multicast na rede com o propósito de levantar informações sobre o estado da rede. Sendo que, este tráfego adicional, gerado pelo supervisor, não deve ser identificado como um tipo de ataque na rede pelo IDS. 
Já a estação denominada como 'ataque' é responsável por gerar o tráfego adicional na rede que simula a "intrusão" propriamente dita. Os pacotes de dados inseridos no tráfego da rede por esta estação possuem, exclusivamente, a finalidade de invasão a essa rede, seja para levantar informações sigilosas sobre os equipamentos e/ou tentar derrubar algum serviço (mais detalhes sobre os tipos de ataques podem ser obtidos na Seção 2.3.2).

Para gerar o tráfego a ser caracterizado como 'intrusão', são instalados nessa máquina dois softwares específicos para essa finalidade, são eles: Nmap ${ }^{2}$ e Nessus ${ }^{3}$.

Esses softwares possuem inúmeros recursos disponíveis para gerar os mais variados tipos de ataques, principalmente ataques do tipo probing (varredura), podendose ter como alvo toda a rede ou então, algum equipamento específico. Sendo assim, após análises sobre os inúmeros tipos de ataques disponíveis nas configurações dos softwares e, como estes poderiam ser disparados em uma rede PROFINET típica, optou-se por efetuar um ataque de varredura oriundo da estação 'ataque' direcionado especificamente ao 'controlador' (alvo).

Para disparar esse ataque, os seguintes parâmetros são utilizados em conjunto com o software Nmap:

$$
\text { nmap -T4 -F 192.168.0.10 }
$$

Já para o software Nessus, cria-se uma Policy do tipo Host Discovery com o subtipo Port Scan (common ports) tendo como alvo também o endereço IP 192.168 .0 .10 (controlador).

Detalhes sobre as funcionalidades existentes nesses softwares e o que representam cada opção citada acima podem ser obtidas em (NMAP.ORG, 2019) e (TENABLE, 2019).

Em cada cenário de captura realizado em laboratório, é disparado o mesmo tipo de ataque tendo-se sempre o mesmo alvo. Assim, propositalmente, a diferença existente entre cada cenário vai consistir na diversidade do tráfego que, por sua vez, fica progressivamente mais heterogêneo e, ao final, aproxima-se do tráfego encontrado em uma aplicação real na indústria (Cenário 1: mais homogêneo; Cenário 4: mais heterogêneo).

\footnotetext{
${ }^{2}$ Nmap Free Security Scanner for Network Exploration and Security Audits - http://nmap.org/

${ }^{3}$ Nessus Vulnerability Scanner - http://www.tenable.com/products/nessus-vulnerability-scanner
} 
Detalhes a respeito da estrutura e conteúdo dos pacotes de tráfego NORMAL e ANÕMALO estão descritos em (TURCATO, 2015).

\subsubsection{Criação dos cenários para os testes}

Detalhes de como os cenários são projetados, como são feitas as interligações dos equipamentos e como são realizadas as capturas do tráfego na rede são encontrados na sequência. Ao todo, quatro cenários são criados em bancada.

\subsubsection{Cenário 1}

Este primeiro cenário de teste consiste em reproduzir uma situação de tráfego de rede PROFINET que contenha apenas pacotes referentes à troca cíclica de informações entre o IO-Controller e os IO-Devices. Assim, os equipamentos são interligados conforme Figura 52.

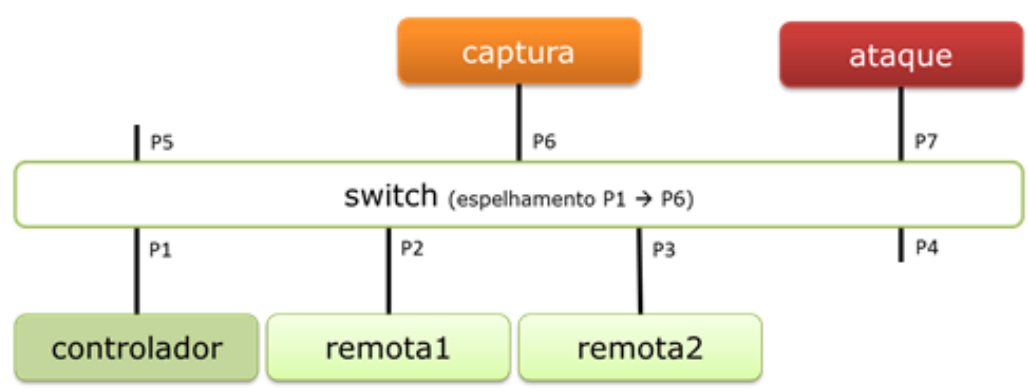

Figura 52: Interligação dos equipamentos para o Cenário 1

FONTE: Própria

\subsubsection{Cenário 2}

Este segundo cenário de teste consiste em reproduzir uma situação de tráfego de rede que contenha dados referentes à troca cíclica de dados entre o IO-Controller e os IODevices e uma troca de informações entre a Estação de Engenharia (representando um sistema SCADA, por exemplo) com o controlador. Essa troca de informações tem a finalidade de monitorar as informações de processo (valores das entradas e saídas digitais das remotas e alguns registradores internos de memória do controlador).

Assim, os equipamentos são interligados conforme Figura 53. 


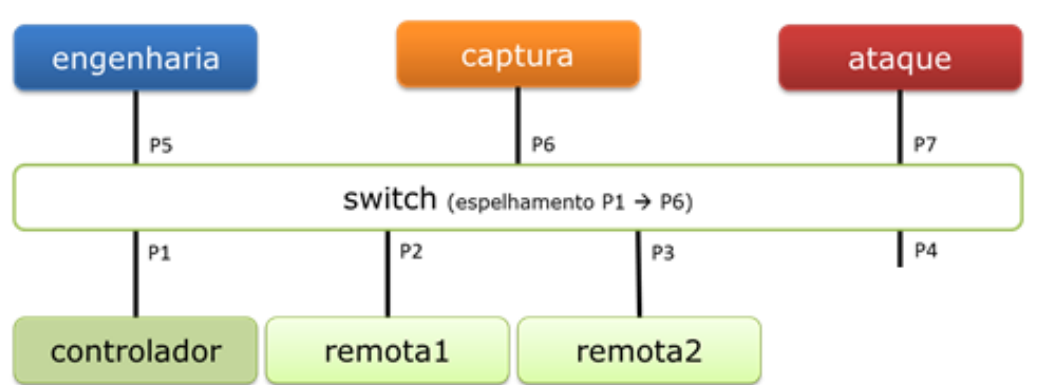

Figura 53: Interligação dos equipamentos para o Cenário 2 FONTE: Própria

\subsubsection{Cenário 3}

Este terceiro cenário foi planejado para reproduzir uma situação de tráfego de rede que contenha dados referentes à troca cíclica de dados entre o IO-Controller e os IODevices e também uma troca de informações entre o IO-Supervisor e os outros elementos da rede com o propósito de se realizar diagnóstico dos componentes da rede.

Desta forma, os equipamentos são interligados conforme Figura 54.

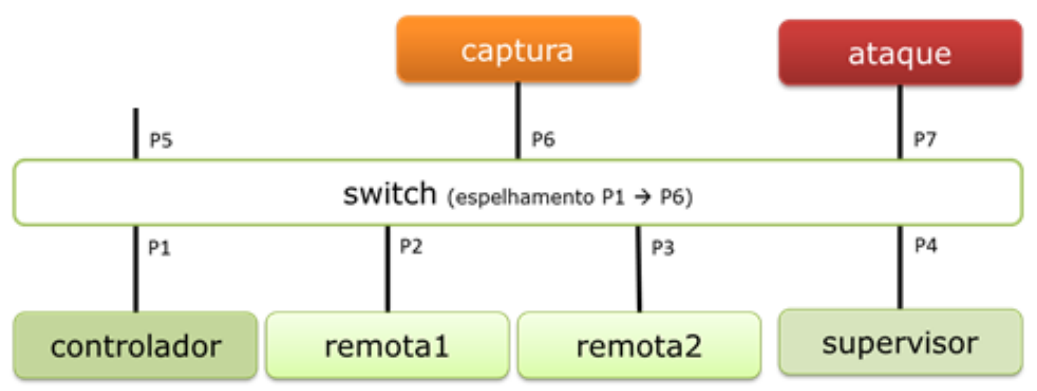

Figura 54: Interligação dos equipamentos para o Cenário 3 FONTE: Própria

\subsubsection{Cenário 4}

Este quarto e último cenário de teste consiste em reproduzir uma situação de tráfego de rede que contenha dados referentes à troca cíclica de dados entre o IOController e os IO-Devices e a troca de informações entre a Estação de Engenharia (representando um sistema SCADA) com o controlador com o propósito de monitorar as informações de processo (valores das entradas e saídas digitais das remotas e alguns registros de memória internos do controlador) e também, troca de informações entre o IO-Supervisor e os outros elementos da rede com o propósito de obter diagnóstico dos componentes da rede. 
Assim, os equipamentos são todos interligados conforme Figura 55.

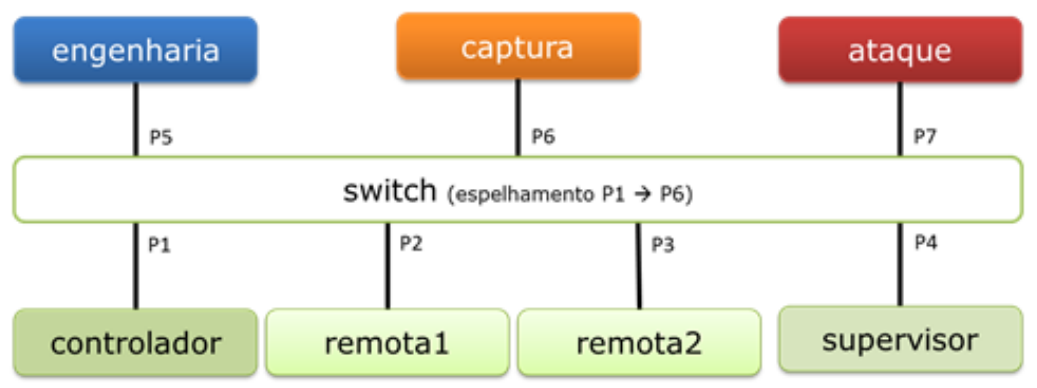

Figura 55: Interligação dos equipamentos para o Cenário 4 FONTE: Própria

O tráfego na rede PROFINET nesse cenário é o mais heterogêneo de todos os anteriores por contemplar pacotes de diversos protocolos, com suas diversas finalidades.

O tráfego "anômalo", em todos os cenários, é gerado por um ataque do tipo 'probing' ao 'controlador' realizado pela estação 'ataque' por meio dos comandos dos softwares Nmap e Nessus listado na Seção 5.1.2

Todo o tráfego direcionado ao 'controlador' é espelhado pelo 'switch' e encaminhado para a estação 'captura' que por sua vez, armazena os dados para posterior análise.

\subsection{Aquisição de Dados}

Esta seção aborda os aspectos relacionados a captura do tráfego da rede PROFINET instalada no laboratório com o software Wireshark e a conversão desse tráfego, armazenado previamente em disco em formato 'proprietário' do Wireshark, para um formato mais adequado para ser trabalhado com o software Matlab, utilizando para isso o software pcap2mat (TURCATO et al., 2017). O software pcap2mat também gera arquivos em formato CSV (Comma Separated Values) que são facilmente processados pelo software Excel e WEKA.

\subsubsection{Captura do tráfego da rede PROFINET com o software Wireshark}

A Estação de Captura pode ser posicionada em diferentes pontos da rede. Em geral, em aplicações com rede PROFINET com apenas um IO-Controller, posiciona-se a 
Estação de Captura no ponto da rede em que todo o tráfego oriundo e/ou destinado ao controlador seja capturado. Essa configuração permite a observação de ataques dirigidos ao IO-Controller (elemento principal da rede) e ataques gerais aos recursos da rede. Uma limitação desta configuração é que um ataque interno que tenha como alvo específico algum IO-Device não é capturado.

Outra técnica que pode ser utilizada é a adoção de vários pontos de captura espalhados pelos segmentos da rede de tal forma que, todo esse tráfego capturado seja mesclado na Estação de Captura e assim, represente, com precisão, todo o tráfego que circula na rede. Em contrapartida, essa técnica exige que vários equipamentos de captura sejam distribuídos pela rede e gera grandes volumes de dados.

Uma estratégia muito comum para a captura de dados do tráfego é a utilização de ferramentas de monitoração de rede, tais como Wireshark (WIRESHARK.ORG, 2019), que realiza a coleta em tempo real para obter os dados brutos do tráfego de rede.

O software Wireshark é uma ferramenta que utiliza a biblioteca de captura de pacotes libpcap (Packet Capture Library) para a comunicação com o dispositivo de rede.

O dispositivo de rede é colocado em "modo promíscuo", o qual permite à máquina ter acesso aos pacotes que não sejam destinados a ela. A Figura 56 ilustra a tela principal do software.

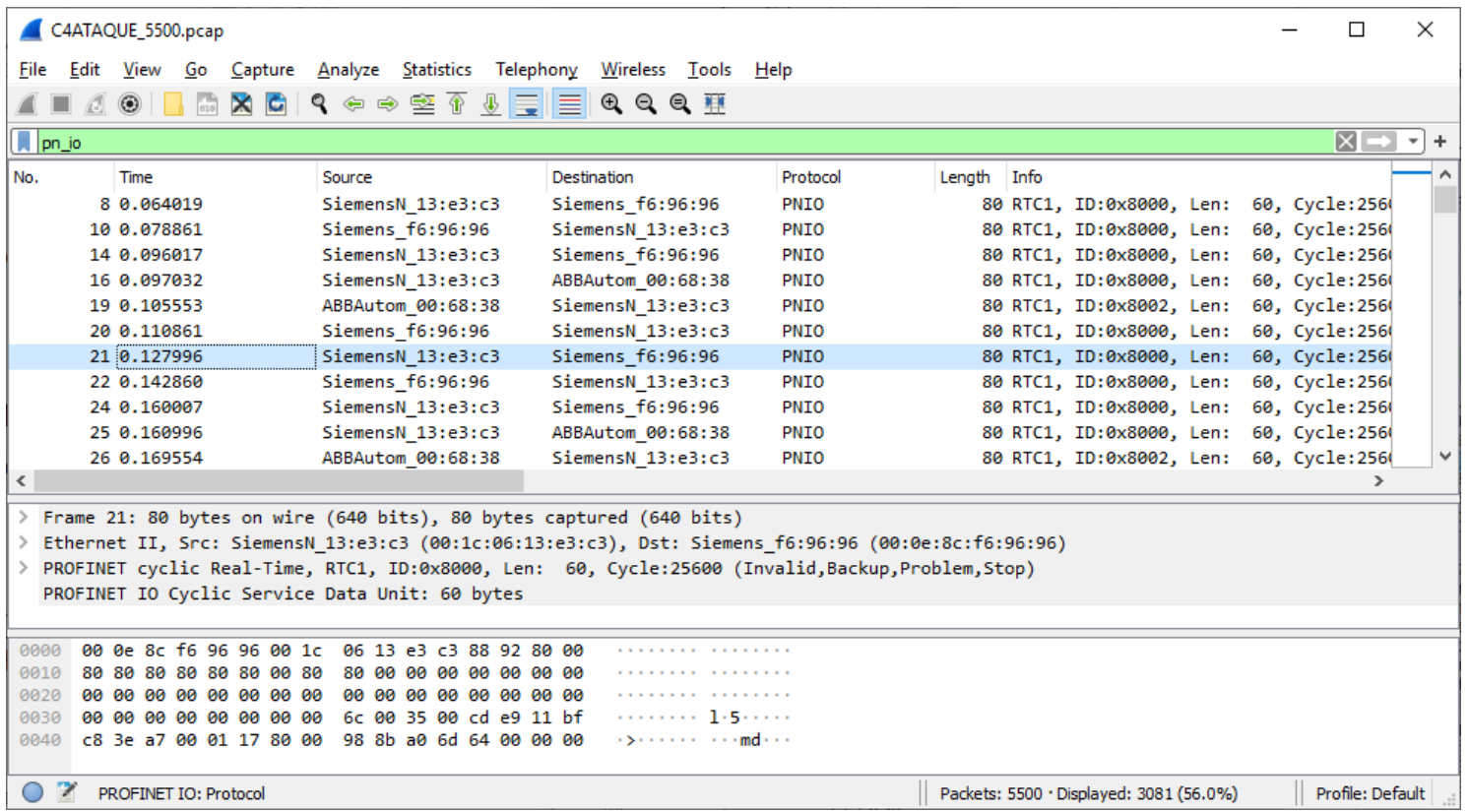

Figura 56: Tela principal do software Wireshark FONTE: Própria 
Para se estabelecer uma metodologia única para todos os cenários, em todos são feitas capturas de $\underline{5500 \text { pacotes }}$ contendo tanto tráfego "NORMAL" quanto tráfego “ANÔMALO”.

\subsubsection{Conversão do formato dos dados com o software pcap2mat}

A grande aceitação dos protocolos de comunicação industrial baseados no padrão Real Time Ethernet pela indústria desperta o interesse da comunidade científica em estudar seus pontos chaves. Há, entretanto, uma incompatibilidade entre os softwares envolvidos no processo de coleta e tratamento dos dados transmitidos. O pcap2mat (antigamente chamado de ProfinetAnalysis) é um software que facilita a integração entre os dois principais softwares utilizados na análise do tráfego da rede: o Wireshark para a captura do tráfego e o Matlab para o processamento dos mesmos (TURCATO et al., 2017).

Neste trabalho foi utilizada a versão mais recente do software pcap2mat que permite acesso remoto via WEB e sem a necessidade de instalação e/ou privilégios de administrador na máquina (TURCATO et al., 2018).

A Figura 57 apresenta a interface principal de acesso à ferramenta pcap2mat.

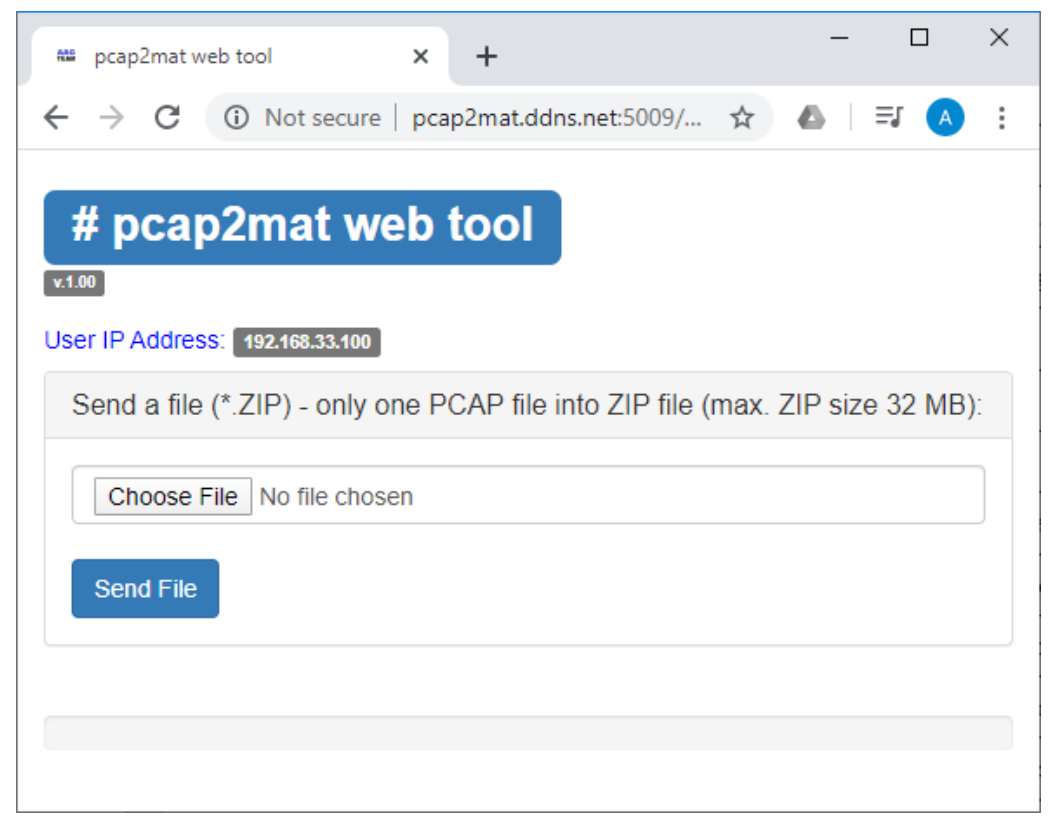

Figura 57: Tela principal do software pcap2mat FONTE: Própria 


\subsection{Extração de Atributos}

Essa seção aborda os principais aspectos sobre a aplicação das técnicas utilizadas nesse trabalho para a extração dos atributos do tráfego capturado. Com o propósito de se efetuar uma comparação de desempenho mais precisa dos algoritmos de aprendizado de máquina (seleção de atributos e classificadores inteligentes), conforme exposto nos objetivos do trabalho, será aplicada a mesma técnica utilizada pelo pesquisador na pesquisa anterior realizada (TURCATO, 2015), o algoritmo da Janela Deslizante com tamanho da janela fixado em $\underline{50 \text { pacotes }}$ e passo de $\underline{1 \text { pacote. }}$.

Os mesmos atributos utilizados em (TURCATO, 2015) são utilizados.

A Tabela 17 descreve a lista dos atributos utilizados.

Tabela 17: Lista dos atributos a serem extraídos do tráfego

\begin{tabular}{ll} 
Nome & Descrição \\
\hline A01 & Número de pacotes que contém Datagrama IP \\
\hline A02 & Número Máximo de pacotes que contêm Datagrama IP de um mesmo endereço IP \\
\hline A03 & Número Mínimo de pacotes que contém Datagrama IP de um mesmo endereço IP \\
\hline A04 & Intervalo Médio de tempo entre pacotes \\
\hline A05 & Tamanho da janela em unidade de tempo \\
\hline A06 & Taxa de transmissão \\
\hline A07 & Número de protocolos distintos dentro de uma mesma janela \\
\hline A08 & Número Máximo de pacotes com o mesmo protocolo dentro de uma mesma janela \\
\hline A09 & Número Mínimo de pacotes com o mesmo protocolo dentro de uma mesma janela \\
\hline A10 & Número de 'flag codes' contidos dentro de uma mesma janela \\
\hline A11 & Número Máximo de pacotes com o mesmo 'flag code' contido dentro de uma mesma janela \\
\hline A12 & Número Mínimo de pacotes com o mesmo 'flag code' contido dentro de uma mesma janela \\
\hline A13 & Número de pacotes com campo Window Size $=0$ \\
\hline A14 & Número de pacotes com campo Data Length =0 \\
\hline A15 & Valor médio do campo Window Size \\
\hline A16 & Valor médio do campo Data Length \\
\hline A17 & Número de pacotes 'non-Profinet' na janela \\
\hline A18 & Número de protocolos distintos dentro de um Datagrama IP em uma mesma janela \\
\hline A19 & Número de portas distintas dentro de um pacote TCP em uma mesma janela \\
\hline A20 & Número de portas distintas dentro de um pacote UDP em uma mesma janela \\
\hline
\end{tabular}

Detalhes acerca do funcionamento desse algoritmo já foram expostos na Seção 4.2.1.1. 


\subsection{Pré-processamento dos atributos}

O pré-processamento dos dados é etapa fundamental para reduzir erros inerentes à aquisição de dados. Nesta etapa é realizada uma análise criteriosa sobre os dados coletados buscando minimizar ambiguidades e possíveis erros associados à etapa de aquisição de dados. Na prática, dois procedimentos são realizados: o primeiro refere-se a uma filtragem dos dados capturados eliminando-se os pacotes oriundos da própria estação de captura e o segundo, refere-se à remoção, do Conjunto de Dados resultante, de instâncias duplicadas, de atributos com valores inválidos, e na normalização conforme (GUYON et al., 2002).

As expressões matemáticas a serem utilizadas para a normalização estão apresentadas abaixo, sendo $\overline{A_{k}}$ o valor médio, $\overline{\overline{A_{k}}}$ o desvio padrão e $\widehat{A_{k, l}}$ o valor final normalizado do atributo $A_{k}$.

$$
\begin{aligned}
& \overline{A_{k}}=\frac{\sum A_{k, i}}{N} \\
& \overline{\overline{A_{k}}}=\sqrt{\frac{\sum\left(A_{k, i}-\overline{A_{k}}\right)^{2}}{N}} \\
& \widehat{A_{k, l}}=\frac{A_{k, i}-\overline{A_{k}}}{\overline{\overline{A_{k}}}}
\end{aligned}
$$

Para cada cenário de teste devem ser aplicadas essas expressões para então se obterem os Conjunto de Dados Iniciais (pós etapa de pré-processamento) para serem utilizados pelos algoritmos de Aprendizado de Máquina. 


\subsection{Aprendizado de Máquinas}

Nesta etapa aplica-se os diversos algoritmos/técnicas considerados nesse trabalho para a Seleção de Atributos, Redução da Dimensionalidade e Classificação de Padrões.

A Figura 58 apresenta o diagrama de blocos com as principais funções envolvidas.

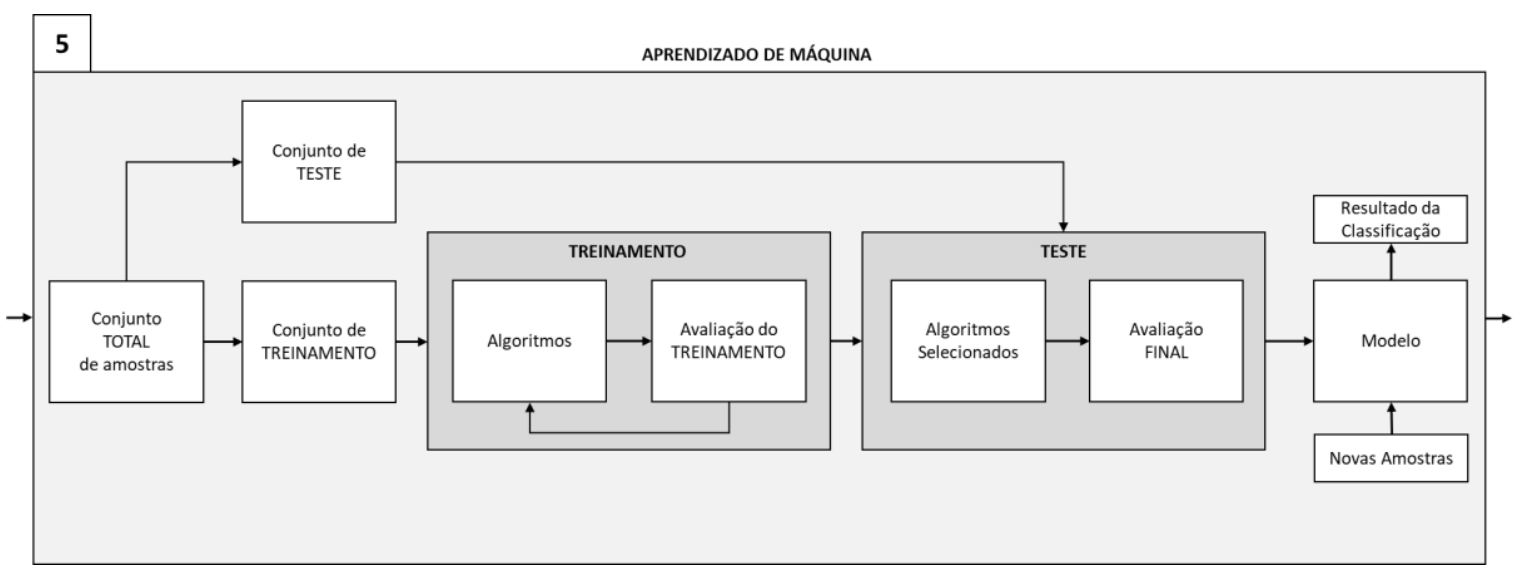

Figura 58: Etapas do Aprendizado de Máquina FONTE: Própria

Para todos os cenários é feita a divisão do Conjunto de Dados resultante da etapa de Pré-Processamento em Conjunto de Treinamento que é utilizado para o treinar o modelo e, em Conjunto de Teste que é utilizado para testar e validar a modelo treinado.

\subsubsection{Separação dos Conjunto de Dados}

A separação do Conjunto de Dados para cada cenário é de $85 \%$ das amostras para o Conjunto de Treinamento e os $15 \%$ restantes para Conjunto de Teste.

A Figura 59 ilustra esse processo que deve ser adotado em todos os cenários.

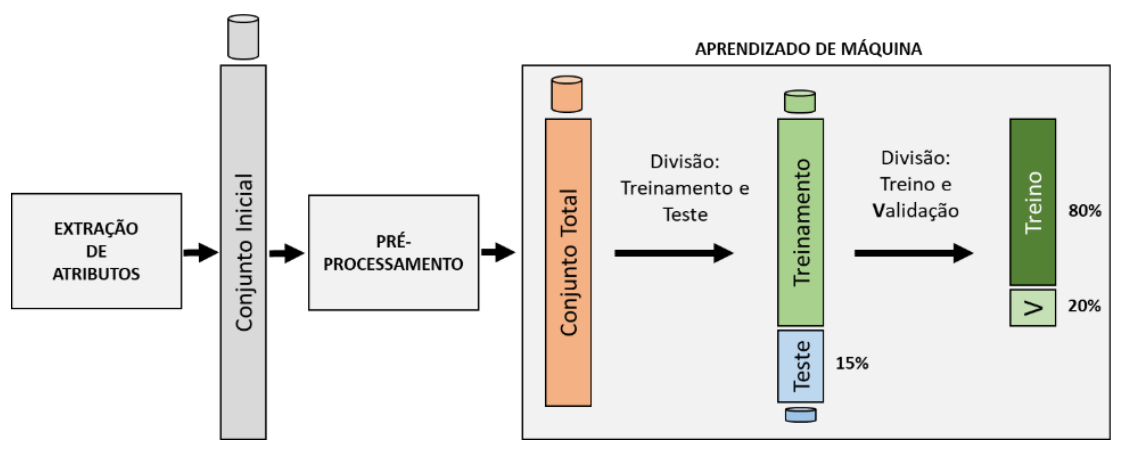

Figura 59: Separação do Conjunto de Dados em Conjunto de Treinamento e Teste FONTE: Própria 
Esse método está descrito na Seção 4.1.

\subsubsection{Treinamento}

Nesse trabalho são consideradas algumas técnicas de Seleção de Atributos e de Classificação de Padrões distintas. Dentre elas, algumas exigem que o Conjunto de Treinamento possua amostras de forma balanceada das duas classes consideradas na classificação (classe NORMAL e classe ANÔMALO).

As técnicas utilizadas são agrupadas e aplicadas em dois tipos de abordagens principais: abordagem com classificadores binários (abordagem clássica) e abordagem por classificadores unários (one-class).

A abordagem binária parte da premissa em que se tem o Conjunto de Dados previamente etiquetado, ou seja, que se tenha amostras da classe NORMAL e ANÔMALO. Enquanto a abordagem unária parte da premissa que se tem, no Conjunto de Dados, apenas amostras de tráfego NORMAL. Detalhes acerca dessa diferenciação serão expostos no transcorrer do texto.

A Figura 60 ilustra as etapas consideradas no treinamento dos classificadores binários avaliados.

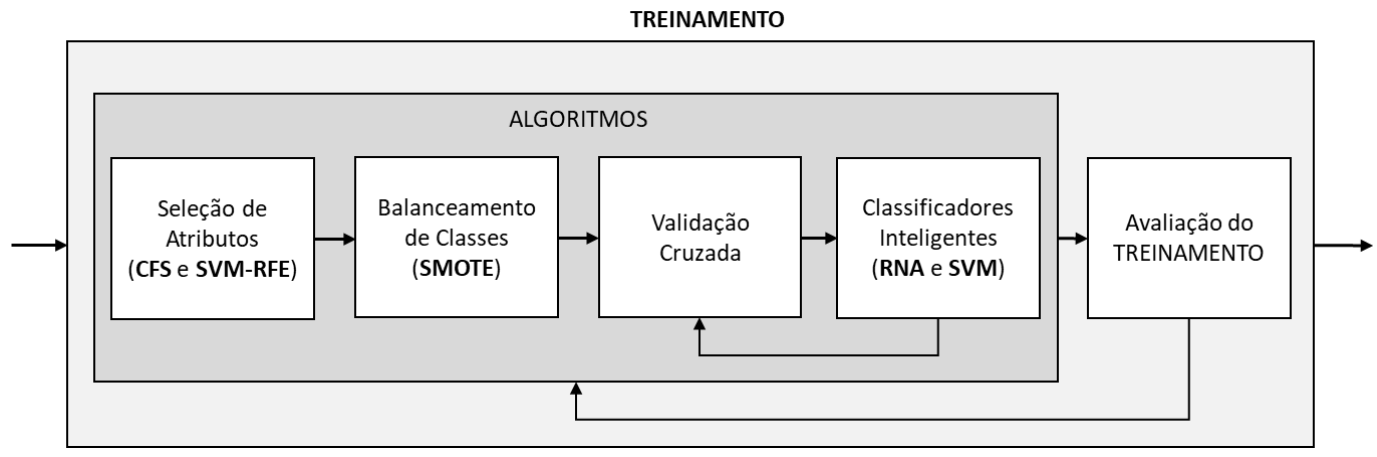

Figura 60: Etapas do treinamento para a abordagem binária FONTE: Própria

A Figura 61 apresenta as etapas envolvidas no treinamento do classificador unário avaliado. 


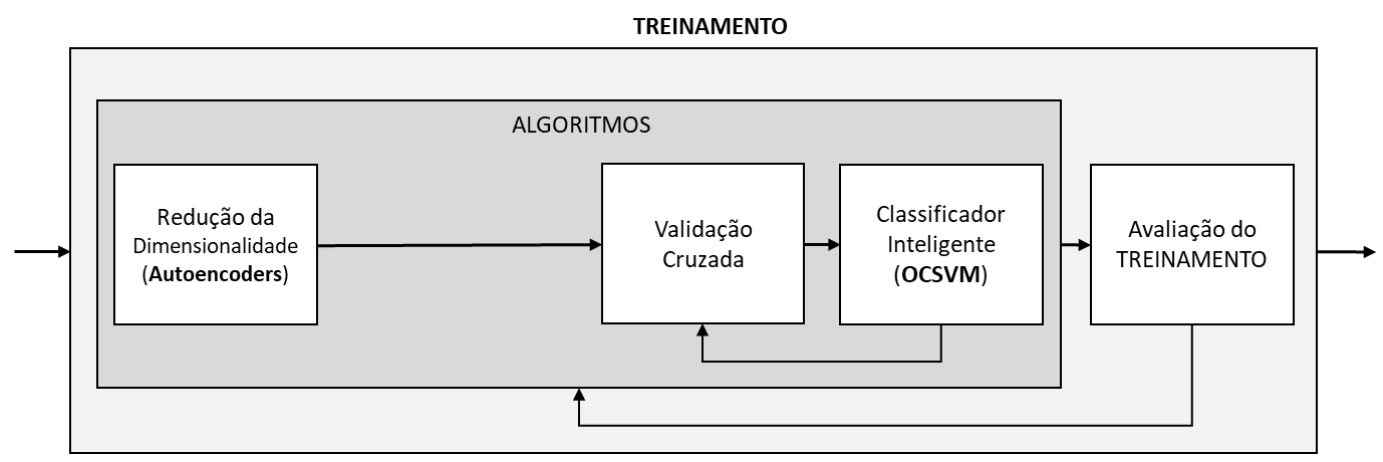

Figura 61: Etapas do treinamento para a abordagem unária FONTE: Própria

\subsubsection{Seleção de Atributos e Redução de Dimensionalidade}

Essa seção aborda os principais aspectos sobre a aplicação nesse trabalho das técnicas utilizadas para a seleção dos atributos mais relevantes do tráfego capturado para a redução da dimensionalidade do problema e retirada de informações redundantes para posterior aplicação com entrada em um sistema de inferência para o reconhecimento de padrões.

Três métodos são investigados: o CFS, SVM RFE (supervisionados) e Rede Autoencoder (não-supervisionado) que já foram descritos na Seção 4.2.2.

\subsubsection{Algoritmos de Treinamento}

A Figura 62 apresenta o algoritmo utilizado para o treinamento e escolha dos melhores classificadores para a abordagem binária.

Os valores dos hiper parâmetros dos classificadores são configurados e, caso o desempenho não seja satisfatório, a metodologia aqui proposta sugere a seleção de um novo conjunto de atributos com uma característica adicional. Este processo é então repetido até que o desempenho requerido do classificador seja alcançado ( $\mathrm{A}_{\text {desejada: }}$ Acurácia Desejada) ou a quantidade máxima de atributos disponíveis seja atingida (limites pré-estabelecidos).

Nos casos em que a Acurácia Desejada não é atingida, mesmo que todos os atributos já tenham sido avaliados, deve-se escolher a quantidade de atributos que apresentou o maior valor de acurácia. 


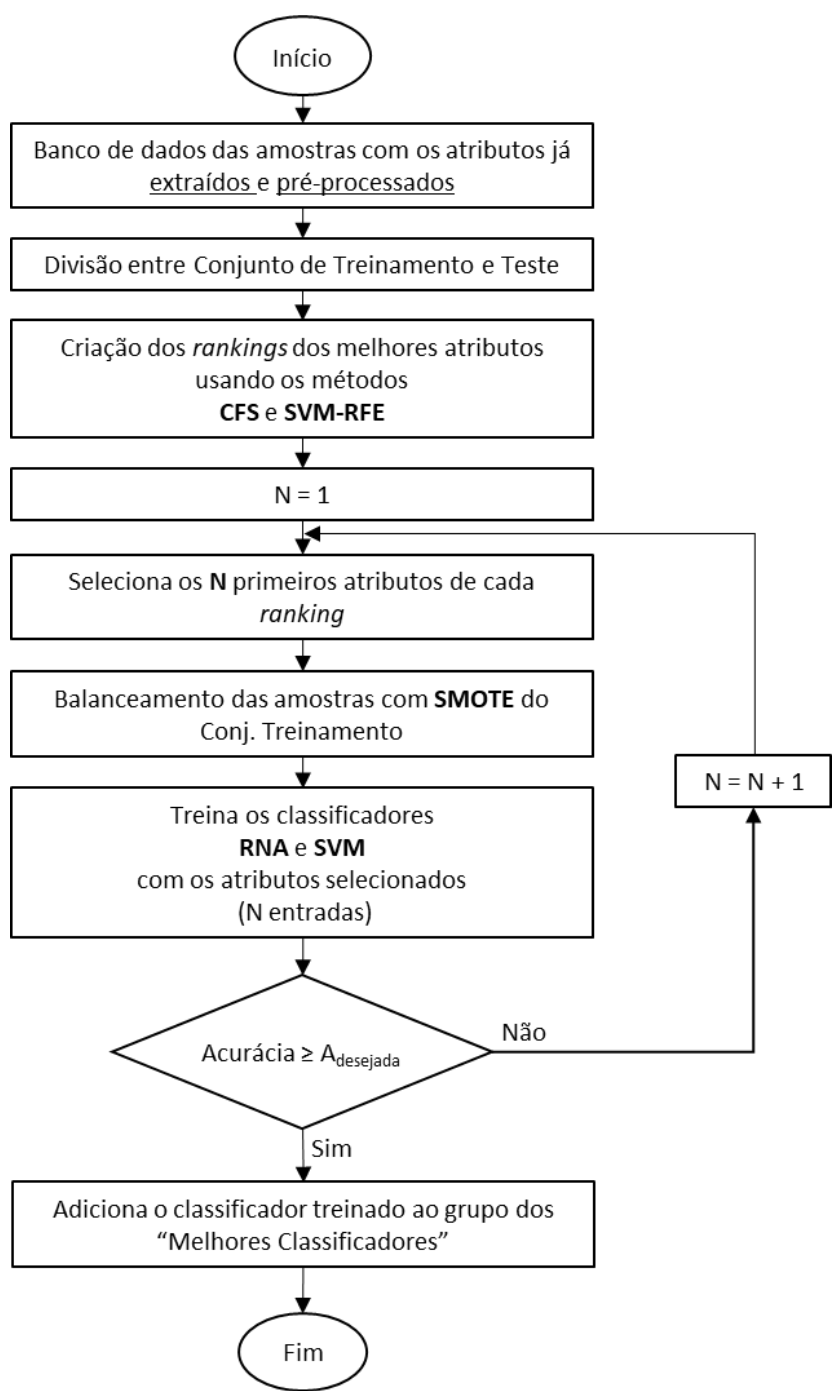

Figura 62: Fluxograma do algoritmo de treinamento dos classificadores binários FONTE: Própria

Esse algoritmo de treinamento é baseado no trabalho (SESTITO, 2018). 
A Figura 63 apresenta o algoritmo utilizado para o treinamento e escolha dos melhores classificadores para a abordagem unária.

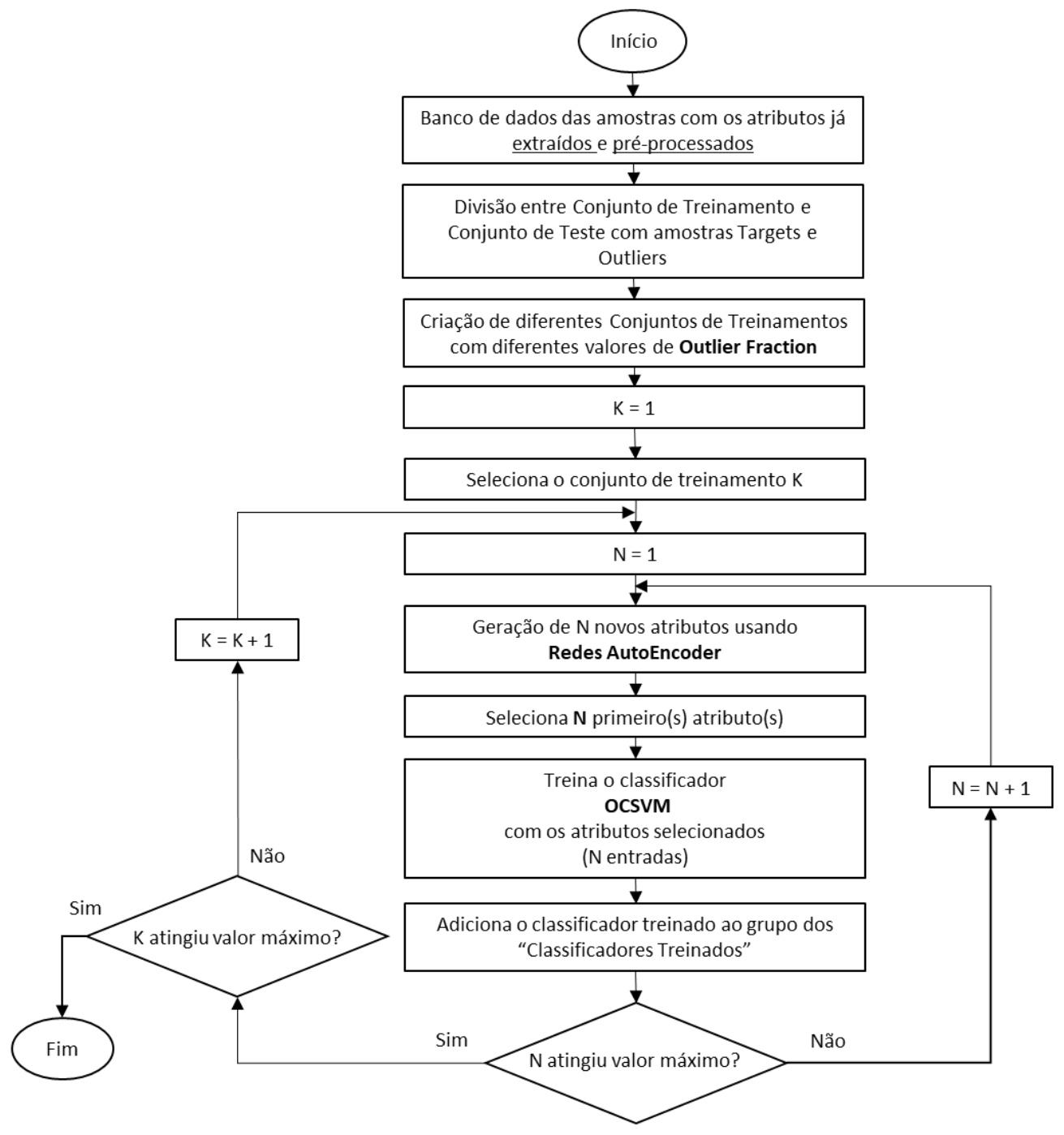

Figura 63: Fluxograma do algoritmo de treinamento dos classificadores unários FONTE: Própria

Esse algoritmo de treinamento é baseado no trabalho (MAGLARAS; JIANG, 2014). 


\subsubsection{Classificadores Inteligentes}

A RNA utilizada nesse trabalho é do tipo Multilayer Perceptron with backpropagation do WEKA com os parâmetros LearningRate igual a 0,3 e parâmetro Momentum igual a 0,2 e o parâmetro Trainingtime igual a 2000 e o parâmetro Validationsetsize igual a 20. Esse algoritmo foi escolhido por ser o padrão adotado pelo software. O treinamento da rede é executado enquanto o erro observado no Conjunto de Validação não diminui ou se o tempo de treinamento ajustado é atingido (número máximo de épocas).

As funções de ativação utilizadas são a Tangente Sigmoidal Hiperbólica para toda a rede. São investigadas configurações de redes neurais com uma e duas camadas escondidas, pois conforme (SILVA; SPATTI; FLAUZINO, 2010) é possível se classificar qualquer problema de reconhecimento de padrões utilizando duas camadas escondidas.

As quantidades de neurônios avaliadas em cada camada são semelhantes as utilizadas no trabalho (TURCATO, 2015) para fins de comparação com trabalhos correlatos.

Todas as RNA avaliadas foram inicializadas e treinadas cinco vezes consecutivas a fim de se evitar a convergência para mínimos locais. Os valores apresentados nas tabelas de resultados representam os valores médios obtidos nesses treinamentos.

Nessa etapa, a quantidade de neurônios em cada camada (N1 e N2) da RNA é obtida. Detalhes desse método já foram apresentados na seção 4.4.1.

A SVM utilizada nesse trabalho é do tipo SMO do WEKA que implementa o algoritmo Sequential Minimal Optimization de John Platt para o treinamento do classificador.

Para a ferramenta SVM são utilizadas margens flexíveis com fator de suavização (hiperparâmetro C) e função kernel do tipo gaussiana (parâmetro KernelType = 'RBFKernel' com hiperparâmetro $\gamma$ ), visto que foi considerado que os conjuntos de classe não são linearmente separáveis.

Nessa etapa, os valores do parâmetro C e $\gamma$ são obtidos. Detalhes desse método já foram apresentados na seção 4.4.2.

A OCSVM utilizada nesse trabalho é a de margens flexíveis com fator de suavização (hiperparâmetro $\mathrm{C}=1$ ) e a função kernel do tipo gaussiana (hiperparâmetro 
$\gamma$ ajustado automaticamente pela toolbox do software Matlab - função fitcsvm) uma vez que foi considerado que os conjuntos não são linearmente separáveis.

O método de teste é o Cross-validation com Folds ajustado para 5. Nessa etapa, os valores do parâmetro $\gamma$ são obtidos. Detalhes desse método já foram apresentados na seção 4.4.2.

\subsubsection{Validação Cruzada}

O método de validação utilizado na etapa de Treinamento é o de Validação Cruzada com 5 partições.

O método de teste é o Cross-validation com Folds ajustado para 5.

Detalhes desse método já foram apresentados na seção 4.5.1.

\subsubsection{Teste}

A etapa de Teste consiste na utilização de amostras não utilizadas na etapa de Treinamento para a análise do desempenho dos algoritmos selecionados ("melhores algoritmos" da etapa de Treinamento).

Nesse trabalho são consideradas as métricas Acurácia, TPR, FPR, Precision, Recall e F-measure para a comparação de desempenho entre os diversos algoritmos avaliados.

Detalhes sobre essas métricas foram apresentados na seção 4.5 .

A Figura 64 apresenta o algoritmo utilizado para o teste e escolha do melhor classificador para a abordagem binária. 


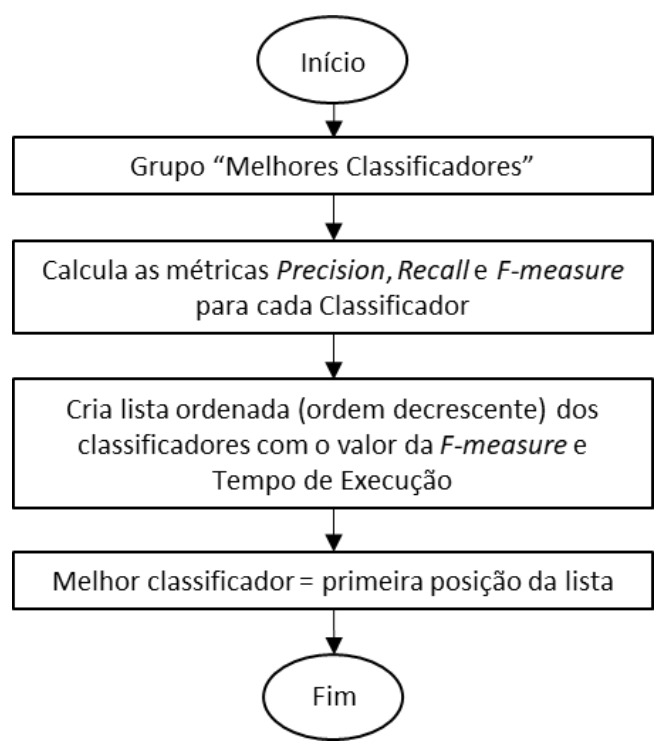

Figura 64: Fluxograma do algoritmo de teste dos classificadores binários FONTE: Própria

A Figura 65 apresenta o algoritmo utilizado para o teste e escolha do melhor classificador para a abordagem unária.

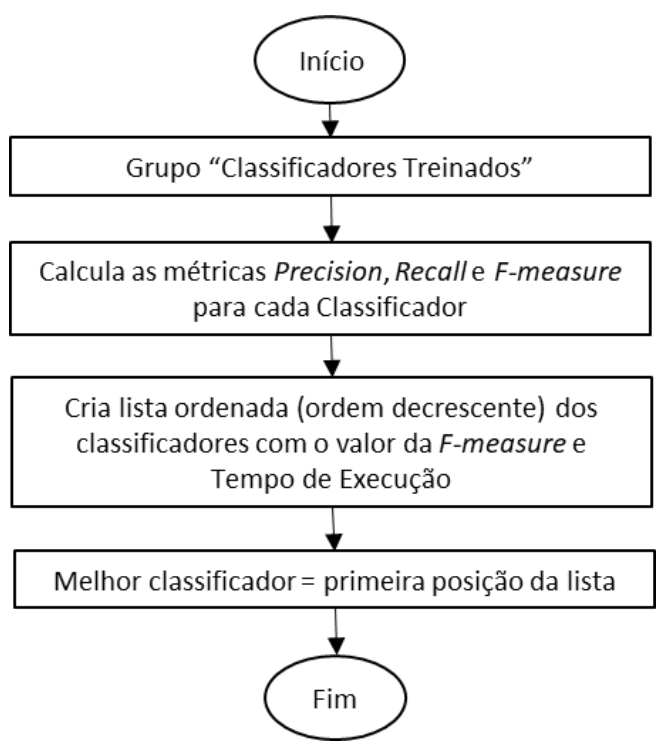

Figura 65: Fluxograma do algoritmo de teste dos classificadores unários FONTE: Própria 


\subsection{Avaliação Final dos Resultados}

A Figura 66 apresenta o diagrama de blocos das principais estruturas do IDS proposto.

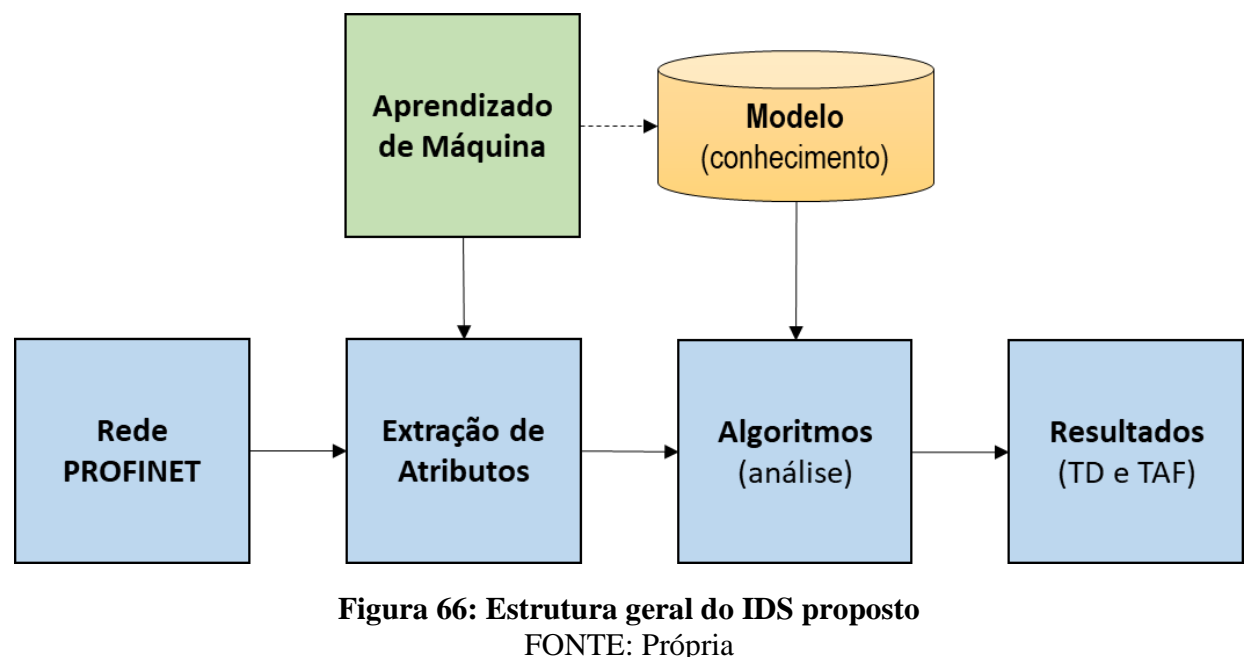

Para a avaliação dos resultados do IDS gerado a partir desta metodologia, alguns indicadores de desempenho são empregados. Para verificar o desempenho do IDS que utiliza o(s) melhor(es) classificador(es) elencado(s) na etapa anterior são calculadas a Taxa de Detecção (TD) e Taxa de Alarmes Falsos (TAF) do IDS derivado para os cenários C1 ao C4.

A TD representa a proporção de amostras ANÔMALAS classificadas corretamente pelo total de amostras ANÔMALAS contidas no Conjunto de Teste.

A TAF representa a proporção de amostras NORMAIS classificadas incorretamente pelo total de amostras NORMAIS contidas no Conjunto de Teste.

Exclusivamente para os classificadores unários, também são avaliadas a TAF para outros seis novos cenários extras (c6 ao c10).

Mais detalhes sobre esses novos cenários estão apresentados na Seção 6.6.3. 


\section{Capítulo 6}

\section{Resultados e Discussões}

Neste capítulo são apresentados os resultados obtidos pela aplicação da metodologia apresentada no Capítulo 5.

Para organização das informações, os resultados estão apresentados em seções organizadas conforme as etapas da metodologia. Como regra geral, espera-se alcançar valores de acurácia elevada e similares a literatura correlata, e ao final, definindo-se um modelo de Sistema de Detecção de Intrusão que empregue os algoritmos mais adequados para a seleção de atributos ou redução de dimensionalidade e para a classificação de padrões. Busca-se, portanto, um IDS que tenha alto valor de Taxa de Detecção e baixo valor da Taxa de Alarmes Falsos.

\subsection{Implementação da rede em bancada experimental}

Após a implementação da rede em bancada experimental: instalação e configuração dos dispositivos na rede PROFINET, instalação e configuração dos softwares para a captura e ataque e, a criação e separação dos quatro cenários de testes,

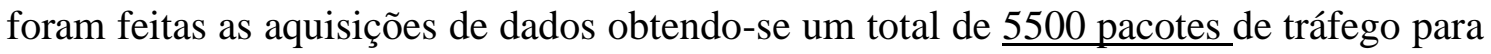
cada cenário.

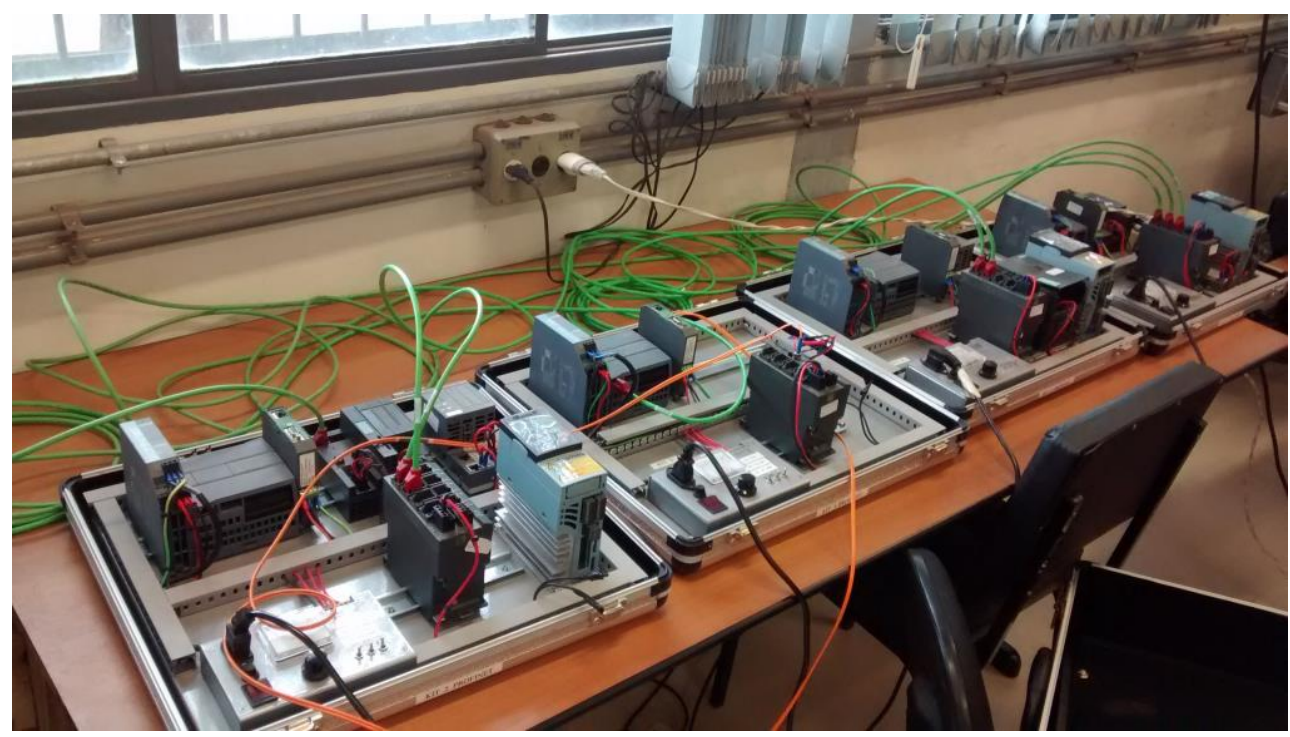

Figura 67: Foto da Banca Experimental FONTE: Própria 
A Tabela 18 apresenta a quantidade de dispositivos em cada cenário.

Tabela 18: Equipamentos PROFINET contidos em cada cenário

Rede PROFINET

\begin{tabular}{cccccc} 
Cenário & \multicolumn{6}{c}{ Rede PROFINET } \\
\cline { 2 - 7 } & IO-Controller & IO-Device & IO-Supervisor & Outros & TOTAL \\
\hline C1 & 1 & 2 & 0 & 2 & 5 \\
\hline C2 & 1 & 2 & 0 & 3 & 6 \\
\hline C3 & 1 & 2 & 1 & 2 & 6 \\
\hline C4 & 1 & 2 & 1 & 3 & 7 \\
\hline
\end{tabular}

A Tabela 19 apresenta algumas características do tráfego de cada cenário.

Tabela 19: Informações do tráfego da rede PROFINET em cada cenário Rede PROFINET

\begin{tabular}{crrrrrrr} 
Cenário & $\begin{array}{r}\text { Taxa } \\
\text { Data Bit } \\
(\text { Kbits/s) }\end{array}$ & $\begin{array}{r}\text { Tamanho } \\
\text { Médio do } \\
\text { Pacote (bytes) }\end{array}$ & $\begin{array}{r}\text { Taxa de } \\
\text { Pacotes } \\
(\mathbf{p a c o t e s} / \mathbf{s})\end{array}$ & $\begin{array}{r}\text { Tráfego } \\
\text { PN-IO } \\
(\%)\end{array}$ & $\begin{array}{r}\text { Tráfego } \\
\text { TCP } \\
(\boldsymbol{\%})\end{array}$ & $\begin{array}{r}\text { Tráfego } \\
\text { UDP } \\
(\%)\end{array}$ & $\begin{array}{r}\text { Tráfego } \\
\text { ARP } \\
(\%)\end{array}$ \\
\hline C1 & 64,0 & 80,4 & 102 & 95,9 & 3,6 & 0,0 & 0,1 \\
\hline C2 & 109 & 90,1 & 155 & 62,9 & 36,8 & 0,0 & 0,1 \\
\hline C3 & 75,9 & 82,7 & 117 & 83,2 & 3,6 & 2,0 & 10,3 \\
\hline C4 & 123 & 90,4 & 174 & 56,0 & 33,2 & 1,2 & 9,3 \\
\hline
\end{tabular}

O Cenário 4 apresentou o tráfego mais heterogêneo por conter maiores proporções de pacotes dos protocolos PN-IO (Profinet Input-Output), TCP (Transmission Control Protocol), UDP (User Datagram Protocol) e ARP (Address Resolution Protocol). Esse tráfego mais heterogêneo se deve ao fato de que, para o Cenário 4, existe uma quantidade maior de equipamentos e com diferentes funções conectados na rede.

Apenas para propósitos ilustrativos, plotou-se os gráficos do tráfego de todos os cenários considerados nesse trabalho. Estes gráficos podem ser visualizados no APÊNDICE A.

\subsection{Aquisição de Dados}

Posteriormente, os dados foram convertidos do formato PCAP (padrão do software Wireshark utilizado para a captura) para o formato MAT (formato este proprietário do software Matlab). Essa conversão foi realizada por meio da ferramenta online pcap2mat tool (http://pcap2mat.hopto.org) desenvolvida em paralelo às atividades desse projeto.

A Figura 68 ilustra o conteúdo da captura do Cenário 4 em formato MAT no software Matlab. 


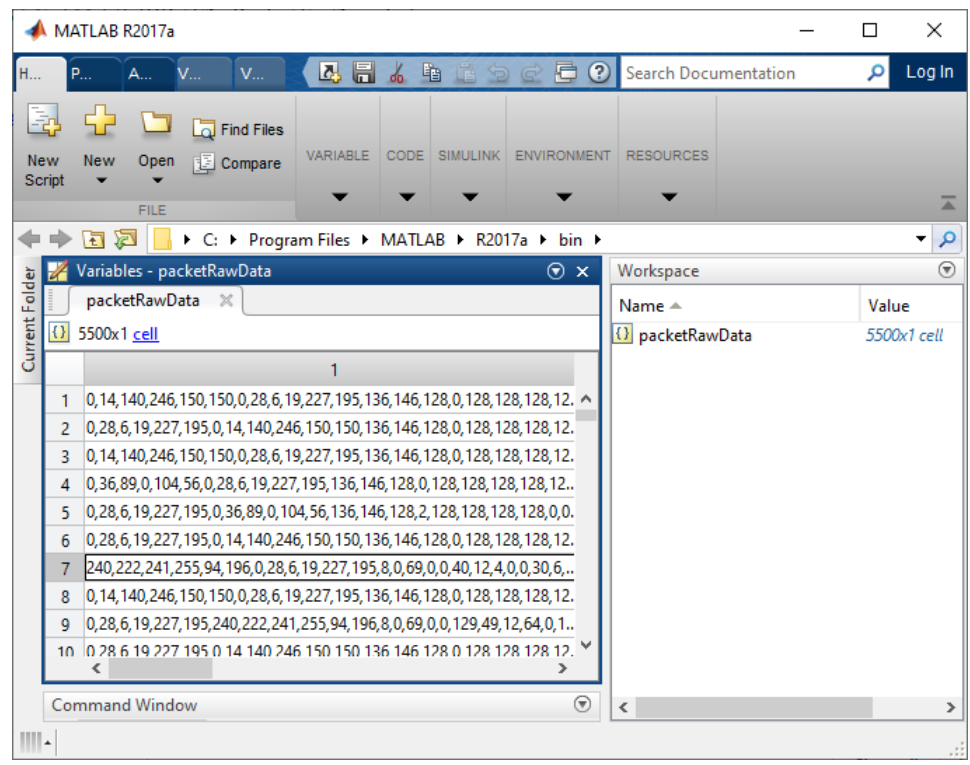

Figura 68: Captura do Cenário 4 no software Matlab FONTE: Própria

A Figura 69 ilustra o conteúdo da captura do Cenário 4 em formato CSV no software Excel.

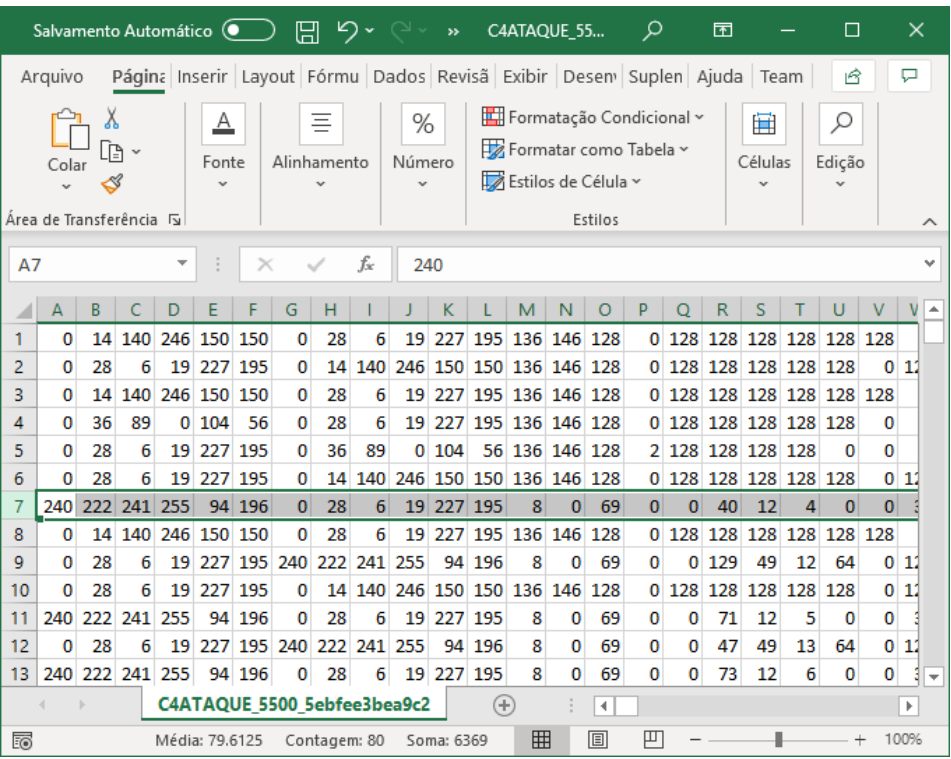

Figura 69: Captura do Cenário 4 no software Excel FONTE: Própria 


\subsection{Extração de Atributos}

Na etapa de Extração de Atributos, conforme já citado no Capítulo 5, foi utilizada a técnica de Janela Deslizante com valor $\underline{50}$ para o tamanho da janela e valor $\underline{1}$ para o passo.

Os valores máximos e mínimo obtidos para cada atributo estão dispostos na Tabela 20.

Tabela 20: Valores Mínimos e Máximos para cada Atributo em cada cenário

Cenário 1

Cenário 2

Cenário 3

Cenário 4

\begin{tabular}{rrrrrrrrr} 
& \multicolumn{2}{c}{ Cenário 1 } & \multicolumn{2}{c}{ Cenário 2 } & \multicolumn{2}{c}{ Cenário 3 } & \multicolumn{2}{c}{ Cenário 4 } \\
\cline { 2 - 10 } & Mín. & \multicolumn{1}{c}{ Máx. } & Mín. & Máx. & Mín. & Máx. & Mín. & Máx. \\
\hline A01 & 0 & 30 & 0 & 34 & 0 & 20 & 0 & 34 \\
\hline A02 & 0 & 30 & 0 & 27 & 0 & 20 & 0 & 27 \\
\hline A03 & 0 & 30 & 0 & 10 & 0 & 20 & 0 & 10 \\
\hline A04 & 0 & 10449 & 0 & 7534 & 0 & 10429 & 0 & 7495 \\
\hline A05 & 0 & 512000 & 0 & 369149 & 0 & 511005 & 0 & 367235 \\
\hline A06 & 0 & 18614 & 0 & 26884 & 0 & 30849 & 0 & 33395 \\
\hline A07 & 0 & 3 & 0 & 4 & 0 & 4 & 0 & 4 \\
\hline A08 & 0 & 50 & 0 & 37 & 0 & 50 & 0 & 37 \\
\hline A09 & 0 & 50 & 0 & 25 & 0 & 50 & 0 & 25 \\
\hline A10 & 0 & 30 & 0 & 46 & 0 & 20 & 0 & 45 \\
\hline A11 & 0 & 30 & 0 & 22 & 0 & 20 & 0 & 23 \\
\hline A12 & 0 & 0 & 0 & 0 & 0 & 0 & 0 & 0 \\
\hline A13 & 0 & 0 & 0 & 0 & 0 & 0 & 0 & 0 \\
\hline A14 & 0 & 30 & 0 & 24 & 0 & 20 & 0 & 25 \\
\hline A15 & 0 & 615 & 0 & 13713 & 0 & 410 & 0 & 13713 \\
\hline A16 & 0 & 0 & 0 & 14 & 0 & 0 & 0 & 14 \\
\hline A17 & 0 & 30 & 0 & 34 & 0 & 37 & 0 & 37 \\
\hline A18 & 0 & 1 & 0 & 1 & 0 & 1 & 0 & 2 \\
\hline A19 & 0 & 22 & 0 & 24 & 0 & 22 & 0 & 24 \\
\hline A20 & 0 & 0 & 0 & 0 & 0 & 2 & 0 & 2 \\
\hline
\end{tabular}

A Tabela 21 mostra a quantidade de instâncias obtidas para o Conjunto de Dados após a extração de atributos para a classe tráfego NORMAL e classe tráfego ANÔMALO.

Tabela 21: Quantidade de instâncias do Conjunto de Dados em cada cenário

\begin{tabular}{cccc} 
Cenário & TOTAL & NORMAL & ANÔMALO \\
\hline C1 & 5450 & 4961 & 489 \\
\hline C2 & 5450 & 4855 & 595 \\
\hline C3 & 5450 & 4767 & 683 \\
\hline C4 & 5450 & 4854 & 596 \\
\hline
\end{tabular}




\subsection{Pré-processamento}

A Tabela 22 mostra as caraterísticas estatísticas de cada atributo extraído para o Cenário 1 após a etapa de pré-processamento que normaliza os valores e elimina as instâncias repetidas.

Tabela 22: Características estatísticas de cada atributo, após pré-processamento, para o Cenário 1.

\begin{tabular}{cccccc} 
At. & Média & DVP & Mín. & Máx. & Soma \\
\hline A01 & 0,00 & 1,00 & $-1,31$ & 1,33 & 0,00 \\
\hline A02 & 0,00 & 1,00 & $-1,31$ & 1,33 & 0,00 \\
\hline A03 & 0,00 & 1,00 & $-1,31$ & 1,33 & 0,00 \\
\hline A04 & 0,00 & 1,00 & $-1,17$ & 1,46 & 0,00 \\
\hline A05 & 0,00 & 1,00 & $-1,17$ & 1,46 & 0,00 \\
\hline A06 & 0,00 & 1,00 & $-1,30$ & 1,65 & 0,00 \\
\hline A07 & 0,00 & 1,00 & $-2,12$ & 1,86 & 0,00 \\
\hline A08 & 0,00 & 1,00 & $-1,06$ & 1,41 & 0,00 \\
\hline A09 & 0,00 & 1,00 & $-1,04$ & 2,28 & 0,00 \\
\hline A10 & 0,00 & 1,00 & $-1,31$ & 1,33 & 0,00 \\
\hline A11 & 0,00 & 1,00 & $-1,31$ & 1,33 & 0,00 \\
\hline A12 & - & - & - & - & - \\
\hline A13 & - & - & - & - & - \\
\hline A14 & 0,00 & 1,00 & $-1,31$ & 1,33 & 0,00 \\
\hline A15 & 0,00 & 1,00 & $-1,31$ & 1,33 & 0,00 \\
\hline A16 & - & - & - & - & - \\
\hline A17 & 0,00 & 1,00 & $-1,38$ & 1,33 & 0,00 \\
\hline A18 & 0,00 & 1,00 & $-1,49$ & 0,67 & 0,00 \\
\hline A19 & 0,00 & 1,00 & $-1,32$ & 1,10 & 0,00 \\
\hline A20 & - & - & - & - & - \\
\hline
\end{tabular}

Os atributos A12, A13, A16 e A20 não apresentaram relevância estatística e, portanto, foram descartados. Assim, o conjunto de dados resultante apresenta um total de 16 atributos.

A Tabela 23 mostra as caraterísticas estatísticas de cada atributo extraído para o Cenário 2 após a etapa de pré-processamento.

Tabela 23: Características estatísticas de cada atributo, após pré-processamento, para o Cenário 2

\begin{tabular}{cccccc} 
At. & Média & DVP & Mín. & Máx. & Soma \\
\hline A01 & 0,00 & 1,00 & $-1,33$ & 3,71 & 0,00 \\
\hline A02 & 0,00 & 1,00 & $-0,76$ & 3,47 & 0,00 \\
\hline A03 & 0,00 & 1,00 & $-5,14$ & 1,61 & 0,00 \\
\hline A04 & 0,00 & 1,00 & $-3,63$ & 1,29 & 0,00 \\
\hline A05 & 0,00 & 1,00 & $-3,64$ & 1,29 & 0,00 \\
\hline A06 & 0,00 & 1,00 & $-0,98$ & 5,05 & 0,00 \\
\hline A07 & 0,00 & 1,00 & $-0,43$ & 4,95 & 0,00 \\
\hline
\end{tabular}




\begin{tabular}{cccccc} 
At. & Média & DVP & Mín. & Máx. & Soma \\
\hline A08 & 0,00 & 1,00 & $-3,55$ & 2,32 & 0,00 \\
\hline A09 & 0,00 & 1,00 & $-2,21$ & 1,57 & 0,00 \\
\hline A10 & 0,00 & 1,00 & $-2,28$ & 3,58 & 0,00 \\
\hline A11 & 0,00 & 1,00 & $-2,92$ & 2,67 & 0,00 \\
\hline A12 & - & - & - & - & - \\
\hline A13 & - & - & - & - & - \\
\hline A14 & 0,00 & 1,00 & $-0,56$ & 3,42 & 0,00 \\
\hline A15 & 0,00 & 1,00 & $-3,72$ & 1,66 & 0,00 \\
\hline A16 & 0,00 & 1,00 & $-3,67$ & 1,33 & 0,00 \\
\hline A17 & 0,00 & 1,00 & $-1,38$ & 3,71 & 0,00 \\
\hline A18 & - & - & - & - & - \\
\hline A19 & 0,00 & 1,00 & $-0,36$ & 3,80 & 0,00 \\
\hline A20 & - & - & - & - & - \\
\hline
\end{tabular}

Os atributos A12, A13, A18 e A20 não apresentaram relevância estatística e, portanto, foram descartados. Assim, o conjunto de dados resultante apresenta um total de 16 atributos.

A Tabela 24 mostra as caraterísticas estatísticas de cada atributo extraído para o Cenário 3 após a etapa de pré-processamento.

Tabela 24: Características estatísticas de cada atributo, após pré-processamento, para o Cenário 3

\begin{tabular}{cccccc} 
At. & Média & DVP & Mín. & Máx. & Soma \\
\hline A01 & 0,00 & 1,00 & $-1,07$ & 1,72 & 0,00 \\
\hline A02 & 0,00 & 1,00 & $-0,93$ & 1,85 & 0,00 \\
\hline A03 & 0,00 & 1,00 & $-0,92$ & 1,85 & 0,00 \\
\hline A04 & 0,00 & 1,00 & $-1,42$ & 1,50 & 0,00 \\
\hline A05 & 0,00 & 1,00 & $-1,42$ & 1,50 & 0,00 \\
\hline A06 & 0,00 & 1,00 & $-1,24$ & 2,31 & 0,00 \\
\hline A07 & 0,00 & 1,00 & $-2,42$ & 2,41 & 0,00 \\
\hline A08 & 0,00 & 1,00 & $-1,31$ & 1,48 & 0,00 \\
\hline A09 & 0,00 & 1,00 & $-0,99$ & 3,72 & 0,00 \\
\hline A10 & 0,00 & 1,00 & $-0,73$ & 1,85 & 0,00 \\
\hline A11 & 0,00 & 1,00 & $-0,73$ & 1,85 & 0,00 \\
\hline A12 & - & - & & - & - \\
\hline A13 & - & - & & - & - \\
\hline A14 & 0,00 & 1,00 & $-0,73$ & 1,85 & 0,00 \\
\hline A15 & 0,00 & 1,00 & $-0,73$ & 1,85 & 0,00 \\
\hline A16 & - & - & & - & - \\
\hline A17 & 0,00 & 1,00 & $-1,44$ & 1,45 & 0,00 \\
\hline A18 & 0,00 & 1,00 & $-1,52$ & 0,66 & 0,00 \\
\hline A19 & 0,00 & 1,00 & $-0,73$ & 2,26 & 0,00 \\
\hline A20 & 0,00 & 1,00 & $-0,68$ & 1,46 & 0,00 \\
\hline & & & & &
\end{tabular}


Os atributos A12, A13 e A16 não apresentaram relevância estatística e, portanto, foram descartados. Assim, o conjunto de dados resultante apresenta um total de $\underline{17}$ atributos.

A Tabela 25 mostra as caraterísticas estatísticas de cada atributo extraído para o Cenário 4 após a etapa de pré-processamento.

Tabela 25: Características estatísticas de cada atributo, após pré-processamento, para o Cenário 4

\begin{tabular}{cccccc} 
At. & Média & DVP & Mín. & Máx. & Soma \\
\hline A01 & 0,00 & 1,00 & $-1,85$ & 3,04 & 0,00 \\
\hline A02 & 0,00 & 1,00 & $-1,16$ & 3,41 & 0,00 \\
\hline A03 & 0,00 & 1,00 & $-2,58$ & 1,50 & 0,00 \\
\hline A04 & 0,00 & 1,00 & $-2,32$ & 1,41 & 0,00 \\
\hline A05 & 0,00 & 1,00 & $-2,33$ & 1,41 & 0,00 \\
\hline A06 & 0,00 & 1,00 & $-1,15$ & 4,02 & 0,00 \\
\hline A07 & 0,00 & 1,00 & $-0,75$ & 3,02 & 0,00 \\
\hline A08 & 0,00 & 1,00 & $-2,34$ & 1,53 & 0,00 \\
\hline A09 & 0,00 & 1,00 & $-1,94$ & 1,68 & 0,00 \\
\hline A10 & 0,00 & 1,00 & $-2,42$ & 2,39 & 0,00 \\
\hline A11 & 0,00 & 1,00 & $-2,43$ & 2,16 & 0,00 \\
\hline A12 & - & - & - & - & - \\
\hline A13 & - & - & - & - & - \\
\hline A14 & 0,00 & 1,00 & $-0,67$ & 3,80 & 0,00 \\
\hline A15 & 0,00 & 1,00 & $-2,34$ & 1,66 & 0,00 \\
\hline A16 & 0,00 & 1,00 & $-2,24$ & 1,44 & 0,00 \\
\hline A17 & 0,00 & 1,00 & $-1,48$ & 2,45 & 0,00 \\
\hline A18 & 0,00 & 1,00 & $-0,33$ & 3,05 & 0,00 \\
\hline A19 & 0,00 & 1,00 & $-0,34$ & 4,00 & 0,00 \\
\hline A20 & 0,00 & 1,00 & $-0,33$ & 3,05 & 0,00 \\
\hline & & & & &
\end{tabular}

Os atributos A12, A13 não apresentam relevância estatística e, portanto, devem ser descartados. Assim, o conjunto de dados resultante apresenta um total de 18 atributos.

A quantidade de amostras contidas em cada conjunto de dados para cada cenário está apresentada na Tabela 26.

Tabela 26: Quantidade de instâncias do Conjunto de Dados em cada cenário após a etapa de préprocessamento

Cenário TOTAL NORMAL ANÔMALO

\begin{tabular}{cccc}
\hline C1 & 597 & 185 & 412 \\
\hline C2 & 4700 & 4110 & 590 \\
\hline C3 & 1590 & 985 & 605 \\
\hline C4 & 4955 & 4386 & 569 \\
\hline
\end{tabular}


Nota-se que, após a etapa de pré-processamento de dados, alguns atributos e grande parte das instâncias, inicialmente contidas no Conjunto de Dados, foram removidos, diminuindo assim a dimensionalidade do problema e, consequentemente o esforço computacional envolvido.

Na Tabela 27 mostra a redução do número de amostras dos conjuntos de dados após a etapa de pré-processamento.

Tabela 27: Quantidade de amostras do Conjunto de Dados antes e depois da etapa de pré-processamento

\begin{tabular}{cccr} 
Cenário & ANTES & DEPOIS & $\begin{array}{r}\text { Taxa de } \\
\text { Redução }\end{array}$ \\
\hline C1 & 5450 & 597 & $89,0 \%$ \\
\hline C2 & 5450 & 4700 & $13,8 \%$ \\
\hline C3 & 5450 & 1590 & $70,8 \%$ \\
\hline C4 & 5450 & 4955 & $9,08 \%$ \\
\hline
\end{tabular}

Apenas para propósitos ilustrativos, plotou-se os gráficos de todos os atributos, após a etapa de pré-processamento, e para todos os cenários considerados nesse trabalho. Estes gráficos podem ser visualizados no APÊNDICE B.

\subsection{Aprendizado de Máquinas}

Conforme apresentado na Tabela 19, o Cenário 4 é o que apresentou o tráfego da rede PROFINET mais heterogêneo em relação aos outros. Assim, a fim de analisar com mais profundidade o comportamento dos algoritmos de classificação frente a esse tráfego mais complexo e, portanto, mais difícil de se diferenciar entre 'tráfego NORMAL' e 'tráfego ANÔMALO', optou-se por apresentar detalhadamente os resultados obtidos para o Cenário 4 e ao final, com a definição das melhores estruturas de classificação (previamente elencadas pela análise do Cenário 4), aplicá-las aos dados extraídos para os Cenários 1,2 e 3.

Isto posto, a

Tabela 28 apresenta as diversas sequências com suas respectivas técnicas avaliadas nesse trabalho para as abordagens binárias e unárias, seguindo os fluxogramas das Figura 60 e Figura 61. 
Tabela 28: Sequências e técnicas avaliadas nesse trabalho

\begin{tabular}{|c|c|c|c|c|}
\hline Seq. & Abordagem & Seleção & Balanceamento & Classificador \\
\hline 1.1 & \multirow{6}{*}{ Binária } & \multirow{2}{*}{ CFS } & \multirow{6}{*}{ SMOTE } & RNA \\
\hline 1.2 & & & & SVM \\
\hline 1.3 & & & & RNA \\
\hline 1.4 & & SVM RFE & & SVM \\
\hline 1.5 & & \multirow{2}{*}{-} & & RNA \\
\hline 1.6 & & & & SVM \\
\hline 1.7 & \multirow{2}{*}{ Unária } & Autoencoder & \multirow{2}{*}{ Não } & \multirow{2}{*}{ OCSVM } \\
\hline 1.8 & & - & & \\
\hline
\end{tabular}

Para abordagem binária foram analisadas as técnicas CFS e SVM RFE para a Seleção de Atributos, o uso da técnica SMOTE para o Balanceamento das Classes e os algoritmos RNA e SVM para a classificação das amostras. Para a comparação dos efeitos da utilização das técnicas de seleção de atributos, também foram avaliadas os desempenhos dos classificadores RNA e SVM utilizando-se todos os atributos na entrada.

A Figura 70 apresenta de forma ilustrativa a abordagem binária aplicada nesse trabalho.

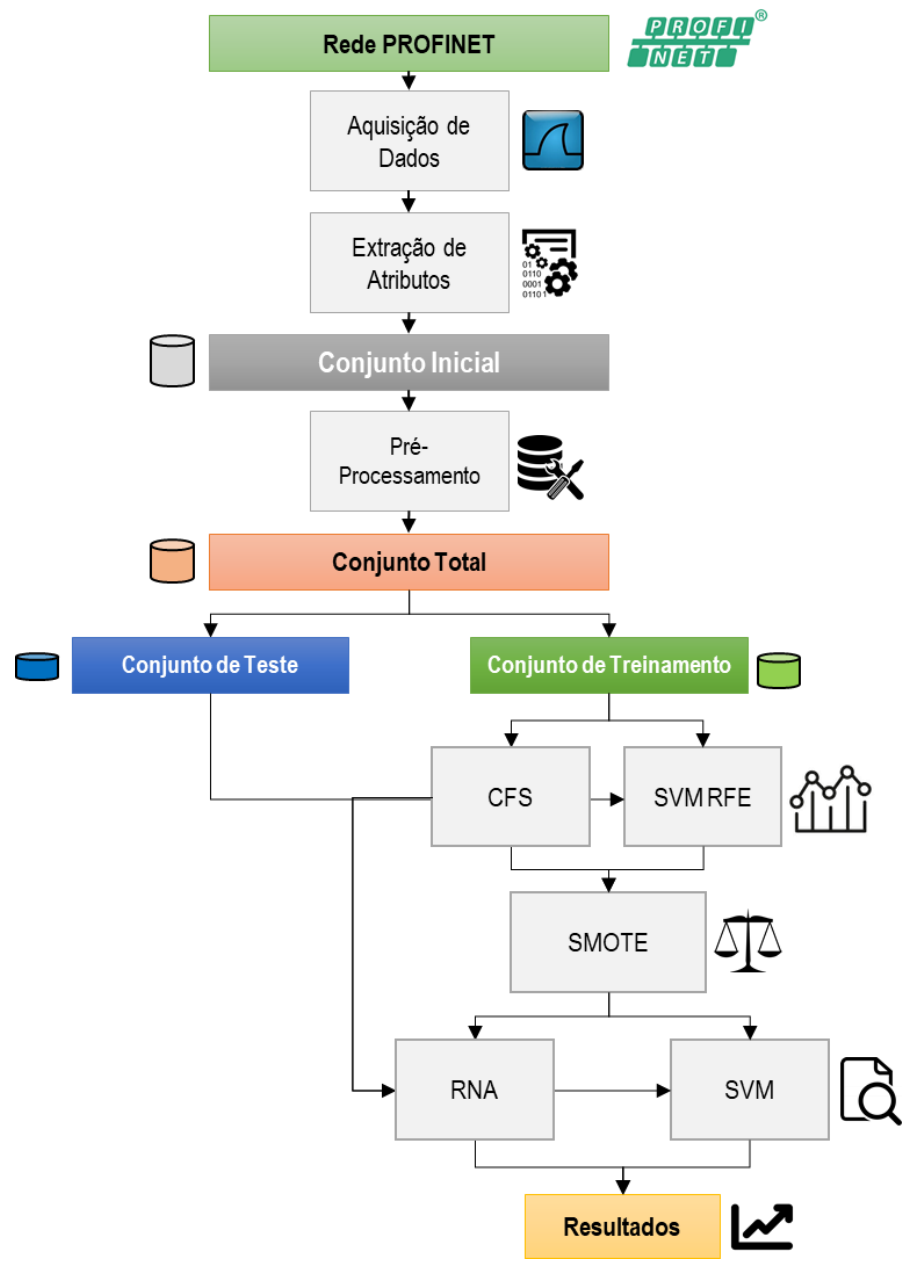


Para a abordagem unária foram analisadas a técnica Autoencoder para a Redução da Dimensionalidade dos dados e o algoritmo OCSVM para a classificação das amostras. Para a comparação do efeito da redução da dimensionalidade, também foi avaliado o desempenho do classificador OCSVM utilizando-se todos os atributos na entrada.

A Figura 71 apresenta de forma ilustrativa a abordagem unária aplicada nesse trabalho.

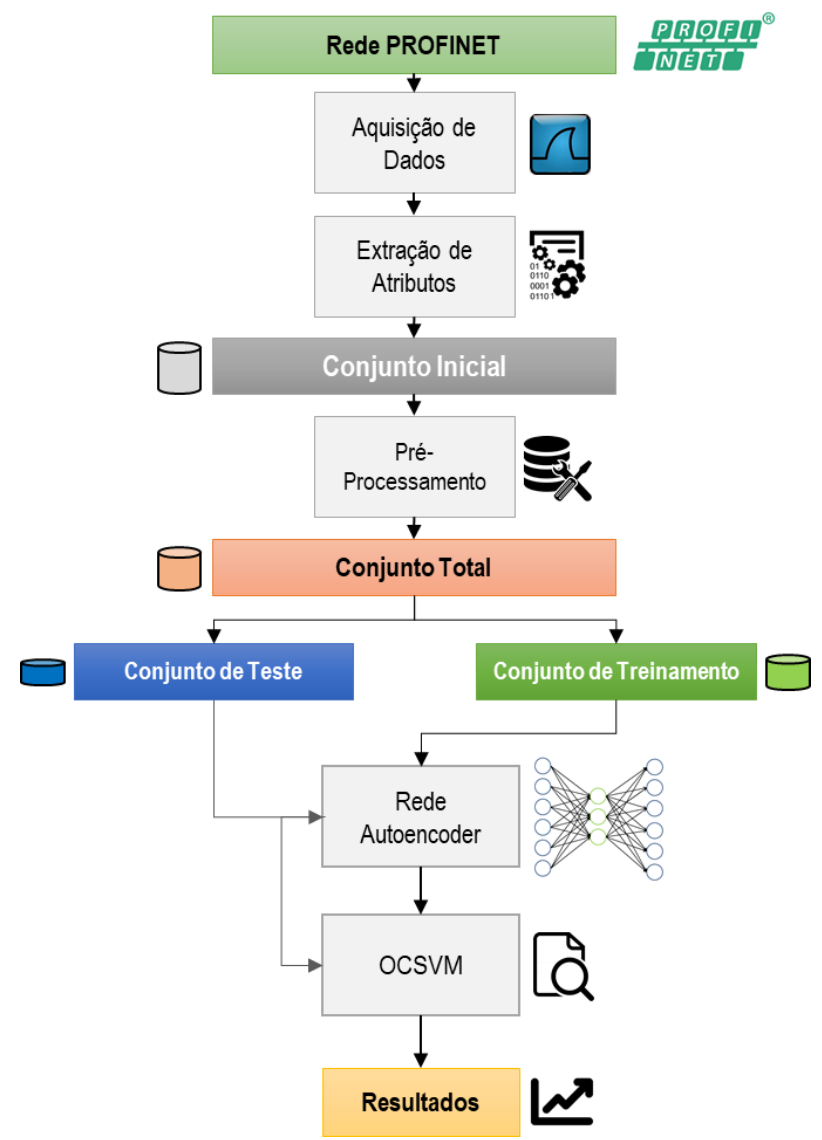

Figura 71: Etapas avaliadas na abordagem unária FONTE: Própria

\subsubsection{Separação dos Conjuntos de Dados}

A Tabela 29 apresenta o Conjunto Total de Amostras assim como sua divisão entre Conjunto de Treinamento e Conjunto de Teste antes e depois de ser aplicada a técnica SMOTE para o balanceamento das classes.

Para a composição do Conjunto de Teste, foi feita uma amostragem no Conjunto Total utilizando o filtro Resample do WEKA ajustando o parâmetro SampleSi zePercent 
em 15\% e BiasToUniformclass igual a zero (esse ajuste é particularmente essencial para que o Conjunto de Teste extraído tenha a mesma proporção de classes do Conjunto de Treinamento). Ao final, o Conjunto de Treinamento fica composto por $85 \%$ das amostras do Conjunto Total.

Para os casos em que são aplicadas RNA, 20\% das amostras do Conjunto de Treinamento são reservadas para comporem o Conjunto de Validação.

Complementarmente, para efetuar o balanceamento das classes, aplica-se o filtro SMOTE do WEKA com os parâmetros NearestNeighbors igual a 5 e Percentage igual a $668,87 \%$ apenas para as amostras do Conjunto de Treinamento.

Tabela 29: Conjunto Total de amostras dividido entre Conjunto de Treinamento e Conjunto de Teste para o Cenário 4

\begin{tabular}{cccccccccc}
\multirow{2}{*}{ SMOTE } & \multicolumn{3}{c}{ TOTAL } & \multicolumn{3}{c}{ TREINAMENTO $\mathbf{- 8 5 \%}$} & \multicolumn{3}{c}{ TESTE - 15\% } \\
\cline { 2 - 10 } & Total & Normal & Anômalo & Total & Normal & Anômalo & Total & Normal & Anômalo \\
\hline ANTES & 4955 & 4386 & 569 & 4214 & 3729 & 485 & \multirow{2}{*}{741} & 657 & 84 \\
\hline APÓS & - & - & - & 7458 & 3729 & 3729 & & & \\
\hline
\end{tabular}

A técnica SMOTE é aplicada ao Conjunto de Treinamento fazendo com que a quantidade inicial de amostras da classe ANÔMALO, que incialmente era de 485, seja aumentada sinteticamente para 3729, valor este exatamente igual à quantidade de amostras da classe NORMAL contidas no Conjunto de Treinamento. Assim, a relação entre amostras da classe ANÔMALO e da classe NORMAL que, inicialmente era de $11,5 \%$ | $88,5 \%$, passa a ser $50 \%$ | 50\% que representa um balanceamento perfeito das classes.

As próximas seções apresentam os resultados das sequências e técnicas descritas na Tabela 28, inicialmente para a abordagem binária e depois para a abordagem unária.

\subsubsection{Aprendizado de Máquinas - Abordagem Binária}

\subsubsection{Seleção de Atributos - CFS}

Para a seleção de atributos utilizando a técnica CFS, foi utilizada a função CorrelationAttributeEval + Ranker do WEKA no Conjunto Total de amostras e o resultado está apresentado na Tabela 30.

Detalhes sobre essa técnica podem ser obtidos na Seção 4.2.2.1. 
Tabela 30: Ranqueamento dos atributos com o método CFS para o Cenário 4.

\begin{tabular}{cc} 
Posição & Atributo \\
\hline $1^{\mathrm{a}}$ & $\mathrm{A} 14$ \\
\hline $2^{\mathrm{a}}$ & $\mathrm{A} 02$ \\
\hline $3^{\mathrm{a}}$ & $\mathrm{A} 19$ \\
\hline $4^{\mathrm{a}}$ & $\mathrm{A} 01$ \\
\hline $5^{\mathrm{a}}$ & $\mathrm{A} 17$ \\
\hline $6^{\mathrm{a}}$ & $\mathrm{A} 05$ \\
\hline $7^{\mathrm{a}}$ & $\mathrm{A} 04$ \\
\hline $8^{\mathrm{a}}$ & $\mathrm{A} 06$ \\
\hline $9^{\mathrm{a}}$ & $\mathrm{A} 10$ \\
\hline $10^{\mathrm{a}}$ & $\mathrm{A} 16$ \\
\hline $11^{\mathrm{a}}$ & A03 \\
\hline $12^{\mathrm{a}}$ & A15 \\
\hline $13^{\mathrm{a}}$ & A09 \\
\hline $14^{\mathrm{a}}$ & $\mathrm{A} 11$ \\
\hline $15^{\mathrm{a}}$ & A07 \\
\hline $16^{\mathrm{a}}$ & A20 \\
\hline $17^{\mathrm{a}}$ & A18 \\
\hline $18^{\mathrm{a}}$ & A08 \\
\hline
\end{tabular}

O atributo A14, que aparece na primeira posição da tabela, é o que apresentou maior correlação com a classe quando utilizada a técnica CFS e, portanto, deve ser o primeiro a ser escolhido para a análise utilizando-se o algoritmo da Figura 60.

A descrição de todos os atributos utilizados já foi apresentada na Tabela 17. 


\subsection{Algoritmo de Classificação - RNA}

Considerando o ranqueamento da Tabela 30 e aplicando o algoritmo da Figura 62 com Adesejada $\geq \mathbf{9 9 , 9 \%}$ para as amostras do Conjunto de Treinamento, obteve-se os seguintes resultados:

\section{$\mathrm{N}=1$ : atributo selecionado: $\mathbf{A 1 4}$}

Para uma camada escondida e número variado de neurônios.

\begin{tabular}{rrrrrrrr}
\multicolumn{7}{c}{ Tabela 31: Treinamentos realizados com vários valores de N } & \\
N & $\begin{array}{r}\text { Tempo } \\
(\mathbf{s})\end{array}$ & $\begin{array}{r}\text { Acurácia } \\
(\boldsymbol{\%})\end{array}$ & TPR & FPR & Precision & Recall & $\begin{array}{r}\text { RMSE } \\
\left(\mathbf{1 0}^{-3}\right)\end{array}$ \\
\hline 5 & 4,97 & 99,40 & 0,994 & 0,006 & 0,994 & 0,994 & 77 \\
\hline 10 & 8,70 & 99,40 & 0,994 & 0,006 & 0,994 & 0,994 & 77 \\
\hline 15 & 11,84 & 99,40 & 0,994 & 0,006 & 0,994 & 0,994 & 77 \\
\hline 20 & 15,68 & 99,40 & 0,994 & 0,006 & 0,994 & 0,994 & 77 \\
\hline
\end{tabular}

Obteve-se os seguintes resultados para duas camadas escondidas e número variado de neurônios para cada camada (N1 e N2).

Tabela 32: Treinamentos realizados com vários valores de N1 e N2 com todos os atributos

\begin{tabular}{crrrrrrrr}
$\mathbf{N 1}$ & $\mathbf{N 2}$ & $\begin{array}{r}\text { Tempo } \\
(\mathbf{s})\end{array}$ & $\begin{array}{r}\text { Acurácia } \\
(\boldsymbol{\%})\end{array}$ & $\mathbf{T P R}$ & $\mathbf{F P R}$ & Precision & Recall & $\begin{array}{r}\text { RMSE } \\
\left(\mathbf{1 0}^{-3}\right)\end{array}$ \\
\hline 5 & 10 & 15,14 & 99,40 & 0,994 & 0,006 & 0,994 & 0,994 & 77 \\
\hline 5 & 15 & 20,81 & 99,40 & 0,994 & 0,006 & 0,994 & 0,994 & 77 \\
\hline 10 & 10 & 23,28 & 99,40 & 0,994 & 0,006 & 0,994 & 0,994 & 77 \\
\hline 10 & 15 & 33,01 & 99,40 & 0,994 & 0,006 & 0,994 & 0,994 & 77 \\
\hline 15 & 10 & 32,85 & 99,40 & 0,994 & 0,006 & 0,994 & 0,994 & 77 \\
\hline 15 & 15 & 42,93 & 99,40 & 0,994 & 0,006 & 0,994 & 0,994 & 77 \\
\hline 20 & 10 & 42,32 & 99,40 & 0,994 & 0,006 & 0,994 & 0,994 & 77 \\
\hline 20 & 15 & 50,66 & 99,40 & 0,994 & 0,006 & 0,994 & 0,994 & 77 \\
\hline
\end{tabular}

$\mathrm{N}=2$ : atributos selecionados: $\underline{\mathrm{A14}}, \underline{\mathrm{A02}}$

Obteve-se os seguintes resultados para uma camada escondida e número variado de neurônios na camada.

Tabela 33: Treinamentos realizados com vários valores de $\mathbf{N}$

\begin{tabular}{rrrrrrrr}
$\mathbf{N}$ & $\begin{array}{r}\text { Tempo } \\
(\mathbf{s})\end{array}$ & $\begin{array}{r}\text { Acurácia } \\
(\boldsymbol{\%})\end{array}$ & $\mathbf{T P R}$ & $\mathbf{F P R}$ & Precision & Recall & RMSE \\
\hline 5 & 3,44 & 99,64 & 0,996 & 0,004 & 0,996 & 0,996 & 59 \\
\hline 10 & 6,55 & 99,64 & 0,996 & 0,004 & 0,996 & 0,996 & 59 \\
\hline 15 & 9,22 & 99,64 & 0,996 & 0,004 & 0,996 & 0,996 & 59 \\
\hline 20 & 12,38 & 99,4 & 0,996 & 0,004 & 0,996 & 0,996 & 59 \\
\hline
\end{tabular}


Obteve-se os seguintes resultados para duas camadas escondidas e número variado de neurônios para cada camada (N1 e N2).

Tabela 34: Treinamentos realizados com vários valores de N1 e N2 com todos os atributos

\begin{tabular}{crrrrrrrr} 
N1 & $\mathbf{N 2}$ & $\begin{array}{r}\text { Tempo } \\
(\mathbf{s})\end{array}$ & $\begin{array}{r}\text { Acurácia } \\
(\mathbf{\%})\end{array}$ & $\mathbf{T P R}$ & $\mathbf{F P R}$ & Precision & Recall & $\begin{array}{r}\text { RMSE } \\
\left(\mathbf{1 0}^{-3}\right)\end{array}$ \\
\hline 5 & 10 & 6,85 & 99,64 & 0,996 & 0,004 & 0,996 & 0,996 & 59 \\
\hline 5 & 15 & 5,21 & 99,63 & 0,996 & 0,004 & 0,996 & 0,996 & 60 \\
\hline 10 & 10 & 4,98 & 99,63 & 0,996 & 0,004 & 0,996 & 0,996 & 60 \\
\hline 10 & 15 & 7,35 & 99,63 & 0,996 & 0,004 & 0,996 & 0,996 & 60 \\
\hline 15 & 10 & 6,20 & 99,61 & 0,996 & 0,004 & 0,996 & 0,996 & 60 \\
\hline 15 & 15 & 8,10 & 99,61 & 0,996 & 0,004 & 0,996 & 0,996 & 60 \\
\hline 20 & 10 & 8,62 & 99,63 & 0,996 & 0,004 & 0,996 & 0,996 & 60 \\
\hline 20 & 15 & 9,62 & 99,61 & 0,996 & 0,004 & 0,996 & 0,996 & 60 \\
\hline
\end{tabular}

$\mathrm{N}=3$ : atributos selecionados: $\underline{\mathrm{A14}}, \underline{\mathrm{A02}}, \underline{\mathrm{A19}}$

Obteve-se os seguintes resultados para uma camada escondida e número variado de neurônios na camada.

Tabela 35: Treinamentos realizados com vários valores de $\mathbf{N}$

\begin{tabular}{rrrrrrrr}
$\mathbf{N}$ & $\begin{array}{r}\text { Tempo } \\
(\mathbf{s})\end{array}$ & $\begin{array}{r}\text { Acurácia } \\
(\boldsymbol{\%})\end{array}$ & TPR & FPR & Precision & Recall & $\begin{array}{r}\text { RMSE } \\
\left(\mathbf{1 0}^{-3}\right)\end{array}$ \\
\hline 5 & 6,58 & 100 & 1 & 1 & 1 & 1 & 1,6 \\
\hline 10 & 11,09 & 100 & 1 & 1 & 1 & 1 & 1,5 \\
\hline 15 & 15,40 & 100 & 1 & 1 & 1 & 1 & 1,4 \\
\hline 20 & 21,82 & 100 & 1 & 1 & 1 & 1 & 1,5 \\
\hline
\end{tabular}

Obteve-se os seguintes resultados para duas camadas escondidas e número variado de neurônios para cada camada (N1 e N2).

Tabela 36: Treinamentos realizados com vários valores de N1 e N2 com todos os atributos

\begin{tabular}{rrrrrrrrr} 
N1 & $\mathbf{N 2}$ & $\begin{array}{r}\text { Tempo } \\
(\mathbf{s})\end{array}$ & $\begin{array}{r}\text { Acurácia } \\
(\mathbf{\%})\end{array}$ & $\mathbf{T P R}$ & $\mathbf{F P R}$ & Precision & Recall & $\begin{array}{r}\text { RMSE } \\
\left(\mathbf{1 0}^{-3}\right)\end{array}$ \\
\hline 5 & 10 & 17,32 & 100 & 1 & 1 & 1 & 1 & 1,0 \\
\hline 5 & 15 & 21,28 & 100 & 1 & 1 & 1 & 1 & 0,9 \\
\hline 10 & 10 & 25,93 & 100 & 1 & 1 & 1 & 1 & 1,1 \\
\hline 10 & 15 & 32,31 & 100 & 1 & 1 & 1 & 1 & 1,1 \\
\hline 15 & 10 & 35,43 & 100 & 1 & 1 & 1 & 1 & 1,1 \\
\hline 15 & 15 & 44,06 & 100 & 1 & 1 & 1 & 1 & 1,1 \\
\hline 20 & 10 & 43,55 & 100 & 1 & 1 & 1 & 1 & 1,0 \\
\hline 20 & 15 & 58,87 & 100 & 1 & 1 & 1 & 1 & 1,0 \\
\hline
\end{tabular}


6.5.2.1.2 Algoritmo de Classificação - SVM

Considerando o ranqueamento da Tabela 30 e aplicando o algoritmo da Figura 62 com Adesejada $\geq \mathbf{9 9 , 9 \%}$ para as amostras do Conjunto de Treinamento, obteve-se os seguintes resultados:

$\rightarrow \mathrm{N}=1$ : atributo selecionado: $\underline{\underline{A 14}}$

Análise foi feita para um número variado de valores para $\mathrm{C}$ e $\gamma$.

Tabela 37: Treinamentos realizados com vários valores de $\mathrm{C}$ e $\gamma$

\begin{tabular}{|c|c|c|c|c|c|c|c|c|}
\hline C & $\gamma$ & $\begin{array}{r}\text { Tempo } \\
(\mathbf{s})\end{array}$ & $\begin{array}{r}\text { Acurácia } \\
(\%)\end{array}$ & TPR & FPR & Precision & Recall & $\begin{array}{r}\text { RMSE } \\
\left(10^{-3}\right)\end{array}$ \\
\hline \multirow{4}{*}{0,1} & 0,001 & 874,6 & 91,33 & 0,913 & 0,087 & 0,913 & 0,913 & 295 \\
\hline & 0,01 & 69,1 & 94,86 & 0,949 & 0,051 & 0,953 & 0,953 & 227 \\
\hline & 0,1 & 28,8 & 97,93 & 0,979 & 0,021 & 0,980 & 0,979 & 144 \\
\hline & 1 & 2,8 & 98,20 & 0,982 & 0,018 & 0,983 & 0,982 & 134 \\
\hline \multirow{4}{*}{1} & 0,001 & 71,6 & 94,86 & 0,949 & 0,051 & 0,953 & 0,949 & 227 \\
\hline & 0,01 & 32,2 & 97,93 & 0,979 & 0,021 & 0,980 & 0,979 & 144 \\
\hline & 0,1 & 4,23 & 98,31 & 0,983 & 0,017 & 0,984 & 0,983 & 130 \\
\hline & 1 & 1,84 & 98,95 & 0,990 & 0,010 & 0,990 & 0,990 & 102 \\
\hline \multirow{4}{*}{10} & 0,001 & 24,5 & 97,93 & 0,979 & 0,021 & 0,980 & 0,979 & 144 \\
\hline & 0,01 & 4,07 & 98,31 & 0,983 & 0,017 & 0,984 & 0,983 & 130 \\
\hline & 0,1 & 1,82 & 98,97 & 0,990 & 0,010 & 0,990 & 0,990 & 101 \\
\hline & 1 & 1,05 & 99,18 & 0,992 & 0,008 & 0,992 & 0,992 & 90 \\
\hline \multirow{4}{*}{100} & 0,001 & 4,29 & 98,31 & 0,983 & 0,017 & 0,984 & 0,983 & 130 \\
\hline & 0,01 & 1,85 & 98,97 & 0,990 & 0,010 & 0,990 & 0,990 & 101 \\
\hline & 0,1 & 1,47 & 99,40 & 0,994 & 0,006 & 0,994 & 0,994 & 78 \\
\hline & 1 & 1,11 & 99,40 & 0,994 & 0,006 & 0,994 & 0,994 & 78 \\
\hline
\end{tabular}

\section{$\mathrm{N}=2$ : atributos selecionados: $\underline{\mathrm{A14}}, \underline{\mathrm{A02}}$}

Obteve-se os seguintes resultados para um número variado de valores para $\mathrm{C}$ e $\gamma$.

Tabela 38: Treinamentos realizados com vários valores de $\mathrm{C}$ e $\gamma$

\begin{tabular}{|c|c|c|c|c|c|c|c|c|}
\hline $\mathbf{C}$ & $\gamma$ & $\begin{array}{r}\text { Tempo } \\
(\mathbf{s}) \\
\end{array}$ & $\begin{array}{r}\text { Acurácia } \\
(\%) \\
\end{array}$ & TPR & FPR & Precision & Recall & $\begin{array}{r}\text { RMSE } \\
\left(10^{-3}\right) \\
\end{array}$ \\
\hline \multirow{4}{*}{0,1} & 0,001 & 896,7 & 91,13 & 0,911 & 0,089 & 0,925 & 0,911 & 298 \\
\hline & 0,01 & 59,9 & 93,79 & 0,938 & 0,062 & 0,945 & 0,938 & 249 \\
\hline & 0,1 & 17,0 & 97,87 & 0,979 & 0,021 & 0,980 & 0,979 & 146 \\
\hline & 1 & 5,00 & 98,14 & 0,981 & 0,019 & 0,982 & 0,981 & 137 \\
\hline \multirow{4}{*}{1} & 0,001 & 87,5 & 93,79 & 0,938 & 0,062 & 0,945 & 0,938 & 249 \\
\hline & 0,01 & 30,8 & 97,86 & 0,979 & 0,021 & 0,979 & 0,979 & 146 \\
\hline & 0,1 & 8,40 & 98,29 & 0,983 & 0,017 & 0,983 & 0,983 & 131 \\
\hline & 1 & 2,60 & 98,90 & 0,989 & 0,011 & 0,989 & 0,989 & 105 \\
\hline \multirow{3}{*}{10} & 0,001 & 23,9 & 97,86 & 0,979 & 0,021 & 0,979 & 0,979 & 146 \\
\hline & 0,01 & 7,30 & 98,29 & 0,983 & 0,017 & 0,983 & 0,983 & 131 \\
\hline & 0,1 & 2,30 & 98,94 & 0,989 & 0,011 & 0,990 & 0,989 & 103 \\
\hline
\end{tabular}




\begin{tabular}{rrrrrrrrr}
$\mathbf{C}$ & $\boldsymbol{\gamma}$ & $\begin{array}{r}\text { Tempo } \\
(\mathbf{s})\end{array}$ & $\begin{array}{r}\text { Acurácia } \\
(\boldsymbol{\%})\end{array}$ & TPR & FPR & Precision & Recall & $\begin{array}{r}\text { RMSE } \\
\left(\mathbf{1 0}^{-3}\right)\end{array}$ \\
\hline & 1,30 & 99,42 & 0,994 & 0,006 & 0,994 & 0,994 & 76 \\
\hline & 0,001 & 7,55 & 98,29 & 0,983 & 0,017 & 0,983 & 0,983 & 131 \\
\cline { 2 - 9 } 100 & 2,34 & 98,94 & 0,989 & 0,011 & 0,990 & 0,989 & 103 \\
\cline { 2 - 9 } & 0,01 & 2,61 & 99,33 & 0,993 & 0,007 & 0,993 & 0,993 & 82 \\
\hline 0,1 & 2,04 & 99,57 & 0,996 & 0,004 & 0,996 & 0,996 & 66 \\
\hline 1 & & & & & & &
\end{tabular}

$\mathrm{N}=3$ : atributos selecionados: $\underline{\mathrm{A14}}, \underline{\mathrm{A} 02}, \underline{\mathrm{A19}}$

Obteve-se os seguintes resultados para um número variado de valores para $\mathrm{C}$ e $\gamma$.

Tabela 39: Treinamentos realizados com vários valores de $\mathrm{C}$ e $\gamma$

\begin{tabular}{|c|c|c|c|c|c|c|c|c|}
\hline C & $\gamma$ & $\begin{array}{r}\text { Tempo } \\
(\mathbf{s})\end{array}$ & $\begin{array}{r}\text { Acurácia } \\
(\%)\end{array}$ & TPR & FPR & Precision & Recall & $\begin{array}{r}\text { RMSE } \\
\left(10^{-3}\right) \\
\end{array}$ \\
\hline \multirow{4}{*}{0,1} & 0,001 & 1040 & 94,51 & 0,945 & 0,055 & 0,951 & 0,945 & 234 \\
\hline & 0,01 & 165 & 97,38 & 0,974 & 0,026 & 0,975 & 0,974 & 162 \\
\hline & 0,1 & 25 & 98,43 & 0,984 & 0,016 & 0,985 & 0,984 & 125 \\
\hline & 1 & 3,6 & 99,22 & 0,992 & 0,008 & 0,992 & 0,992 & 88 \\
\hline \multirow{4}{*}{1} & 0,001 & 188 & 97,33 & 0,973 & 0,027 & 0,975 & 0,973 & 163 \\
\hline & 0,01 & 21 & 98,40 & 0,984 & 0,016 & 0,985 & 0,984 & 126 \\
\hline & 0,1 & 2,8 & 99,27 & 0,993 & 0,007 & 0,993 & 0,993 & 85 \\
\hline & 1 & 1,6 & 100 & 1 & 0 & 1 & 1 & 0 \\
\hline \multirow{4}{*}{10} & 0,001 & 19 & 98,40 & 0,984 & 0,016 & 0,985 & 0,984 & 126 \\
\hline & 0,01 & 2,9 & 99,27 & 0,993 & 0,007 & 0,993 & 0,993 & 85 \\
\hline & 0,1 & 1,6 & 100 & 1 & 0 & 1 & 1 & 0 \\
\hline & 1 & 2,3 & 99,22 & 0,992 & 0,008 & 0,992 & 0,992 & 77 \\
\hline \multirow{4}{*}{100} & 0,001 & 2,9 & 99,27 & 0,993 & 0,007 & 0,993 & 0,993 & 85 \\
\hline & 0,01 & 1,3 & 100 & 1 & 0 & 1 & 1 & 0 \\
\hline & 0,1 & 1,8 & 99,22 & 0,992 & 0,008 & 0,992 & 0,992 & 83 \\
\hline & 1 & 1,1 & 98,40 & 0,984 & 0,016 & 0,985 & 0,984 & 107 \\
\hline
\end{tabular}




\subsubsection{Seleção de Atributos - SVM-RFE}

Para a seleção de atributos utilizando a técnica SVM RFE, foi utilizada a função SVMAttributeEval + Ranker do WEKA e o resultado está apresentado na Tabela 40.

Tabela 40: Ranqueamento dos atributos com o método SVM RFE para o Cenário 4

\begin{tabular}{cc} 
Posição & Atributo \\
\hline $1^{\mathrm{a}}$ & A14 \\
\hline $2^{\mathrm{a}}$ & $\mathrm{A} 11$ \\
\hline $3^{\mathrm{a}}$ & $\mathrm{A} 10$ \\
\hline $4^{\mathrm{a}}$ & $\mathrm{A} 02$ \\
\hline $5^{\mathrm{a}}$ & $\mathrm{A} 01$ \\
\hline $6^{\mathrm{a}}$ & $\mathrm{A} 03$ \\
\hline $7^{\mathrm{a}}$ & $\mathrm{A} 19$ \\
\hline $8^{\mathrm{a}}$ & $\mathrm{A} 20$ \\
\hline $9^{\mathrm{a}}$ & $\mathrm{A} 18$ \\
\hline $10^{\mathrm{a}}$ & $\mathrm{A} 06$ \\
\hline $11^{\mathrm{a}}$ & A08 \\
\hline $12^{\mathrm{a}}$ & A07 \\
\hline $13^{\mathrm{a}}$ & A09 \\
\hline $14^{\mathrm{a}}$ & A16 \\
\hline $15^{\mathrm{a}}$ & A15 \\
\hline $16^{\mathrm{a}}$ & A04 \\
\hline $17^{\mathrm{a}}$ & A05 \\
\hline $18^{\mathrm{a}}$ & A17 \\
\hline
\end{tabular}

O atributo A14, que aparece na primeira posição da tabela, é o que apresentou melhor desempenho quando utilizada a técnica SVM RFE e, portanto, deve ser o primeiro a ser escolhido para a análise utilizando-se o algoritmo da Figura 60.

A descrição de todos os atributos utilizados já foi apresentada na Tabela 17. 
6.5.2.2.1 Algoritmo de Classificação - RNA

Considerando o ranqueamento da Tabela 30 e aplicando o algoritmo da Figura 62 com Adesejada $\geq \mathbf{9 9 , 9 \%}$ para as amostras do Conjunto de Treinamento, obteve-se os seguintes resultados:

\section{$\mathrm{N}=1$ : atributo selecionado: $\mathbf{A 1 4}$}

Obteve-se os seguintes resultados para uma camada escondida e número variado de neurônios na camada.

Tabela 41: Treinamentos realizados com vários valores de $\mathbf{N}$

\begin{tabular}{cccccccc}
$\mathbf{N}$ & $\begin{array}{c}\text { Tempo } \\
(\mathbf{s})\end{array}$ & $\begin{array}{c}\text { Acurácia } \\
(\boldsymbol{\%})\end{array}$ & TPR & FPR & Precision & Recall & $\begin{array}{c}\text { RMSE } \\
(\mathbf{1 0}\end{array}$ \\
\hline 5 & 5,1 & 99,4 & 0,994 & 0,006 & 0,994 & 0,994 & 77 \\
\hline 10 & 9,0 & 99,4 & 0,994 & 0,006 & 0,994 & 0,994 & 77 \\
\hline 15 & 12,3 & 99,4 & 0,994 & 0,006 & 0,994 & 0,994 & 77 \\
\hline 20 & 16,8 & 99,4 & 0,994 & 0,006 & 0,994 & 0,994 & 77 \\
\hline
\end{tabular}

Obteve-se os seguintes resultados para duas camadas escondidas e número variado de neurônios para cada camada (N1 e N2).

\begin{tabular}{ccccccccc} 
& \multicolumn{7}{c}{ Tabela 42: Treinamentos realizados com vários valores de N1 e N2 } & \\
$\mathbf{N 1}$ & $\mathbf{N 2}$ & $\begin{array}{c}\text { Tempo } \\
(\mathbf{s})\end{array}$ & $\begin{array}{c}\text { Acurácia } \\
(\boldsymbol{\%})\end{array}$ & $\mathbf{T P R}$ & $\mathbf{F P R}$ & Precision & Recall & RMSE \\
\hline $\mathbf{( 1 0}$ & & & & & \\
\hline 5 & 10 & 16,7 & 99,4 & 0,994 & 0,006 & 0,994 & 0,994 & 77 \\
\hline 5 & 15 & 21,8 & 99,4 & 0,994 & 0,006 & 0,994 & 0,994 & 77 \\
\hline 10 & 10 & 26,7 & 99,4 & 0,994 & 0,006 & 0,994 & 0,994 & 77 \\
\hline 10 & 15 & 38,2 & 99,4 & 0,994 & 0,006 & 0,994 & 0,994 & 77 \\
\hline 15 & 10 & 36,9 & 99,4 & 0,994 & 0,006 & 0,994 & 0,994 & 77 \\
\hline 15 & 15 & 46,7 & 99,4 & 0,994 & 0,006 & 0,994 & 0,994 & 77 \\
\hline 20 & 10 & 41,6 & 99,4 & 0,994 & 0,006 & 0,994 & 0,994 & 77 \\
\hline 20 & 15 & 56,8 & 99,4 & 0,994 & 0,006 & 0,994 & 0,994 & 77 \\
\hline
\end{tabular}

\section{N=2: atributos selecionados: $\underline{\mathrm{A} 14}, \underline{\mathrm{A} 11}$}

Obteve-se os seguintes resultados para uma camada escondida e número variado de neurônios na camada.

Tabela 43: Treinamentos realizados com vários valores de $\mathbf{N}$

\begin{tabular}{crrrrrrrr}
$\mathbf{N}$ & $\begin{array}{r}\text { Tempo } \\
(\mathbf{s})\end{array}$ & $\begin{array}{rrrrr}\text { Acurácia } \\
(\mathbf{\%})\end{array}$ & TPR & FPR & Precision & Recall & $\begin{array}{r}\text { RMSE } \\
\left(\mathbf{1 0}^{-3}\right)\end{array}$ \\
\hline 5 & 7,0 & 99,7 & 0,997 & 0,003 & 0,998 & 0,997 & 48 \\
\hline 10 & 12,0 & 99,7 & 0,997 & 0,003 & 0,998 & 0,997 & 49 \\
\hline 15 & 16,3 & 99,7 & 0,997 & 0,003 & 0,998 & 0,997 & 49 \\
\hline 20 & 20,2 & 99,7 & 0,997 & 0,003 & 0,998 & 0,997 & 49 \\
\hline
\end{tabular}


Obteve-se os seguintes resultados para duas camadas escondidas e número variado de neurônios para cada camada (N1 e N2).

Tabela 44: Treinamentos realizados com vários valores de N1 e N2

\begin{tabular}{crrrrrrrr}
$\mathbf{N 1}$ & $\mathbf{N 2}$ & $\begin{array}{r}\text { Tempo } \\
(\mathbf{s})\end{array}$ & $\begin{array}{r}\text { Acurácia } \\
(\boldsymbol{\%})\end{array}$ & $\mathbf{T P R}$ & FPR & Precision & Recall & $\begin{array}{r}\text { RMSE } \\
(\mathbf{1 0})\end{array}$ \\
\hline 5 & 10 & 17,0 & 99,7 & 0,997 & 0,003 & 0,998 & 0,997 & 49 \\
\hline 5 & 15 & 23,9 & 99,7 & 0,997 & 0,003 & 0,997 & 0,997 & 49 \\
\hline 10 & 10 & 26,6 & 99,7 & 0,997 & 0,003 & 0,998 & 0,997 & 48 \\
\hline 10 & 15 & 39,2 & 99,7 & 0,997 & 0,003 & 0,998 & 0,997 & 49 \\
\hline 15 & 10 & 34,9 & 99,7 & 0,997 & 0,003 & 0,998 & 0,997 & 49 \\
\hline 15 & 15 & 45,0 & 99,7 & 0,997 & 0,003 & 0,997 & 0,997 & 53 \\
\hline 20 & 10 & 46,0 & 99,7 & 0,997 & 0,003 & 0,998 & 0,997 & 49 \\
\hline 20 & 15 & 60,2 & 99,7 & 0,997 & 0,003 & 0,998 & 0,997 & 49 \\
\hline
\end{tabular}

$\mathrm{N}=3$ : atributos selecionados: $\underline{\mathrm{A14}}, \underline{\mathrm{A11}}, \underline{\mathrm{A10}}$

Obteve-se os seguintes resultados para uma camada escondida e número variado de neurônios na camada.

Tabela 45: Treinamentos realizados com vários valores de $\mathbf{N}$

\begin{tabular}{rrrrrrrr}
$\mathbf{N}$ & $\begin{array}{r}\text { Tempo } \\
(\mathbf{s})\end{array}$ & $\begin{array}{r}\text { Acurácia } \\
(\boldsymbol{\%})\end{array}$ & $\mathbf{T P R}$ & FPR & Precision & Recall & $\begin{array}{r}\text { RMSE } \\
\left(\mathbf{1 0}^{-\mathbf{3}}\right)\end{array}$ \\
\hline 5 & 7,7 & 100 & 1 & 0 & 1 & 1 & 2,2 \\
\hline 10 & 11,7 & 100 & 1 & 0 & 1 & 1 & 2,2 \\
\hline 15 & 17,4 & 100 & 1 & 0 & 1 & 1 & 2,1 \\
\hline 20 & 20,9 & 100 & 1 & 0 & 1 & 1 & 2,5 \\
\hline
\end{tabular}

Obteve-se os seguintes resultados para duas camadas escondidas e número variado de neurônios para cada camada (N1 e N2).

Tabela 46: Treinamentos realizados com vários valores de N1 e N2

\begin{tabular}{|c|c|c|c|c|c|c|c|c|}
\hline N1 & N2 & $\begin{array}{r}\text { Tempo } \\
(\mathrm{s})\end{array}$ & $\begin{array}{r}\text { Acurácia } \\
(\%)\end{array}$ & TPR & FPR & Precision & Recall & $\begin{array}{r}\text { RMSE } \\
\left(10^{-3}\right) \\
\end{array}$ \\
\hline 5 & 10 & 18,2 & 100 & 1 & 0 & 1 & 1 & 1,1 \\
\hline 5 & 15 & 29,6 & 100 & 1 & 0 & 1 & 1 & 1,3 \\
\hline 10 & 10 & 29,8 & 100 & 1 & 0 & 1 & 1 & 1,2 \\
\hline 10 & 15 & 35,5 & 100 & 1 & 0 & 1 & 1 & 1,2 \\
\hline 15 & 10 & 36,3 & 100 & 1 & 0 & 1 & 1 & 1,1 \\
\hline 15 & 15 & 48,0 & 100 & 1 & 0 & 1 & 1 & 1,3 \\
\hline 20 & 10 & 48,7 & 100 & 1 & 0 & 1 & 1 & 1,2 \\
\hline 20 & 15 & 65,6 & 100 & 1 & 0 & 1 & 1 & 1,4 \\
\hline
\end{tabular}


6.5.2.2.2 Algoritmo de Classificação - SVM

Considerando o ranqueamento da Tabela 30 e aplicando o algoritmo da Figura 62 com Adesejada $\geq \mathbf{9 9 , 9 \%}$ para as amostras do Conjunto de Treinamento, obteve-se os seguintes resultados:

$\rightarrow \mathrm{N}=1:$ atributo selecionado: $\underline{\mathrm{A} 14}$

Obteve-se os seguintes resultados para um número variado de valores para $\mathrm{C}$ e $\gamma$.

Tabela 47: Treinamentos realizados com vários valores de $\mathrm{C}$ e $\gamma$

\begin{tabular}{|c|c|c|c|c|c|c|c|c|}
\hline C & $\gamma$ & $\begin{array}{r}\text { Tempo } \\
(\mathbf{s})\end{array}$ & $\begin{array}{r}\text { Acurácia } \\
(\%)\end{array}$ & TPR & FPR & Precision & Recall & $\begin{array}{r}\text { RMSE } \\
\left(10^{-3}\right)\end{array}$ \\
\hline \multirow{4}{*}{0,1} & 0,001 & 847,5 & 91,3 & 0,913 & 0,087 & 0,926 & 0,913 & 295 \\
\hline & 0,01 & 68,9 & 94,9 & 0,949 & 0,051 & 0,953 & 0,949 & 227 \\
\hline & 0,1 & 22,8 & 97,9 & 0,979 & 0,021 & 0,980 & 0,979 & 144 \\
\hline & 1 & 5,1 & 98,3 & 0,983 & 0,017 & 0,984 & 0,983 & 130 \\
\hline \multirow{4}{*}{1} & 0,001 & 63,9 & 94,9 & 0,949 & 0,051 & 0,953 & 0,949 & 227 \\
\hline & 0,01 & 27,6 & 97,9 & 0,979 & 0,021 & 0,980 & 0,979 & 144 \\
\hline & 0,1 & 4,2 & 98,3 & 0,983 & 0,017 & 0,984 & 0,983 & 130 \\
\hline & 1 & 2,1 & 99,0 & 0,990 & 0,010 & 0,990 & 0,990 & 101 \\
\hline \multirow{4}{*}{10} & 0,001 & 23,1 & 97,9 & 0,979 & 0,021 & 0,980 & 0,979 & 144 \\
\hline & 0,01 & 4,1 & 98,3 & 0,983 & 0,017 & 0,984 & 0,983 & 130 \\
\hline & 0,1 & 1,7 & 99,0 & 0,990 & 0,010 & 0,990 & 0,990 & 101 \\
\hline & 1 & 1,7 & 99,4 & 0,994 & 0,006 & 0,994 & 0,994 & 78 \\
\hline \multirow{4}{*}{100} & 0,001 & 4,8 & 98,3 & 0,983 & 0,017 & 0,984 & 0,983 & 130 \\
\hline & 0,01 & 1,9 & 99,0 & 0,990 & 0,010 & 0,990 & 0,990 & 101 \\
\hline & 0,1 & 1,5 & 99,4 & 0,994 & 0,006 & 0,994 & 0,994 & 78 \\
\hline & 1 & 2,4 & 99,4 & 0,994 & 0,006 & 0,994 & 0,994 & 78 \\
\hline
\end{tabular}

\section{$\mathrm{N}=2$ : atributos selecionados: $\underline{\mathrm{A14}}, \underline{\mathrm{A11}}$}

Obteve-se os seguintes resultados para um número variado de valores para $\mathrm{C}$ e $\gamma$.

Tabela 48: Treinamentos realizados com vários valores de $\mathrm{C}$ e $\gamma$

\begin{tabular}{|c|c|c|c|c|c|c|c|c|}
\hline $\mathbf{C}$ & $\gamma$ & $\begin{array}{r}\text { Tempo } \\
(\mathbf{s})\end{array}$ & $\begin{array}{r}\text { Acurácia } \\
(\%)\end{array}$ & TPR & FPR & Precision & Recall & $\begin{array}{r}\text { RMSE } \\
\left(10^{-3}\right) \\
\end{array}$ \\
\hline \multirow{4}{*}{0,1} & 0,001 & 913 & 90,5 & 0,904 & 0,096 & 0,920 & 0,904 & 309 \\
\hline & 0,01 & 129 & 95,0 & 0,950 & 0,050 & 0,955 & 0,950 & 223 \\
\hline & 0,1 & 14 & 98,3 & 0,983 & 0,017 & 0,983 & 0,983 & 132 \\
\hline & 1 & 7,6 & 98,7 & 0,987 & 0,013 & 0,987 & 0,987 & 114 \\
\hline \multirow{4}{*}{1} & 0,001 & 138,7 & 95,0 & 0,950 & 0,050 & 0,955 & 0,950 & 223 \\
\hline & 0,01 & 22,7 & 98,2 & 0,982 & 0,018 & 0,983 & 0,982 & 133 \\
\hline & 0,1 & 5,8 & 98,6 & 0,986 & 0,014 & 0,987 & 0,986 & 117 \\
\hline & 1 & 3,2 & 99,3 & 0,993 & 0,007 & 0,993 & 0,993 & 84 \\
\hline \multirow{3}{*}{10} & 0,001 & 32,9 & 98,2 & 0,982 & 0,018 & 0,983 & 0,982 & 133 \\
\hline & 0,01 & 5,8 & 98,6 & 0,987 & 0,014 & 0,987 & 0,986 & 117 \\
\hline & 0,1 & 3,5 & 99,3 & 0,993 & 0,007 & 0,993 & 0,993 & 83 \\
\hline
\end{tabular}




\begin{tabular}{rrrrrrrrr}
$\mathbf{C}$ & $\boldsymbol{\gamma}$ & $\begin{array}{r}\text { Tempo } \\
(\mathbf{s})\end{array}$ & $\begin{array}{r}\text { Acurácia } \\
(\mathbf{\%})\end{array}$ & TPR & FPR & Precision & Recall & $\begin{array}{r}\text { RMSE } \\
\left(\mathbf{1 0}^{-3}\right)\end{array}$ \\
\hline 1 & 1,6 & 99,6 & 0,996 & 0,004 & 0,996 & 0,996 & 66 \\
\hline & 5,8 & 98,6 & 0,986 & 0,014 & 0,987 & 0,986 & 117 \\
\hline 100 & 2,8 & 99,3 & 0,993 & 0,007 & 0,993 & 0,993 & 84 \\
\hline 0,001 & 0,01 & 1,8 & 99,5 & 0,995 & 0,005 & 0,995 & 0,995 & 68 \\
\hline 0,1 & 2,1 & 99,7 & 0,997 & 0,003 & 0,997 & 0,997 & 56 \\
\hline 1 & & & & & & & \\
\hline
\end{tabular}

$\mathrm{N}=3$ : atributos selecionados: $\underline{\mathrm{A14}}, \underline{\mathrm{A11}}, \underline{\mathrm{A10}}$

Obteve-se os seguintes resultados para um número variado de valores para $\mathrm{C}$ e $\gamma$.

Tabela 49: Treinamentos realizados com vários valores de $\mathrm{C}$ e $\gamma$

\begin{tabular}{|c|c|c|c|c|c|c|c|c|}
\hline C & $\gamma$ & $\begin{array}{r}\text { Tempo } \\
\text { (s) }\end{array}$ & $\begin{array}{r}\text { Acurácia } \\
(\%)\end{array}$ & TPR & FPR & Precision & Recall & $\begin{array}{r}\text { RMSE } \\
\left(1^{-3}\right)\end{array}$ \\
\hline \multirow{4}{*}{0,1} & 0,001 & 1133 & 93,2 & 0,932 & 0,068 & 0,940 & 0,932 & 260 \\
\hline & 0,01 & 187 & 96,1 & 0,961 & 0,039 & 0,964 & 0,961 & 198 \\
\hline & 0,1 & 26,9 & 98,4 & 0,984 & 0,016 & 0,985 & 0,984 & 125 \\
\hline & 1 & 6,6 & 98,9 & 0,988 & 0,012 & 0,989 & 0,988 & 107 \\
\hline \multirow{4}{*}{1} & 0,001 & 169 & 96,1 & 0,961 & 0,039 & 0,964 & 0,961 & 197 \\
\hline & 0,01 & 26,2 & 98,4 & 0,984 & 0,016 & 0,985 & 0,984 & 125 \\
\hline & 0,1 & 4,0 & 98,9 & 0,989 & 0,011 & 0,989 & 0,989 & 106 \\
\hline & 1 & 5,9 & 99,7 & 0,997 & 0,003 & 0,997 & 0,997 & 56 \\
\hline \multirow{4}{*}{10} & 0,001 & 26,5 & 98,4 & 0,984 & 0,016 & 0,985 & 0,984 & 125 \\
\hline & 0,01 & 5,4 & 98,9 & 0,988 & 0,012 & 0,989 & 0,988 & 107 \\
\hline & 0,1 & 4,5 & 99,7 & 0,997 & 0,003 & 0,997 & 0,997 & 53 \\
\hline & 1 & 4,9 & 99,9 & 1 & 0 & 1 & 1 & 19 \\
\hline \multirow{4}{*}{100} & 0,001 & 4,6 & 98,9 & 0,988 & 0,012 & 0,989 & 0,988 & 107 \\
\hline & 0,01 & 4,6 & 99,7 & 0,997 & 0,003 & 0,997 & 0,997 & 53 \\
\hline & 0,1 & 4,4 & 99,9 & 1 & 0 & 1 & 1 & 18 \\
\hline & 1 & 4,8 & 100 & 1 & 0 & 1 & 1 & 0 \\
\hline
\end{tabular}

\subsubsection{Seleção de Atributos - TODOS os atributos}

Nesta etapa nenhuma técnica de seleção de atributos foi utilizada, ou seja, todos os atributos contidos em cada conjunto de dados de seus respectivos cenários foram utilizados. A ideia aqui é verificar se de fato os classificadores apresentam uma melhora de acurácia quando trabalham com uma quantidade menor de atributos.

\subsection{Algoritmo de Classificação - RNA}

Obteve-se os seguintes resultados para uma camada escondida e número variado de neurônios na camada. 


\begin{tabular}{rrrrrrrrr}
\multicolumn{7}{c}{ Tabela 50: Treinamentos realizados com vários valores de N } & \\
$\mathbf{N}$ & $\begin{array}{r}\text { Tempo } \\
\mathbf{( s )}\end{array}$ & $\begin{array}{r}\text { Acurácia } \\
(\boldsymbol{\%})\end{array}$ & $\mathbf{T P R}$ & $\mathbf{F P R}$ & Precision & Recall & RMSE \\
\hline 5 & 19,4 & 99,4 & 0,994 & 0,006 & 0,994 & 0,994 & 97 \\
\hline 10 & 32,6 & 99,7 & 0,997 & 0,003 & 0,998 & 0,997 & 57 \\
\hline 15 & 46,3 & 100 & 1 & 0 & 1 & 1 & 1,5 \\
\hline 20 & 62,5 & 100 & 1 & 0 & 1 & 1 & 2,3 \\
\hline
\end{tabular}

Obteve-se os seguintes resultados para duas camadas escondidas e número variado de neurônios para cada camada (N1 e N2).

\begin{tabular}{|c|c|c|c|c|c|c|c|c|}
\hline N1 & N2 & $\begin{array}{r}\text { Tempo } \\
(\mathbf{s})\end{array}$ & $\begin{array}{r}\text { Acurácia } \\
(\%)\end{array}$ & TPR & FPR & Precision & Recall & $\begin{array}{r}\text { RMSE } \\
\left(10^{-3}\right) \\
\end{array}$ \\
\hline 5 & 10 & 37,8 & 100 & 1 & 0 & 1 & 1 & 1,3 \\
\hline 5 & 15 & 38,7 & 100 & 1 & 0 & 1 & 1 & 1,5 \\
\hline 10 & 10 & 49,4 & 100 & 1 & 0 & 1 & 1 & 1,2 \\
\hline 10 & 15 & 56,8 & 100 & 1 & 0 & 1 & 1 & 1,4 \\
\hline 15 & 10 & 54,3 & 100 & 1 & 0 & 1 & 1 & 1,3 \\
\hline 15 & 15 & 85,8 & 100 & 1 & 0 & 1 & 1 & 1,4 \\
\hline 20 & 10 & 86,1 & 100 & 1 & 0 & 1 & 1 & 1,3 \\
\hline 20 & 15 & 102 & 100 & 1 & 0 & 1 & 1 & 1,3 \\
\hline
\end{tabular}

\subsection{Algoritmo de Classificação - SVM}

Obteve-se os seguintes resultados para um número variado de valores para $\mathrm{C}$ e $\gamma$.

Tabela 52: Treinamentos realizados com vários valores de $\mathrm{C}$ e $\gamma$

\begin{tabular}{|c|c|c|c|c|c|c|c|c|}
\hline C & $\gamma$ & $\begin{array}{r}\text { Tempo } \\
(\mathbf{s})\end{array}$ & $\begin{array}{r}\text { Acurácia } \\
(\%)\end{array}$ & TPR & FPR & Precision & Recall & $\begin{array}{r}\text { RMSE } \\
\left(10^{-3}\right)\end{array}$ \\
\hline \multirow{4}{*}{0,1} & 0,001 & 1010 & 96,1 & 0,961 & 0,039 & 0,964 & 0,961 & 198 \\
\hline & 0,01 & 93 & 97,9 & 0,979 & 0,021 & 0,980 & 0,979 & 146 \\
\hline & 0,1 & 34 & 98,9 & 0,989 & 0,011 & 0,989 & 0,989 & 104 \\
\hline & 1 & 10 & 99,8 & 0,998 & 0,002 & 0,998 & 0,998 & 47 \\
\hline \multirow{4}{*}{1} & 0,001 & 76 & 97,8 & 0,978 & 0,022 & 0,979 & 0,978 & 148 \\
\hline & 0,01 & 22 & 98,8 & 0,988 & 0,012 & 0,989 & 0,988 & 108 \\
\hline & 0,1 & 8,3 & 100 & 1 & 0 & 1 & 1 & 0 \\
\hline & 1 & 6,1 & 99,9 & 0,999 & 0,001 & 0,999 & 0,999 & 26 \\
\hline \multirow{4}{*}{10} & 0,001 & 24 & 98,8 & 0,988 & 0,012 & 0,989 & 0,988 & 108 \\
\hline & 0,01 & 7,6 & 99,9 & 0,999 & 0,001 & 0,999 & 0,999 & 32 \\
\hline & 0,1 & 2,1 & 100 & 1 & 0 & 1 & 1 & 0 \\
\hline & 1 & 3,8 & 97,8 & 0,978 & 0,022 & 0,979 & 0,978 & 127 \\
\hline \multirow{4}{*}{100} & 0,001 & 6,2 & 99,8 & 0,998 & 0,002 & 0,998 & 0,998 & 41 \\
\hline & 0,01 & 1,9 & 99,9 & 0,999 & 0,001 & 0,999 & 0,999 & 27 \\
\hline & 0,1 & 1,4 & 100 & 1 & 0 & 1 & 1 & 0 \\
\hline & 1 & 2,6 & 99,8 & 0,998 & 0,002 & 0,998 & 0,998 & 33 \\
\hline
\end{tabular}




\subsubsection{Melhores Classificadores Binários - Avaliação Final}

Conforme os resultados apresentados, os classificadores com os melhores desempenhos (acurácia igual a 100\% frente ao Conjunto de Treinamento e menores valores de RMSE em suas respectivas categorias) foram pré-selecionados e avaliados frente ao mesmo Conjunto de Teste previamente separado. Esses classificadores estão destacados em suas respectivas tabelas.

Os resultados obtidos considerando-se esse Conjunto de Teste único para todos os classificadores pré-selecionados estão apresentados na Tabela 53.

\begin{tabular}{|c|c|c|c|c|c|c|c|c|c|c|}
\hline ID & $\begin{array}{l}\text { Sel. } \\
\text { Atr. }\end{array}$ & $\begin{array}{l}\text { Atr. } \\
\text { Sel. }\end{array}$ & Classif. & Descrição & $\begin{array}{r}\text { Acur. } \\
(\%)\end{array}$ & $\begin{array}{r}\text { Tempo } \\
(\mathrm{ms})\end{array}$ & $\mathbf{P}$ & $\mathbf{R}$ & $\mathbf{F}$ & $\begin{array}{r}\text { RMSE } \\
\left(10^{-3}\right) \\
\end{array}$ \\
\hline CL1 & \multirow{5}{*}{ CFS } & \multirow{5}{*}{$\begin{array}{l}\text { A14 } \\
\text { A02 } \\
\text { A19 }\end{array}$} & \multirow{2}{*}{ RNA } & 15 neurônios & 100 & 15 & 1,000 & 1,000 & 1,000 & 2,7 \\
\hline CL2 & & & & \begin{tabular}{l|l}
5 & 15 neurônios
\end{tabular} & 100 & 20 & 1,000 & 1,000 & 1,000 & 2,2 \\
\hline CL3 & & & \multirow{3}{*}{ SVM } & $\mathrm{C}=1 \gamma=1$ & 100 & 40 & 1,000 & 1,000 & 1,000 & 0 \\
\hline CL4 & & & & $\mathrm{C}=10 \gamma=0,1$ & 100 & 50 & 1,000 & 1,000 & 1,000 & 0 \\
\hline CL5 & & & & $\mathrm{C}=100 \gamma=0,01$ & 100 & 40 & 1,000 & 1,000 & 1,000 & 0 \\
\hline CL6 & \multirow{4}{*}{$\begin{array}{l}\text { SVM } \\
\text { RFE }\end{array}$} & \multirow{4}{*}{$\begin{array}{l}\text { A14 } \\
\text { A11 } \\
\text { A10 }\end{array}$} & \multirow{3}{*}{ RNA } & 15 neurônios & 100 & 10 & 1,000 & 1,000 & 1,000 & 1,1 \\
\hline CL7 & & & & 5|10 neurônios & 100 & 15 & 1,000 & 1,000 & 1,000 & 2,9 \\
\hline CL8 & & & & 15 | 10 neurônios & 100 & 20 & 1,000 & 1,000 & 1,000 & 1,4 \\
\hline CL9 & & & SVM & $\mathrm{C}=100 \gamma=1$ & 100 & 30 & 1,000 & 1,000 & 1,000 & 0 \\
\hline CL10 & \multirow{6}{*}{-} & \multirow{5}{*}{ Todos } & \multirow{2}{*}{ RNA } & 15 neurônios & 100 & 15 & 1,000 & 1,000 & 1,000 & 1,2 \\
\hline CL11 & & & & $10 \mid 10$ neurônios & 100 & 20 & 1,000 & 1,000 & 1,000 & 1,3 \\
\hline CL12 & & & \multirow{3}{*}{ SVM } & $\mathrm{C}=1 \gamma=0,1$ & 99,87 & 120 & 0,999 & 0,999 & 0,999 & 36,7 \\
\hline CL13 & & & & $\mathrm{C}=10 \gamma=0,1$ & 100 & 160 & 1,000 & 1,000 & 1,000 & 0 \\
\hline CL14 & & & & $\mathrm{C}=100 \gamma=0,1$ & 100 & 50 & 1,000 & 1,000 & 1,000 & 0 \\
\hline & & & & Médias & 99,99 & 39,3 & - & - & - & 3,5 \\
\hline
\end{tabular}

A fim de avaliar a importância da etapa de balanceamento de classes (no Conjunto de Treinamento), foi feita uma análise de desempenho dos classificadores listados na Tabela 53 frente a um treinamento utilizando um Conjunto de Treinamento desbalanceado (contendo as amostras originais de cada cenário antes de serem balanceadas com o SMOTE).

Tabela 54: Acurácia, tempo de execução e erro dos melhores classificadores frente ao Conjunto de Teste treinados previamente sem o balanceamento de classes

\begin{tabular}{crrr} 
ID & $\begin{array}{r}\text { Acurácia } \\
(\boldsymbol{\%})\end{array}$ & $\begin{array}{r}\text { Tempo } \\
(\mathbf{m s})\end{array}$ & $\begin{array}{r}\text { RMSE } \\
\left(\mathbf{1 0}^{-3}\right)\end{array}$ \\
\hline CL1 & 100 & 10 & 1,7 \\
\hline CL2 & 100 & 10 & 0,9 \\
\hline
\end{tabular}




\begin{tabular}{crrr} 
ID & $\begin{array}{r}\text { Acurácia } \\
(\mathbf{\%})\end{array}$ & $\begin{array}{r}\text { Tempo } \\
(\mathbf{m s})\end{array}$ & $\begin{array}{r}\text { RMSE } \\
\left(\mathbf{1 0}^{-3}\right)\end{array}$ \\
\hline CL3 & 98,85 & 20 & 36,7 \\
\hline CL4 & 99,87 & 10 & 36,7 \\
\hline CL5 & 99,87 & 40 & 36,7 \\
\hline CL6 & 100 & 10 & 19,7 \\
\hline CL7 & 100 & 70 & 1,0 \\
\hline CL8 & 100 & 30 & 1,1 \\
\hline CL9 & 100 & 20 & 0 \\
\hline CL10 & 100 & 20 & 2,3 \\
\hline CL11 & 99,87 & 20 & 22,7 \\
\hline CL12 & 99,87 & 70 & 36,7 \\
\hline CL13 & 99,87 & 40 & 36,7 \\
\hline CL14 & 100 & 30 & 0 \\
\hline Médias & $\mathbf{9 9 , 8 7}$ & $\mathbf{2 8 , 6}$ & $\mathbf{1 6 , 6}$ \\
\hline & & &
\end{tabular}

Posteriormente, para avaliar a importância da etapa de pré-processamento dos dados, mais especificamente a influência do cálculo indicado por (GUYON et al., 2002) na Seção 4.2.2.2, foi feita também uma análise de desempenho dos classificadores listados na Tabela 49 frente a um treinamento utilizando um Conjunto de Treinamento sem o cálculo sugerido (aquele de subtrair a média de determinado atributo e dividir o resultado pelo desvio padrão).

Tabela 55: Acurácia, tempo de execução e erro dos melhores classificadores frente ao Conjunto de Teste treinados previamente sem o Pré-processamento.

\begin{tabular}{crrr} 
ID & $\begin{array}{r}\text { Acurácia } \\
(\mathbf{\%})\end{array}$ & $\begin{array}{r}\text { Tempo } \\
(\mathbf{m s})\end{array}$ & $\begin{array}{r}\text { RMSE } \\
(\mathbf{1 0})\end{array}$ \\
\hline CL1 & 100 & 10 & 0 \\
\hline CL2 & 100 & 10 & 0,1 \\
\hline CL3 & 88,83 & 60 & 334,2 \\
\hline CL4 & 100 & 60 & 0 \\
\hline CL5 & 100 & 40 & 0 \\
\hline CL6 & 100 & 10 & 0 \\
\hline CL7 & 100 & 10 & 0 \\
\hline CL8 & 100 & 10 & 0 \\
\hline CL9 & 88,96 & 40 & 332,2 \\
\hline CL10 & 87,35 & 30 & 341,9 \\
\hline CL11 & 96,23 & 10 & 180,6 \\
\hline CL12 & 88,56 & 130 & 338,2 \\
\hline CL13 & 88,56 & 90 & 338,2 \\
\hline CL14 & 88,56 & 30 & 338,2 \\
\hline Médias & $\mathbf{9 4 , 7 9}$ & $\mathbf{3 8 , 6}$ & $\mathbf{1 5 7 , 4}$ \\
\hline & & &
\end{tabular}


Mesma análise, mas agora se excluindo também a etapa de balanceamento as classes.

Tabela 56: Acurácia, tempo de execução e erro dos melhores classificadores frente ao Conjunto de Teste treinados previamente sem o pré-processamento e sem o balanceamento de classes

\begin{tabular}{crrr} 
ID & $\begin{array}{r}\text { Acurácia } \\
(\boldsymbol{\%})\end{array}$ & $\begin{array}{r}\text { Tempo } \\
(\mathbf{m s})\end{array}$ & $\begin{array}{r}\text { RMSE } \\
(\mathbf{1 0})\end{array}$ \\
\hline CL1 & 100 & 20 & 0 \\
\hline CL2 & 100 & 10 & 0 \\
\hline CL3 & 88,96 & 30 & 332,2 \\
\hline CL4 & 99,87 & 20 & 36,7 \\
\hline CL5 & 99,87 & 30 & 36,7 \\
\hline CL6 & 100 & 20 & 0 \\
\hline CL7 & 100 & 10 & 0 \\
\hline CL8 & 100 & 10 & 0,1 \\
\hline CL9 & 88,56 & 10 & 338,2 \\
\hline CL10 & 99,33 & 30 & 78,7 \\
\hline CL11 & 97,71 & 10 & 178,9 \\
\hline CL12 & 89,10 & 90 & 330,2 \\
\hline CL13 & 88,56 & 30 & 338,2 \\
\hline CL14 & 88,83 & 30 & 334,2 \\
\hline Médias & $\mathbf{9 5 , 7 7}$ & $\mathbf{2 5 , 0}$ & $\mathbf{1 4 3 , 2}$ \\
\hline & & &
\end{tabular}

Pela análise dos resultados das tabelas acima, nota-se que a Acurácia Média dos melhores classificadores é maior para o caso onde as técnicas de Pré-processamento e Balanceamento de Classes é utilizada (Tabela 53). Os valores médios para cada caso analisado estão sumarizados na Tabela 57.

Tabela 57: Acurácia média, tempo de execução médio e erro médio dos melhores classificadores para cada caso analisado

\begin{tabular}{crrr} 
Tabela & $\begin{array}{r}\text { Acurácia } \\
(\boldsymbol{\%})\end{array}$ & $\begin{array}{r}\text { Tempo } \\
(\mathbf{m s})\end{array}$ & $\begin{array}{r}\text { RMSE } \\
\left(\mathbf{1 0}^{-3}\right)\end{array}$ \\
\hline Tabela 53 & 99,99 & 39,3 & 3,5 \\
\hline Tabela 54 & 99,87 & 28,6 & 16,6 \\
\hline Tabela 55 & 94,79 & 38,6 & 157,4 \\
\hline Tabela 56 & 95,77 & 25,0 & 143,2 \\
\hline
\end{tabular}

A Figura 72 ilustra os valores médios apresentados na tabela. 

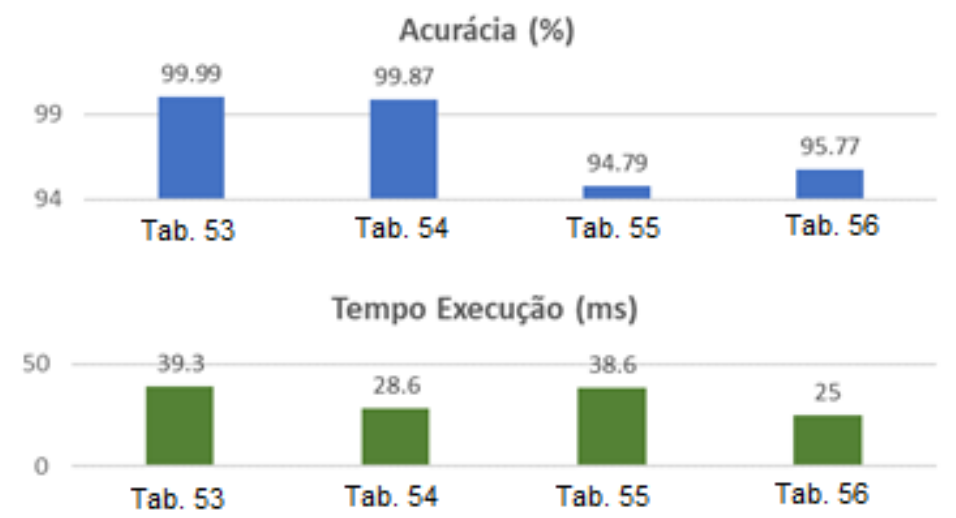

RMSE $\left(10^{-3}\right)$

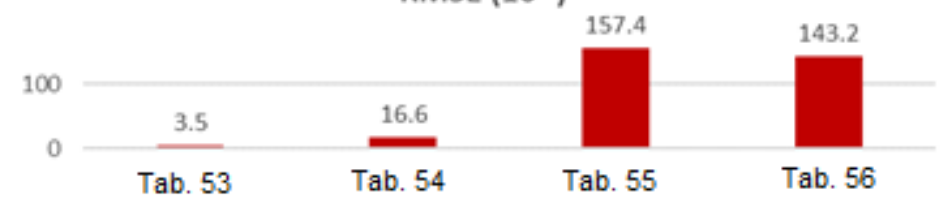

Figura 72: Comparativo de Acurácia média, Tempo de Execução médio e RMSE médio dos melhores classificadores avaliados.

FONTE: Própria

Quando foi feito o pré-processamento dos dados e o Balanceamento de Classes, a Acurácia média dos melhores classificadores foi de 99,99\%, o Tempo de Execução médio foi de 39,3ms e o RMSE médio foi de 0,0035.

Quando não se fez o Balanceamento de Classes, a Acurácia Média dos melhores classificadores caiu para 99,87\%, o Tempo de Execução caiu para 28,6ms e o RMSE subiu para 0,0166 .

Além disso, quando não se fez o Pré-processamento dos dados, a Acurácia Média dos melhores classificadores caiu para 94,79\%, o Tempo de Execução subiu para 38,6ms e o RMSE subiu para 0,1574 .

Por fim, quando não se fez o Pré-processamento dos dados e não se fez também o Balanceamento de Classe, a Acurácia Média dos melhores classificadores caiu para 95,77\%, o Tempo de Execução caiu para 25ms e o RMSE subiu para 0,1432.

Com isso, nota-se que as etapas de Pré-processamento dos dados e de Balanceamento de Classes incrementaram a Acurácia dos classificadores, fato esse que corrobora com as informações encontradas na literatura correlata. 


\subsubsection{Aprendizado de Máquinas - Abordagem Unária}

Neste trabalho, para a composição dos conjuntos de Treinamento e Teste, o conjunto Total de Amostras foi subdividido conforme Tabela 58.

Tabela 58: Conjunto Total de amostras dividido entre Conjunto de Treinamento e Conjunto de Teste

TOTAL

\begin{tabular}{ccccccccc} 
& TOTAL & \multicolumn{3}{c}{ TREINAMENTO $\mathbf{- 8 5 \%}$} & \multicolumn{3}{c}{ TESTE - 15\% } \\
\hline Total & Target & Outlier & Total & Target & Outlier & Total & Target & Outlier \\
\hline 4955 & 4386 & 569 & 4214 & 3729 & 485 & 741 & 657 & 84 \\
\hline
\end{tabular}

Na Tabela 59 estão apresentados os conjuntos de Treinamentos criados para a avaliação do classificador. O classificador OCSVM foi treinado individualmente com cada Conjunto de Treinamento criado e, posteriormente, foi apresentado ao mesmo Conjunto de Teste para comparação de desempenho.

Conforme apresentado na seção 4.4.3, pode haver uma melhoria na acurácia dos classificadores unários quando estes são treinados com algumas amostras Outliers contidas no Conjunto de Treinamento, seguindo o algoritmo da Figura 61. Para tanto, foram criados seis conjuntos de treinamentos cada qual com uma quantidade diferente de amostras Outliers (parâmetro Outlier Fraction), conforme apresentado na Tabela 59.

Tabela 59: Conjuntos de Treinamentos avaliados com diferentes valores de Outlier Fraction CONJUNTOS DE TREINAMENTO

\begin{tabular}{ccccc}
\hline ID & Total & Targets & Outliers & $\begin{array}{c}\text { Outlier } \\
\text { Fraction }\end{array}$ \\
\hline CJ000 & 3729 & 3729 & 0 & 0,000 \\
\hline CJ001 & 3732 & 3729 & 3 & 0,001 \\
\hline CJ002 & 3737 & 3729 & 8 & 0,002 \\
\hline CJ003 & 3741 & 3729 & 12 & 0,003 \\
\hline CJ010 & 3767 & 3729 & 38 & 0,010 \\
\hline CJ020 & 3806 & 3729 & 77 & 0,020 \\
\hline
\end{tabular}

Como seis diferentes conjuntos de treinamento foram avaliados, escolheu-se como critério de escolha do melhor classificador aquele que apresentar o menor erro de classificação das amostras Targets e Outliers frente ao mesmo Conjunto de Teste. Em caso de empate do erro, opta-se por aquele que necessitar de uma menor quantidade de amostras Outliers no conjunto de treinamento, ou seja, um menor valor do parâmetro Outlier Fraction.

As diversas combinações analisadas estão apresentadas nas seções seguintes. 


\subsubsection{Com Redução da Dimensionalidade usando Autoencoder e classificação usando $\underline{\text { OCSVM }}$}

A rede Autoencoder com uma camada escondida foi criada com o software Matlab ajustando-se os parâmetros: EncoderTransferfunction com o valor logsig, o parâmetro DecoderTransferfunction com o valor logsig, o parâmetro MaxEpochs com valor 5000, TrainingAlgorithm com trainscg e ScaleData para true variandose a quantidade de neurônios na camada escondida de 1 até 18 (número máximo de atributos do Conjunto de Amostras).

A Figura 73 ilustra a rede Autoencoder utilizada.

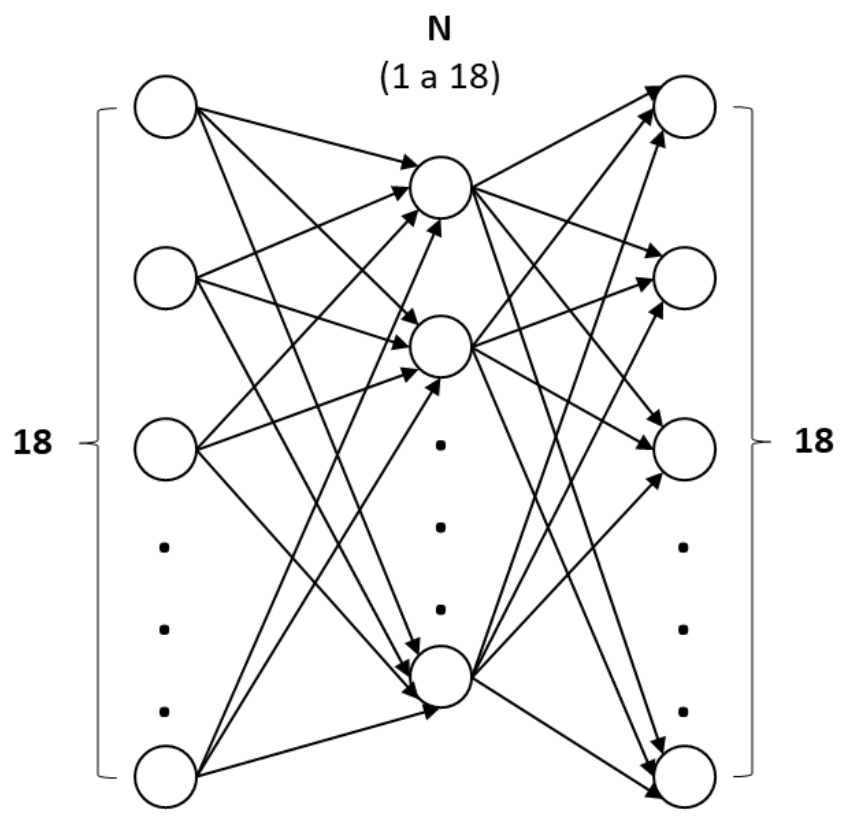

Figura 73: Rede Autoencoder utilizada FONTE: Própria

Para cada valor de $\mathrm{N}$, a rede foi treinada 5 vezes e os valores médios foram anotados na tabela abaixo. 
A Tabela 60 apresenta os valores obtidos com o treinamento da rede Autoencoder com vários valores de $\mathrm{N}$ (neurônios da camada escondida) frente ao Conjunto de Treinamento ç000 da Tabela 59. Adicionalmente, também foi calculado o MSE frente ao Conjunto de Teste, e os resultados também estão dispostos na tabela.

Tabela 60: Treinamentos do Autoencoder realizados com vários valores de $\mathrm{N}$ frente ao Conjunto de Treinamento CJ000

\begin{tabular}{|c|c|c|c|c|c|}
\hline \multirow[b]{2}{*}{$\mathbf{N}$} & \multicolumn{3}{|c|}{ Conjunto de Treinamento } & \multicolumn{2}{|c|}{ Conjunto de Teste } \\
\hline & $\begin{array}{r}\text { Tempo } \\
(\mathrm{s})\end{array}$ & Épocas & $\begin{array}{l}\text { MSE } \\
\left(10^{-3}\right) \\
\end{array}$ & $\begin{array}{r}\text { Targets } \\
\text { MSE }\left(\mathbf{1 0}^{-3}\right) \\
\end{array}$ & $\begin{array}{r}\text { Outliers } \\
\text { MSE }\left(1^{-3}\right) \\
\end{array}$ \\
\hline 1 & 3,31 & 827 & 306,1 & 292,7 & 2941 \\
\hline 2 & 10,5 & 1015 & 127,4 & 130,4 & 2452 \\
\hline 3 & 15,7 & 2120 & 63,4 & 65,8 & 2376 \\
\hline 4 & 17,2 & 1890 & 45,6 & 44,1 & 2496 \\
\hline 5 & 19,3 & 1284 & 36,4 & 36,0 & 2254 \\
\hline 6 & 15,7 & 1009 & 29,0 & 28,7 & 2193 \\
\hline 7 & 21,3 & 1419 & 27,7 & 27,5 & 2179 \\
\hline 8 & 16,8 & 1574 & 26,8 & 26,8 & 2282 \\
\hline 9 & 23,1 & 1421 & 27,5 & 27,3 & 2202 \\
\hline 10 & 27,2 & 1516 & 25,7 & 25,6 & 2296 \\
\hline 11 & 26,7 & 1770 & 25,6 & 26,7 & 2180 \\
\hline 12 & 32,5 & 1396 & 26,7 & 26,4 & 2185 \\
\hline 13 & 23,1 & 1500 & 26,7 & 26,5 & 2186 \\
\hline 14 & 27,3 & 1733 & 26,8 & 26,6 & 2184 \\
\hline 15 & 33,7 & 1849 & 26,0 & 26,0 & 2296 \\
\hline 16 & 31,6 & 1951 & 26,0 & 26,0 & 2300 \\
\hline 17 & 35,4 & 2021 & 25,9 & 25,9 & 2304 \\
\hline 18 & 34,1 & 2030 & 25,9 & 25,9 & 2308 \\
\hline
\end{tabular}

O classificador OCSVM foi então treinado com os novos atributos gerados pelo processo de redução de dimensionalidade (rede Autoencoder) utilizando o algoritmo da Figura 63.

Os resultados obtidos estão apresentados nas tabelas a seguir.

Legenda das nomenclaturas utilizadas nas tabelas:

- O.F.Tr.: OutlierFraction do Conjunto de Treinamento utilizado;

- O.F.Te.: OutlierFraction do Conjunto de Teste utilizado;

- $\gamma$ : parâmetro do kernel gaussiano ajustado automaticamente pelo algoritmo de otimização do software Matlab durante a etapa de treinamento;

- T.Tr.: Tempo decorrido para o Treinamento (construção do modelo); 
- O.R.Tr.: OutlierRate gerada pelo classificador frente ao Conjunto de Treinamento;

- E.R.Tr.: Erro Relativo do classificador frente ao Conjunto de Treinamento. Calculado pelo módulo da diferença entre o valor da OutlierFraction ajustada e a OutlierRate obtida pelo classificador durante a etapa de Treinamento (construção do modelo);

- T.Ex.: Tempo de Execução do classificador frente ao Conjunto de Teste;

- O.R.Te.: OutlierRate gerada pelo classificador frente ao Conjunto de Teste;

- E.R.Te.: Erro Relativo da OutlierRate do classificador frente ao Conjunto de Teste. É calcula pelo módulo da diferença entre o valor da OutlierRate ajustada e a OutlierRate obtida pelo classificador.

\begin{tabular}{|c|c|c|c|c|}
\hline Classificador & $\mathbf{N}$ & $\gamma$ & $\begin{array}{r}\text { T.Tr. } \\
(\mathrm{ms})\end{array}$ & O.R.Tr. \\
\hline CL1 & 1 & 162,1 & 1144 & 0 \\
\hline CL2 & 2 & 42,61 & 1016 & 0 \\
\hline CL3 & 3 & 6,595 & 876 & 0,0003 \\
\hline CL4 & 4 & 14,70 & 927 & 0 \\
\hline CL5 & 5 & 23,87 & 1055 & 0 \\
\hline CL6 & 6 & 27,93 & 1737 & 0 \\
\hline CL 7 & 7 & 4,543 & 831 & 0 \\
\hline CL8 & 8 & 5,349 & 1022 & 0 \\
\hline CL9 & 9 & 5,309 & 1006 & 0 \\
\hline CL10 & 10 & 1,917 & 1028 & 0 \\
\hline CL11 & 11 & 2,144 & 1019 & 0 \\
\hline CL12 & 12 & 2,199 & 1146 & 0 \\
\hline CL13 & 13 & 2,495 & 1094 & 0 \\
\hline CL14 & 14 & 2,552 & 1103 & 0 \\
\hline CL15 & 15 & 2,621 & 943 & 0 \\
\hline CL16 & 16 & 2,392 & 855 & 0 \\
\hline CL17 & 17 & 2,148 & 1103 & 0 \\
\hline CL18 & 18 & 1,965 & 973 & 0 \\
\hline
\end{tabular}

Os classificadores foram então submetidos ao mesmo Conjunto de Teste (da Tabela 58) e os resultados obtidos estão listados na Tabela 62.

Tabela 62: Desempenho dos classificadores frente ao Conjunto de Teste (O.F.Te. $=0,1134)$

\begin{tabular}{ccccccrc} 
Classificador & $\begin{array}{c}\text { T.Ex. } \\
(\mathbf{m s})\end{array}$ & O.R.Te. & $\begin{array}{c}\text { Acurácia } \\
(\boldsymbol{\%})\end{array}$ & TPR & FPR & Precision & Recall \\
\hline CL1 & 28,5 & 0,0121 & 89,61 & 0,8889 & 0,1038 & 0,0952 & 0,8889 \\
\hline CL2 & 23,0 & 0,1039 & 98,25 & 0,9610 & 0,0151 & 0,8810 & 0,9610 \\
\hline CL3 & 18,3 & 0,0567 & 94,06 & 0,9762 & 0,0615 & 0,4881 & 0,9762 \\
\hline CL4 & 24,1 & 0,0513 & 89,74 & 0,6053 & 0,0868 & 0,2738 & 0,6053 \\
\hline
\end{tabular}




\begin{tabular}{ccccrrrr} 
Classificador & $\begin{array}{c}\text { T.Ex. } \\
(\mathbf{m s})\end{array}$ & O.R.Te. & $\begin{array}{c}\text { Acurácia } \\
(\boldsymbol{\%})\end{array}$ & TPR & FPR & Precision & Recall \\
\hline CL5 & 35,7 & 0,1552 & 95,82 & 0,7304 & 0 & 1 & 0,7304 \\
\hline CL6 & 40,0 & 0,1633 & 95,01 & 0,6942 & 0 & 1 & 0,6942 \\
\hline CL7 & 27,7 & 0,1296 & 98,11 & 0,8646 & 0,0016 & 0,9881 & 0,8646 \\
\hline CL8 & 31,7 & 0,1336 & 97,71 & 0,8384 & 0,0016 & 0,9881 & 0,8384 \\
\hline CL9 & 23,6 & 0,1323 & 97,84 & 0,8469 & 0,0016 & 0,9881 & 0,8469 \\
\hline CL10 & 37,0 & 0,1147 & 98,79 & 0,9412 & 0,0061 & 0,9524 & 0,9412 \\
\hline CL11 & 24,8 & 0,1242 & 97,84 & 0,8696 & 0,0062 & 0,9524 & 0,8696 \\
\hline CL12 & 22,8 & 0,1242 & 97,84 & 0,8696 & 0,0062 & 0,9524 & 0,8696 \\
\hline CL13 & 23,2 & 0,1269 & 97,57 & 0,8511 & 0,0062 & 0,9524 & 0,8511 \\
\hline CL14 & 26,3 & 0,1296 & 97,30 & 0,8333 & 0,0062 & 0,9524 & 0,8333 \\
\hline CL15 & 27,7 & 0,1296 & 97,30 & 0,8333 & 0,0062 & 0,9524 & 0,8333 \\
\hline CL16 & 24,9 & 0,1282 & 97,44 & 0,8421 & 0,0062 & 0,9524 & 0,8421 \\
\hline CL17 & 25,8 & 0,1282 & 97,17 & 0,8316 & 0,0077 & 0,9405 & 0,8316 \\
\hline CL18 & 23,1 & 0,1242 & 97,57 & 0,8587 & 0,0077 & 0,9405 & 0,8587 \\
\hline & & Média & $\mathbf{9 6 , 3 9}$ & - & - & $\mathbf{0 , 8 4 7 2}$ & $\mathbf{0 , 8 4 0 9}$ \\
\hline & & & & & & &
\end{tabular}

A Figura 74 mostra o gráfico da acurácia dos classificadores para cada valor de $\mathrm{N}$ analisado. A linha pontilhada azul representa o valor médio da acurácia $(96,39 \%)$ para todos os valores de $\mathrm{N}$ e a linha tracejada vermelha representa o valor da acurácia $(96,10 \%)$ utilizando todos os atributos sem o uso do Autoencoder.

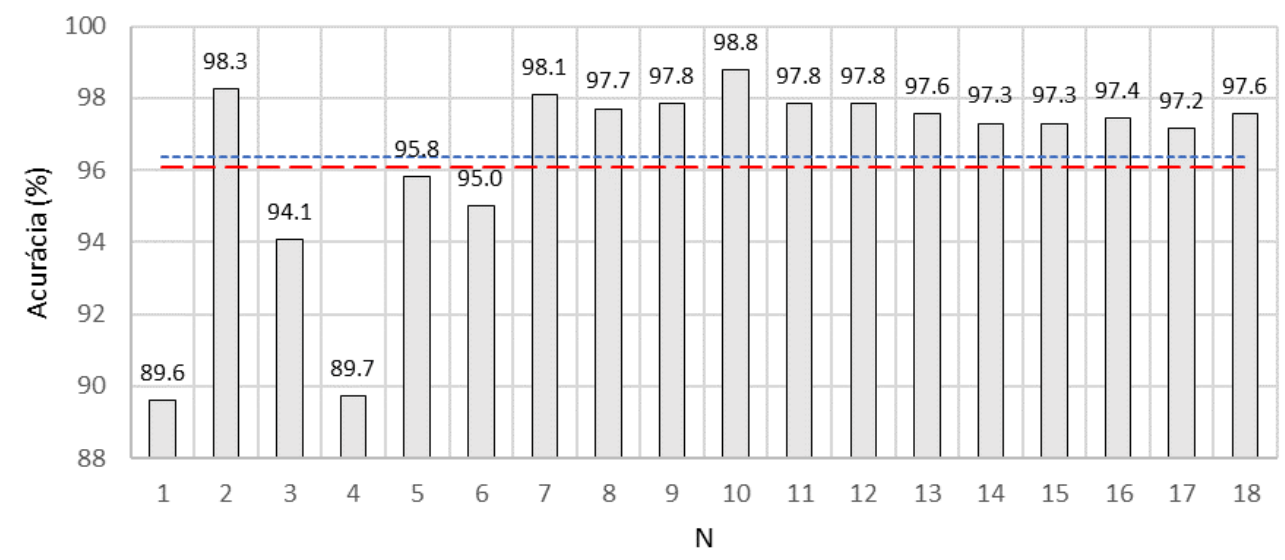

Figura 74: Valores de acurácia para cada valor de $\mathrm{N}$ analisado (O.F.Tr. = 0,000) FONTE: Própria

A Tabela 63 apresenta os valores obtidos com o treinamento da rede Autoencoder com vários valores de $\mathrm{N}$ (neurônios da camada escondida) frente ao Conjunto de Treinamento $\underline{\mathrm{CJ001}}$ da Tabela 59. Adicionalmente, também foi calculado o MSE frente ao Conjunto de Teste, e os resultados também estão dispostos na tabela. 
Tabela 63: Treinamentos do Autoencoder realizados com vários valores de $\mathrm{N}$ frente ao Conjunto de Treinamento CJ001

\begin{tabular}{rrrr} 
& \multicolumn{3}{c}{ Conjunto de Treinamento } \\
\cline { 2 - 4 } $\mathbf{N}$ & $\begin{array}{r}\text { Tempo } \\
(\mathbf{s})\end{array}$ & Épocas & $\begin{array}{r}\text { MSE } \\
\left(\mathbf{1 0} \mathbf{H}^{-3}\right.\end{array}$ \\
\hline 1 & 2,3 & 254 & 302,6 \\
\hline 2 & 6,1 & 609 & 123,8 \\
\hline 3 & 5,5 & 390 & 105,9 \\
\hline 4 & 11,3 & 721 & 41,6 \\
\hline 5 & 13,9 & 904 & 31,9 \\
\hline 6 & 6,9 & 483 & 24,8 \\
\hline 7 & 15,3 & 1060 & 23,8 \\
\hline 8 & 15,7 & 1262 & 22,4 \\
\hline 9 & 18,4 & 1285 & 22,1 \\
\hline 10 & 17,5 & 1357 & 22,1 \\
\hline 11 & 18,3 & 1285 & 22,2 \\
\hline 12 & 17,2 & 1195 & 22,5 \\
\hline 13 & 45,5 & 3417 & 21,5 \\
\hline 14 & 36,8 & 2193 & 21,6 \\
\hline 15 & 27,8 & 1858 & 21,5 \\
\hline 16 & 25,3 & 1764 & 21,3 \\
\hline 17 & 26,2 & 1656 & 21,3 \\
\hline 18 & 32,1 & 1959 & 21,3 \\
\hline & & & \\
\hline
\end{tabular}

Conjunto de Teste

\begin{tabular}{rr}
\hline $\begin{array}{r}\text { Targets } \\
\text { MSE }\left(\mathbf{1 0}^{-3}\right)\end{array}$ & $\begin{array}{r}\text { Outliers } \\
\text { MSE }\left(\mathbf{1 0}^{-3}\right)\end{array}$ \\
\hline 286,3 & 2990 \\
\hline 123,9 & 2540 \\
\hline 101,4 & 2495 \\
\hline 37,3 & 2333 \\
\hline 29,1 & 2119 \\
\hline 22,2 & 2049 \\
\hline 21,4 & 2020 \\
\hline 20,2 & 2036 \\
\hline 19,6 & 2041 \\
\hline 19,6 & 2040 \\
\hline 19,7 & 2043 \\
\hline 20,4 & 1905 \\
\hline 19,3 & 2012 \\
\hline 19,4 & 2006 \\
\hline 19,4 & 1980 \\
\hline 19,2 & 1908 \\
\hline 19,3 & 1909 \\
\hline 19,3 & 1897 \\
\hline
\end{tabular}

O classificador OCSVM foi então treinado com os novos atributos gerados pelo processo de redução de dimensionalidade (rede Autoencoder) utilizando o algoritmo da Figura 63.

Tabela 64: Treinamentos realizados com vários valores de OutlierFraction frente ao Conjunto de Treinamento CJ001 (O.F.Tr. = 0,001)

\begin{tabular}{cccrr} 
Classificador & $\mathbf{N}$ & $\boldsymbol{\gamma}$ & $\begin{array}{r}\text { T.Tr. } \\
\text { (ms) }\end{array}$ & O.R.Tr. \\
\hline CL1 & 1 & 94,82 & 925,4 & 0,0011 \\
\hline CL2 & 2 & 53,03 & 1025 & 0,0011 \\
\hline CL3 & 3 & 132,3 & 1631 & 0,0011 \\
\hline CL4 & 4 & 13,08 & 977,8 & 0,0011 \\
\hline CL5 & 5 & 18,55 & 986,2 & 0,0011 \\
\hline CL6 & 6 & 20,91 & 1073 & 0,0011 \\
\hline CL7 & 7 & 25,91 & 1291 & 0,0008 \\
\hline CL8 & 8 & 10,16 & 982 & 0,0011 \\
\hline CL9 & 9 & 4,339 & 1162 & 0,0011 \\
\hline CL10 & 10 & 4,725 & 1021 & 0,0011 \\
\hline CL11 & 11 & 4,650 & 1014 & 0,0011 \\
\hline CL12 & 12 & 5,528 & 968 & 0,0011 \\
\hline CL13 & 13 & 4,468 & 1124 & 0,0011 \\
\hline
\end{tabular}




\begin{tabular}{cccrr} 
Classificador & $\mathbf{N}$ & $\boldsymbol{\gamma}$ & $\begin{array}{r}\text { T.Tr. } \\
(\mathbf{m s})\end{array}$ & O.R.Tr. \\
\hline CL14 & 14 & 5,138 & 1115 & 0,0011 \\
\hline CL15 & 15 & 4,945 & 1153 & 0,0011 \\
\hline CL16 & 16 & 4,994 & 1123 & 0,0011 \\
\hline CL17 & 17 & 5,256 & 1228 & 0,0011 \\
\hline CL18 & 18 & 5,197 & 1818 & 0,0011 \\
\hline
\end{tabular}

Os classificadores foram então submetidos ao mesmo Conjunto de Teste (da Tabela 58) e os resultados obtidos estão listados na Tabela 65.

Tabela 65: Desempenho dos classificadores frente ao Conjunto de Teste (O.F.Te. $=\mathbf{0 , 1 1 3 4}$ )

\begin{tabular}{ccccrrrr} 
Classificador & $\begin{array}{c}\text { T.Ex. } \\
(\mathbf{m s})\end{array}$ & O.R.Te. & $\begin{array}{c}\text { Acurácia } \\
(\mathbf{\%})\end{array}$ & TPR & FPR & Precision & Recall \\
\hline CL1 & 22,9 & 0,0027 & 88,93 & 1 & 0,1110 & 0,0238 & 1 \\
\hline CL2 & 22,0 & 0,1053 & 98,11 & 0,9487 & 0,0151 & 0,8810 & 0,9487 \\
\hline CL3 & 34,7 & 0,1404 & 97,30 & 0,8077 & 0 & 1 & 0,8077 \\
\hline CL4 & 22,6 & 0,1134 & 95,95 & 0,8214 & 0,0228 & 0,8214 & 0,8214 \\
\hline CL5 & 59,9 & 0,1404 & 95,95 & 0,7596 & 0,0078 & 0,9405 & 0,7596 \\
\hline CL6 & 33,6 & 0,1511 & 96,22 & 0,7500 & 0 & 1 & 0,7500 \\
\hline CL7 & 34,4 & 0,1687 & 94,47 & 0,6720 & 0 & 1 & 0,6720 \\
\hline CL8 & 31,5 & 0,1484 & 96,49 & 0,7636 & 0 & 1 & 0,7636 \\
\hline CL9 & 25,0 & 0,1323 & 97,84 & 0,8469 & 0,0016 & 0,9881 & 0,8469 \\
\hline CL10 & 25,1 & 0,1350 & 97,57 & 0,8300 & 0,0016 & 0,9881 & 0,8300 \\
\hline CL11 & 21,3 & 0,1363 & 97,44 & 0,8218 & 0,0016 & 0,9881 & 0,8218 \\
\hline C112 & 27,8 & 0,1390 & 97,17 & 0,8058 & 0,0016 & 0,9881 & 0,8058 \\
\hline CL13 & 23,5 & 0,1404 & 97,03 & 0,7981 & 0,0016 & 0,9881 & 0,7981 \\
\hline CL14 & 24,8 & 0,1471 & 96,36 & 0,7615 & 0,0016 & 0,9881 & 0,7615 \\
\hline CL15 & 27,8 & 0,1471 & 96,36 & 0,7615 & 0,0016 & 0,9881 & 0,7615 \\
\hline CL16 & 30,9 & 0,1471 & 96,63 & 0,7706 & 0 & 1 & 0,7706 \\
\hline CL17 & 27,9 & 0,1538 & 95,95 & 0,7368 & 0 & 1 & 0,7368 \\
\hline CL18 & 65,8 & 0,1552 & 95,82 & 0,7304 & 0 & 1 & 0,7304 \\
\hline & & Média & $\mathbf{9 6 , 2 0}$ & & - & $\mathbf{0 , 9 2 1 3}$ & $\mathbf{0 , 7 9 9 2}$ \\
\hline & & & & & &
\end{tabular}

A Figura 75 mostra o gráfico da acurácia dos classificadores para cada valor de $\mathrm{N}$ analisado. A linha pontilhada azul representa o valor médio da acurácia $(96,20 \%)$ para todos os valores de $\mathrm{N}$ e a linha tracejada vermelha representa o valor da acurácia $(95,69 \%)$ utilizando todos os atributos $\underline{\text { sem }}$ o uso do Autoencoder. 


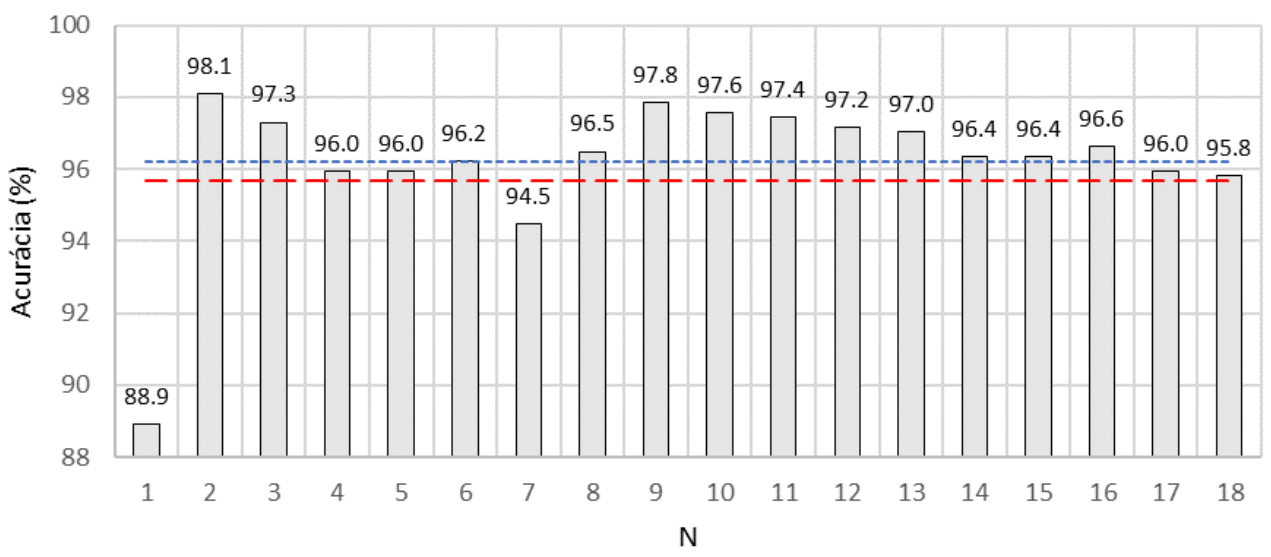

Figura 75: Valores de acurácia para cada valor de $\mathrm{N}$ analisado (O.F.Tr. = 0,001) FONTE: Própria

A Tabela 66 apresenta os valores obtidos com o treinamento da rede Autoencoder com vários valores de $\mathrm{N}$ (neurônios da camada escondida) frente ao Conjunto de Treinamento CJ002 da Tabela 59. Adicionalmente, também foi calculado o MSE frente ao Conjunto de Teste, e os resultados também estão dispostos na tabela.

Tabela 66: Treinamentos do Autoencoder realizados com vários valores de $\mathrm{N}$ frente ao Conjunto de Treinamento CJ002

\begin{tabular}{rrrr} 
& \multicolumn{3}{c}{ Conjunto de Treinamento } \\
\cline { 2 - 4 } $\mathbf{N}$ & $\begin{array}{r}\text { Tempo } \\
(\mathbf{s})\end{array}$ & Épocas & $\begin{array}{r}\text { MSE } \\
(\mathbf{1 0}\end{array}$ \\
\hline 1 & 2,1 & 286 & 305,6 \\
\hline 2 & 5,3 & 515 & 126,7 \\
\hline 3 & 13,3 & 1087 & 62,1 \\
\hline 4 & 8,7 & 675 & 44,1 \\
\hline 5 & 9,1 & 831 & 33,9 \\
\hline 6 & 15,7 & 1385 & 26,7 \\
\hline 7 & 12,5 & 925 & 25,4 \\
\hline 8 & 12,9 & 795 & 25,2 \\
\hline 9 & 21,1 & 1684 & 22,5 \\
\hline 10 & 12,3 & 974 & 23,4 \\
\hline 11 & 23,7 & 1451 & 22,8 \\
\hline 12 & 28,1 & 1685 & 22,4 \\
\hline 13 & 18,7 & 1298 & 22,4 \\
\hline 14 & 39,1 & 2358 & 21,8 \\
\hline 15 & 36,0 & 2226 & 21,8 \\
\hline 16 & 21,6 & 1482 & 22,4 \\
\hline 17 & 29,4 & 1943 & 21,8 \\
\hline 18 & 25,6 & 1589 & 21,5 \\
\hline & & & \\
\hline
\end{tabular}

\begin{tabular}{rr}
\multicolumn{2}{c}{ Conjunto de Teste } \\
\hline $\begin{array}{r}\text { Targets } \\
\text { MSE }\left(\mathbf{1 0}^{-3}\right)\end{array}$ & $\begin{array}{r}\text { Outliers } \\
\text { MSE }\left(\mathbf{1 0}^{-3}\right)\end{array}$ \\
\hline 286,4 & 2982 \\
\hline 124,0 & 2531 \\
\hline 59,1 & 2356 \\
\hline 37,2 & 2306 \\
\hline 29,3 & 1865 \\
\hline 22,5 & 1785 \\
\hline 21,7 & 1544 \\
\hline 21,0 & 1818 \\
\hline 19,2 & 1405 \\
\hline 20,2 & 1423 \\
\hline 19,7 & 1335 \\
\hline 19,5 & 1128 \\
\hline 19,7 & 1130 \\
\hline 19,2 & 1109 \\
\hline 19,3 & 1111 \\
\hline 19,6 & 1137 \\
\hline 19,4 & 1112 \\
\hline 19,3 & 1057 \\
\hline
\end{tabular}


O classificador OCSVM foi então treinado com os novos atributos gerados pelo processo de redução de dimensionalidade (rede Autoencoder) utilizando o algoritmo da Figura 63.

Tabela 67: Treinamentos realizados com vários valores de OutlierFraction frente ao Conjunto de Treinamento CJ002 (O.F.Tr. = 0,002)

\begin{tabular}{cccrr} 
Classificador & $\mathbf{N}$ & $\boldsymbol{\gamma}$ & $\begin{array}{r}\text { T.Tr. } \\
(\mathbf{m s})\end{array}$ & O.R.Tr. \\
\hline CL1 & 1 & 185,5 & 1205 & 0,0019 \\
\hline CL2 & 2 & 51,24 & 1294 & 0,0019 \\
\hline CL3 & 3 & 4,308 & 933 & 0,0019 \\
\hline CL4 & 4 & 15,26 & 961 & 0,0019 \\
\hline CL5 & 5 & 14,09 & 1323 & 0,0019 \\
\hline CL6 & 6 & 10,11 & 1409 & 0,0019 \\
\hline CL7 & 7 & 11,14 & 1464 & 0,0019 \\
\hline CL8 & 8 & 4,561 & 815 & 0,0019 \\
\hline CL9 & 9 & 3,882 & 878 & 0,0019 \\
\hline CL10 & 10 & 4,324 & 1178 & 0,0019 \\
\hline CL11 & 11 & 3,470 & 833 & 0,0019 \\
\hline CL12 & 12 & 2,376 & 993 & 0,0019 \\
\hline CL13 & 13 & 2,356 & 794 & 0,0019 \\
\hline CL14 & 14 & 2,702 & 1075 & 0,0019 \\
\hline CL15 & 15 & 2,794 & 946 & 0,0019 \\
\hline CL16 & 16 & 2,573 & 1186 & 0,0019 \\
\hline CL17 & 17 & 2,612 & 924 & 0,0019 \\
\hline CL18 & 18 & 3,593 & 948 & 0,0019 \\
\hline & & & &
\end{tabular}

Os classificadores foram então submetidos ao mesmo Conjunto de Teste (da Tabela 58) e os resultados obtidos estão listados na Tabela 68.

Tabela 68: Desempenho dos classificadores frente ao Conjunto de Teste (O.F.Te. $=\mathbf{0 , 1 1 3 4 )}$

\begin{tabular}{ccccccrc} 
Classificador & $\begin{array}{c}\text { T.Ex. } \\
(\mathbf{m s})\end{array}$ & O.R.Te. & $\begin{array}{c}\text { Acurácia } \\
(\mathbf{\%})\end{array}$ & TPR & FPR & Precision & Recall \\
\hline CL1 & 21,1 & 0,0121 & 88,53 & 0,4444 & 0,1093 & 0,0476 & 0,4444 \\
\hline CL2 & 31,4 & 0,1080 & 97,57 & 0,9125 & 0,0166 & 0,8690 & 0,9125 \\
\hline CL3 & 18,4 & 0,0810 & 95,95 & 0,9500 & 0,0396 & 0,6786 & 0,9500 \\
\hline CL4 & 22,8 & 0,1161 & 95,68 & 0,8023 & 0,0229 & 0,8214 & 0,8023 \\
\hline CL5 & 37,2 & 0,1255 & 95,01 & 0,7527 & 0,0216 & 0,8333 & 0,7527 \\
\hline CL6 & 27,7 & 0,1363 & 96,90 & 0,8020 & 0,0047 & 0,9643 & 0,8020 \\
\hline CL7 & 35,6 & 0,1471 & 96,36 & 0,7615 & 0,0016 & 0,9881 & 0,7615 \\
\hline CL8 & 19,2 & 0,1269 & 97,57 & 0,8511 & 0,0062 & 0,9524 & 0,8511 \\
\hline CL9 & 27,0 & 0,1188 & 97,30 & 0,8636 & 0,0123 & 0,9048 & 0,8636 \\
\hline CL10 & 24,5 & 0,1255 & 96,90 & 0,8280 & 0,0108 & 0,9167 & 0,8280 \\
\hline CL11 & 23,5 & 0,1215 & 96,49 & 0,8222 & 0,0154 & 0,8810 & 0,8222 \\
\hline CL12 & 33,7 & 0,1174 & 97,71 & 0,8851 & 0,0107 & 0,9167 & 0,8851 \\
\hline CL13 & 23,3 & 0,1201 & 97,17 & 0,8539 & 0,0123 & 0,9048 & 0,8539 \\
\hline
\end{tabular}




\begin{tabular}{rrrrrrrr} 
CL14 & 23,0 & 0,1269 & 97,57 & 0,8511 & 0,0062 & 0,9524 & 0,8511 \\
\hline CL15 & 23,5 & 0,1282 & 97,71 & 0,8526 & 0,0046 & 0,9643 & 0,8526 \\
\hline CL16 & 39,3 & 0,1255 & 97,44 & 0,8495 & 0,0077 & 0,9405 & 0,8495 \\
\hline CL17 & 22,8 & 0,1282 & 97,44 & 0,8421 & 0,0062 & 0,9524 & 0,8421 \\
\hline CL18 & 36,4 & 0,1377 & 96,76 & 0,7941 & 0,0047 & 0,9643 & 0,7941 \\
\hline & & Média & $\mathbf{9 6 , 4 5}$ & - & - & $\mathbf{0 , 8 5 8 5}$ & $\mathbf{0 , 8 1 7 7}$ \\
\cline { 3 - 7 }
\end{tabular}

A Figura 76 mostra o gráfico da acurácia dos classificadores para cada valor de $\mathrm{N}$ analisado. A linha pontilhada azul representa o valor médio da acurácia $(96,45 \%)$ para todos os valores de $\mathrm{N}$ e a linha tracejada vermelha representa o valor da acurácia $(96,77 \%)$ utilizando todos os atributos sem o uso do Autoencoder.

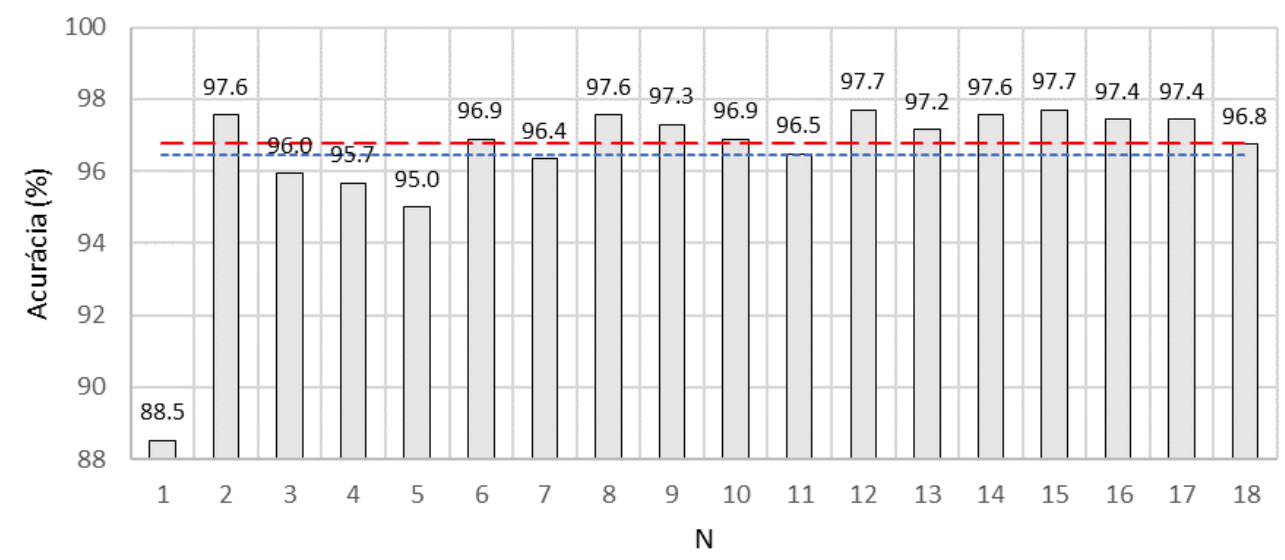

Figura 76: Valores de acurácia para cada valor de $\mathrm{N}$ analisado $($ O.F.Tr. $=0,002)$ FONTE: Própria

A Tabela 69 apresenta os valores obtidos com o treinamento da rede Autoencoder com vários valores de $\mathrm{N}$ (neurônios da camada escondida) frente ao Conjunto de Treinamento $\underline{\mathrm{CJ} 003}$ da Tabela 59. Adicionalmente, também foi calculado o MSE frente ao Conjunto de Teste, e os resultados também estão dispostos na tabela.

Tabela 69: Treinamentos do Autoencoder realizados com vários valores de $\mathrm{N}$ frente ao Conjunto de Treinamento CJ003

\begin{tabular}{rrrr} 
& \multicolumn{3}{c}{ Conjunto de Treinamento } \\
\cline { 2 - 4 } $\mathbf{N}$ & $\begin{array}{r}\text { Tempo } \\
(\mathbf{s})\end{array}$ & Épocas & $\begin{array}{r}\text { MSE } \\
\left(\mathbf{1 0}^{-3}\right)\end{array}$ \\
\hline 1 & 5,7 & 444 & 309,6 \\
\hline 2 & 8,3 & 735 & 130,7 \\
\hline 3 & 10,3 & 868 & 65,5 \\
\hline 4 & 11,5 & 917 & 45,0 \\
\hline 5 & 12,9 & 852 & 35,6
\end{tabular}

Conjunto de Teste

\begin{tabular}{rr}
\hline $\begin{array}{r}\text { Targets } \\
\text { MSE }\left(\mathbf{1 0}^{-3}\right)\end{array}$ & $\begin{array}{r}\text { Outliers } \\
\text { MSE }\left(\mathbf{1 0}^{-3}\right)\end{array}$ \\
\hline 286,5 & 2973 \\
\hline 124,2 & 2508 \\
\hline 59,0 & 2329 \\
\hline 37,0 & 2263 \\
\hline 29,6 & 1518 \\
\hline
\end{tabular}




\begin{tabular}{rrrr} 
& \multicolumn{3}{c}{ Conjunto de Treinamento } \\
\cline { 2 - 4 } $\mathbf{N}$ & $\begin{array}{r}\text { Tempo } \\
(\mathbf{s})\end{array}$ & Épocas & $\begin{array}{r}\text { MSE } \\
\left(\mathbf{1 0}^{-3} \mathbf{)}\right.\end{array}$ \\
\hline 6 & 11,4 & 931 & 28,6 \\
\hline 7 & 15,8 & 1038 & 27,2 \\
\hline 8 & 17,3 & 1296 & 22,7 \\
\hline 9 & 32,6 & 2239 & 20,1 \\
\hline 10 & 11,9 & 896 & 21,0 \\
\hline 11 & 31,5 & 1865 & 20,2 \\
\hline 12 & 23,2 & 1538 & 23,4 \\
\hline 13 & 21,8 & 1360 & 23,5 \\
\hline 14 & 31,2 & 1951 & 20,4 \\
\hline 15 & 19,6 & 1061 & 20,5 \\
\hline 16 & 36,7 & 2210 & 20,6 \\
\hline 17 & 31,3 & 1788 & 20,0 \\
\hline 18 & 20,3 & 1154 & 20,6 \\
\hline
\end{tabular}

\begin{tabular}{rr}
\multicolumn{2}{c}{ Conjunto de Teste } \\
\hline $\begin{array}{r}\text { Targets } \\
\text { MSE }\left(\mathbf{1 0}^{-3}\right)\end{array}$ & $\begin{array}{r}\text { Outliers } \\
\text { MSE }^{\left(\mathbf{1 0}^{-3}\right)}\end{array}$ \\
\hline 22,9 & 1510 \\
\hline 21,7 & 1490 \\
\hline 21,2 & 559,2 \\
\hline 19,0 & 443,4 \\
\hline 20,1 & 429,7 \\
\hline 19,2 & 423,7 \\
\hline 19,5 & 915,4 \\
\hline 19,6 & 915,7 \\
\hline 19,5 & 423,3 \\
\hline 19,6 & 424,3 \\
\hline 19,6 & 425,1 \\
\hline 19,3 & 384,1 \\
\hline 19,7 & 429,2 \\
\hline
\end{tabular}

O classificador OCSVM foi então treinado com os novos atributos gerados pelo processo de redução de dimensionalidade (rede Autoencoder) utilizando o algoritmo da Figura 63.

Tabela 70: Treinamentos realizados com vários valores de $\mathbf{N}$ frente ao Conjunto de Treinamento CJ003 (O.F.Tr. = 0,003)

\begin{tabular}{ccccc} 
Classificador & $\mathbf{N}$ & $\boldsymbol{\gamma}$ & $\begin{array}{c}\text { T.Tr. } \\
\text { (ms) }\end{array}$ & O.R.Tr. \\
\hline CL1 & 1 & 293,0 & 1590 & 0,0029 \\
\hline CL2 & 2 & 42,02 & 1052 & 0,0029 \\
\hline CL3 & 3 & 8,463 & 982 & 0,0029 \\
\hline CL4 & 4 & 22,25 & 1179 & 0,0029 \\
\hline CL5 & 5 & 17,54 & 1049 & 0,0029 \\
\hline CL6 & 6 & 13,29 & 1019 & 0,0029 \\
\hline CL7 & 7 & 6,55 & 838 & 0,0029 \\
\hline CL8 & 8 & 6,95 & 913 & 0,0029 \\
\hline CL9 & 9 & 4,60 & 1843 & 0,0029 \\
\hline CL10 & 10 & 5,52 & 1094 & 0,0029 \\
\hline CL11 & 11 & 3,38 & 1148 & 0,0029 \\
\hline CL12 & 12 & 3,54 & 948 & 0,0029 \\
\hline CL13 & 13 & 4,27 & 1221 & 0,0029 \\
\hline CL14 & 14 & 4,47 & 1473 & 0,0029 \\
\hline CL15 & 15 & 4,25 & 1236 & 0,0029 \\
\hline CL16 & 16 & 4,49 & 1352 & 0,0029 \\
\hline CL17 & 17 & 4,67 & 1323 & 0,0029 \\
\hline CL18 & 18 & 5,50 & 1406 & 0,0029 \\
\hline & & & &
\end{tabular}

Os classificadores foram então submetidos ao mesmo Conjunto de Teste (da Tabela 58) e os resultados obtidos estão listados na Tabela 71. 
Tabela 71: Desempenho dos classificadores frente ao Conjunto de Teste (O.F.Te. $=\mathbf{0 , 1 1 3 4 )}$

\begin{tabular}{ccccccrc} 
Classificador & $\begin{array}{c}\text { T.Ex. } \\
(\mathbf{m s})\end{array}$ & O.R.Te. & $\begin{array}{c}\text { Acurácia } \\
(\mathbf{\%})\end{array}$ & TPR & FPR & Precision & Recall \\
\hline CL1 & 22,7 & 0,0216 & 89,20 & 0,6250 & 0,1021 & 0,1190 & 0,6250 \\
\hline CL2 & 22,8 & 0,1066 & 97,44 & 0,9114 & 0,0181 & 0,8571 & 0,9114 \\
\hline CL3 & 16,2 & 0,0742 & 93,66 & 0,8364 & 0,0554 & 0,5476 & 0,8364 \\
\hline CL4 & 68,5 & 0,1282 & 96,09 & 0,7895 & 0,0139 & 0,8929 & 0,7895 \\
\hline CL5 & 48,3 & 0,0945 & 91,63 & 0,6571 & 0,0566 & 0,5476 & 0,6571 \\
\hline CL6 & 34,3 & 0,1323 & 96,22 & 0,7857 & 0,0109 & 0,9167 & 0,7857 \\
\hline CL7 & 28,7 & 0,1269 & 97,03 & 0,8298 & 0,0093 & 0,9286 & 0,8298 \\
\hline CL8 & 29,0 & 0,1255 & 95,28 & 0,7634 & 0,0201 & 0,8452 & 0,7634 \\
\hline CL9 & 27,8 & 0,1296 & 96,49 & 0,8021 & 0,0109 & 0,9167 & 0,8021 \\
\hline CL10 & 31,1 & 0,1201 & 96,09 & 0,8090 & 0,0184 & 0,8571 & 0,8090 \\
\hline CL11 & 29,8 & 0,1201 & 96,63 & 0,8315 & 0,0153 & 0,8810 & 0,8315 \\
\hline CL12 & 28,1 & 0,1188 & 96,22 & 0,8182 & 0,0184 & 0,8571 & 0,8182 \\
\hline CL13 & 30,1 & 0,1242 & 95,95 & 0,7935 & 0,0169 & 0,8690 & 0,7935 \\
\hline CL14 & 31,3 & 0,1282 & 95,82 & 0,7789 & 0,0155 & 0,8810 & 0,7789 \\
\hline CL15 & 28,8 & 0,1296 & 95,68 & 0,7708 & 0,0155 & 0,8810 & 0,7708 \\
\hline CL16 & 35,4 & 0,1323 & 95,41 & 0,7551 & 0,0156 & 0,8810 & 0,7551 \\
\hline CL17 & 33,9 & 0,1404 & 94,87 & 0,7212 & 0,0141 & 0,8929 & 0,7212 \\
\hline CL18 & 41,5 & 0,1444 & 95,01 & 0,7196 & 0,0110 & 0,9167 & 0,7196 \\
\hline & & Média & $\mathbf{9 5 , 2 6}$ & & - & $\mathbf{0 , 8 0 4 9}$ & $\mathbf{0 , 7 7 7 7}$ \\
\hline & & & & & & \\
\hline & & & & & & \\
\hline & & & & & & \\
\hline
\end{tabular}

A Figura 77 mostra o gráfico da acurácia dos classificadores para cada valor de $\mathrm{N}$ analisado. A linha pontilhada azul representa o valor médio da acurácia (95,26\%) para todos os valores de $\mathrm{N}$ e a linha tracejada vermelha representa o valor da acurácia $(97,31 \%)$ utilizando todos os atributos sem o uso do Autoencoder.

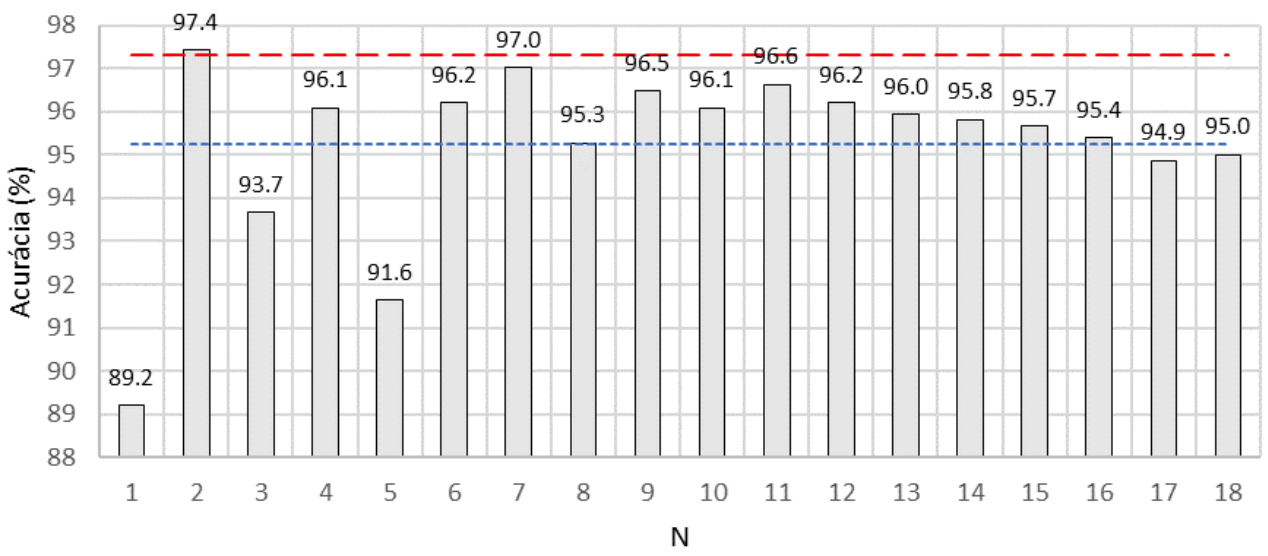

Figura 77: Valores de acurácia para cada valor de $\mathrm{N}$ analisado (O.F.Tr. $=0,003$ ) FONTE: Própria 
A Tabela 72 apresenta os valores obtidos com o treinamento da rede Autoencoder com vários valores de $\mathrm{N}$ (neurônios da camada escondida) frente ao Conjunto de Treinamento $\underline{\mathrm{CJ} 010}$ da Tabela 59. Adicionalmente, também foi calculado o MSE frente ao Conjunto de Teste, e os resultados também estão dispostos na tabela.

Tabela 72: Treinamentos do Autoencoder realizados com vários valores de $\mathrm{N}$ frente ao Conjunto de Treinamento CJ010

\begin{tabular}{|c|c|c|c|c|c|}
\hline \multirow[b]{2}{*}{$\mathbf{N}$} & \multicolumn{3}{|c|}{ Conjunto de Treinamento } & \multicolumn{2}{|c|}{ Conjunto de Teste } \\
\hline & $\begin{array}{r}\text { Tempo } \\
(\mathbf{s})\end{array}$ & Épocas & $\begin{array}{l}\text { MSE } \\
\left(10^{-3}\right)\end{array}$ & $\begin{array}{r}\text { Targets } \\
\text { MSE }\left(1^{-3}\right)\end{array}$ & $\begin{array}{r}\text { Outliers } \\
\text { MSE }\left(10^{-3}\right)\end{array}$ \\
\hline 1 & 4,7 & 430 & 313,1 & 286,7 & 2959 \\
\hline 2 & 9,3 & 760 & 134,2 & 124,5 & 2491 \\
\hline 3 & 10,1 & 763 & 116,1 & 101,4 & 2381 \\
\hline 4 & 8,5 & 593 & 50,8 & 37,0 & 2211 \\
\hline 5 & 11,4 & 891 & 34,7 & 30,3 & 947,5 \\
\hline 6 & 15,8 & 1093 & 27,8 & 23,6 & 949,8 \\
\hline 7 & 19,6 & 1325 & 23,9 & 21,8 & 421,1 \\
\hline 8 & 13,1 & 1078 & 22,5 & 20,7 & 411,5 \\
\hline 9 & 16,7 & 1142 & 21,7 & 19,9 & 413,4 \\
\hline 10 & 14,3 & 997 & 22,3 & 20,5 & 413,7 \\
\hline 11 & 15,6 & 1011 & 21,4 & 20,0 & 379,9 \\
\hline 12 & 17,9 & 1206 & 20,7 & 19,1 & 377,2 \\
\hline 13 & 29,1 & 1816 & 20,8 & 19,2 & 376,7 \\
\hline 14 & 26,5 & 1615 & 20,9 & 19,3 & 375,5 \\
\hline 15 & 18,7 & 1112 & 21,0 & 19,4 & 375,1 \\
\hline 16 & 25,2 & 1623 & 21,0 & 19,5 & 375,4 \\
\hline 17 & 40,1 & 2415 & 21,0 & 19,5 & 374,9 \\
\hline 18 & 46,7 & 2250 & 20,6 & 19,2 & 346,1 \\
\hline
\end{tabular}

O classificador OCSVM foi então treinado com os novos atributos gerados pelo processo de redução de dimensionalidade (rede Autoencoder) utilizando o algoritmo da Figura 63.

Tabela 73: Treinamentos realizados com vários valores de $\mathbf{N}$ frente ao Conjunto de Treinamento CJ010 (O.F.Tr. = 0,010)

\begin{tabular}{ccccc} 
Classificador & $\mathbf{N}$ & $\boldsymbol{\gamma}$ & $\begin{array}{c}\text { T.Tr. } \\
(\mathbf{m s})\end{array}$ & O.R.Tr. \\
\hline CL1 & 1 & 87,14 & 1121 & 0,0101 \\
\hline CL2 & 2 & 48,93 & 1387 & 0,0101 \\
\hline CL3 & 3 & 61,37 & 1206 & 0,0101 \\
\hline CL4 & 4 & 12,00 & 869 & 0,0101 \\
\hline CL5 & 5 & 10,72 & 1093 & 0,0101 \\
\hline CL6 & 6 & 13,79 & 1073 & 0,0101 \\
\hline CL7 & 7 & 11,36 & 1099 & 0,0101 \\
\hline CL8 & 8 & 4,661 & 887,4 & 0,0101 \\
\hline CL9 & 9 & 3,811 & 1032 & 0,0101 \\
\hline CL10 & 10 & 5,122 & 1077 & 0,0101 \\
\hline
\end{tabular}




\begin{tabular}{ccccc} 
Classificador & $\mathbf{N}$ & $\boldsymbol{\gamma}$ & $\begin{array}{c}\text { T.Tr. } \\
(\mathbf{m s})\end{array}$ & O.R.Tr. \\
\hline CL11 & 11 & 5,529 & 856 & 0,0101 \\
\hline CL12 & 12 & 2,650 & 951 & 0,0101 \\
\hline CL13 & 13 & 2,750 & 976 & 0,0101 \\
\hline CL14 & 14 & 2,943 & 1111 & 0,0101 \\
\hline CL15 & 15 & 3,564 & 1428 & 0,0101 \\
\hline CL16 & 16 & 3,782 & 1055 & 0,0101 \\
\hline CL17 & 17 & 3,862 & 906 & 0,0101 \\
\hline CL18 & 18 & 4,005 & 988 & 0,0101 \\
\hline
\end{tabular}

Os classificadores foram então submetidos ao mesmo Conjunto de Teste (da Tabela 58) e os resultados obtidos estão listados na Tabela 74.

\begin{tabular}{cccccccc}
\multicolumn{2}{c}{ Tabela 74: Desempenho dos classificadores frente ao Conjunto de Teste (O.F.Te. $=\mathbf{0 , 1 1 3 4})$} \\
Classificador & $\begin{array}{c}\text { T.Ex. } \\
\text { (ms) }\end{array}$ & O.R.Te. & $\begin{array}{c}\text { Acurácia } \\
(\boldsymbol{\%})\end{array}$ & TPR & FPR & Precision & Recall \\
\hline CL1 & 66,7 & 0,0364 & 89,88 & 0,6667 & 0,0924 & 0,2143 & 0,6667 \\
\hline CL2 & 30,8 & 0,1080 & 97,30 & 0,9000 & 0,0182 & 0,8571 & 0,9000 \\
\hline CL3 & 25,6 & 0,1201 & 96,90 & 0,8427 & 0,0138 & 0,8929 & 0,8427 \\
\hline CL4 & 25,4 & 0,1039 & 93,66 & 0,7403 & 0,0407 & 0,6786 & 0,7403 \\
\hline CL5 & 30,7 & 0,0783 & 90,28 & 0,6034 & 0,0717 & 0,4167 & 0,6034 \\
\hline CL6 & 37,1 & 0,1255 & 95,55 & 0,7742 & 0,0185 & 0,8571 & 0,7742 \\
\hline CL8 & 50,4 & 0,1255 & 95,28 & 0,7643 & 0,0201 & 0,8452 & 0,7634 \\
\hline CL9 & 30,6 & 0,1120 & 95,55 & 0,8072 & 0,0258 & 0,7976 & 0,8072 \\
\hline CL10 & 35,6 & 0,1147 & 95,01 & 0,7765 & 0,0274 & 0,7857 & 0,7765 \\
\hline CL11 & 65,8 & 0,1134 & 95,41 & 0,7976 & 0,0259 & 0,7976 & 0,7976 \\
\hline CL12 & 31,4 & 0,1161 & 94,87 & 0,7674 & 0,0275 & 0,7857 & 0,7674 \\
\hline CL13 & 31,3 & 0,1161 & 95,14 & 0,7791 & 0,0260 & 0,7976 & 0,7791 \\
\hline CL14 & 38,1 & 0,1147 & 95,01 & 0,7765 & 0,0274 & 0,7857 & 0,7765 \\
\hline CL15 & 31,2 & 0,1147 & 94,74 & 0,7647 & 0,0290 & 0,7738 & 0,7647 \\
\hline CL16 & 42,7 & 0,1161 & 94,87 & 0,7674 & 0,0275 & 0,7857 & 0,7674 \\
\hline CL17 & 28,7 & 0,1174 & 94,74 & 0,7586 & 0,0275 & 0,7857 & 0,7586 \\
\hline CL18 & 30,3 & 0,1242 & 94,60 & 0,7391 & 0,0247 & 0,8095 & 0,7391 \\
\hline & 30,5 & 0,1309 & 94,20 & 0,7113 & 0,0233 & 0,8214 & 0,7113 \\
\hline & & Média & $\mathbf{9 4 , 6 1}$ & - & - & $\mathbf{0 , 7 4 9 3}$ & $\mathbf{0 , 7 6 3 1}$ \\
\hline
\end{tabular}

A Figura 78 mostra o gráfico da acurácia dos classificadores para cada valor de $\mathrm{N}$ analisado. A linha pontilhada azul representa o valor médio da acurácia $(94,61 \%)$ para todos os valores de $\mathrm{N}$ e a linha tracejada vermelha representa o valor da acurácia $(97,30 \%)$ utilizando todos os atributos sem o uso do Autoencoder. 


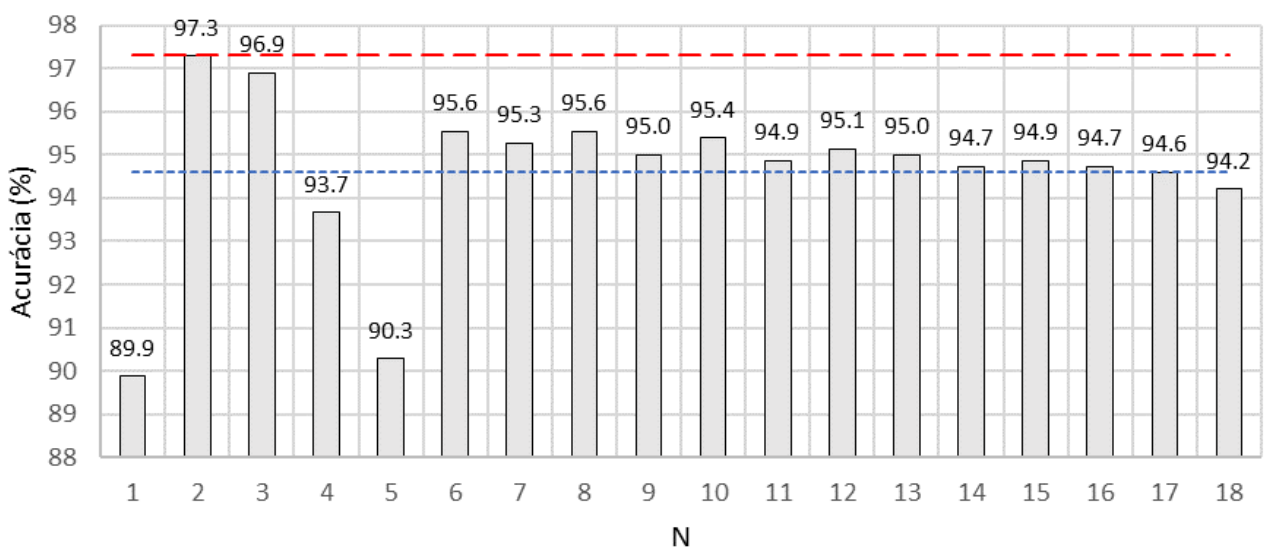

Figura 78: Valores de acurácia para cada valor de $\mathrm{N}$ analisado (O.F.Tr. $=0,010)$ FONTE: Própria

A Tabela 75 apresenta os valores obtidos com o treinamento da rede Autoencoder com vários valores de $\mathrm{N}$ (neurônios da camada escondida) frente ao Conjunto de Treinamento CJ020 da Tabela 59. Adicionalmente, também foi calculado o MSE frente ao Conjunto de Teste, e os resultados também estão dispostos na tabela.

Tabela 75: Treinamentos do Autoencoder realizados com vários valores de $\mathrm{N}$ frente ao Conjunto de Treinamento CJ020

\begin{tabular}{rrrr} 
& \multicolumn{3}{c}{ Conjunto de Treinamento } \\
\cline { 2 - 4 } $\mathbf{N}$ & $\begin{array}{r}\text { Tempo } \\
(\mathbf{s})\end{array}$ & Épocas & $\begin{array}{r}\text { MSE } \\
\left(\mathbf{1 0}^{-3}\right)\end{array}$ \\
\hline 1 & 4,5 & 339 & 342,0 \\
\hline 2 & 5,7 & 510 & 161,5 \\
\hline 3 & 11,3 & 974 & 83,3 \\
\hline 4 & 8,8 & 881 & 53,4 \\
\hline 5 & 7,1 & 647 & 40,2 \\
\hline 6 & 7,5 & 661 & 28,8 \\
\hline 7 & 10,3 & 812 & 25,5 \\
\hline 8 & 16,9 & 1164 & 24,3 \\
\hline 9 & 18,1 & 1433 & 23,1 \\
\hline 10 & 13,3 & 1093 & 22,5 \\
\hline 11 & 12,7 & 920 & 22,9 \\
\hline 12 & 19,6 & 1493 & 23,0 \\
\hline 13 & 23,1 & 1757 & 22,2 \\
\hline 14 & 20,1 & 1503 & 22,3 \\
\hline 15 & 28,3 & 2003 & 22,3 \\
\hline 16 & 22,5 & 1585 & 21,3 \\
\hline 17 & 44,3 & 2225 & 21,3 \\
\hline 18 & 45,1 & 2264 & 22,1 \\
\hline & & &
\end{tabular}

Conjunto de Teste

\begin{tabular}{rr}
\hline $\begin{array}{r}\text { Targets } \\
\text { MSE (10 }\end{array} \mathbf{)}$ & $\begin{array}{r}\text { Outliers } \\
\left.\text { MSE (10 }^{-3}\right)\end{array}$ \\
\hline 287,7 & 2888 \\
\hline 126,7 & 2333 \\
\hline 69,1 & 1071 \\
\hline 45,9 & 567,6 \\
\hline 35,3 & 258,0 \\
\hline 25,3 & 217,3 \\
\hline 22,0 & 194,9 \\
\hline 21,8 & 168,0 \\
\hline 20,3 & 179,6 \\
\hline 20,2 & 158,4 \\
\hline 20,1 & 179,8 \\
\hline 19,6 & 188,6 \\
\hline 19,2 & 180,1 \\
\hline 19,3 & 179,9 \\
\hline 19,4 & 179,7 \\
\hline 18,9 & 155,0 \\
\hline 19,0 & 154,4 \\
\hline 19,2 & 178,8 \\
\hline &
\end{tabular}


O classificador OCSVM foi então treinado com os novos atributos gerados pelo processo de redução de dimensionalidade (rede Autoencoder) utilizando o algoritmo da Figura 63.

Tabela 76: Treinamentos realizados com vários valores de OutlierFraction frente ao Conjunto de Treinamento CJ020 (O.F.Tr. = 0,020)

\begin{tabular}{ccccc} 
Classificador & $\mathbf{N}$ & $\boldsymbol{\gamma}$ & $\begin{array}{c}\text { T.Tr. } \\
(\mathbf{m s})\end{array}$ & O.R.Tr. \\
\hline CL1 & 1 & 136,5 & 2887 & 0,0200 \\
\hline CL2 & 2 & 47,89 & 1390 & 0,0200 \\
\hline CL3 & 3 & 14,13 & 1032 & 0,0200 \\
\hline CL4 & 4 & 6,246 & 825 & 0,0200 \\
\hline CL5 & 5 & 11,54 & 1145 & 0,0200 \\
\hline CL6 & 6 & 11,54 & 1043 & 0,0200 \\
\hline CL7 & 7 & 8,231 & 860 & 0,0200 \\
\hline CL8 & 8 & 9,050 & 1187 & 0,0200 \\
\hline CL9 & 9 & 4,536 & 782 & 0,0200 \\
\hline CL10 & 10 & 4,443 & 901 & 0,0200 \\
\hline CL11 & 11 & 4,478 & 926 & 0,0200 \\
\hline CL12 & 12 & 3,630 & 1161 & 0,0200 \\
\hline CL13 & 13 & 3,672 & 1052 & 0,0200 \\
\hline CL14 & 14 & 3,640 & 1100 & 0,0200 \\
\hline CL15 & 15 & 3,369 & 1023 & 0,0200 \\
\hline CL16 & 16 & 3,691 & 1136 & 0,0200 \\
\hline CL17 & 17 & 3,496 & 1279 & 0,0200 \\
\hline CL18 & 18 & 3,536 & 974 & 0,0200 \\
\hline & & & &
\end{tabular}

Os classificadores foram então submetidos ao mesmo Conjunto de Teste (da Tabela 58) e os resultados obtidos estão listados na Tabela 77.

Tabela 77: Desempenho dos classificadores frente ao Conjunto de Teste (O.F.Te. $=\mathbf{0 , 1 1 3 4}$ )

\begin{tabular}{ccccccrc} 
Classificador & $\begin{array}{c}\text { T.Ex. } \\
(\mathbf{m s})\end{array}$ & O.R.Te. & $\begin{array}{c}\text { Acurácia } \\
(\mathbf{\%})\end{array}$ & TPR & FPR & Precision & Recall \\
\hline CL1 & 31,8 & 0,0526 & 88,53 & 0,4872 & 0,0926 & 0,2262 & 0,4872 \\
\hline CL2 & 39,3 & 0,0810 & 92,17 & 0,7167 & 0,0602 & 0,5119 & 0,7167 \\
\hline CL3 & 18,7 & 0,0648 & 91,09 & 0,6875 & 0,0736 & 0,3929 & 0,6875 \\
\hline CL4 & 24,1 & 0,0715 & 92,31 & 0,7547 & 0,0640 & 0,4762 & 0,7547 \\
\hline CL5 & 25,8 & 0,0783 & 89,47 & 0,5517 & 0,0761 & 0,3810 & 0,5517 \\
\hline CL6 & 29,4 & 0,1134 & 93,52 & 0,7143 & 0,0365 & 0,7143 & 0,7143 \\
\hline CL7 & 26,7 & 0,0918 & 92,17 & 0,6912 & 0,0550 & 0,5595 & 0,6912 \\
\hline CL8 & 34,3 & 0,1107 & 92,98 & 0,6951 & 0,0410 & 0,6786 & 0,6951 \\
\hline CL9 & 24,0 & 0,0810 & 91,63 & 0,6833 & 0,0631 & 0,4881 & 0,6833 \\
\hline CL10 & 22,8 & 0,0850 & 92,04 & 0,6984 & 0,0590 & 0,5238 & 0,6984 \\
\hline CL11 & 22,8 & 0,0810 & 91,36 & 0,6667 & 0,0646 & 0,4762 & 0,6667 \\
\hline CL12 & 44,7 & 0,0837 & 91,90 & 0,6935 & 0,0604 & 0,5119 & 0,6935 \\
\hline CL13 & 25,0 & 0,0864 & 91,36 & 0,6563 & 0,0620 & 0,5000 & 0,6563 \\
\hline CL14 & 29,4 & 0,0891 & 91,09 & 0,6364 & 0,0622 & 0,5000 & 0,6364 \\
\hline CL15 & 25,3 & 0,0981 & 90,82 & 0,6176 & 0,0624 & 0,5000 & 0,6176 \\
\hline
\end{tabular}




\begin{tabular}{ccccrrrr} 
Classificador & $\begin{array}{c}\text { T.Ex. } \\
(\mathbf{m s})\end{array}$ & O.R.Te. & $\begin{array}{c}\text { Acurácia } \\
(\boldsymbol{\%})\end{array}$ & TPR & FPR & Precision & Recall \\
\hline CL16 & 29,6 & 0,1081 & 91,90 & 0,6500 & 0,0484 & 0,6190 & 0,6500 \\
\hline CL17 & 25,8 & 0,1093 & 91,77 & 0,6420 & 0,0485 & 0,6190 & 0,6420 \\
\hline CL18 & 27,8 & 0,1012 & 90,15 & 0,5733 & 0,0616 & 0,5119 & 0,5733 \\
\hline & & Média & $\mathbf{9 1 , 4 6}$ & - & - & $\mathbf{0 , 5 1 0 6}$ & $\mathbf{0 , 6 5 6 4}$ \\
\cline { 3 - 7 }
\end{tabular}

A Figura 79 mostra o gráfico da acurácia dos classificadores para cada valor de $\mathrm{N}$ analisado. A linha pontilhada azul representa o valor médio da acurácia $(91,46 \%)$ para todos os valores de $\mathrm{N}$ e a linha tracejada vermelha representa o valor da acurácia $(96,64 \%)$ utilizando todos os atributos sem o uso do Autoencoder.

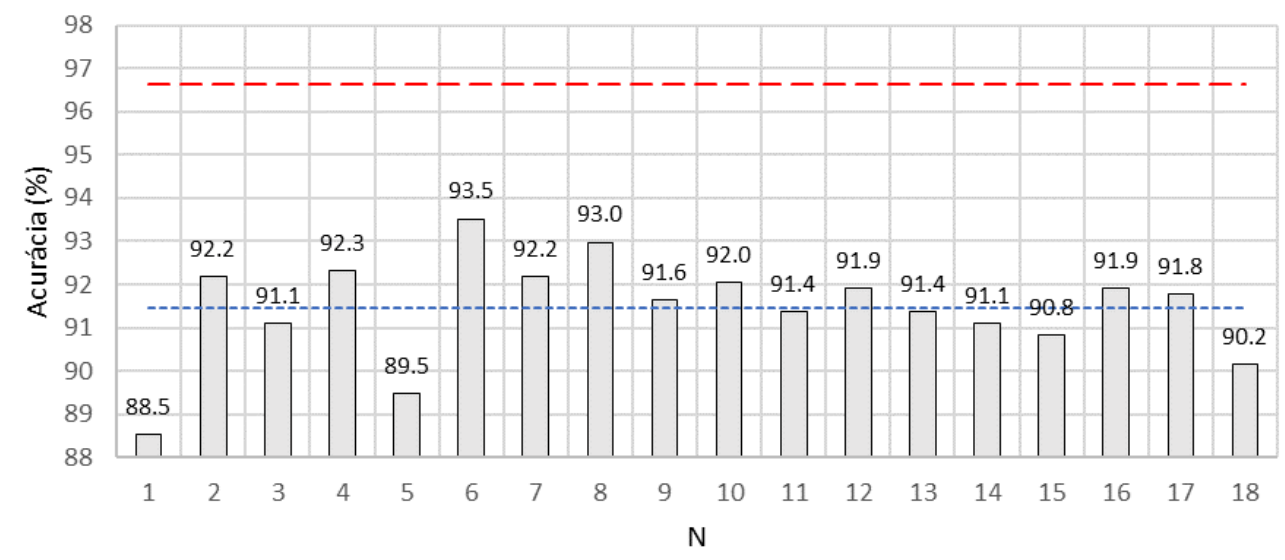

Figura 79: Valores de acurácia para cada valor de $\mathrm{N}$ analisado $($ O.F.Tr. $=0,020)$ FONTE: Própria

\subsubsection{Sem Redução da Dimensionalidade e classificação usando OCSVM}

Para esse caso, não foi realizada a etapa de Redução da Dimensionalidade (com o Autoencoder), assim todos os atributos contidos nas amostras contidas do Conjunto de Treinamento e do Conjunto de Teste foram diretamente aplicados às entradas dos classificadores.

Utilizando-se os conjuntos de treinamento apresentados na Tabela 59 foram obtidos os resultados apresentados na Tabela 78 .

Tabela 78: Treinamentos realizados sem a redução da dimensionalidade.

\begin{tabular}{cccccc} 
Classificador & $\begin{array}{c}\text { Conjunto } \\
\text { Treinamento }\end{array}$ & O.F.Tr. & $\boldsymbol{\gamma}$ & $\begin{array}{c}\text { T.Tr. } \\
\text { (ms) }\end{array}$ & O.R.Tr. \\
\hline CL1 & CJ000 & 0,000 & 1,9505 & 993,1 & 0,0000 \\
\hline CL2 & CJ001 & 0,001 & 2,3071 & 1081 & 0,0011 \\
\hline
\end{tabular}




\begin{tabular}{cccccc} 
Classificador & $\begin{array}{c}\text { Conjunto } \\
\text { Treinamento }\end{array}$ & O.F.Tr. & $\boldsymbol{\gamma}$ & $\begin{array}{c}\text { T.Tr. } \\
\text { (ms) }\end{array}$ & O.R.Tr. \\
\hline CL3 & CJ002 & 0,002 & 1,5904 & 955 & 0,0019 \\
\hline CL4 & CJ003 & 0,003 & 1,4294 & 886 & 0,0029 \\
\hline CL5 & CJ010 & 0,010 & 1,2365 & 1047 & 0,0101 \\
\hline CL6 & CJ020 & 0,020 & 1,3106 & 946 & 0,0200 \\
\hline
\end{tabular}

Os classificadores foram então submetidos ao mesmo Conjunto de Teste e os resultados obtidos estão listados na Tabela 79.

\begin{tabular}{|c|c|c|c|c|c|c|c|}
\hline Classificador & $\begin{array}{l}\text { T.Ex. } \\
\text { (ms) }\end{array}$ & O.R.Te. & $\begin{array}{c}\text { Acurácia } \\
(\%)\end{array}$ & TPR & FPR & Precision & Recall \\
\hline CL1 & 29,3 & 0,1534 & 96,10 & 0,7456 & 0 & 1 & 0,7456 \\
\hline CL2 & 35,7 & 0,1575 & 95,69 & 0,7265 & 0 & 1 & 0,7265 \\
\hline CL3 & 25,9 & 0,1440 & 96,77 & 0,7850 & 0,0016 & 0,9882 & 0,7850 \\
\hline CL4 & 31,9 & 0,1359 & 97,31 & 0,8218 & 0,0031 & 0,9765 & 0,8218 \\
\hline CL5 & 33,2 & 0,1144 & 97,30 & 0,8351 & 0,0062 & 0,9529 & 0,8351 \\
\hline \multirow[t]{2}{*}{ CL6 } & 25,0 & 0,1346 & 96,64 & 0,8000 & 0,0078 & 0,9412 & 0,8000 \\
\hline & & Média & 96,64 & - & - & 0,9765 & $\mathbf{0 , 7 8 5 7}$ \\
\hline
\end{tabular}

\subsubsection{Classificadores Unários - Avaliação Final}

Conforme os resultados apresentados, os classificadores unários com os melhores desempenhos (Acurácia superior a $\mathbf{9 7 \%}$ frente ao Conjunto de Teste) foram préselecionados para serem avaliados frente aos outros Conjuntos de Teste com dados capturados nos Cenários 1, 2 e 3. Esse valor de limiar da acurácia foi escolhido baseandose nos valores de acurácia obtidos por classificadores unários em trabalhos correlatos já citados. Esses classificadores estão destacados em suas respectivas tabelas.

Os resultados obtidos considerando-se esse Conjunto de Teste único para todos os classificadores pré-selecionados estão apresentados na Tabela 80.

\begin{tabular}{|c|c|c|c|c|c|c|c|}
\hline Classif. & $\begin{array}{c}\text { Outlier } \\
\text { Fraction }\end{array}$ & $\mathbf{N}^{\mathbf{o}}$ Entradas & $\begin{array}{r}\text { Conjunto d } \\
\text { Tempo } \\
(\mathrm{ms}) \\
\end{array}$ & $\begin{array}{l}\text { Teste } \\
\text { Acurácia } \\
(\%)\end{array}$ & Precision & Recall & F-score \\
\hline CL1 & \multirow{4}{*}{0,000} & 2 & 23,0 & 98,25 & 0,8810 & 0,9610 & 0,9193 \\
\hline CL2 & & 7 & 27,7 & 98,11 & 0,9881 & 0,8646 & 0,9222 \\
\hline CL3 & & 8 & 31,7 & 97,71 & 0,9881 & 0,8384 & 0,9071 \\
\hline CL4 & & 9 & 23,6 & 97,84 & 0,9881 & 0,8469 & 0,9121 \\
\hline
\end{tabular}




\begin{tabular}{|c|c|c|c|c|c|c|c|}
\hline Classif. & $\begin{array}{c}\text { Outlier } \\
\text { Fraction }\end{array}$ & $\mathbf{N}^{0}$ Entradas & $\begin{array}{r}\text { Tempo } \\
(\mathbf{m s})\end{array}$ & $\begin{array}{r}\text { Acurácia } \\
(\%)\end{array}$ & Precision & Recall & F-score \\
\hline CL5 & & 10 & 37,0 & 98,79 & 0,9524 & 0,9412 & 0,9468 \\
\hline CL6 & & 11 & 24,8 & 97,84 & 0,9524 & 0,8696 & 0,9091 \\
\hline CL7 & & 12 & 22,8 & 97,84 & 0,9524 & 0,8696 & 0,9091 \\
\hline CL8 & & 13 & 23,2 & 97,57 & 0,9524 & 0,8511 & 0,8989 \\
\hline CL9 & & 14 & 26,3 & 97,30 & 0,9524 & 0,8333 & 0,8889 \\
\hline CL10 & & 15 & 27,7 & 97,30 & 0,9524 & 0,8333 & 0,8889 \\
\hline CL11 & & 16 & 24,9 & 97,44 & 0,9524 & 0,8421 & 0,8939 \\
\hline CL12 & & 17 & 25,8 & 97,17 & 0,9405 & 0,8316 & 0,8827 \\
\hline CL13 & & 18 & 23,1 & 97,57 & 0,9405 & 0,8587 & 0,8977 \\
\hline CL14 & \multirow{6}{*}{0,001} & 2 & 22,0 & 98,11 & 0,8810 & 0,9487 & 0,9136 \\
\hline CL15 & & 9 & 25,0 & 97,84 & 0,9881 & 0,8469 & 0,9121 \\
\hline CL16 & & 10 & 25,1 & 97,57 & 0,9881 & 0,8300 & 0,9022 \\
\hline CL17 & & 11 & 21,3 & 97,44 & 0,9881 & 0,8218 & 0,8973 \\
\hline CL18 & & 12 & 27,8 & 97,17 & 0,9881 & 0,8058 & 0,8877 \\
\hline CL19 & & 13 & 23,5 & 97,03 & 0,9881 & 0,7981 & 0,8830 \\
\hline CL20 & \multirow{9}{*}{0,002} & 2 & 31,4 & 97,57 & 0,8690 & 0,9125 & 0,8902 \\
\hline CL21 & & 8 & 19,2 & 97,57 & 0,9524 & 0,8511 & 0,8989 \\
\hline CL22 & & 9 & 27,0 & 97,30 & 0,9048 & 0,8636 & 0,8837 \\
\hline CL23 & & 12 & 33,7 & 97,71 & 0,9167 & 0,8851 & 0,9006 \\
\hline CL24 & & 13 & 23,3 & 97,17 & 0,9048 & 0,8539 & 0,8786 \\
\hline CL25 & & 14 & 23,0 & 97,57 & 0,9524 & 0,8511 & 0,8989 \\
\hline CL26 & & 15 & 23,5 & 97,71 & 0,9643 & 0,8526 & 0,9050 \\
\hline CL27 & & 16 & 39,3 & 97,44 & 0,9405 & 0,8495 & 0,8927 \\
\hline CL28 & & 17 & 22,8 & 97,44 & 0,9524 & 0,8421 & 0,8939 \\
\hline CL29 & \multirow{3}{*}{0,003} & 2 & 22,8 & 97,44 & 0,8571 & 0,9114 & 0,8834 \\
\hline CL30 & & 7 & 28,7 & 97,03 & 0,9286 & 0,8298 & 0,8764 \\
\hline CL31 & & TODOS & 31,9 & 97,31 & 0,9765 & 0,8218 & 0,8925 \\
\hline CL32 & \multirow{2}{*}{0,010} & 2 & 30,8 & 97,30 & 0,8571 & 0,9000 & 0,8780 \\
\hline CL33 & & TODOS & 33,2 & 97,30 & 0,9529 & 0,8351 & 0,8901 \\
\hline
\end{tabular}

A análise dos dados da Tabela 80 permite inferir que o classificador CL5 (com 10 entradas) é o que apresentou melhor desempenho, dentre os classificadores previamente selecionados, frente ao Conjunto de Teste com Acurácia de 98,79\% e F-score de 0,9468.

Uma importante consideração a ser feita é que, nos casos em que se deseja obter um IDS com alta Taxa de Detecção (que é diretamente proporcional à métrica Precision) em detrimento da Taxa de Alarmes Falsos (que é inversamente proporcional à métrica Recall), pode-se escolher um classificador que obtenha uma maior Precision abrindo mão da maior Acurácia. Nesse caso, analisando a tabela, o classificador que apresenta maior Precision com a maior Recall é o CL2 com valores 0,9881 e 0,8646 respectivamente. Esse caso foi discutido na Seção 4.5.4. 
Complementarmente, a fim de avaliar se o desempenho do classificador é melhorada com a utilização, mesmo que poucas, de amostras Outliers no Conjunto de Treinamento, conforme sugerido por (MAGLARAS; JIANG, 2014), calculou-se o valor total do MSE para cada valor de O.F.Tr. avaliado. Calculou-se a média de cada valor entre os 18 valores de $\mathrm{N}$ avaliados. Esses resultados estão dispostos na Tabela 81.

Tabela 81: Valores de MSE Total dos Autoencoders para cada valor de O.F.Tr. avaliado MSE Médio

\begin{tabular}{rrrrr}
\cline { 2 - 4 } O.F.Tr. & \multicolumn{3}{c}{ Treinamento } & \multicolumn{2}{c}{ Teste } & \multirow{2}{*}{ Total } \\
\cline { 2 - 4 } & Targets & Targets & Outliers & \\
\hline 0,000 & 51,4 & 50,8 & 2311,9 & 2311,9 \\
\hline 0,001 & 49,7 & 46,5 & 2129,1 & 2129,1 \\
\hline 0,002 & 48,5 & 44,2 & 1618,6 & 1618,6 \\
\hline 0,003 & 48,6 & 44,3 & 1131,3 & 1131,3 \\
\hline 0,010 & 51,9 & 46,8 & 921,1 & 921,1 \\
\hline 0,020 & 54,6 & 46,1 & 524,0 & 524,0 \\
\hline
\end{tabular}

Nota-se que o valor total de MSE dos autoencoders utilizados diminuiu a medida em que foram utilizadas mais amostras outliers no Conjunto de Treinamento para ajustar os pesos sinápticos das redes autoencoders.

Ademais, continuando a análise, elencou-se os melhores classificadores (com os maiores valores de F-score) da Tabela 80 para cada valor de O.F.Tr. avaliado. Esses classificadores estão dispostos na Tabela 82.

\begin{tabular}{|c|c|c|c|c|c|c|}
\hline O.F.Tr. & Classificador & $\begin{array}{r}\text { Tempo } \\
(\mathrm{ms}) \\
\end{array}$ & $\begin{array}{r}\text { Acurácia } \\
(\%)\end{array}$ & Precision & Recall & F-score \\
\hline 0,000 & CL5 & 37,0 & 98,79 & 0,9524 & 0,9412 & 0,9468 \\
\hline 0,001 & CL13 & 22,0 & 98,11 & 0,8810 & 0,9487 & 0,9136 \\
\hline 0,002 & CL25 & 23,5 & 97,71 & 0,9643 & 0,8526 & 0,9050 \\
\hline 0,003 & CL30 & 31,9 & 97,31 & 0,9765 & 0,8218 & 0,8925 \\
\hline 0,010 & CL32 & 33,2 & 97,30 & 0,9529 & 0,8351 & 0,8901 \\
\hline
\end{tabular}

Pela análise dos dados da tabela verifica-se que houve uma diminuição do tempo de classificação dos melhores classificadores quando estes foram treinados com algumas amostras Outliers no Conjunto de Treinamento (classificadores CL13, CL25, CL30 e CL32). Além disso, apesar de apresentarem menores valores de Acurácia, alguns deles 
apresentaram um leve aumento da Precision, que implica uma maior Taxa de Detecção por parte do IDS (classificadores CL25, CL30 e CL32). Assim, para os casos em que se deseja uma maior taxa de detecção e se tenha em mãos algumas poucas amostras de tráfego anômalo, pode ser interessante utilizá-las no Conjunto de Treinamento dos classificadores OCSVM.

Contudo, nesse trabalho, o valor da F-score foi previamente definido como sendo o principal índice de desempenho a ser considerado. Desta forma, o classificador CL5, treinado com nenhuma amostra Outlier no Conjunto de Treinamento, foi considerado como melhor e, portanto, o escolhido para compor o IDS a ser avaliado nas seções posteriores em outros cenários de tráfego da rede PROFINET.

\subsection{Avaliação Final do IDS}

Para a avaliação final dos resultados das etapas anteriores, foram escolhidas as estruturas que apresentaram os melhores desempenhos para a Abordagem Binária (Tabela 53) e para a Abordagem Unária (Tabela 80).

\subsubsection{Avaliação final do IDS com classificação binária}

Para a abordagem binária houve empate (índice $F$-measure $=1$ ) entre 13 estruturas analisadas (CL1, CL2... CL11, CL13 e CL14 apresentadas na Tabela 53). Desta forma, foi então escolhida a estrutura que apresentou o menor tempo de Execução: a estrutura CL6.

A estrutura CL6 é aquela que utilizou os atributos A10, A11 e A14 que foram selecionados pela técnica SVM RFE e foram classificados com RNA com 15 neurônios na camada escondida ilustrada na Figura 80. 


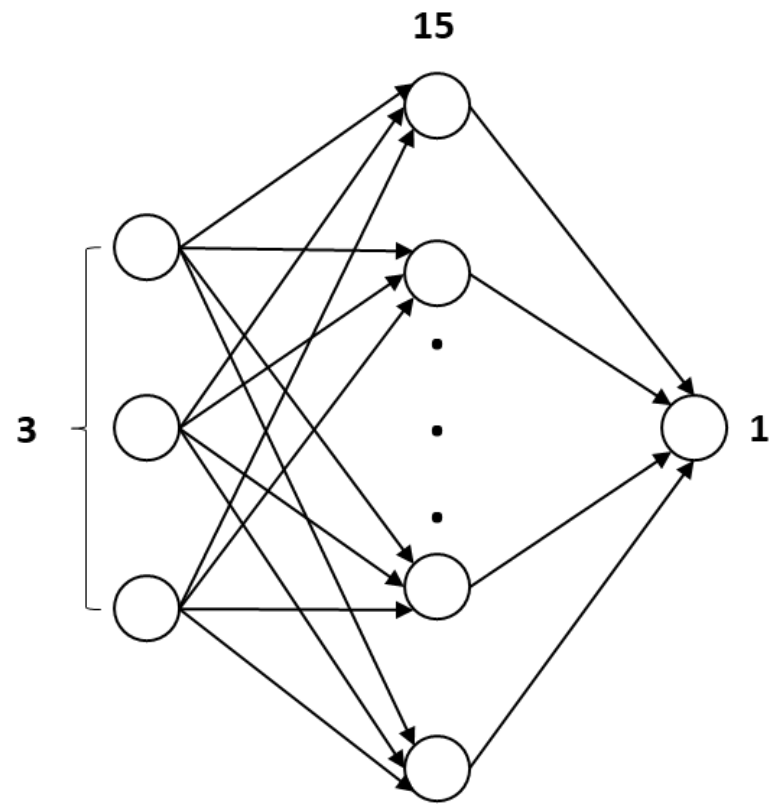

Figura 80: RNA com 3 entradas e 15 neurônios na camada escondida FONTE: Própria

A estrutura de classificação C6 foi então utilizada para compor um IDS e foi treinada com os dados dos outros cenários (Cenário 1, 2 e 3) utilizando-se a mesma metodologia.

Os resultados dessa classificação, utilizando-se seus respectivos conjuntos de teste (apresentados na Tabela 83), estão dispostos na Tabela 84 (os resultados para o Cenário 4 estão também contidos na tabela para efeito de comparação).

Tabela 83: Conjuntos de Amostras utilizadas em cada cenário

\begin{tabular}{|c|c|c|c|c|c|}
\hline \multirow{2}{*}{ Cenário } & \multicolumn{2}{|c|}{ Treinamento $(85 \%)$} & \multicolumn{2}{|c|}{ Teste $(15 \%)$} & \multirow{2}{*}{$\begin{array}{l}\text { Número } \\
\text { Atributos }\end{array}$} \\
\hline & Normal & Anômalo & Normal & Anômalo & \\
\hline C1 & 158 & 351 & 27 & 61 & 16 \\
\hline $\mathrm{C} 2$ & 3494 & 502 & 616 & 88 & 16 \\
\hline C3 & 838 & 515 & 147 & 90 & 17 \\
\hline $\mathrm{C} 4$ & 3729 & 485 & 657 & 84 & 18 \\
\hline
\end{tabular}

Os conjuntos de amostras para cada cenário foram divididos em conjunto de treinamento e teste conforme Figura 59. O respectivo Conjunto de Treinamento foi utilizado para treinar o classificador e a Taxa de Detecção (TD) e a Taxa de Alarmes Falsos (TAF) foram obtidas frente ao respectivo Conjunto de Teste. 


\begin{tabular}{crrrr}
\multicolumn{6}{c}{ Tabela 84: Resultados do IDS com o classificador binário } \\
Cenário & $\begin{array}{r}\text { Tempo } \\
(\mathbf{m s})\end{array}$ & $\begin{array}{r}\text { Acurácia } \\
(\boldsymbol{\%})\end{array}$ & $\begin{array}{r}\text { Taxa } \\
\text { Detecção }\end{array}$ & $\begin{array}{r}\text { Taxa } \\
\text { Alarmes Falsos }\end{array}$ \\
\hline \multirow{2}{*}{ C1 } & \multirow{2}{*}{5} & 100 & $\begin{array}{r}61 / 61 \\
\mathbf{1 0 0 \%}\end{array}$ & $\begin{array}{r}0 / 27 \\
\mathbf{0 \%}\end{array}$ \\
\hline \multirow{2}{*}{ C2 } & \multirow{2}{*}{10} & \multirow{2}{*}{100} & $\begin{array}{r}88 / 88 \\
\mathbf{1 0 0 \%}\end{array}$ & $\begin{array}{r}0 / 616 \\
\mathbf{0 \%}\end{array}$ \\
\hline \multirow{2}{*}{ C3 } & \multirow{2}{*}{10} & \multirow{2}{*}{100} & $\begin{array}{r}90 / 90 \\
\mathbf{1 0 0 \%}\end{array}$ & $\begin{array}{r}0 / 147 \\
\mathbf{0 \%}\end{array}$ \\
\hline \multirow{2}{*}{ C4 } & \multirow{2}{*}{10} & \multirow{2}{*}{100} & $\begin{array}{r}84 / 84 \\
\mathbf{1 0 0 \%}\end{array}$ & $\begin{array}{r}0 / 657 \\
\mathbf{0 \%}\end{array}$ \\
\hline
\end{tabular}

Assim como ocorreu no Cenário 4, a TD foi de $100 \%$ e a TAF foi de $0 \%$ para todos os cenários. Como houve um processo de pré-processamento dos dados, de seleção dos atributos que, por sua vez, foram previamente aprovados em (TURCATO, 2015) para a anomalia gerada (ataque a rede PROFINET descrito na Seção 5.1.2), o desempenho foi maximizado.

\subsubsection{Avaliação final do IDS com classificação unária}

Para a abordagem unária a estrutura de classificação CL5 foi a que apresentou o melhor desempenho (maior valor de $F$-measure).

A partir dessa constatação, utilizou-se o mesmo algoritmo da Figura 63 para o treinamento do classificador OCSVM com redução de dimensionalidade realizada com Autoencoder e com OutlierFraction igual a 0 (zero) para os respectivos Conjuntos de Treinamentos de cada cenário.

Posteriormente ao treinamento, a Taxa de Detecção (TD) e a Taxa de Alarmes Falsos (TAF) foram obtidas frente aos respectivos Conjuntos de Teste de cada cenário. Os melhores resultados para cada cenário estão apresentados na Tabela 85.

Tabela 85: Resultados do IDS com o classificador unário

\begin{tabular}{|c|c|c|c|c|c|c|}
\hline Cenário & $\mathbf{N}$ & $\begin{array}{r}\text { Acurácia } \\
(\%)\end{array}$ & $\begin{array}{c}\text { Outlier } \\
\text { como } \\
\text { Target }\end{array}$ & $\begin{array}{c}\text { Target } \\
\text { como } \\
\text { Outlier }\end{array}$ & $\begin{array}{r}\text { Taxa } \\
\text { Detecção }\end{array}$ & $\begin{array}{r}\text { Taxa } \\
\text { Alarmes Falsos }\end{array}$ \\
\hline $\mathrm{C} 1$ & 6 & 97,73 & 2 & 0 & $\begin{array}{r}59 / 61 \\
\mathbf{9 6 , 7 \%} \\
\end{array}$ & $\begin{array}{r}0 / 27 \\
\mathbf{0 \%} \\
\end{array}$ \\
\hline $\mathrm{C} 2$ & 3 & 100 & 0 & 0 & $\begin{array}{r}88 / 88 \\
\mathbf{1 0 0 \%} \\
\end{array}$ & $\begin{array}{r}0 / 616 \\
\mathbf{0 \%} \\
\end{array}$ \\
\hline C3 & $17 *$ & 99,58 & 0 & 1 & $\begin{array}{r}90 / 90 \\
\mathbf{1 0 0 \%} \\
\end{array}$ & $\begin{array}{r}1 / 147 \\
\mathbf{0 , 6 8 \%} \\
\end{array}$ \\
\hline C4 & 10 & 98,79 & 4 & 5 & $\begin{array}{r}80 / 84 \\
\mathbf{9 5 , 2 \%}\end{array}$ & $\begin{array}{r}5 / 657 \\
0,76 \%\end{array}$ \\
\hline
\end{tabular}

* sem redução de dimensionalidade 
Com os dados do Cenário 1, o IDS proposto, ao analisar 61 amostras de tráfego ANÔMALO, não detectou apenas 2 e, portanto, a Taxa de Detecção foi de 96,7\%. Adicionalmente, quando analisou 27 amostras de tráfego NORMAL, todas não foram detectadas, ou seja, a Taxa de Alarmes Falsos foi de $0 \%$.

Por sua vez, com os dados do Cenário 4, o IDS proposto, ao analisar 84 amostras de tráfego ANÔMALO, não detectou apenas 4 e, portanto, a Taxa de Detecção foi de 95,2\%. Assim como, quando analisou 657 amostras de tráfego NORMAL, 5 foram detectadas erroneamente como ANÔMALO, ou seja, a Taxa de Alarmes Falsos foi de $0,76 \%$.

Comportamento similar ao descrito foi também encontrado para o Cenário 2 e Cenário 3.

\subsubsection{Avaliação final do IDS com classificação unária com redes PROFINET reais}

A fim de avaliar o desempenho do IDS desenvolvido frente a um tráfego real em rede PROFINET de plantas industriais existente, foram analisadas outras 6 capturas realizadas em plantas industriais reais (indústria automobilística, agroindústria e usina de açúcar e etanol). A essas novas capturas foram associados os cenários C5 ao C10.

Detalhes desses novos cenários podem ser obtidos na Tabela 86.

Tabela 86: Dispositivos da rede PROFINET em cada novo cenário

Rede PROFINET

\begin{tabular}{ccccccc} 
Cenário & IO-Controller & IO-Device & IO-Supervisor & Outros & TOTAL & Topologia \\
\cline { 2 - 7 } C5 & 1 & 58 & 1 & 13 & 73 & anel \\
\hline C6 & 1 & 37 & 0 & 12 & 50 & estrela \\
\hline C7 & 1 & 60 & 0 & 12 & 73 & anel \\
\hline C8 & 1 & 18 & 0 & 4 & 23 & estrela \\
\hline C9 & 1 & 6 & 0 & 0 & 7 & estrela \\
\hline C10 & 2 & 211 & 0 & 0 & 213 & anel \\
\hline
\end{tabular}

Informações dessas novas redes PROFINET estão apresentados na Tabela 87. 
Tabela 87: Informações do tráfego da rede PROFINET em cada novo cenário Rede PROFINET

\begin{tabular}{crrrrrrr}
\cline { 2 - 8 } Cenário & $\begin{array}{r}\text { Taxa } \\
\text { Data Bit } \\
\text { (Mbits/s) }\end{array}$ & $\begin{array}{r}\text { Tamanho } \\
\text { Médio do } \\
\text { Pacote } \\
\text { (bytes) }\end{array}$ & $\begin{array}{r}\text { Taxa de } \\
\text { Pacotes } \\
(\text { pacotes/s) }\end{array}$ & $\begin{array}{r}\text { Tráfego } \\
\text { PN-IO } \\
(\%)\end{array}$ & $\begin{array}{r}\text { Tráfego } \\
\text { TCP } \\
(\%)\end{array}$ & $\begin{array}{r}\text { Tráfego } \\
\text { UDP } \\
(\%)\end{array}$ & $\begin{array}{r}\text { Tráfego } \\
\text { ARP } \\
(\%)\end{array}$ \\
\hline C5 & 20,4 & 81,2 & 32930 & 99,9 & 0,1 & 0 & 0 \\
\hline C6 & 5,21 & 101,9 & 6689 & 92,7 & 2,9 & 4,4 & 0 \\
\hline C7 & 31,3 & 83,3 & 49175 & 99,9 & 0,1 & 0 & 0 \\
\hline C8 & 8,37 & 84,0 & 13069 & 99,7 & 0,2 & 0 & 0 \\
\hline C9 & 1,99 & 86,56 & 3006 & 99,9 & 0 & 0,1 & 0 \\
\hline C10 & 22,1 & 84,96 & 34087 & 99,8 & 0,2 & 0 & 0 \\
\hline
\end{tabular}

Devido à impossibilidade de se obter capturas de tráfego ANÔMALO nas redes PROFINET dos cenários citados (rede sob algum tipo de ataque), a análise do IDS foi realizada com apenas os valores da Taxa de Alarmes Falsos.

\begin{tabular}{cccccc}
\multirow{2}{*}{$\begin{array}{c}\text { Tabela 88: Conjuntos de Amostras utilizadas em cada novo cenário } \\
\text { Cenário }\end{array}$} & \multicolumn{2}{c}{ Treinamento } & \multicolumn{2}{c}{ Teste } & $\begin{array}{c}\text { Número de } \\
\text { Atributos }\end{array}$ \\
\cline { 2 - 5 } & Targets & Outliers & Targets & Outliers & 16 \\
\hline C5 & 2109 & 0 & 372 & 0 & 18 \\
\hline C6 & 2110 & 0 & 372 & 0 & 16 \\
\hline C7 & 1500 & 0 & 265 & 0 & 18 \\
\hline C8 & 856 & 0 & 151 & 0 & 12 \\
\hline C9 & 1113 & 0 & 197 & 0 & 18 \\
\hline C10 & 1738 & 0 & 307 & 0 & \\
\hline
\end{tabular}

Para todos os cenários, apresentados na Tabela 86, foram extraídos os mesmos 20 atributos listados na Tabela 17 Assim como ocorreu para os cenários anteriormente avaliados ( $\mathrm{C} 1$ ao $\mathrm{C} 4)$, alguns atributos foram eliminados pela etapa de Pré-Processamento dos dados. Assim, o Cenário 5 ficou com 16 atributos, o Cenário 6 com 18 atributos, o Cenário 7 com 16 atributos, o Cenário 8 com 18 atributos, o Cenário 9 com 12 atributos e o Cenário 10 com 18 atributos.

O número de atributos contidos na Tabela 88 é a quantidade de entradas do OCSVM (dimensão dos dados) após a etapa de Redução de Dimensionalidade. Para cada cenário foram obtidos valores distintos de $\mathrm{N}$ para as estruturas de classificação que apresentaram os melhores desempenhos.

Tabela 89: Resultados da classificação unária em cada cenário

\begin{tabular}{ccrcccr} 
Cenário & $\mathbf{N}$ & $\begin{array}{r}\text { Acurácia } \\
(\%)\end{array}$ & $\begin{array}{c}\text { Outlier } \\
\text { como } \\
\text { Target }\end{array}$ & $\begin{array}{c}\text { Target } \\
\text { como } \\
\text { Outlier }\end{array}$ & $\begin{array}{r}\text { Taxa } \\
\text { Detecção }\end{array}$ & $\begin{array}{r}\text { Taxa } \\
\text { Alarmes } \\
\text { Falsos }\end{array}$ \\
\hline C5 & $16^{*}$ & 100 & - & 0 & - & $0 / 372$ \\
$\mathbf{0 \%}$
\end{tabular}




\begin{tabular}{|c|c|c|c|c|c|c|}
\hline Cenário & $\mathbf{N}$ & $\begin{array}{r}\text { Acurácia } \\
(\%)\end{array}$ & $\begin{array}{c}\text { Outlier } \\
\text { como } \\
\text { Target }\end{array}$ & $\begin{array}{c}\text { Target } \\
\text { como } \\
\text { Outlier }\end{array}$ & $\begin{array}{r}\text { Taxa } \\
\text { Detecção }\end{array}$ & $\begin{array}{r}\text { Taxa } \\
\text { Alarmes } \\
\text { Falsos } \\
\end{array}$ \\
\hline $\mathrm{C} 6$ & 4 & 100 & - & 0 & - & $\begin{array}{r}0 / 372 \\
\mathbf{0 \%} \\
\end{array}$ \\
\hline C7 & 1 & 99,2 & - & 2 & - & $\begin{array}{l}2 / 265 \\
\mathbf{0 , 8 \%} \\
\end{array}$ \\
\hline C8 & 2 & 97,3 & - & 4 & - & $\begin{array}{l}4 / 151 \\
\mathbf{2 , 7 \%}\end{array}$ \\
\hline C9 & 1 & 100 & - & 0 & - & $\begin{array}{r}0 / 197 \\
\mathbf{0 \%}\end{array}$ \\
\hline C10 & 2 & 100 & - & 0 & - & $\begin{array}{r}0 / 307 \\
0 \%\end{array}$ \\
\hline
\end{tabular}

Para o Cenário 5, a menor Taxa de Alarmes Falsos (TAF) foi obtida quando não foi feita a redução da dimensionalidade e, portanto, o número de atributos utilizados na classificação foram os 16 atributos originais (conforme aponta $\mathrm{o} *$ na tabela).

Para o Cenário 6, a menor TAF foi obtida quando foi feita a redução da dimensionalidade dos 18 atributos iniciais para 4 novos atributos por meio do Autoencoder. Já para o Cenário 7, a menor TAF foi obtida quando foi feita a redução da dimensionalidade dos 16 atributos iniciais para apenas 1 novo atributo por meio do Autoencoder. Para o Cenário 8, o melhor desempenho foi obtida quando se reduziu de 18 para 2, para o Cenário 9 de 12 para 1 e para o Cenário 10 de 18 para 2 usando o Autoencoder.

Cabe destacar que, para os dez cenários avaliados com os classificadores unários (C1 ao C10), em oito deles, as estruturas de classificação que apresentaram os melhores índices (maior Taxa de Detecção e menor Taxa de Alarmes Falsos) foram aquelas que utilizaram o Autoencoder pra a redução da dimensionalidade (somente no Cenário 3 e no Cenário 5 que não foi constatada a melhoria nos índices quando foi feita a redução da dimensionalidade com o Autoencoder). Esses resultados corroboram com a literatura correlata no que diz respeito ao uso de Autoencoder para redução da dimensionalidade com o propósito do incremento na acurácia de classificação.

\subsection{Discussão final}

Em geral, os resultados obtidos pelo método proposto foram bastante satisfatórios e equivalentes às pesquisas correlatas sobre o tema. É natural que um IDS com 
classificador binário apresente desempenho superior, visto que ele é treinado com amostras de ambas as classes. No entanto, o custo operacional e/ou financeiro envolvido com a coleta de amostras da classe anômala pode não justificar a utilização da abordagem binária. Nesses casos, a abordagem unária mostra-se bastante plausível de ser aplicada.

Nesse trabalho, a Taxa de Detecção obtida foi de $100 \%$ e a Taxa de Alarmes Falsos foi de $0 \%$ para os cenários investigados com classificadores binários. Já a Taxa de Detecção ficou entre 95,2 e 100\% e Taxa de Alarmes Falsos entre 0 e 2,7\% para os cenários investigados com classificadores unários.

Os resultados mostram que os valores de Acurácia, Taxa de Detecção e Taxa de Alarmes Falsos são bastante aceitáveis quando comparados a estudos anteriores. Das pesquisas correlatas citadas, as que possuem maior semelhança em termos de algoritmos aplicados e de ambiente de teste com esse trabalho estão resumidamente apresentadas em ordem cronológica abaixo.

Em (TURCATO, 2015) apenas classificadores binários com RNA foram avaliados. Uma interessante característica desse trabalho é que as amostras anômalas do conjunto de treinamento foram artificialmente geradas de forma randômica, assim, os dados reais de ataque coletados estavam contidos apenas no conjunto de teste. Nesse contexto, obteve-se Taxa de Detecção Média de 99,28\% e Taxa de Alarmes Falsos Média de $0,12 \%$.

Em (WENLI SHANG et al., 2015) foi investigado o uso de OCSVM para detectar intrusão em redes industriais com protocolo Modbus-TCP em um sistema de controle industrial simulado por software. A acurácia obtida foi de $100 \%$ para os dois casos avaliados.

Em (JUNEJO; GOH, 2016) foram classificadas anomalias de um processo industrial de tratamento de água, simulado em bancada, aplicando algoritmos com RNA, SVM entre outros. Neste trabalho, informações relacionadas ao processo industrial foram utilizadas, tais como: vazão de água, nível do reservatório, posição das válvulas e velocidade das bombas. Com o uso de RNA foi obtida Taxa de Detecção de 98,40\% e Taxa de Alarme Falso de 3\%. Já para SVM, a Taxa de Detecção 98,00\% e a Taxa de Alarmes Falso de $31 \%$.

Em (SHANG et al., 2016) os autores exploram a detecção de ataques em redes Modbus-TCP simulando situações reais de tráfego em laboratório. A seleção de atributos 
e posterior classificação usando SVM é avaliada. Os resultados apresentam Acurácia de $98,25 \%$ quando é feita a seleção dos atributos principais e $87,25 \%$ quando não.

Em (BUCZAK; GUVEN, 2016) é apresentada uma extensa revisão bibliográfica sobre métodos de mineração de dados e aprendizado de máquina para detecção de intrusão na área da segurança cibernética. Nesse trabalho são apresentados inúmeros trabalhos que reportaram Taxa de Detecção em torno de 99\% e Taxa de Alarmes Falsos de $0,09 \%$ para ataques do tipo probing.

Em (SHIRAZI et al., 2016) apresenta um ampla revisão das abordagens de detecção de intrusões baseadas em aprendizado de máquina para sistemas de controle industrial. Nesse trabalho foram utilizados dados criados a partir de um sistema SCADA de gasoduto do laboratório da universidade estadual de Mississippi com amostras normais e anômalas. Foram utilizados classificadores K-means e Nä̈ve Bayesian para classificação binária com acurácia média de 56,80\% e 90,36\% respectivamente. Para a abordagem unária foram avaliados os classificadores PCA-SVD (Principal Component Analysis usando Singular Value Decomposition) e GMM (Gaussian Mixture Model) com acurácia média de $27,10 \%$ e 55,83\% respectivamente.

Em (YANG et al., 2017) foi utilizado um algoritmo de detecção de intrusão chamado de OPSO-BPNN, que utiliza um algoritmo de Enxame de Partículas para otimizar os pesos sinápticos da rede neural usando conjunto de amostras de Sistemas Elétricos de Potência, e encontrou-se Taxa de Detecção entre 92,4 e 98,6\% e Taxa de Alarmes Falsos entre 1,46 e 5,65\%.

Em (LEE; JO; HWANG, 2017) foi utilizada uma DPN (Deep Neural Network) para a detecção de falhas no rotor e nos rolamentos de motores de indução trifásicos aplicando algumas técnicas de balanceamento de classe. Com os dados não balanceados, a Acurácia Média obtida foi 69,97\% enquanto, para os dados balanceados com o SMOTE, a Acurácia Média obtida foi $86,74 \%$.

Já em (AL-YASEEN; OTHMAN; NAZRI, 2017) foi proposto e avaliado um IDS que utiliza um modelo híbrido de SVM onde a acurácia média encontrada foi de 95,75\% com Taxa de Detecção de 95,17\% e Taxa de Alarmes Falsos de 1,87\% para a classificação de ataques em redes de computadores utilizando o conjunto popular KDD Cup 1999.

Em (VAVRA; HROMADA, 2017) é avaliado um sistema de detecção de anomalia em sistemas SCADA onde são investigados os desempenhos de cinco tipos de 
classificadores (Bayes Network, Nä̈ve Bayes, Random Forest, Decision Table e IB1). A TPR média obtida foi de 0,873 e a FPR média foi de 0,023.

Em (QU et al., 2018) foi avaliado o desempenho de um classificador OCSVM frente ao tráfego do sistema SCADA em uma planta industrial de Gás e Óleo. A Taxa de Detecção foi de $98,54 \%$ e a Taxa de Alarmes Falsos foi de 1,60\%.

Em (SESTITO, 2018) um método para a detecção de anomalias em tráfego de redes Real Time Ethernet foi desenvolvido e a Acurácia dos classificadores binários ficou entre 92 e $99 \%$ para os vários modelos de RNA avaliados. Nesse trabalho, foram analisados e classificados eventos de falhas em redes PROFINET.

Em (NGUYEN et al., 2018) foi avaliado o uso de classificador OCSVM para detectar intrusões em redes de computadores. Foram obtidas Taxa de Detecção entre 97,29 e 98,25\% e Taxa de Alarme Falsos entre 0,12 e 1,55\%.

Em (MAGLARAS, 2018) foi proposto um mecanismo de detecção de intrusão integrado, chamado de IT-OCSVM, que é distribuído em uma rede SCADA como parte de um sistema de detecção de intrusão distribuído (DIDS), fornecendo dados precisos sobre a origem e a hora de uma invasão. Nesse trabalho é feita a análise da Taxa de Detecção e da Taxa de Alarmes Falsos quando a rede foi submetida a quatro tipos de ataques: ARP spoofing, Probing, DoS e MITM. A Taxa de Detecção obtida ficou entre 94,6 e 98,8\% e a Taxa de Alarmes Falsos ficou entre 1,51 e 3,25\%.

Em (MISHRA et al., 2019) foi feita uma ampla investigação e análise detalhada de várias técnicas de aprendizado de máquinas encontradas nas bases de dados científicas. Nesse trabalho são apontadas Taxas de Detecção entre 71,63 e 99,85\% quando se utilizou RNA ou SVM para a classificação.

Em (DIAS, 2019), técnicas de seleção de atributos e algoritmos de classificação foram investigados para o diagnóstico de anomalias em aplicações de acionamento de motores elétricos a partir de dados de processo de rede PROFINET. A Taxa de Detecção encontrada ficou entre 98,7 e $100 \%$ e a Taxa de Alarmes Falsos entre 0 e 1,3\% utilizando classificadores binários e Taxa de Detecção entre 97,7 e 99,8\% e Taxa de Alarmes Falsos entre 0,2 e 2,3\% utilizando classificador OCSVM.

Em (ANTON; SINHA; DIETER SCHOTTEN, 2019) dados de rede de comunicação contendo informações de processo industrial são analisados com algoritmos de detecção de anomalias baseados em aprendizado de máquina e em séries temporais, a 
fim de descobrir ataques injetados no tráfego. São avaliados dois conjuntos de dados distintos, um com tráfego de controle de gasoduto com protocolo Modbus e outro com o controle em batelada com protocolo OPC-UA. Para a detecção do ataque, dois algoritmos foram utilizados: SVM e Random Forest (RF). Ambos apresentaram bom desempenho, o SVM apresentou acurácia média de $91,67 \%$ e o RF 99,91\%.

Em (AKPINAR; OZCELIK, 2019) foram analisados tráfegos de redes EtherCAT em uma planta industrial para controle de nível de água. Foi obtida Acurácia Média de $98,28 \%$ com RNAs e $99,81 \%$ com SVM.

Em (ALEESA et al., 2019) é feito um estudo que fornece uma extensa base de publicações científicas baseadas em técnicas de Aprendizado Profundo. Nesse estudo que considerou 68 pesquisas publicadas entre 2015 e 2018 revela que a combinação entre duas técnicas, a SAE (Stacked Autoencoder) e a RF (Random Forest) apresentou os melhores valores de acurácia entre 85 e 99,92\%.

Em (ZHOU et al., 2020) os autores desenvolveram um método baseado em GAN (Generative Adversarial Network) em conjunto com autoencoders para lidarem com dados não-balanceados característicos da área de diagnóstico de falhas. A Acurácia média obtida ficou entre 84,64 e 86,49\% sem usar o SMOTE e entre 91,71 e 93,94\% quando o SMOTE foi usado para o balanceamento dos conjuntos com várias taxas de desbalanceamento.

Em (ALDWEESH; DERHAB; EMAM, 2020) os autores reuniram informações sobre diversos trabalhos científicos que utilizaram dois famosos datasets (KDD99 e NSLKDD) muito utilizados internacionalmente para a avaliação de métodos de detecção de intrusão. Os autores ilustram em um gráfico de barras as acurácias obtidas por cinco diferentes técnicas de Aprendizado Profundo: AutoEncoder (AE), Deep Belief Network (DBN), Recurrent Neural Network (RNN), Convolutional Neural Network (CNN) e Ensemble. Em todos os casos, a acurácia obtida foi entre 85 e $99 \%$.

Em (GONZÁLEZ-MUÑIZ; DÍAZ; CUADRADO, 2020) foi proposto e avaliado um sistema para monitoramento de condições e detecção de falhas em máquinas rotativas com base em uma rede neural convolucional profunda, que mescla as tarefas de extração e classificação de atributos em um único estágio de aprendizado. O sistema proposto foi projetado para uso em uma máquina rotativa com sete estados operacionais possíveis e provou ser capaz de determinar as condições operacionais da máquina quase com a 
mesma precisão que os classificadores convencionais, mas sem a necessidade de conhecimento prévio da máquina. A acurácia obtida pelo modelo proposto foi de $98,43 \%$ com tempo de classificação médio de 4,32 ms.

Em (LI; LI; MA, 2020) foi adotado um método de treinamento baseado em três estágios: pré-treinamento com autoencoders, agrupamento com $k$-means e classificação com redes neurais para aprendizado não-supervisionado em dois conjuntos de dados de máquinas rotativas. A Acurácia Média obtida com o método proposto usando autoencoders foi de $93,8 \%$ e de $89,7 \%$ quando não foram utilizados autoencoders no estágio de pré-treinamento.

Deve-se ter sempre em mente a diversidade de cenários, técnicas, conjunto de dados e análises possíveis que podem resultar em valores muito distintos e, portanto, uma análise comparativa ampla e contextualizada deve ser realizada. 


\section{Capítulo 7}

\section{Considerações finais do trabalho}

O trabalho aqui apresentado visou investigar, desenvolver, implementar e validar um método para detectar intrusão em redes PROFINET com uso de técnicas de Aprendizado de Máquina.

\subsection{Conclusões}

A método desenvolvido está fundamentado na análise das características de comunicação do protocolo PROFINET e na identificação e classificação de padrões, sendo esta, uma das principais áreas de aplicação de Classificadores Inteligentes e Aprendizado de Máquina.

No desenvolvimento desse trabalho, foi feita uma profunda revisão bibliográfica acerca dos trabalhos científicos referentes ao detalhamento do protocolo PROFINET, sobre os principais mecanismos de segurança em redes, sobre os métodos tradicionais de captura de tráfego e sobre os principais tipos de ataques às redes de comunicação conhecidos na literatura e, como estes podem ser classificados. Foi também realizada uma investigação sobre as possíveis vulnerabilidades do protocolo e, embora o trabalho tenha sido focado apenas no protocolo PROFINET, estima-se que os resultados possam ser extrapolados para outros protocolos de redes de automação utilizados pelas indústrias.

O trabalho apresentou a integração de técnicas de extração e seleção de atributos, em conjunto com o método SMOTE para o balanceamento das amostras utilizadas no treinamento dos classificadores binários e, posteriormente, a aplicação de redução de dimensionalidade com redes autoencoders em conjunto com classificadores unários.

Os ensaios realizados mostraram a factibilidade do método proposto para detecção de ataques em redes PROFINET em modo off-line. Ao todo, dez diferentes cenários de interconexão de redes PROFINET foram analisados tendo suas anomalias identificadas por meio da análise do tráfego da rede em sua fase de operação. Anomalias estas que podem ser desde defeitos comuns apresentados pelos equipamentos da rede e/ou 
tentativas de ataques externos a esta, que por sua vez, podem gerar instabilidade e mau funcionamento da unidade industrial.

Em aplicações de detecção de anomalia do mundo real, é comum o conjunto de dados serem fortemente desbalanceados. Aprender a partir de conjuntos de dados desbalanceados pode produzir classificadores tendenciosos. Em muitos casos, também é proibitiva obtenção de amostras anômalas devido aos enormes prejuízos financeiros envolvidos com essas coletas. Assim, para esses casos, aumenta-se a pertinência da abordagem por classificadores unários utilizada nesse trabalho.

É pertinente destacar que este método pode também ser aplicado para a análise do tráfego de outras redes baseadas no protocolo Ethernet com poucas alterações/ajustes. $\mathrm{Na}$ Seção 3.1 é apresentada uma lista dos protocolos industriais derivados do protocolo Ethernet.

Comparando os resultados obtidos pelo método proposto com pesquisas similares aplicadas em dados gerados em laboratório ou de plantas fabris reais, foi possível observar que foram obtidas Acurácias, Taxas de Detecção e Taxas de Alarmes Falsos equivalentes ou até melhores em determinados cenários. Cabe enaltecer aqui a utilização de dados coletados em ambiente industrial real, onde é comum se encontrar uma maior diversidade de dispositivos de diferentes fabricantes e em com não conformidades relacionadas à instalação física e lógica das redes.

Mesmo nas pesquisas apresentadas na discussão final, em que foram utilizadas técnicas mais modernas (como as de aprendizado profundo), o desempenho dos classificadores foi bastante semelhante. Isso é um indicativo que, devido a simplicidade da estrutura dos dados e dos atributos extraídos nesse trabalho, as técnicas de Aprendizado de Máquina clássicas têm sido suficientes para atingir altas Taxa de Detecção e baixos valores da Taxa de Alarmes Falsos.

Os diferentes resultados produzidos pela série de algoritmos revelam uma característica bastante peculiar das redes industriais: o controle de processo é diferente para diferentes processos de produção industrial. Assim, mesmo que o processo esteja submetido ao mesmo tipo de ataque, o alvo pode ser diferente. Conforme afirmado em (QU et al., 2018), a escolha do algoritmo correto requer testes, comparações e triagens manuais. 
Nesse contexto, os objetivos específicos também foram alcançados, uma vez que foram desenvolvidas estratégias baseadas na técnica de janela deslizante para a extração de atributos do tráfego de redes PROFINET para auxiliar a identificação de intrusão à rede. Também, foram selecionadas, projetadas e aplicadas ferramentas de aprendizagem de máquinas que, a partir do tráfego extraído de diferentes redes PROFINET, foram capazes de identificar a ocorrência de intrusão com altos valores da Taxa de Detecção e baixos valores da Taxa de Alarmes Falsos.

Adicionalmente, espera-se que com esse trabalho, muito conteúdo sobre o tema 'segurança em redes industriais' seja adquirido e utilizado em trabalhos científicos futuros por parte do próprio autor dessa tese e por parte de outros pesquisadores envolvidos com os temas correlatos de pesquisa.

\subsection{Trabalhos Futuros}

Conforme relatado em (ALEESA et al., 2019), dois grandes desafios surgem no desenvolvimento de Sistemas de Detecção de Intrusão com altos valores de acurácia e adaptáveis para novos tipos de ataques.

O primeiro desafio é a seleção adequada dos atributos. Dado que as os casos de ataque estão constantemente mudando e avançando, os atributos selecionados para um tipo de ataque podem não serem eficazes para outras classes de invasão.

O segundo desafio é a inacessibilidade a dados de tráfego anômalo em redes industriais reais. Criar um conjunto de dados rotulados a partir de tráfego bruto da rede durante um determinado período ou em tempo real é um grande esforço. Os conjuntos de dados a serem utilizados no treinamento dos modelos de classificação e detecção são desbalanceados e de natureza diversa. Esse desequilíbrio pode distorcer o comportamento do tráfego e fazer com que uma invasão seja considerada normal ou vice-versa.

As atuais tecnologias de IDS têm se esforçado para lidar com grandes volumes de dados e taxa de falsos negativos. Novos tipos de ataques e valores de acurácia não atendem aos requisitos contemporâneos de segurança de rede estão sendo descobertos. 
Assim, durante o desenvolvimento desse trabalho, novas frentes de investigação, correlacionadas aos temas focados nessa tese, surgiram e estão listadas a seguir como sugestões para serem realizadas em trabalhos futuros:

- Implementar e validar o método para a classificação online do tráfego em redes RTE com as estruturas de classificação sugeridas por esse trabalho, executando em estruturas distribuídas na Nuvem (Cloud Computing) e em equipamento eletrônico com baixo poder computacional (appliance) dando sequência ao trabalho publicado em (TURCATO et al., 2020).

- Investigar o desempenho de métodos modernos de Aprendizado de Máquina, como o Ensemble com algoritmo Random Forest, para, em conjunto com redes autoencoders, criar estruturas de classificação unárias na tentativa de obter melhores de taxas de detecção e de alarmes falsos a exemplo do que foi apresentado em (ALEESA et al., 2019).

- Aplicar, validar e comparar os resultados de arquiteturas híbridas de aprendizado profundo (LEI et al., 2020), como modelos GAN (Generative Adversarial Network) ainda pouco aplicados, mas que mostraram resultados promissores conforme apontado em (ALDWEESH; DERHAB; EMAM, 2020). 


\section{Referências Bibliográficas}

A.A. OJUGO, A.O. EBOKA, O.E. OKONTA, R.E YORO (MRS), F. O. A. Genetic Algorithm Rule-Based Intrusion Detection System ( GAIDS ). Journal of Emerging Trends in Computing and Information Sciences, v. 3, n. 8, p. 1182-1194, 2012.

ABDOLLAH, M. F. et al. Revealing the Influence of Feature Selection for Fast Attack Detection. International Journal of Computer Science and Network Security, v. 8, n. 8, p. 107, 2008.

ABUROMMAN, A. A.; REAZ, M. B. I. A survey of intrusion detection systems based on ensemble and hybrid classifiers. Computers and Security, v. 65, p. 135-152, 2017.

AHMED, K. E. Intelligent traffic analysis to detect malicious activity, 2014. Disponível em: <https://patents.google.com/patent/US9483742B1/en?oq=US2019014134>

AKASHDEEP; MANZOOR, I.; KUMAR, N. A feature reduced intrusion detection system using ANN classifier. Expert Systems with Applications, v. 88, p. 249-257, 2017.

AKPINAR, K. O.; OZCELIK, I. Analysis of Machine Learning Methods in EtherCATBased Anomaly Detection. IEEE Access, v. 7, p. 184365-184374, 2019.

AL-YASEEN, W. L.; OTHMAN, Z. A.; NAZRI, M. Z. A. Multi-level hybrid support vector machine and extreme learning machine based on modified K-means for intrusion detection system. Expert Systems with Applications, 2017.

ALDWEESH, A.; DERHAB, A.; EMAM, A. Z. Deep learning approaches for anomalybased intrusion detection systems: A survey, taxonomy, and open issues. KnowledgeBased Systems, v. 189, p. 105124, Feb. 2020.

ALEESA, A. M. et al. Review of intrusion detection systems based on deep learning techniques: coherent taxonomy, challenges, motivations, recommendations, substantial analysis and future directions. Neural Computing and Applications, 18 Oct. 2019.

ALMEIDA, M. DE B. Treinamento de SVMs utilizando reamostragem baseada em erro e estratégias a priori de selção de amostras. [s.l.] Universidade Federal de Minas Gerais, 2002.

ANDERSON, J. P. Computer Security Threat Monitoring and Surveillance. Washington: [s.n.].

ANDERSON, R. Chapter 18: Network Attack and Defense (Security Engineering: A Guide to Building Dependable Distributed Systems). Wiley, p. 367-390, 2001.

ANTON, S. D. D.; SINHA, S.; DIETER SCHOTTEN, H. Anomaly-based intrusion detection in industrial data with SVM and random forests. 2019 27th International Conference on Software, Telecommunications and Computer Networks, SoftCOM 2019. Anais...2019

ASLI, P. S.; SUTIC, D. Intrusion Detections SystemsSecure Computer Systems, , 2009.

AXELSSON, S. The base-rate fallacy and the difficulty of intrusion detection. ACM 
Transactions on Information and System Security, v. 3, n. 3, p. 186-205, 2000.

AZUREMLSTUDIODOCS. How to choose algorithms for Azure Machine Learning Studio. Disponível em: <https://github.com/MicrosoftDocs/azuredocs/blob/master/articles/machine-learning/studio/algorithm-choice.md>. Acesso em: 10 oct. 2018.

BACE, R.; MELL, P. Intrusion Detection. NIST Special Publication on Intrusion Detection System, v. 3, n. October 2002, 2015.

BARFORD, P. et al. A Signal Analysis of Network Traffic Anomalies. PROCEEDINGS OF ACM SIGCOMM INTERNET MEASUREMENT WORKSHOP, p. 1-12, 2002.

BEALE, J. et al. Snort 2.1 Intrusion Detection. [s.1.] Syngress, 2004.

BENGIO, Y. Learning Deep Architectures for AI. [s.l: s.n.]. v. 2

BENGIO, Y.; COURVILLE, A.; VINCENT, P. Representation learning: A review and new perspectives. IEEE Transactions on Pattern Analysis and Machine Intelligence, v. 35, n. 8, p. 1798-1828, 2013.

BENNETT, K. P.; CAMPBELL, C. Support vector machines: Hype or Hallelujah? Journal of Chemical Information and Modeling, v. 2, n. 2, p. 1-13, 2000.

BHUYAN, M. H.; BHATTACHARYYA, D. K.; KALITA, J. K. Network Anomaly Detection: Methods, Systems and Tools. IEEE COMMUNICATIONS SURVEYS \& TUTORIALS, v. 16, n. 1, 2014.

BIESIADA, J.; DUCH, W. Feature selection for high-dimensional data - A pearson redundancy based filter. Advances in Soft Computing, v. 45, p. 242-249, 2007.

BLAGUS, R.; LUSA, L. SMOTE for high-dimensional class-imbalanced data. BMC Bioinformatics, v. 14, 2013.

BORISOV, N.; GOLDBERG, I.; WAGNER, D. Intercepting mobile communications. Proceedings of the 7th annual international conference on Mobile computing and networking - MobiCom '01, p. 180-189, 2001.

BOURLARD, H.; KAMP, Y. Auto-association by multilayer perceptrons and singular value decomposition. Biological Cybernetics, v. 59, n. 4-5, p. 291-294, 1988.

BRANQUINHO, M. A. et al. Segurança de Automação Industrial e SCADA. 1. ed. Rio de Janeiro: Elsevier, 2014.

BUCZAK, A. L.; GUVEN, E. A Survey of Data Mining and Machine Learning Methods for Cyber Security Intrusion Detection. IEEE Communications Surveys and Tutorials, 2016.

BURGES, C. J. C. A Tutorial on Support Vector Machines for Pattern Recognition. Knowledge Discovery and Data Mining, 1998.

BYRES, E. The myths and facts behind cyber security risks for industrial control systems. Proceedings of the VDE Kongress, p. 1-6, 2004.

CARLSSON, T. Industrial network market shares 2020 according to HMS 
Networks.

CERT.BR. CERT.br - Centro de Estudos, Resposta e Tratamento de Incidentes de Segurança no Brasil. Disponível em: <http://www.cert.br/>. Acesso em: 17 jan. 2019.

CHANDRASHEKAR, G.; SAHIN, F. A survey on feature selection methods. Computers and Electrical Engineering, v. 40, n. 1, p. 16-28, 2014.

CHAWLA, N. V. et al. SMOTE: Synthetic minority over-sampling technique. Journal of Artificial Intelligence Research, v. 16, p. 321-357, 2002.

CHAWLA, N. V. Data Mining for imbalanced datasets: An Overview. 2010.

CHAWLA, N. V et al. SMOTEBoost: Improving Prediction. Lavrač N., Gamberger D., Todorovski L., Blockeel H. (eds) Knowledge Discovery in Databases: PKDD 2003. LNCS, v. 2838, p. 107-119, 2003.

CHEMINOD, M. et al. Detecting chains of vulnerabilities in industrial networks. IEEE Transactions on Industrial Informatics, v. 5, n. 2, p. 181-193, 2009.

CHEMINOD, M.; PIRONTI, A.; SISTO, R. Formal vulnerability analysis of a security system for remote fieldbus access. IEEE Transactions on Industrial Informatics, v. 7, n. 1, p. 30-40, 2011.

CHORMUNGE, S.; JENA, S. Correlation based feature selection with clustering for high dimensional data. Journal of Electrical Systems and Information Technology, p. 4$11,2017$.

CHOU, T. S.; YEN, K. K.; LUO, J. Selection of Soft Computing Paradigms. International Journal of Computational Intelligence, v. 4, n. 3, p. 196-208, 2008.

COSTA, N. S. Proteção de Sistemas Elétricos Considerando Aspectos de Segurança da Rede de Comunicação. [s.1.] EESC-USP, 2007.

Cyber Security for Industrial Automation and Control Systems (IACS). . [s.l: s.n.]. Disponível em: <http://www.hse.gov.uk/foi/internalops/og/og-0086.pdf〉.

DAS, S. Filters, Wrappers and a Boosting-Based Hybrid for Feature Selection. 2001.

DEMIRAY, S. Improving Misuse Detection with Neural Networks. [s.1.] Izmir Institute of Technology, 2005.

DEPRIEST, M. S. Network security considerations in TCP/IP-based manufacturing automation. ISA Transactions, v. 36, n. 1, p. 37-48, 1997.

DIAS, A. L. Diagnóstico de anomalias em aplicações de acionamento de motores elétricos a partir de dados de processo de rede PROFINET e aprendizagem de máquinas. [s.l: s.n.].

DONG, B.; WANG, X. Comparison deep learning method to traditional methods using for network intrusion detection. 2016 8th IEEE International Conference on Communication Software and Networks (ICCSN). Anais...IEEE, Jun. 2016Disponível em: <http://ieeexplore.ieee.org/document/7586590/>

DWIPUTRANTO, T. H.; SETIAWAN, N. A.; AJI, T. B. Machinery equipment early 
fault detection using Artificial Neural Network based Autoencoder. Proceeding - 2017 3rd International Conference on Science and Technology-Computer, ICST 2017, n. Ml, p. 66-69, 2017.

EXIDA LLC. Repository of Industrial Security Incidents (RISI) Online Incident Database. Disponível em: <http://www.risidata.com/Database>. Acesso em: 17 jan. 2019.

FARQUAD, M. A. H.; BOSE, I. Preprocessing unbalanced data using support vector machine. Decision Support Systems, 2012.

FARRAJ, A.; HAMMAD, E.; KUNDUR, D. Impact of Cyber Attacks on Data Integrity in Transient Stability Control. Proceedings of the 2nd Workshop on Cyber-Physical Security and Resilience in Smart Grids - CPSR-SG'17, v. 13, n. 6, p. 29-34, 2017.

FELSER, M.; SAUTER, T. Standardization of Industrial Ethernet - - the Next Battlefield? Berne University of Applied Sciences Technology Austrian Academy of Sciences Research Unit for Integrated Sensor Systems. IEEE International Workshop on Factory Communication Systems, 2004. Proceedings, 2004.

FRASER, B. Site Security Handbook. Disponível em: <http://www.ietf.org/rfc/rfc2196.txt?number =2196>. Acesso em: 19 nov. 2018.

FUREY, T. S. et al. Support vector machine classification and validation of cancer tissue samples using microarray expression data. [s.l: s.n.].

GALLOWAY, B.; HANCKE, G. P. Introduction to Industrial Control Networks. IEEE Communications Surveys \& Tutorials, v. 15, n. 2, p. 860-880, 2013.

GHALI, N. I. Feature Selection for Effective Anomaly-Based Intrusion Detection. IJCSNS International Journal of Computer Science and Network Security, v. 9, n. 3, p. 285-289, 2009.

GHORBANI, A. A.; LU, W.; TAVALLAEE, M. Network Intrusion Detection and Prevention. [s.1.] Springer US, 2010. v. 47

GOLUB, T. R. et al. Molecular Classification of Cancer: Class Discovery and Class Prediction by Gene Expression Monitoring. Science, v. 286, n. 5439, p. 531-537, 1999.

GONCALVES, M. Firewalls Complete. [s.1.] McGraw-Hill Osborne Media, 1998.

GONZÁLEZ-MUÑIZ, A.; DÍAZ, I.; CUADRADO, A. A. DCNN for condition monitoring and fault detection in rotating machines and its contribution to the understanding of machine nature. Heliyon, v. 6, n. 2, p. e03395, Feb. 2020.

GRANZER, W. et al. Security in networked building automation systems. 2006 IEEE International Workshop on Factory Communication Systems, p. 283-292, 2006.

GRANZER, W.; PRAUS, F.; KASTNER, W. Security in building automation systems. IEEE Transactions on Industrial Electronics, v. 57, n. 11, p. 3622-3630, 2010.

GUYON, I. et al. Gene Selection for Cancer Classification using Support Vector Machines. 2002.

GUYON, I. An Introduction To Variable And Feauture Selection. v. 3, p. 1157-1182, 
2003.

HAHN, J.; GUILLEN, D. P.; ANDERSON, T. Process control systems in the chemical industry: Safety vs. security. Process Safety Progress, v. 25, n. 1, p. 40-43, 2005.

HALL, M. A.; SMITH, L. A. Feature Selection for Machine Learning : Comparing a Correlation-based Filter Approach to the Wrapper. International FLAIRS Conference, p. $5,1999$.

HANKS, C. J.; DORRIS, S. A.; AYYAGARI, A. Methods and systems for use in identifying abnormal behavior in a control systemUSA, 2011. Disponível em: <https://patents.google.com/patent/US20120304007A1/en?oq=US2019014134>

HAYKIN, S. Neural Networks - A Compreensive Foundation. $2^{\mathrm{a}}$ ed. New Jersey: [s.n.].

HE, H.; GARCIA, E. A. Learning from Imbalanced Data. IEEE Transactions on Knowledge and Data Engineering, 2009.

HILAS, C. S. Designing an expert system for fraud detection in private telecommunications networks. Expert Systems with Applications, 2009.

HINTON, G. E.; SALAKHUTDINOV, R. R. Reducing the dimensionality of data with neural networks. Science, v. 313, n. 5786, p. 504-507, 2006.

HORNG, S. J. et al. A novel intrusion detection system based on hierarchical clustering and support vector machines. Expert Systems with Applications, v. 38, n. 1, p. 306313, 2011.

IEC (INTERNATIONAL ELECTROTECHNICAL COMMISSION). Digital data communications for measurement and control - Fieldbus for use in industrial control systems - Part 1: Overview and guidance for the IEC 61158 series, 2003.

IEEE. IEEE Xplore Digital Library. Disponível em: <https://ieeexplore.ieee.org/Xplore/home.jsp>. Acesso em: 21 jan. 2019.

INTERNATIONAL ELECTROTECHNICAL COMMISSION (IEC). IEC61784 International Standard: Digital data communications for measurement and control. Part 1: Profile sets for continuous and discrete manufacturing relative to fieldbus use in industrial control systems, 2007.

INTERNATIONAL, P. PROFINET Design Guideline. [s.l: s.n.].

INTERNATIONAL SOCIETY OF AUTOMATION. The 62443 Series of Standards: Industrial Automation and Control Systems Security. International Society of Automation, n. December, p. 1-4, 2018.

ISO. ISO 7498-2 Basic reference model for open system interconnection-Part 2: Security architecture, 1989.

ISO. ISO/IEC 17799:2000 - Information technology-Code of practice for information security management. [s.l: s.n.].

ISO. ISO/IEC 15408-1:2009International Organization for Standardization, , 2009. Disponível em: 〈https://www.iso.org/standard/50341.html> 
JASPERNEITE, J.; FELD, J. PROFINET: an integration platform for heterogeneous industrial communication systems. 2005 IEEE Conference on Emerging Technologies and Factory Automation, v. 1, p. 815-822, 2005.

JEON, M.; PARK, H.; ROSEN, J. B. Dimension reduction based on centroids and least squares for efficient processing of text data. Proceedings of the 2001 SIAM International Conference on Data Mining, p. 1-13, 2013.

JOACHIMS, T. Learning to Classify Text Using Support Vector Machines. [s.l.] Springer US, 2002.

JOHN, G. H.; KOHAVI, R.; PFLEGER, K. Irrelevant Features and the Subset Selection Problem. Machine Learning Proceedings 1994, p. 121-129, 1994.

JOSHI, MAHESH, AGARWAL, RAMESH, KUMAR, V. Predicting Rare Classes: Can Boosting Make Any Weak Learner Strong? Proceedings of the eighth ACM SIGKDD, v. 7, p. 297-306, 2002.

JUNEJO, K. N.; GOH, J. Behaviour-based attack detection and classification in cyber physical systems using machine learning. CPSS 2016 - Proceedings of the 2nd ACM International Workshop on Cyber-Physical System Security, Co-located with Asia CCS 2016. Anais...2016

KANG, S. H.; KIM, K. J. A feature selection approach to find optimal feature subsets for the network intrusion detection system. Cluster Computing, v. 19, n. 1, p. 325-333, 2016.

KASPERSKY. O que é exploração de “dia zero"? Disponível em: <https://www.kaspersky.com.br/resource-center/definitions/zero-day-exploit>. Acesso em: 2 jan. 2019.

KHALID, S.; KHALIL, T.; NASREEN, S. A survey of feature selection and feature extraction techniques in machine learning. Proceedings of 2014 Science and Information Conference, SAI 2014, p. 372-378, 2014.

KHAN, B. A.; MAD, J.; TREYTL, A. Security in agent-based automation systems. IEEE International Conference on Emerging Technologies and Factory Automation, ETFA, p. 768-771, 2007.

KHAN, S. S.; MADDEN, M. G. One-class classification: Taxonomy of study and review of techniques. Knowledge Engineering Review, v. 29, n. 3, p. 345-374, 2014.

KIM, K. I. et al. Support vector machines for texture classification. IEEE Transactions on Pattern Analysis and Machine Intelligence, v. 24, n. 11, p. 1542-1550, 2002.

KIM, S. S.; REDDY, A L. N. Through Packet Header Data. IEEE/ACM Transactions on Networking, v. 16, n. 3, p. 562-575, 2008.

KIZZA, J. M. Guide to Computer Network Security. [s.l: s.n.].

KNIZAK, M. et al. Modular agent design for field bus management. 7th IEEE International Conference on Emerging Technologies and Factory Automation. Proceedings ETFA '99. Anais...Barcelona, Spain: 1999 
KOHAVI, R. A Study of CrossValidation and Bootstrap for Accuracy Estimation and Model Selection. International Joint Conference on Articial Intelligence, v. 5, 1995.

KONONENKO, I. Machine learning for medical diagnosis: history, state of the art and perspective. Artificial Intelligence in Medicine, v. 23, n. 1, p. 89-109, Aug. 2001.

KOPP, M. et al. Private-Learned IDSUSA, 2017. Disponível em: <https://patents.google.com/patent/US20190014134A1/en?oq=US2019014134>

KRAWCZYK, B. Learning from imbalanced data: open challenges and future directions. Progress in Artificial Intelligence, v. 5, n. 4, p. 221-232, 22 Nov. 2016.

KREUTZMANN, H.; VOLLMER, S.; TEKAMPE, N. Protection profle for the gateway of a smart metering system (Gateway PP). Bundesamt für Sicherheit in der Informationstechnik, v. 2014, n. March, p. 1-28, 2014.

KRUEGEL, C.; VIGNA, G. Anomaly Detection of Web-based Attacks. v. 10, n. 5, p. $118-123,2003$.

KUBAT, M.; HOLTE, R. C.; MATWIN, S. Machine learning for the detection of oil spills in satellite radar images. Machine Learning, 1998.

LAKHINA, A.; CROVELLA, M.; DIOT, C. Diagnosing network-wide traffic anomalies. ACM SIGCOMM Computer Communication Review, v. 34, n. 4, p. 219, 2004.

LANGNER, R. Stuxnet: Dissecting a cyberwarfare weapon. IEEE Security and Privacy, v. 9, n. 3, p. 49-51, 2011.

LAW, M. H. C.; FIGUEIREDO, M. A. T.; JAIN, A. K. Simultaneous feature selection and clustering using mixture models. IEEE Transactions on Pattern Analysis and Machine Intelligence, v. 26, n. 9, p. 1154-1166, Sep. 2004.

LEE, W.; STOLFO, S. J. A framework for constructing features and models for intrusion detection systems. ACM Transactions on Information and System Security (TISSEC), v. 3, n. 4, p. 227-261, Nov. 2000.

LEE, Y. O.; JO, J.; HWANG, J. Application of deep neural network and generative adversarial network to industrial maintenance: A case study of induction motor fault detection. 2017 IEEE International Conference on Big Data (Big Data). Anais...IEEE, Dec. 2017Disponível em: <http://ieeexplore.ieee.org/document/8258307/>

LEI, Y. et al. Applications of machine learning to machine fault diagnosis: A review and roadmap. Mechanical Systems and Signal Processing, v. 138, p. 106587, Apr. 2020.

LI, X.; LI, X.; MA, H. Deep representation clustering-based fault diagnosis method with unsupervised data applied to rotating machinery. Mechanical Systems and Signal Processing, 2020.

LIAO, H. J. et al. Intrusion detection system: A comprehensive review. Journal of Network and Computer Applications, v. 36, n. 1, p. 16-24, 2013.

LIBONI, L. H. B. Diagnóstico de Falhas em Motores de Indução Trifásicos Baseado em Decomposição em Componentes Ortogonais e Aprendizagem de Máquinas. [s.1.] 
EESC-USP, 2017.

LINDA, O.; VOLLMER, T.; MANIC, M. Neural Network based Intrusion Detection System for critical infrastructures. 2009 International Joint Conference on Neural Networks, p. 1827-1834, 2009.

LING, Z.-H. et al. Deep Learning for Acoustic Modeling in Parametric Speech Generation: A systematic review of existing techniques and future trends. IEEE Signal Processing Magazine, v. 32, n. 3, p. 35-52, May 2015.

LIPPMANN, R. P. et al. Evaluating Intrusion Detection Systems: The 1998 DARPA Offline Intrusion Detection Evaluation. Proceedings DARPA Information Survivability Conference and Exposition. DISCEX'00, 2000.

LIU, T. et al. Method for network anomaly detection based on Bayesian statistical model with time slicing. Proceedings of the World Congress on Intelligent Control and Automation (WCICA), p. 3359-3362, 2008.

LIU, W. et al. A survey of deep neural network architectures and their applications. Neurocomputing, v. 234, n. November 2016, p. 11-26, 2017.

LONG, M.; WU, C. H.; HUNG, J. Y. Denial of service attacks on network-based control systems: Impact and mitigation. IEEE Transactions on Industrial Informatics, v. 1, n. 2, p. 85-96, 2005.

LORENA, A. C.; DE CARVALHO, A. C. P. L. F. Uma Introdução às Support Vector Machines. Revista de Informática Teórica e Aplicada, v. 14, n. 2, p. 43-67, 2007.

LU, W.; TAVAllaEE, M.; GHORBANI, A. A. Detecting network anomalies using different wavelet basis functions. Proceedings of the 6th Annual Communication Networks and Services Research Conference, CNSR 2008, p. 149-156, 2008.

LUKASIK, S. J. Why the arpanet was built. IEEE Annals of the History of Computing, v. 33, n. 3, p. 4-21, 2011.

MAGLARAS, L. A. Intrusion detection in SCADA systems using machine learning techniques. [s.l.] University of Huddersfield, 2018.

MAGLARAS, L. A.; JIANG, J. A real time OCSVM Intrusion Detection module with low overhead for SCADA systems. International Journal of Advanced Research in Artificial Intelligence, v. 3, n. 10, 2014.

MAITA, A. R. C. Um estudo da aplicação de técnicas de inteligência computacional e de aprendizado em máquina de mineração de processos de negócio. p. 130, 2016.

MARKOU, M.; SINGH, S. Novelty detection: A review - Part 1: Statistical approaches. Signal Processing, v. 83, n. 12, p. 2481-2497, 2003a.

MARKOU, M.; SINGH, S. Novelty detection: A review - Part 2:: Neural network based approaches. Signal Processing, v. 83, n. 12, p. 2499-2521, 2003 b.

MARTINS, N. et al. Adversarial Machine Learning Applied to Intrusion and Malware Scenarios: A Systematic Review. IEEE Access, v. 8, p. 35403-35419, 2020.

MEHNER, S.; KÖNIG, H. No Need to Marry to Change Your Name! Attacking Profinet 
IO Automation Networks Using DCP. In: Lecture Notes in Computer Science (including subseries Lecture Notes in Artificial Intelligence and Lecture Notes in Bioinformatics). [s.1: s.n.]. p. 396-414.

MENEZES, A.; VAN OORSCHOT, P.; VANSTONE, S. Handbook of Applied Cryptography. Boca Raton, FL: [s.n.].

MENG, Q. et al. Relational autoencoder for feature extraction. 2017 International Joint Conference on Neural Networks (IJCNN). Anais...IEEE, 9 May 2017Disponível em: 〈http://arxiv.org/abs/1802.03145>

MESHRAM, A.; HAAS, C. Machine Learning for Cyber Physical Systems. Machine Learning for Cyber Physical Systems, v. 0, 2017.

MIRANDA, J. C. Segurança Cibernética com Hardware Reconfigurável em Subestações de Energia Elétrica Utilizando o Padrão IEC 61850. 2016.

MISHRA, P. et al. A detailed investigation and analysis of using machine learning techniques for intrusion detection. IEEE Communications Surveys and Tutorials, v. 21, n. 1, p. 686-728, 2019.

MITCHELL, T. Machine Learning. [s.1.] McGraw Hill, 1997.

MIXER, R. A.; LAW, G. K.; CUTCHIN, A. E. Anomaly detection in industrial communications networks, 2015. Disponível em: <https://patents.google.com/patent/US20160261482A1/en?oq=US2019014134>

MONARD, M. C.; BARANAUSKAS, J. A. Conceitos sobre Aprendizado de Máquina. 2003.

MONOSTORI, L. et al. Cyber-physical systems in manufacturing. CIRP Annals, 2016.

MORAES, C. C. DE; CASTRUCCI, P. DE L. Engenharia de Automação Industrial. $2^{\mathrm{a}}$ ed. Rio de Janeiro: LTC - Livros Técnicos e Científicos, 2007.

MOYA, M. M.; HUSH, D. R. Network Constraints and Multi-objective Optimization for One-class Classification. 1996.

NAPOLEON, D.; PAVALAKODI, S. A New Method for Dimensionality Reduction using K- Means Clustering Algorithm for High Dimensional Data Set. International Journal of Computer Applications, v. 13, n. 7, p. 41-17, 2011.

NCSC-UK. 10 Steps to Cyber Security. Disponível em: <https://www.ncsc.gov.uk/guidance/10-steps-cyber-security>. Acesso em: 20 nov. 2018.

NESPOLI, P. et al. Optimal Countermeasures Selection Against Cyber Attacks: A Comprehensive Survey on Reaction Frameworks. IEEE Communications Surveys and Tutorials, v. 20, n. 2, p. 1361-1396, 2018.

NGUYEN, Q. T. et al. Nested One-Class Support Vector Machines for Network Intrusion Detection. 2018 IEEE Seventh International Conference on Communications and Electronics (ICCE), p. 7-12, 2018.

NIELES, M.; DEMPSEY, K.; YAN PILLITTERI, V. NIST Special Publication 800-12 Revision 1 - An Introduction to Information Security. NIST Special Publication, 2017. 
NMAP.ORG. Nmap - Free Security Scanner for Network Exploration and Security Audits. Disponível em: 〈https://nmap.org/>. Acesso em: 1 jan. 2019.

NORTHCUTT, S.; NOVAK, J. Network Intrusion Detection. 3. ed. [s.1.] Sams Publishing, 2002.

NUTZERORGANISATION, P. PROFINET Security Guideline. n. November, p. 1-47, 2013.

OLIVERI, P. Class-modelling in food analytical chemistry: Development, sampling, optimisation and validation issues - A tutorial. Analytica Chimica Acta, v. 982, p. 919, 2017.

ONUT, I.; GHORBANI, A. A. A Feature Classification Scheme for Network Intrusion Detection. v. 5, n. 1, p. 1-15, 2007.

PALENSKY, P.; SAUTER, T. Security Considerations for FAN-Internet connections. Porto, Portugal: IEEE International Workshop on Factory Communication Systems (WFCS), 2000

PARKER, M. Internet of things ( IoT ) IP overview. 2018 2nd International Conference on Trends in Electronics and Informatics (ICOEI), n. Icoei, p. 466-470, 2018.

PFRANG, S.; MEIER, D. Detecting and preventing replay attacks in industrial automation networks operated with profinet IO. Journal of Computer Virology and Hacking Techniques, v. 14, n. 4, p. 253-268, 2018.

PONTIL, M.; VERRI, A. Support vector machines for 3D object recognition. IEEE Transactions on Pattern Analysis and Machine Intelligence, v. 20, n. 6, p. 637-646, 1998.

POPP, M.; WEBER, K. The Rapid Way to PROFINET. $1^{\text {a }}$ ed. [s.1.] PROFIBUS Nutzerorganisation, 2004.

PORTNOY, L.; ESKIN, E.; STOLFO, S. DMCA Intrusion detection with unlabeled data using clustering. Proceedings of ACM CSS Workshop on Data Mining Applied to Security, 2001.

PROFIBUS \& PROFINET INTERNATIONAL. PROFINET-The Solution Platform for Process Automation. n. June, p. 32, 2015.

PROFIBUS NUTZERORGANISATION. PROFINET System Description Technology and Application. [s.l: s.n.].

QIAN, Q. et al. An anomaly intrusion detection method based on PageRank algorithm. Proceedings - 2013 IEEE International Conference on Green Computing and Communications and IEEE Internet of Things and IEEE Cyber, Physical and Social Computing, GreenCom-iThings-CPSCom 2013, p. 2226-2230, 2013.

QU, H. et al. Intrusion Detection in SCADA/Modbus Network Based on Machine Learning. In: Lecture Notes of the Institute for Computer Sciences, SocialInformatics and Telecommunications Engineering, LNICST. [s.l: s.n.]. p. 437-454.

RICH, E.; KNIGHT, K. Artificial Intelligence. 1. ed. [s.1.] McGraw-Hill, 1991. 
RODIONOVA, O. Y.; OLIVERI, P.; POMERANTSEV, A. L. Rigorous and compliant approaches to one-class classification. Chemometrics and Intelligent Laboratory Systems, v. 159, p. 89-96, 2016.

RULAND, C.; SASSMANNSHAUSEN, J. Firewall for Attribute-Based Access Control in Smart Grids. 2018 IEEE International Conference on Smart Energy Grid Engineering (SEGE), p. 336-341, 2018.

SALEM, M. E.; MOHAMED, A.; SAMAD, S. A. Rule based system for power quality disturbance classification incorporating S-transform features. Expert Systems with Applications, v. 37, n. 4, p. 3229-3235, 2010.

SAMAAN, N.; KARMOUCH, A. Network anomaly diagnosis via statistical analysis and evidential reasoning. IEEE Transactions on Network and Service Management, v. 5, n. 2, p. 65-77, 2008.

SÁNCHEZ, D. et al. Association rules applied to credit card fraud detection. Expert Systems with Applications, v. 36, n. 2, p. 3630-3640, Mar. 2009.

SANDHU, R. S. et al. Role-based access control models. IEEE Computer Society, p. 38-47, 1996.

SANGKATSANEE, P.; WATTANAPONGSAKORN, N.; CHARNSRIPINYO, C. Practical real-time intrusion detection using machine learning approaches. Computer Communications, v. 34, n. 18, p. 2227-2235, 2011.

SAUTER, T. The three generations of field-level networks - Evolution and compatibility issues. IEEE Transactions on Industrial Electronics, v. 57, n. 11, p. 3585-3595, 2010.

SAUTER, T.; LOBASHOV, M. How to access factory floor information using internet technologies and gateways. IEEE Transactions on Industrial Informatics, v. 7, n. 4, p. 699-712, 2011.

SAUTER, T.; TREYTL, A. Security in Industrial Communications. In: Industrial Communication Technology Handbook. 2. ed. Boca Raton, FL: CRC Press, 2015. p. 29-1;29-23.

SCARFONE, K.; HOFFMAN, P. NIST SP800-41 Guidelines on firewalls and firewall policy: recommendations of the National Institute of Standards and Technology. NIST Special Publication, p. 74, 2009.

SCHMIDHUBER, J. Deep learning in neural networks: An overview. Neural Networks, v. 61, p. $85-117,2015$.

SCHUSTER, F. et al. Potentials of using one-class SVM for detecting protocol-specific anomalies in industrial networks. Proceedings - 2015 IEEE Symposium Series on Computational Intelligence, SSCI 2015, p. 83-90, 2015.

SCHWAIGER, C.; SAUTER, T. Security strategies for field area networks. IECON Proceedings (Industrial Electronics Conference), v. 4, p. 2915-2920, 2002.

SCHWAIGER, C.; TREYTL, A. Smart card based security for fieldbus systems. IEEE International Conference on Emerging Technologies and Factory Automation, ETFA, v. 1, n. January, p. 398-406, 2003. 
SCOPUS. Scopus. Disponível em: <https://www.scopus.com/>. Acesso em: 21 jan. 2019.

SEBASTIANI, F. Machine learning in automated text categorization. ACM Computing Surveys (CSUR), v. 34, n. 1, p. 1-47, Mar. 2002.

SEKAR, R. et al. A high-performance network intrusion detection system. Proceedings of the 6th ACM conference on Computer and communications security - CCS '99, p. 8-17, 1999.

SESTITO, G. S. MÉTODO PARA DETECÇÃO DE ANOMALIAS EM TRÁFEGO DE REDES REAL TIME ETHERNET APLICADO EM PROFINET E EM SERCOS III. [s.l: s.n.].

SHANG, W. et al. Modbus Communication Behavior Modeling and SVM Intrusion Detection Method. Proceedings of the 6th International Conference on Communication and Network Security. Anais...New York, NY, USA: ACM, 26 Nov. 2016Disponível em: <https://dl.acm.org/doi/10.1145/3017971.3017978>

SHENG, W.; XU, C.; LIU, J. Feature Extraction in Texture Analysis. Proceedings of SPIE, v. 4550, p. 228-233, 2001.

SHIN, S. et al. An experimental study of hierarchical intrusion detection for wireless industrial sensor networks. IEEE Transactions on Industrial Informatics, v. 6, n. 4, p. 744-757, 2010.

SHIRAZI, S. N. et al. Evaluation of anomaly detection techniques for SCADA communication resilience. Proceedings - 2016 Resilience Week, RWS 2016. Anais...2016

SILVA, F. L. DA et al. Evaluating classification and feature selection techniques for honeybee subspecies identification using wing images. Computers and Electronics in Agriculture, v. 114, p. 68-77, 2015.

SILVA, I. N.; SPATTI, D. H.; FLAUZINO, R. . Redes Neurais Artificiais para Engenharia e Ciências Aplicadas. [s.1.] Artliber, 2010.

SILVA, L. DE S. Uma Metodologia Para Detecção De Ataques No Tráfego De Redes Baseada Em Redes Neurais. n. January 2007, 2008.

STEINER, J. G.; NEUMAN, C. B.; SCHILLER, J. I. Kerberos: An Authentication Service for Computer Networks. IEEE Communications Magazine, v. 32, n. 9, p. 3338, 1988.

STEWART, B. et al. Effect of Network Architecture Changes on OCSVM Based Intrusion Detection System. In: Lecture Notes of the Institute for Computer Sciences, Social-Informatics and Telecommunications Engineering, LNICST. [s.l: s.n.]. p. 90100.

STINSON, D. R. Cryptography, Teory and Practice. 3a. ed. Boca Raton, FL: Chapman \& Hall/CRC, 2005.

SUNDARAM, A. An introduction to intrusion detection. Crossroads, v. 2, n. 4, p. 3-7, 1996. 
TAX, D. M. J. One-class classification. p. 187, 2001.

TENABLE. Nessus Vulnerability Scanner. Disponível em: <http://www.tenable.com/products/nessus-vulnerability-scanner>. Acesso em: 1 jan. 2019.

THANTHRIGE, U. S. K. P. M.; SAMARABANDU, J.; WANG, X. Machine learning techniques for intrusion detection on public dataset. Canadian Conference on Electrical and Computer Engineering, v. 2016- Octob, p. 7-10, 2016.

TREYTL, A.; ROBERTS, N.; HANCKE, G. P. Security architecture for power-line metering system. IEEE International Workshop on Factory Communication Systems, 2004. Proceedings., p. 393-396, 2004.

TREYTL, A.; SAUTER, T. Security Concept for Wide-Area Low Bandwith PowerLine Communication System. International Symposium on Power Line Communications and Its Applications, 2005. Anais...Vancouver, Canada: 2005

TREYTL, A.; SAUTER, T.; SCHWAIGER, C. Security measures for industrial fieldbus systems - state of the art and solutions for IP-based approaches. Factory Communication Systems, 2004. Proceedings. 2004 IEEE International Workshop on, p. 201-209--, 2004.

TURCATO, A. C. Desenvolvimento de uma metodologia baseada em redes neurais artificiais para a identificação de anomalias em redes de comunicação Profinet. [s.l.] EESC-USP, 2015.

TURCATO, A. C. et al. Ferramenta em Software para Pré-Processamento de Tráfego de Redes PROFINET. $2^{\circ}$ Congresso de Pós-Graduação Do IFSP. Anais...Cubatão/SP: 2017Disponível em: <http://ocs.ifsp.edu.br/index.php/conpog/2conpog/paper/view/2787>

TURCATO, A. C. et al. Ferramenta em Software Baseado em Web para PréProcessamento de Tráfego de Redes Real Time Ethernet. $3^{\circ}$ Congresso de PósGraduação do IFSP. Anais...Boituva/SP: 2018

TURCATO, A. C. et al. Introducing a cloud-based architecture for the distributed analysis of Real Time Ethernet traffic. IEEE International Workshop on Metrology for Industry 4.0 \& IoT. Anais...Brescia - Itália: 2020

UYAR, M.; YILDIRIM, S.; GENCOGLU, M. T. An expert system based on S-transform and neural network for automatic classification of power quality disturbances. Expert Systems with Applications, v. 36, n. 3 PART 2, p. 5962-5975, 2009.

VAPNIK, V. N.; CHERVONENKIS, A. Y. On the uniform convergence of relative frequencies of events to their probabilities. In: [s.l: s.n.]. p. 7-12.

VAVRA, J.; HROMADA, M. Evaluation of anomaly detection based on classification in relation to SCADA. ICMT 2017 - 6th International Conference on Military Technologies. Anais...2017

WANG, J. Computer Network Security Theory and Practice. [s.1.] High Education Press, 2009. 
WANG, P. et al. A method for HMM-based system calls intrusion detection based on hybrid training algorithm. 2011 IEEE International Conference on Information and Automation, ICIA 2011, n. 2008, p. 339-342, 2011.

WANG, S.; CHEN, Y.; TIAN, H. An intrusion detection algorithm based on chaos theory for selecting the detection window size. Proceedings of 2016 8th IEEE International Conference on Communication Software and Networks, ICCSN 2016, p. 556-560, 2016.

WANG, Y. Statistical Techniques for Network Security: Modern Statistically-Based Intrusion Detection and Protection. [s.1.] Information Science Reference, 2008.

WANG, Y.; YAO, H.; ZHAO, S. Auto-encoder based dimensionality reduction. Neurocomputing, v. 184, p. 232-242, 2016.

WENLI SHANG et al. Industrial communication intrusion detection algorithm based on improved one-class SVM. 2015 World Congress on Industrial Control Systems Security (WCICSS). Anais...IEEE, Dec. 2015Disponível em: $<$ http://ieeexplore.ieee.org/document/7420317/>

WINTER, P.; HERMANN, E.; ZEILINGER, M. Inductive Intrusion Detection in FlowBased Network Data using One-Class Support Vector Machines. 2011.

WIRESHARK.ORG. Wireshark. Disponível em: <https://www.wireshark.org>. Acesso em: 1 jan. 2019.

WITTEN, I.; FRANK, E. Data Mining: Practical Machine Learning Tools and Techniques. 2. ed. [s.1.] Elsevier Science, 2005.

WU, S. X.; BANZHAF, W. The use of computational intelligence in intrusion detection systems: A review. Applied Soft Computing Journal, v. 10, n. 1, p. 1-35, 2010.

WU, X.; XIE, L. Performance evaluation of industrial Ethernet protocols for networked control application. Control Engineering Practice, 2019.

XING, E.; JORDAN, M.; KARP, R. Feature selection for high-dimensional genomic microarray data. Proceedings of the 18th Conference on Machine Learning, p. 601$608,2001$.

XU, Y. M.; WANG, C. D.; LAI, J. H. Weighted Multi-view Clustering with Feature Selection. Pattern Recognition, v. 53, p. 25-35, 2016.

YANG, D.; USYNIN, A.; HINES, J. Anomaly-based intrusion detection for SCADA systems. 5th Intl. Topical Meeting on Nuclear Plant Instrumentation, Control and Human Machine Interface Technologies (NPIC\&HMIT 05), p. 12-16, 2005.

YANG, H. et al. Research on intrusion detection of industrial control system based on OPSO-BPNN algorithm. Proceedings of the 2017 IEEE 2nd Information Technology, Networking, Electronic and Automation Control Conference, ITNEC 2017, v. 2018Janua, p. 957-961, 2017.

YANG, M.; LI, G. Analysis of PROFINET IO communication protocol. Proceedings 2014 4th International Conference on Instrumentation and Measurement, Computer, Communication and Control, IMCCC 2014, p. 945-949, 2014. 
YASAKETHU, S.; JIANG, J. Intrusion Detection via Machine Learning for SCADA System Protection. Proceedings of the 1st International Symposium for ICS \& SCADA Cyber Security Research, p. 101-105, 2013.

ZAMAN, S.; KARRAY, F. Features selection for intrusion detection systems based on support vector machines. 2009 6th IEEE Consumer Communications and Networking Conference, CCNC 2009, p. 1-8, 2009.

ZEID, A. et al. Interoperability in Smart Manufacturing: Research Challenges. Machines, v. 7, n. 2, p. 21, 2 Apr. 2019.

ZHOU, F. et al. Deep learning fault diagnosis method based on global optimization GAN for unbalanced data. Knowledge-Based Systems, v. 187, p. 104837, Jan. 2020. 


\section{APÊNDICE A}

Tráfego NORMAL da rede para os Cenários 1 ao 10 (5500 pacotes capturados).

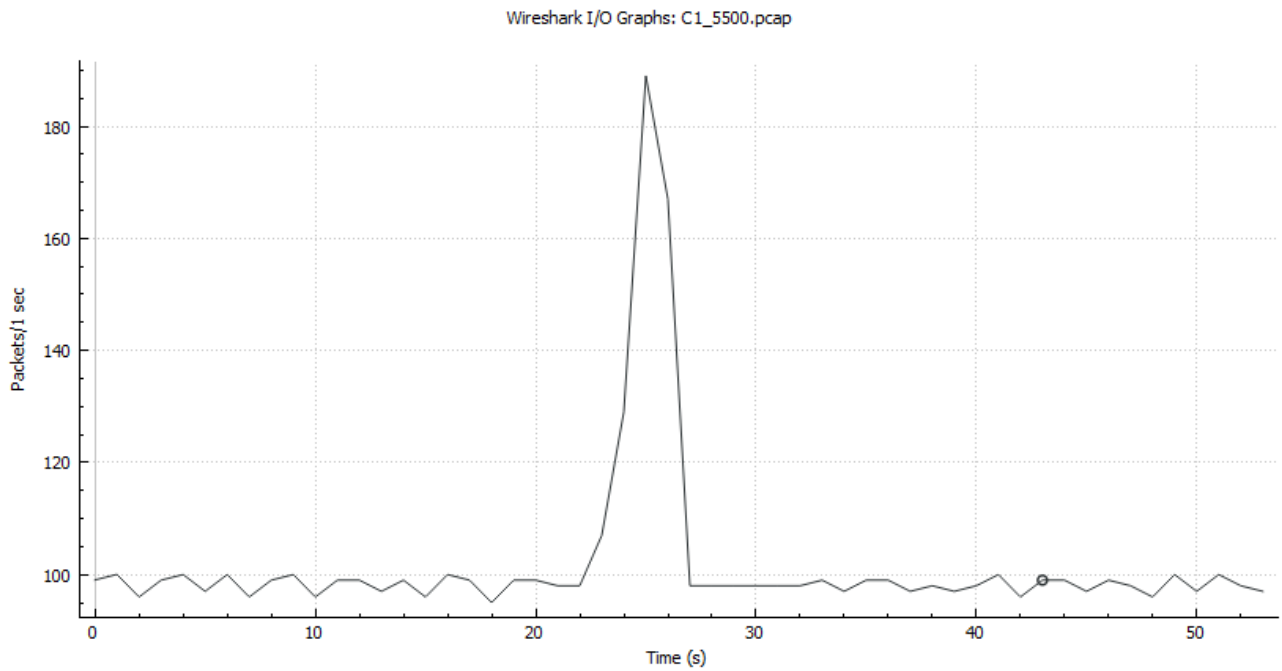

Wireshark I/O Graphs: C2_5500.pcap

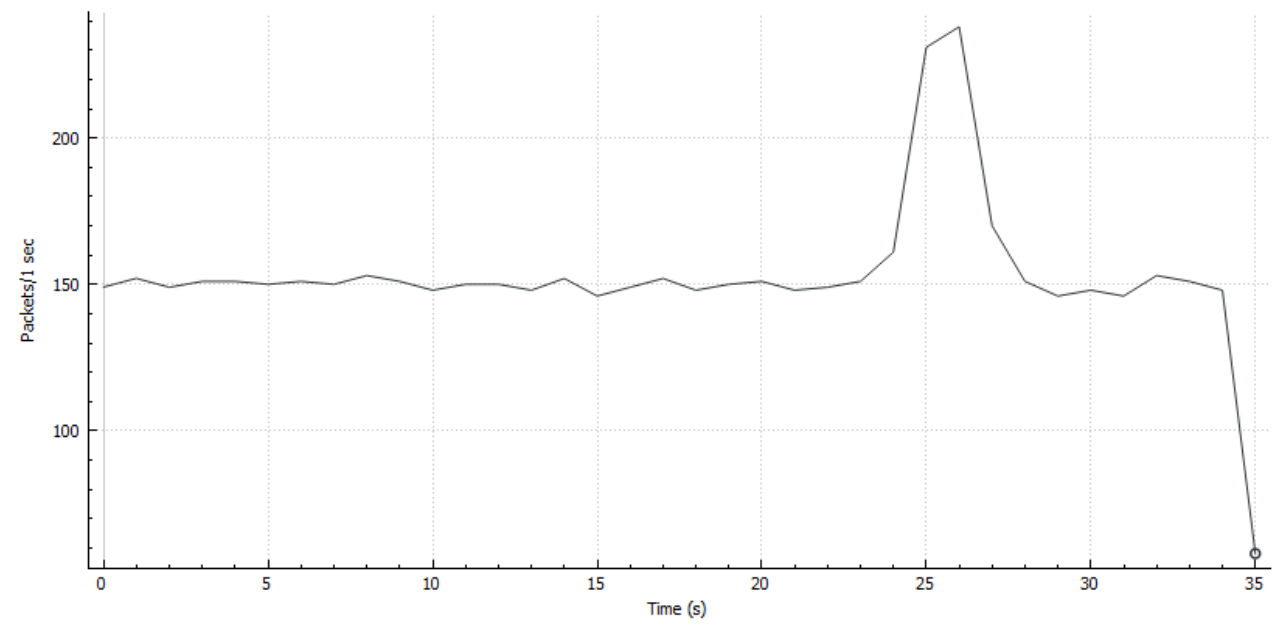

Wireshark I/O Graphs: C3 5500.pcap

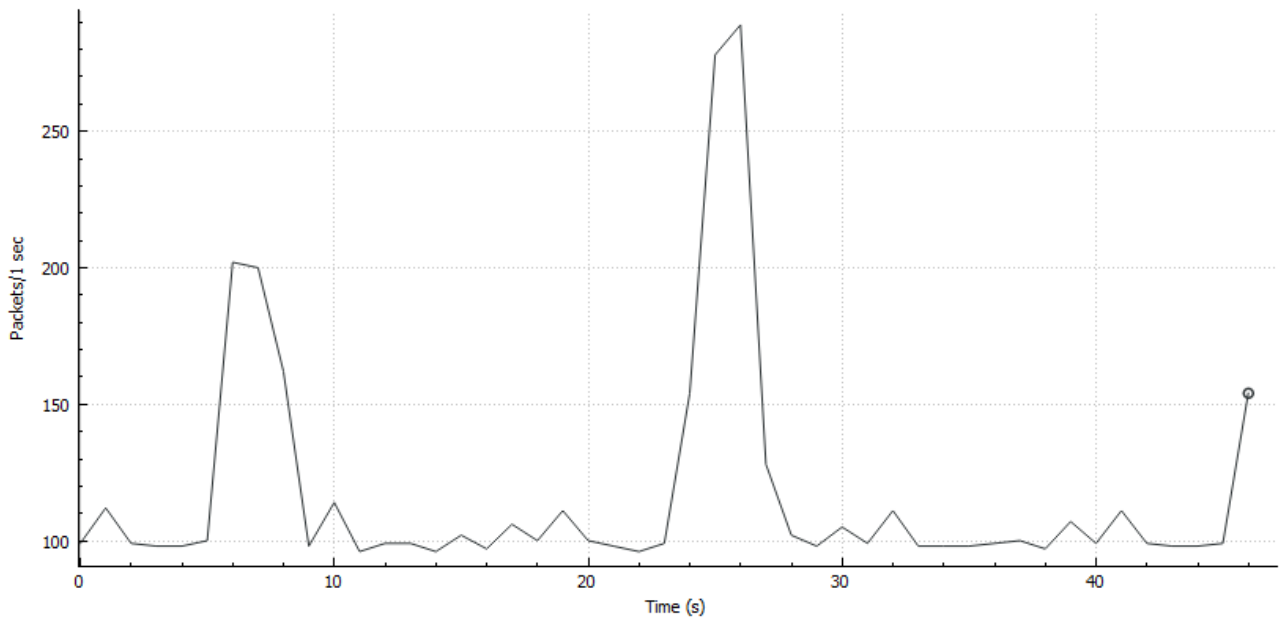



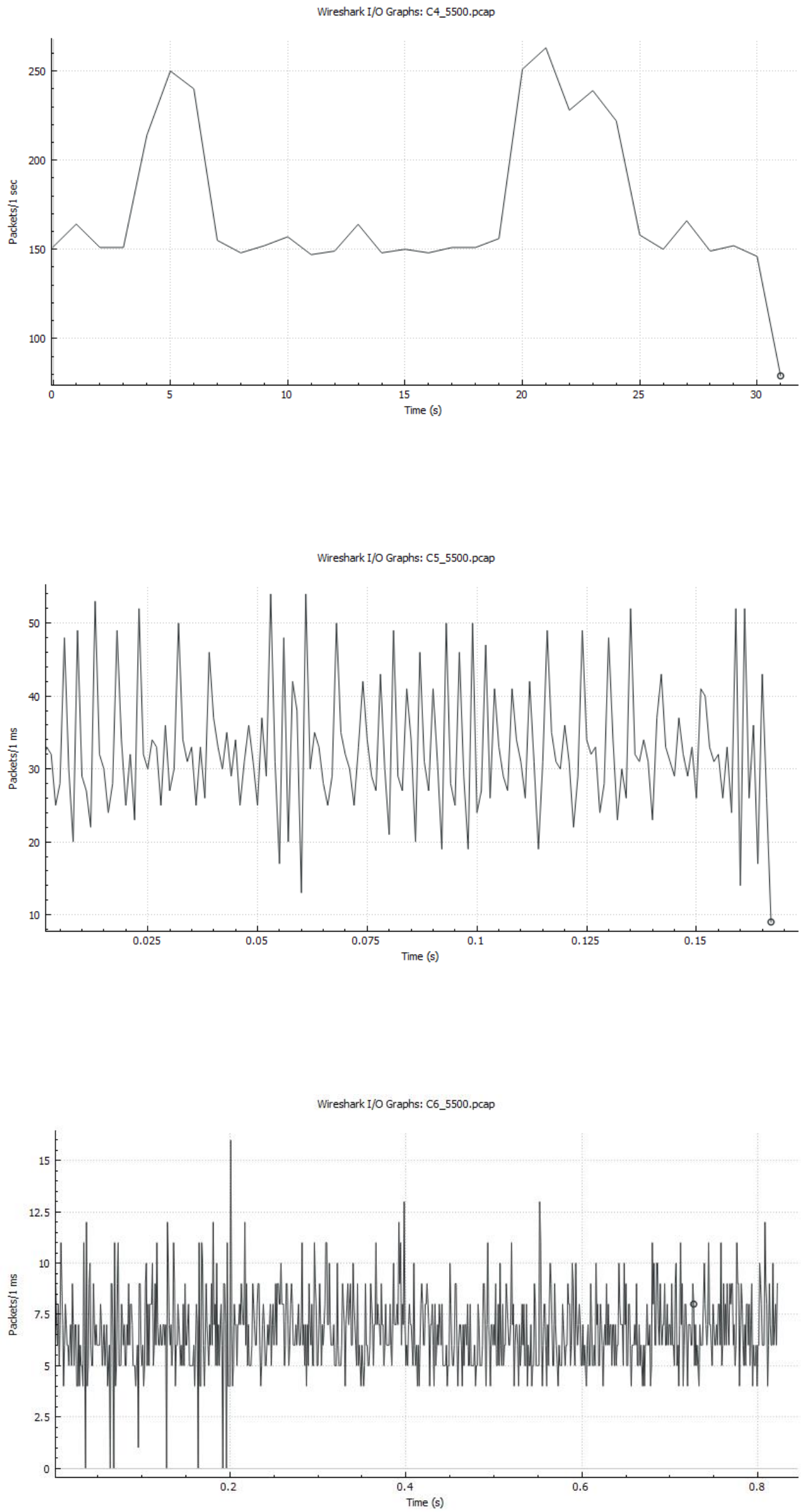

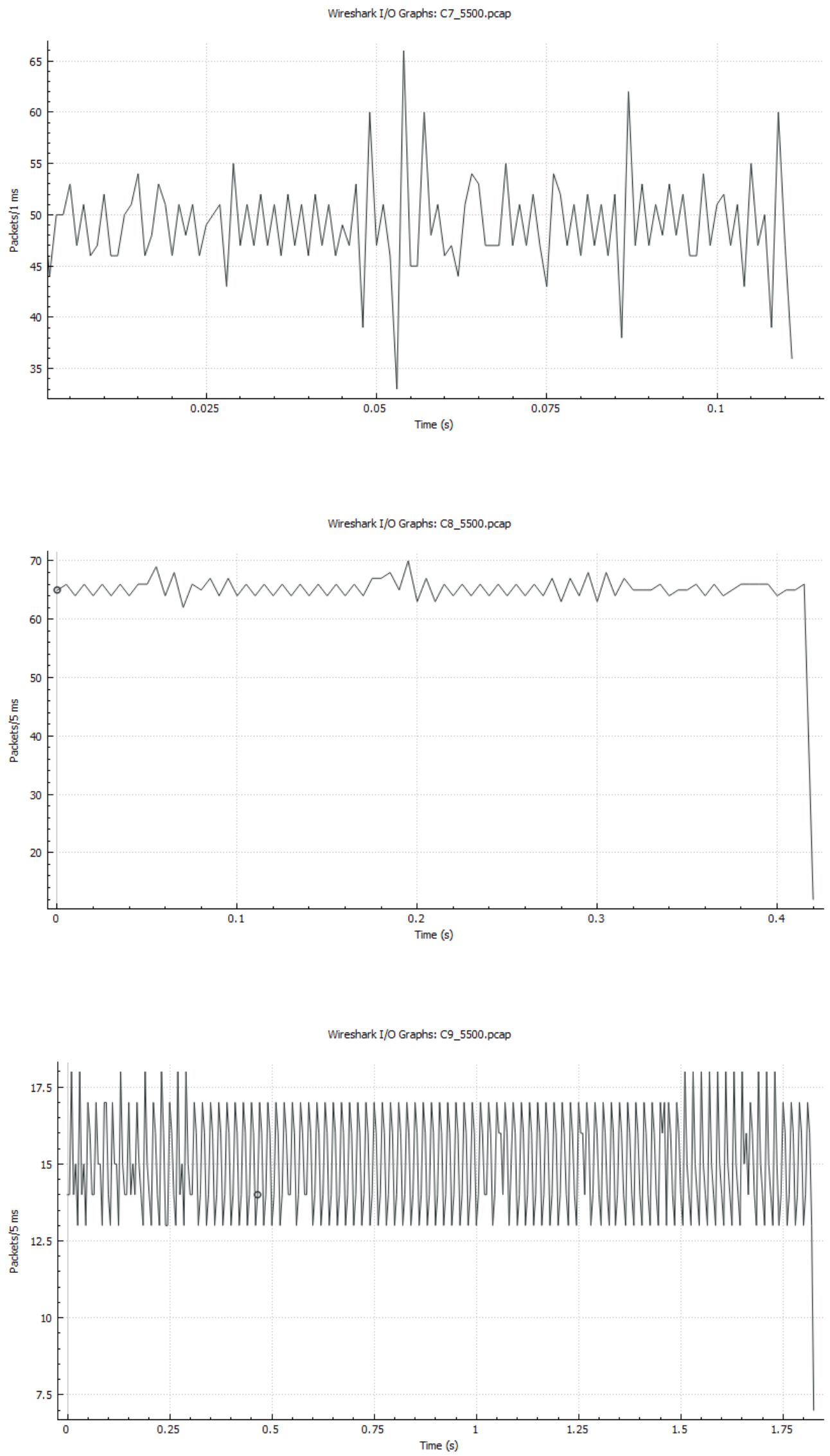


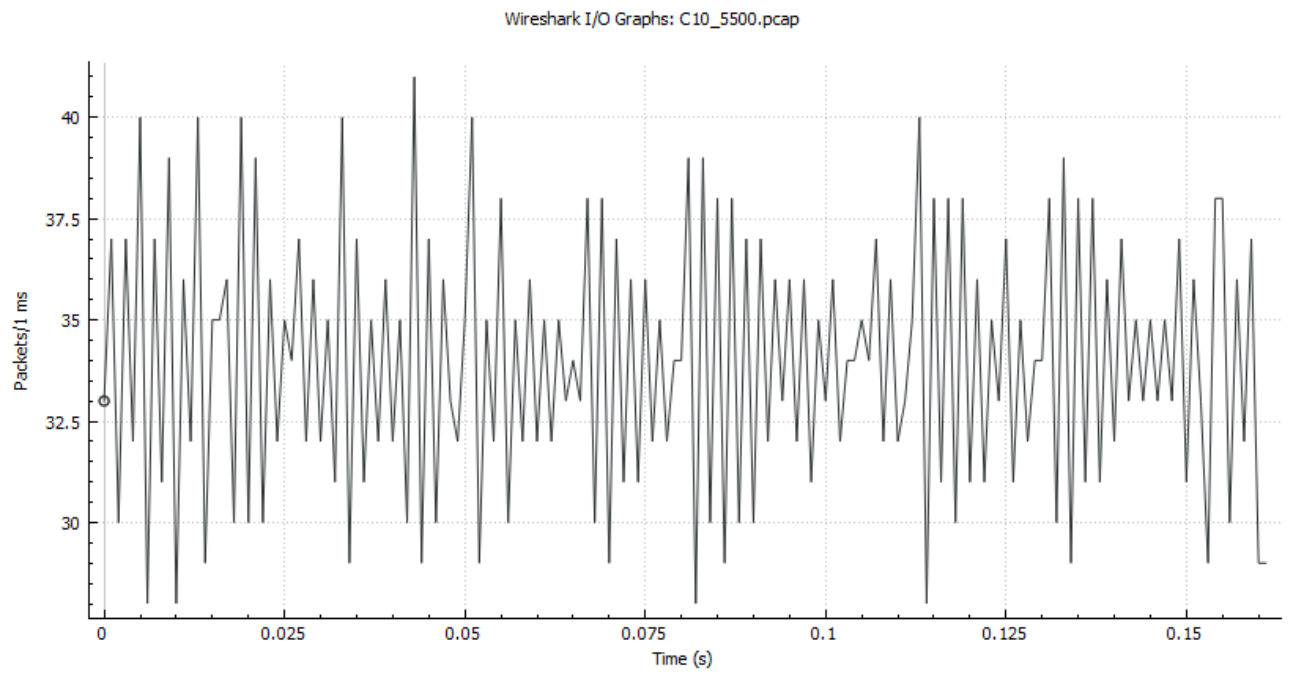




\section{APÊNDICE B}

Gráficos dos atributos A01 ao A20 para os Cenários 1 ao 10.

Em AZUL representa as amostras extraídas do tráfego e em VERMELHO representa o momento do ATAQUE/ANOMALIA.

CENÁRIO 1 - 350 amostras do tráfego

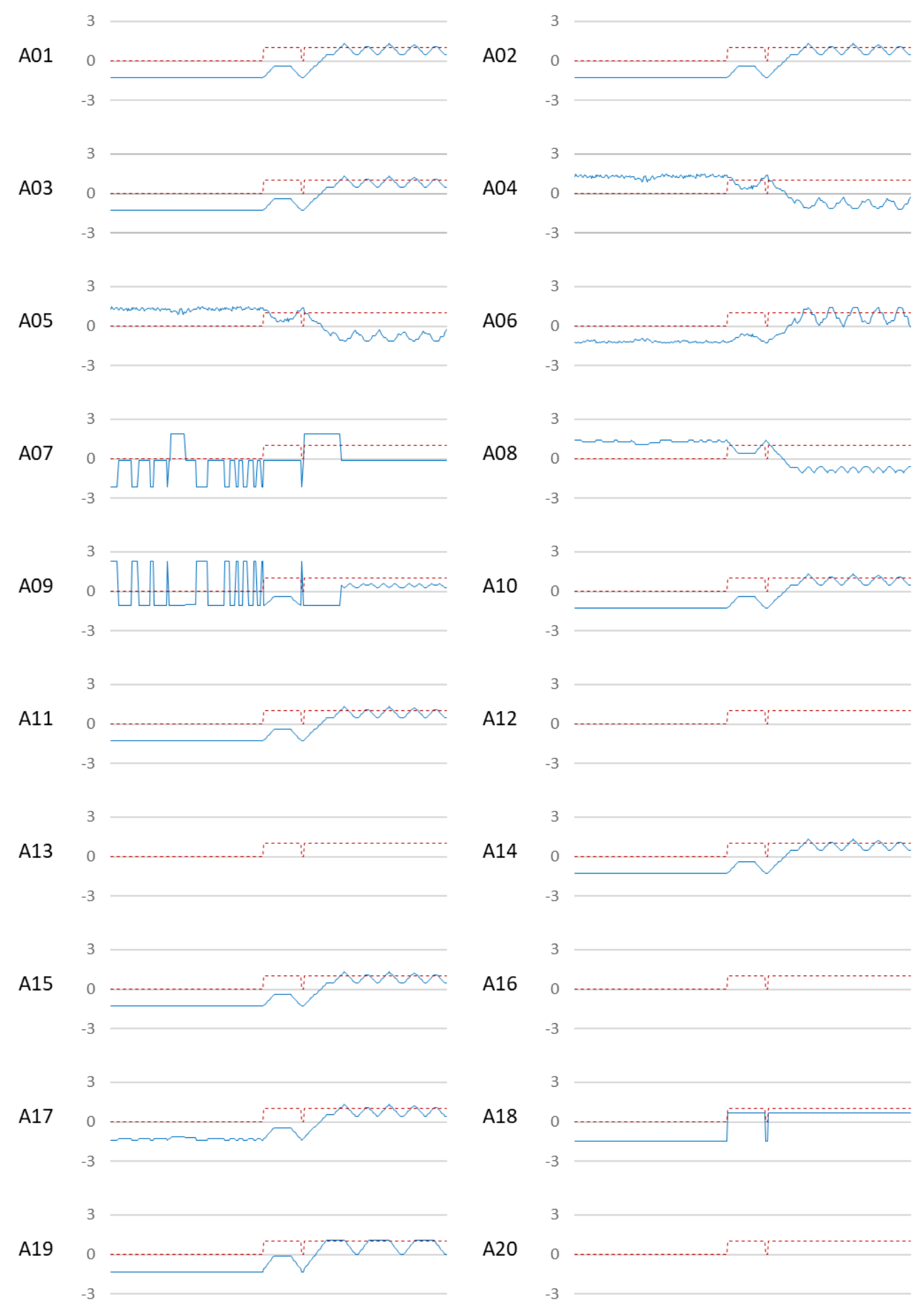


CENÁRIO 2 - 350 amostras do tráfego

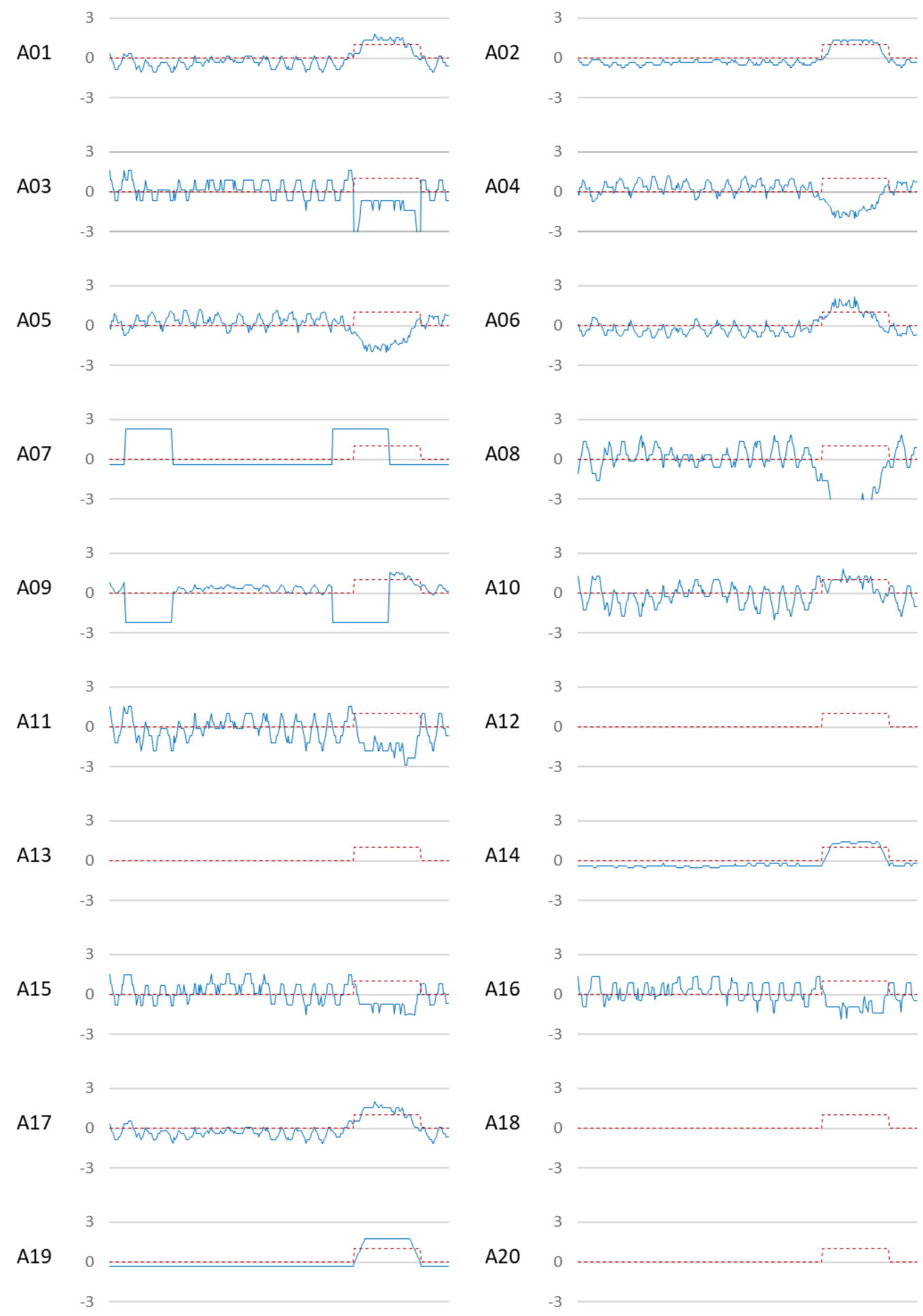


CENÁRIO 3 - 350 amostras do tráfego

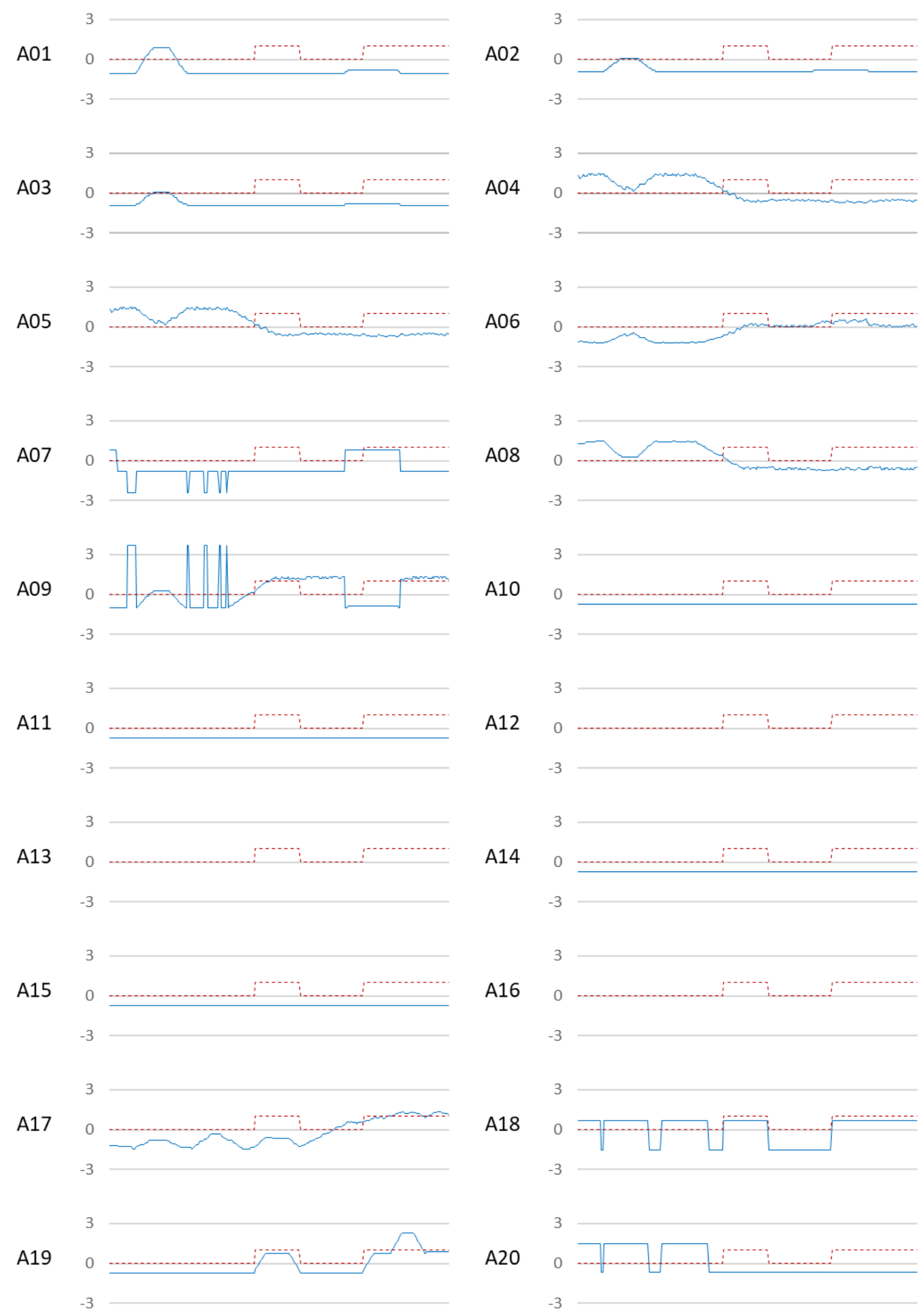


CENÁRIO 4 - 350 amostras do tráfego

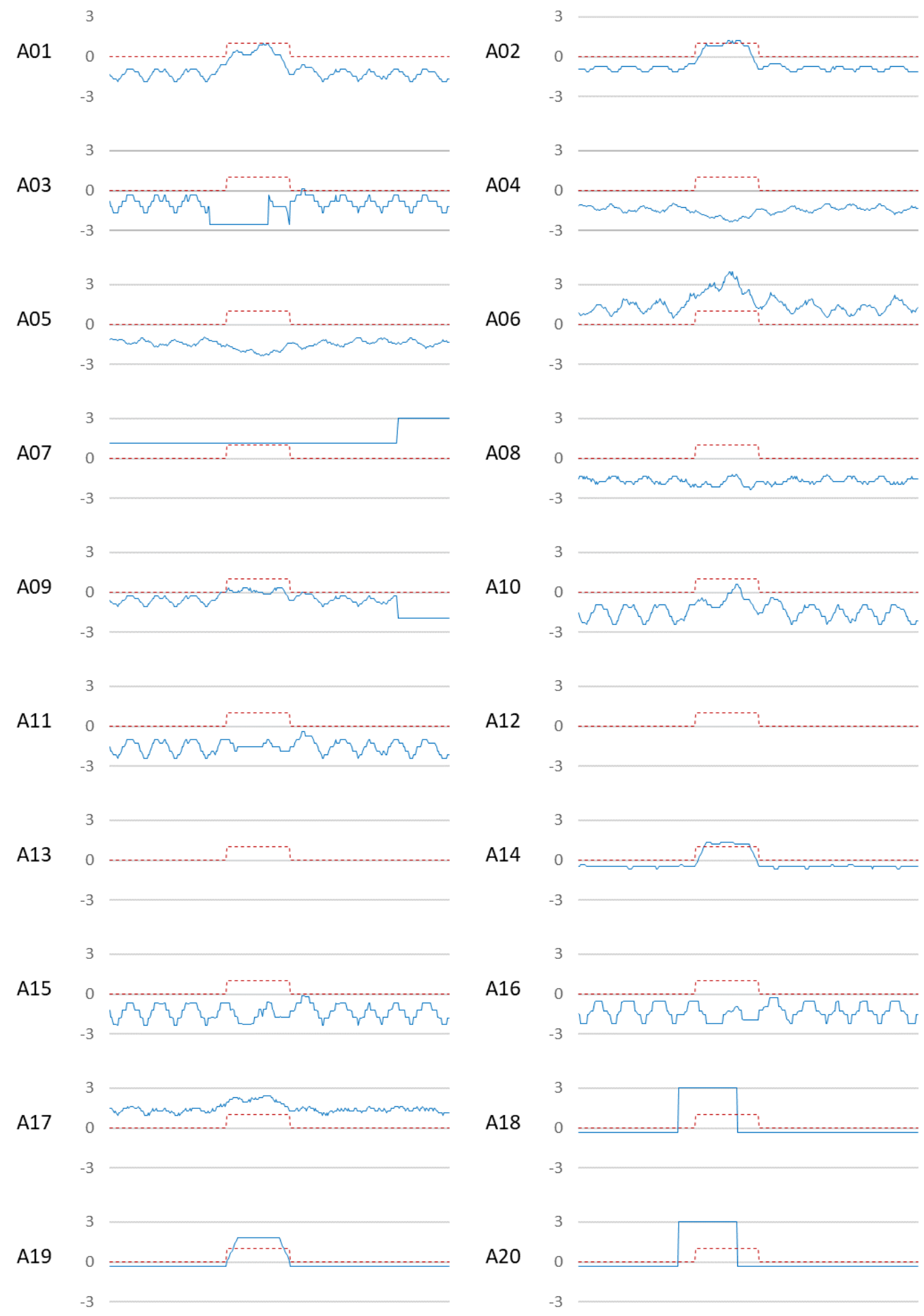


CENÁRIO 5 - 155 amostras Targets

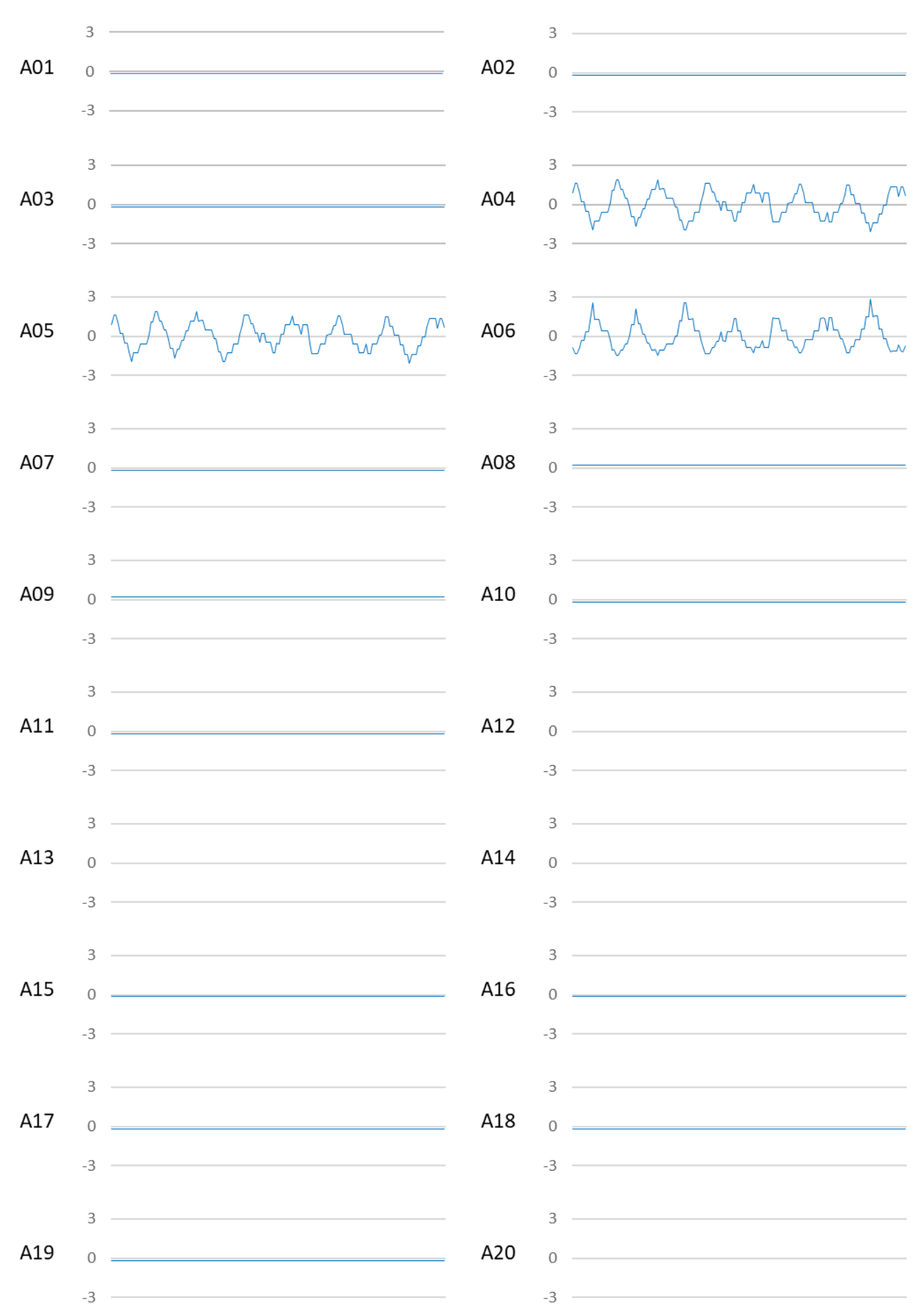


CENÁRIO 6 - 155 amostras Targets

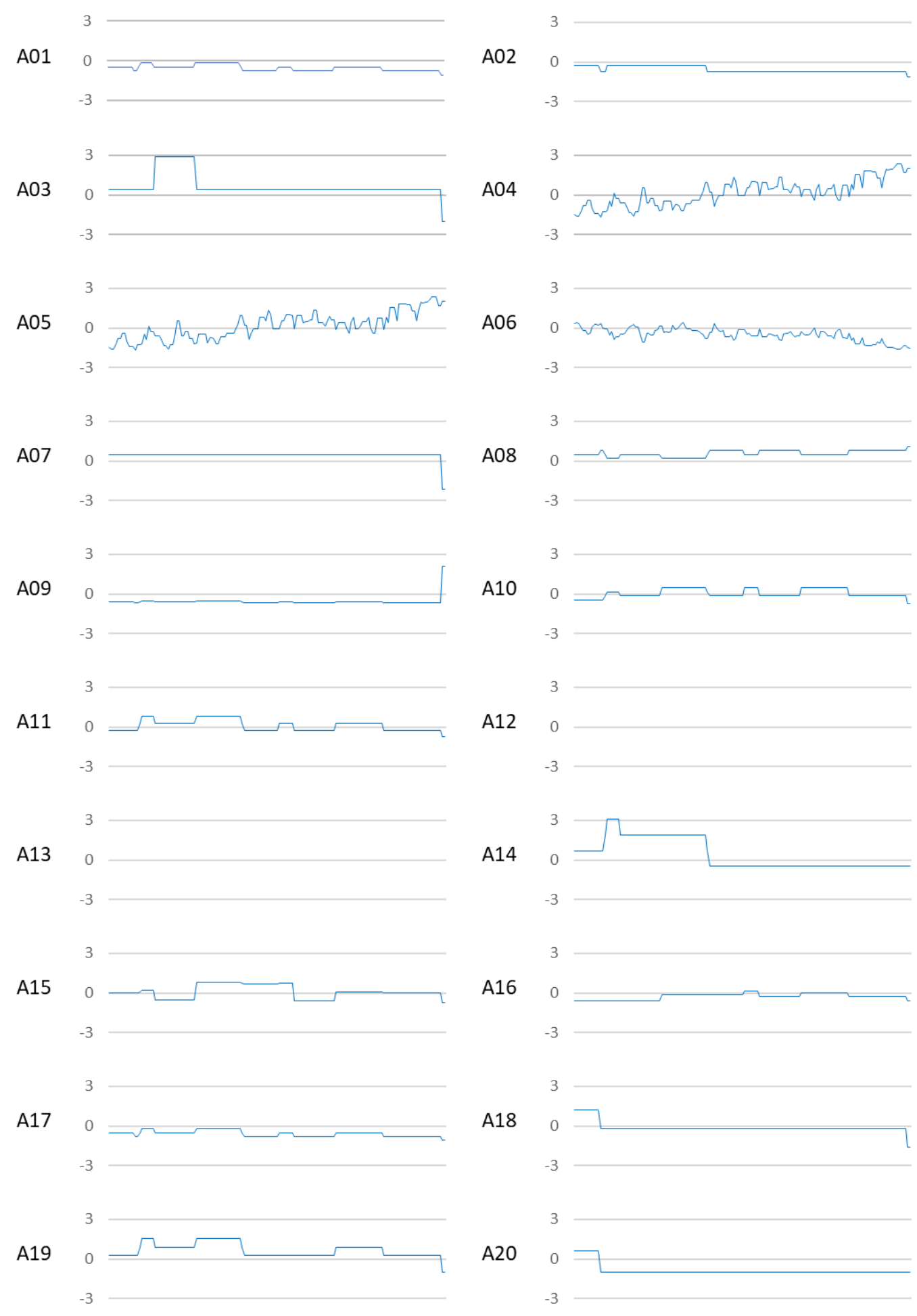


CENÁRIO 7 - 155 amostras Targets

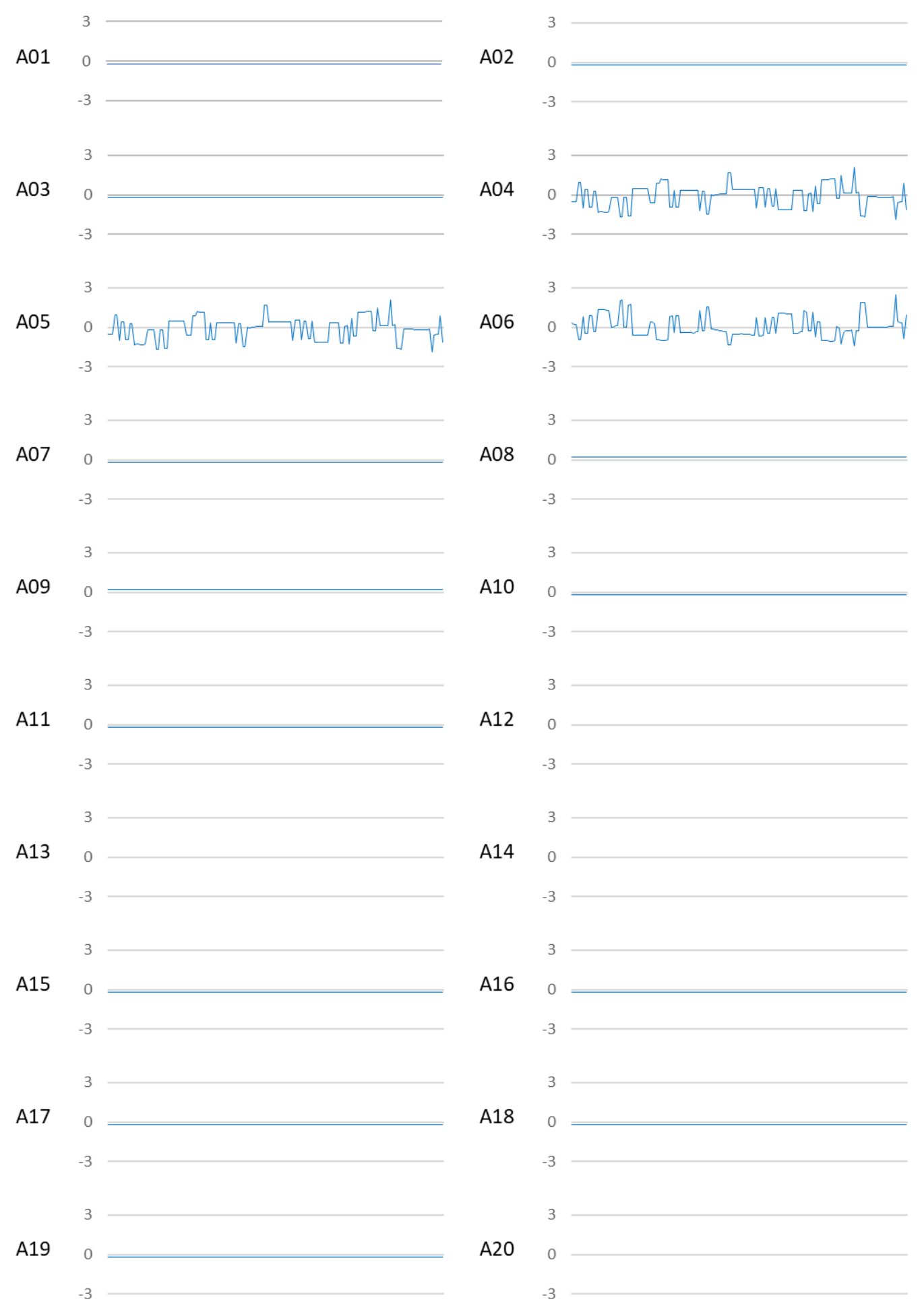


CENÁRIO 8 - 155 amostras Targets

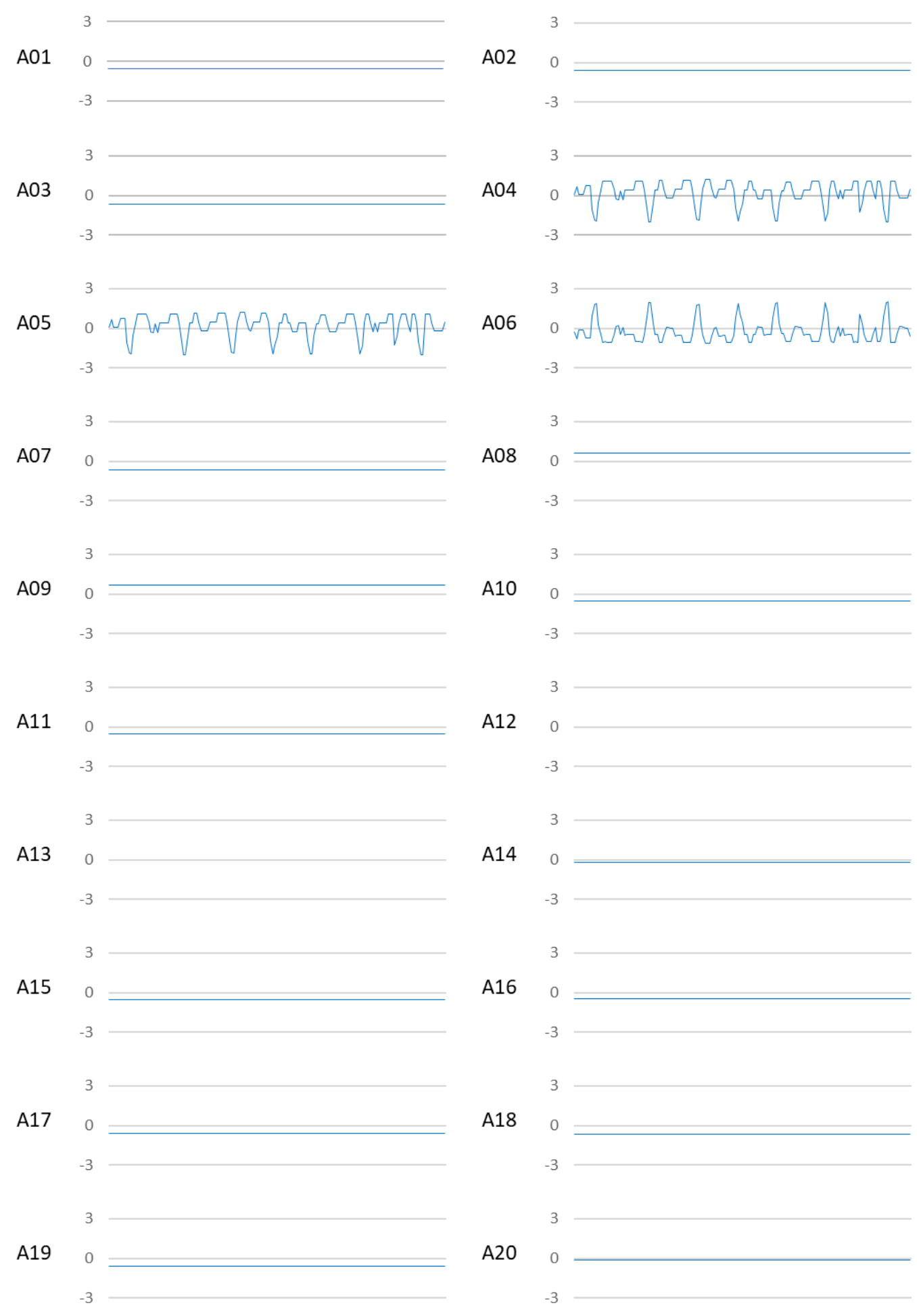


CENÁRIO 9 - 155 amostras Targets

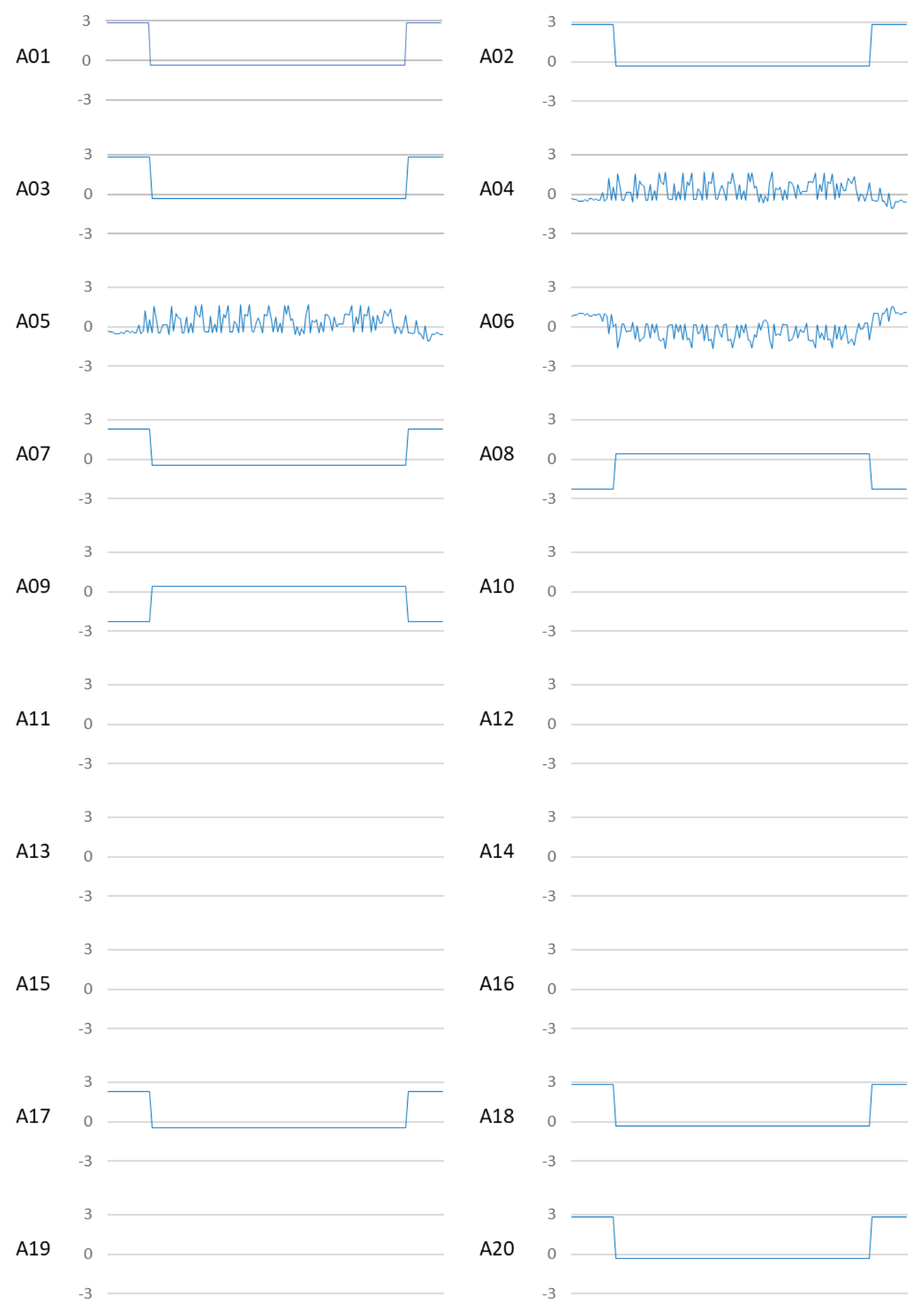


CENÁRIO 10 - 155 amostras Targets

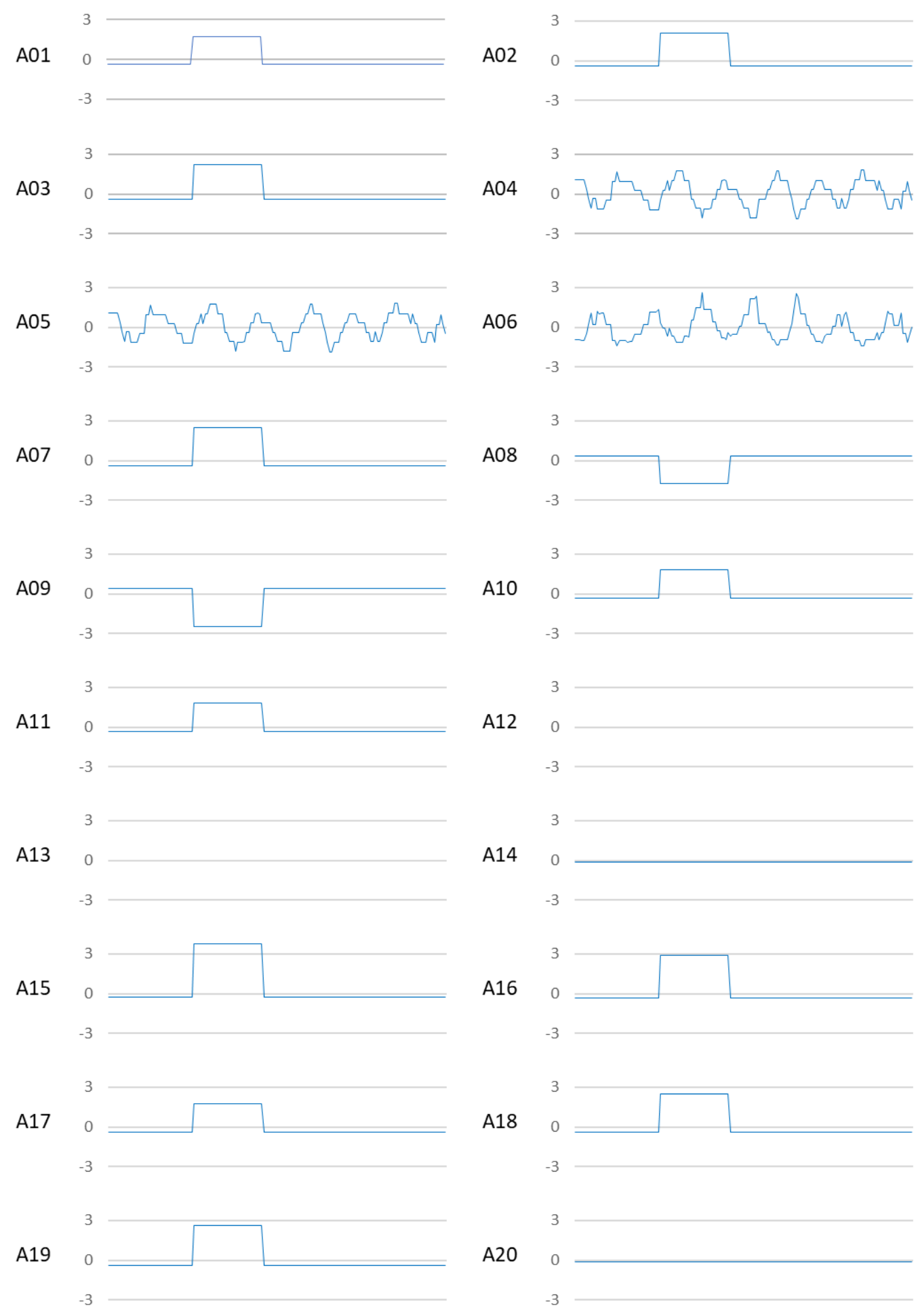


